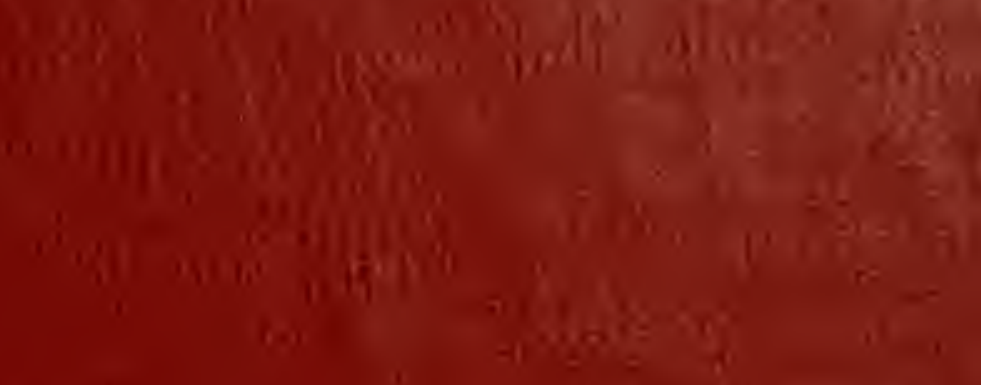

\title{
*⿻一𠃋十
}




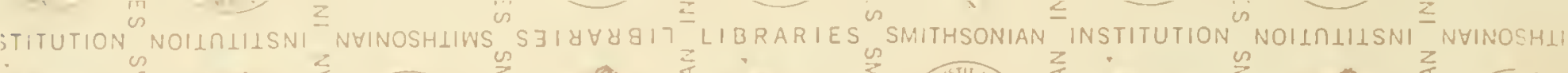


IBRARIES SMITHSONIAN

(embi

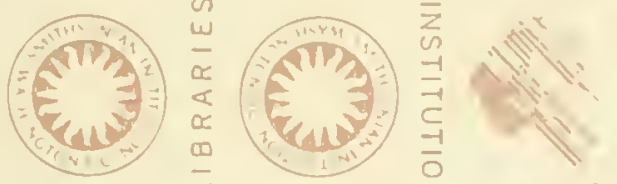

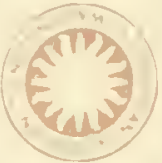

20

$\frac{E}{5}+8.78$

$E^{m} m_{0}$

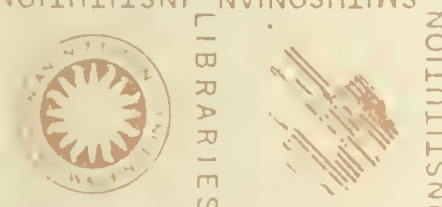
(an?
IBRARIES
(n)
Ent

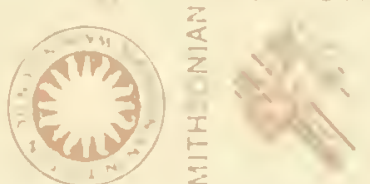

$\varepsilon_{0,3}^{3} 3$

IBRARIES SMITHSONIAN

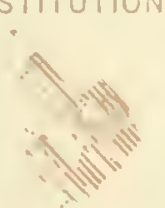

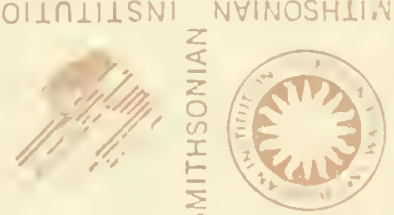

IBRATIE

8

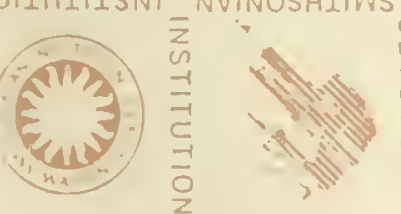

ENiv)

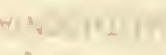

(Nin)

(im)

हm) $\left(\frac{\pi m}{3}\right)$

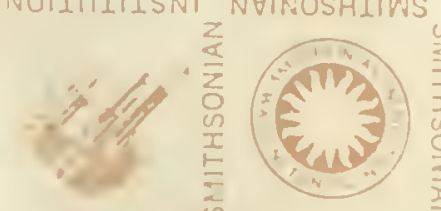
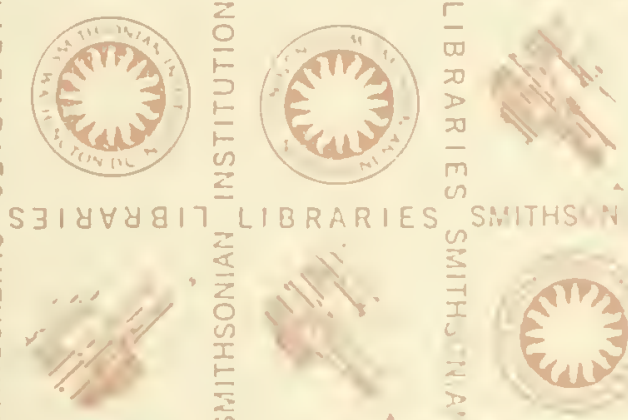

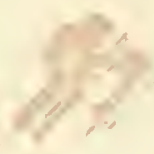

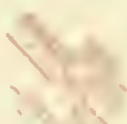

S.MII ctow,

instim
(E)
i)
$\left(\frac{\pi}{2} 3\right)$
हn)
E
$e^{2} \frac{3}{3}$
$\frac{g^{m}}{600}$ 




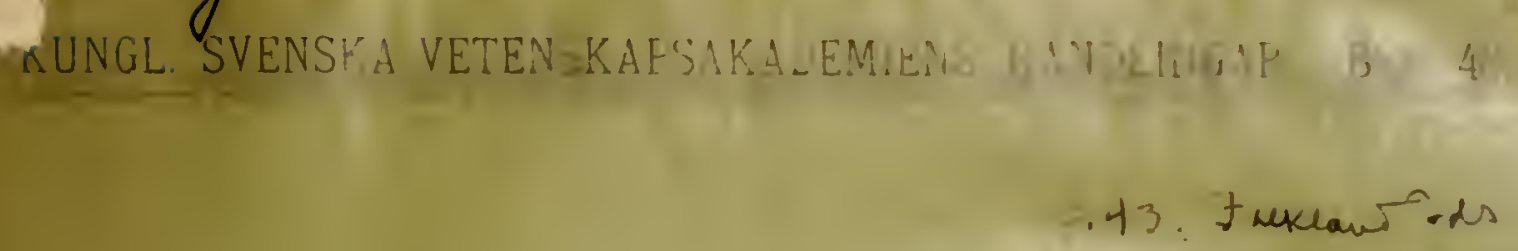

$$
\text { b. Jil na de Thego }
$$

\section{III: ISTHThiN}

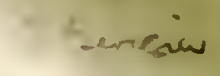

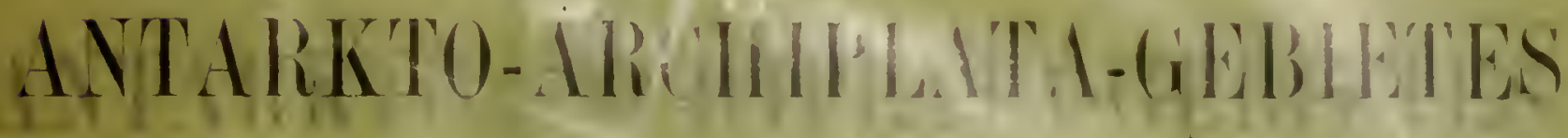

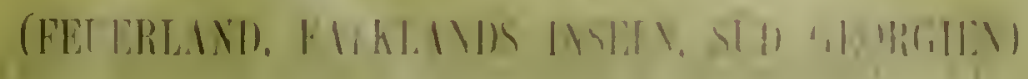

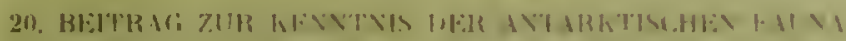

vor

\section{Dr. GÜNTHER ENDERLEIN}

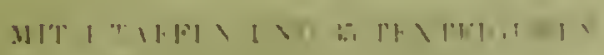

MTGETEILT AM 13 \& . 


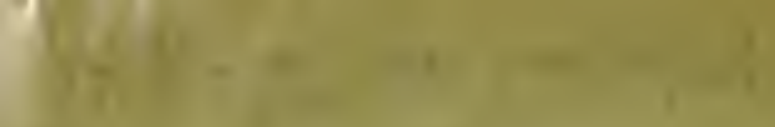

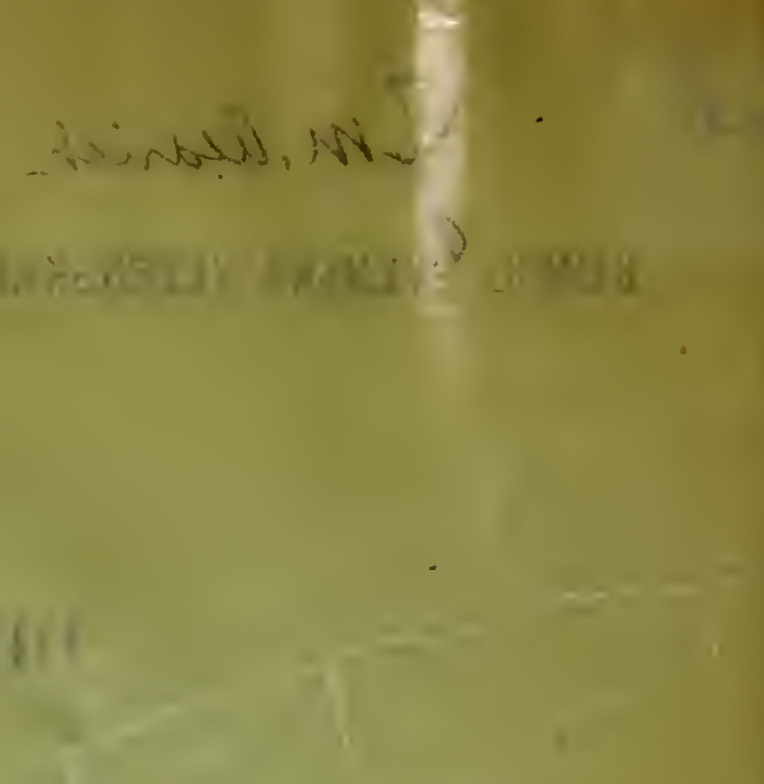

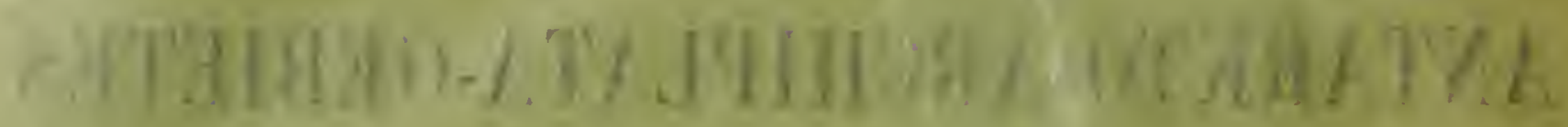

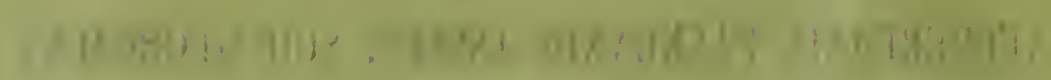

a)

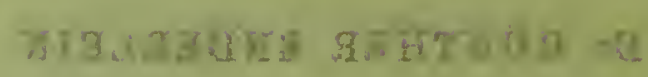

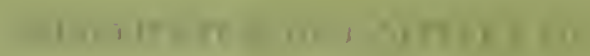

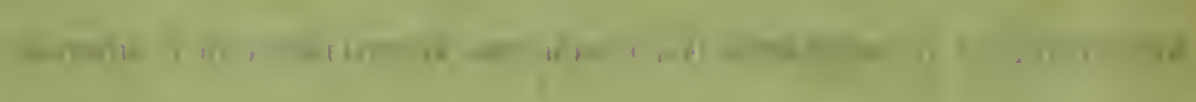

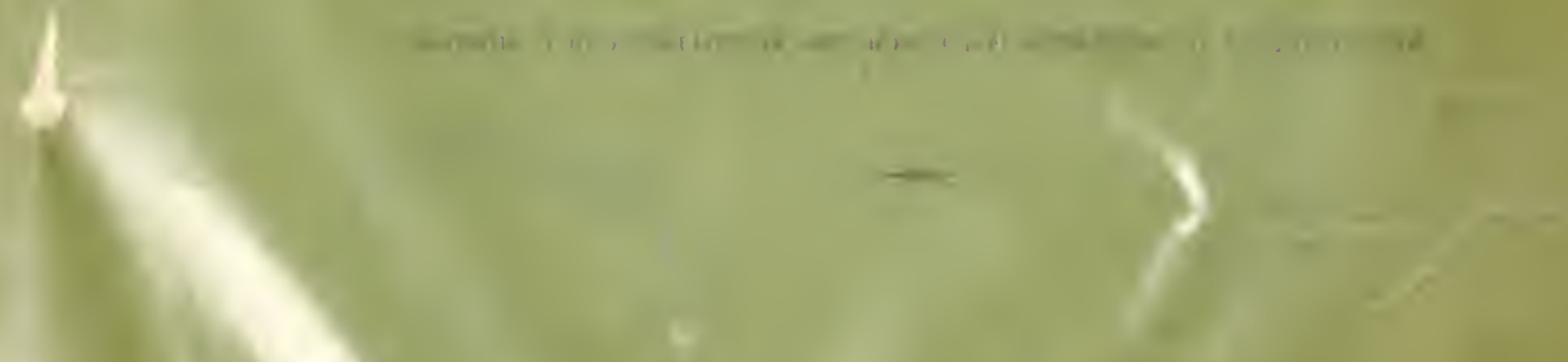

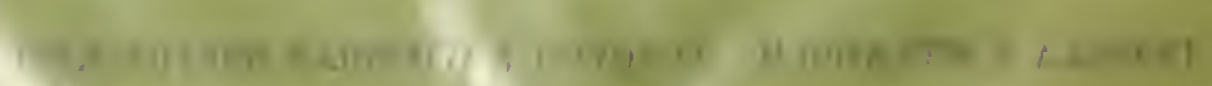

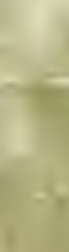


KUNGL. SVENSKA VETENSKAPSAKADEMIENS HANDLINGAR. Band 48. N:0 3.

\section{DIE INSEKTEN}

I) I\%S

\section{ANTARKTO-AROHIPLATA-(AEBEETLS}

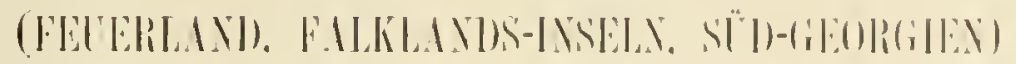

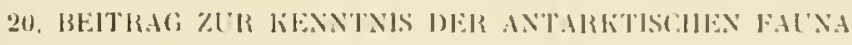

vox

Dr. GÜNTHER ENDERLEIN

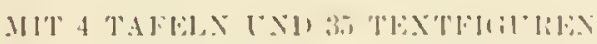



D e Bearbeitung der Insektenfanna ron Feuerland, von den Falklands-Inselu und ron Süd-Georgien anf Grund des ron der schwedischen Südpolar-lirpedition mitgebrachten Materiales erstreckt sich, allerdings mit vielen längeren Unterbrechungen, anf einen Zeitraum ron 7 Jahren; abgesehen daron, dass ich mich nur in meiner (lienstfreien \%eit dieser Arbeit widmen konnte, war der Hanptgrund licrron die Vielseitigkeit des auf heterogene Gebiete verteilten Materiales. Dann hestand aber auch noeh die Sehwierigkeit, die ausserordentlieh zerstrente Literatul zusammenzıfinden. Die grösste Schwierigkeit war es besonders, alle Arten, die ron dem bearbeiteten Gebiete bisher erwähnt wurden. zusammenzubekommen, da ja die Records und Berichte meist nur die Fundorte nener Arten angeben und ieh war dalser gezwungen, viele Arbeiten und Kataloge durehzublättern anf der Suche nach hierhergehörigen Arten. Dass mir trotzdem noch manche Art entgangen sein wird, ist mir sehr wahrseheintieh und ieh bitte daher. Alle, denen in der Literatur etwas hierliergehöriges und ron mir iibersehenes zu Gesicht kommt, un fremndliehe Mitteilung für einen späteren Nachtrag.

Zu besonderem Danke rerpfliehtet bin ich Herrn l'rofessor 1)r. (OTro NorbExskJöL in Göteborg, der mir das wertrolle und umfangreiche Insckten-Material der sehwedisehen Sïdpolar-Expedition zur Bearbeitung anvertrante nud mir betreffs Anfertignng ron Figuren das bereitwilligste Entgegenkommen crwies. Herru Professol'

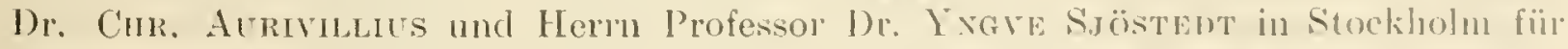
die freundiche Vermittlung der Aufuahne der vorliegenden Arbeit in den lerbandlungen der Königlieh Sehwedischen Akadenue der Wissenschaften. Hern'stadtat 1)r. H. Dours in Stettin für gütiges t'berlassen ron Vergleielsmaterial besonders ans der reichhaltigen Coleopterensammlung seines Vaters zu häusficher lionutzung, Heru Professor Dr. F. Karscu in Berlin fïr lanujühriges Leihen scines \%eiss-Mlikoskopes

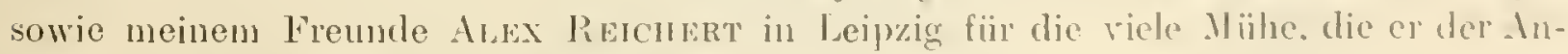
fertigung (ler farbigen Abbildungen gewidmet hat.

Ferner danke ich anch an dieser Stelle bestens fïr duskiinfte. L"ntorititznug mil

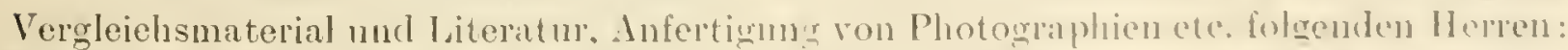

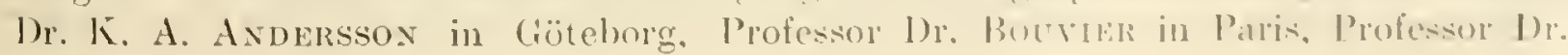


(H. Chutox in Christehurch auf Nen Seeland, Dr. K. Dorneyer in Stettin, Ch. I. ( Professor Dr. F. Karsch in Berlin. Professor Dr. R. Krieger in Leiprig, Lesne in Paris, Professor Dr. von Maenresthal in Berlin, Dr. Eric MJöberg in Stockholm, Dr. MÜller in Leipzig, Professor Dr. F. Richters in Frankfurt am Main, Professor Dr. Redtenbacher in Wien, Alex Relchert in Leipzig, Dr. Carl Skottsberg in Uppsala, Professor Dr. Vanhomfenes in Berlin, Direktor Dr. Oskar Vogt in Berlin, Fred, H. Wateriouse in London und anderen.

Die Anzalı] der ans dem subantarktischen Teile Sïdamerikas (Fenerland, Falklands-lnseln und Süd-Georgien) bekannten Insekten-Arten beträgt 350, die sich anf 215 Gattungen verteilen. Zieht man von diesen die kosmopolitischen oder weit verbreiteten Gattungen ab, so bleiben unter den iibrigen Gattungen eine sehr grosse Anzahl ïbrig, die nur in der Arehiplata-Region sich finden. Auf Grund des sehr wertvollen und umfangreichen vorliegenden Materiales der schwedischen SüdpolarExpedition wurden 17 nene Gattungen aufgestellt, die folgenden Ordnungen angehören: 5 Coleopteren-Gattungen, 7 Dipteren-Gattungen, 1 Rhynchoten-Gattung, 1 OrthopterenGattung, 3 Plecopteren-Gattungen. Neue Arten werden 42 bekannt gemacht und zwar 23 Coleopteren, 1 Lepidoptere, 1 Hymenoptere, 11 Dipteren, 1 Rhynehote, 1 Orthoptere, 1 Copeognathe und 3 Plecopteren; von WAHLGRen wurden auf Grund des Materiales an Collembolen der schwedischen Südpolar-Expedition ausserdem 9 neue Collembolen-Arten und eine nene Gattung beschrieben.

Die nachstehende Tabelle gibt einen Überblick über die Artenanzahl der verschiedenen Ordunngen auf den 3 Inseln.

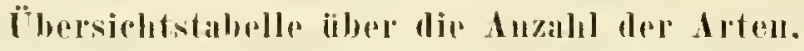

\begin{tabular}{|c|c|c|c|c|c|c|c|c|c|c|c|c|}
\hline & & & & & & & & & & leverland & $\begin{array}{l}\text { Falklands- } \\
\text { Inseln }\end{array}$ & $\begin{array}{l}\text { Süi- } \\
\text { Georgien }\end{array}$ \\
\hline Culeoptera. . & . & & . & . . & . & . . & . & . & . . . & 85 & 35 & 4 \\
\hline Lepidoptera . & & & . & . . & . & . & . & & . . . & 69 & 12 & - \\
\hline Hýmenuptern & . & & . & & . & . & . & . & . . . & 6 & 1 & - \\
\hline Diptera . . & . & . . & . & . . & . & . . & . & & . . . & 65 & i & + \\
\hline Rhynchola . & . & . . & . & . . & . & . . & . & . & . . . . & 23 & 1 & \\
\hline Copeoguatha. & . & . & . & . . & . & . & . & & . . . & - & 1 & \\
\hline Mallophaga . & . & . . & . & . . & . & . . & . & & . . . & - & & 2 \\
\hline Odonata. . & . & . . & . & . & & . . & . & & . . . & 2 & - & - \\
\hline Trichopter . & $\therefore$ & . . & . & . . & . & . . & . & & . . . & 7 & 1 & - \\
\hline Orthoptera. & . & . . & . & . . & 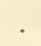 & . & . & & . . . & -- & 1 & - \\
\hline Plecoptera. . & . & . . & . & . . & . & . . & . & & . . . & 5 & 一 & - \\
\hline Agnatha . . & . & . . & . & . . & • & . & . & & . . & 1 & - & - \\
\hline \multirow[t]{2}{*}{ Collembola. . } & . & . . & . & . . & . & . . & . . & . & . . . & 23 & 9 & 8 \\
\hline & & & & & & & & & & 286 & 67 & 18 \\
\hline
\end{tabular}




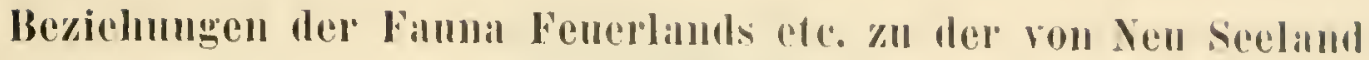 mul Australien.}

Zu den in meiner Bearbeitung der Insekten des antarktischen Gebietes, \%un 'T'ril anf Grund des Materiales der dentsehen Südpolar-Expedition, zusammengestellten hiogeographisehen Bezjehungen zwisehen der Fanna Fenerlands, der Falklands-Inseln, Sïd-Georgien und der ron Nen Seeland und Australien gebe ieh hier noch einige Einfïgmngen und verweise im Lbrigen auf diese ritierte Arbeit.

\section{Ordo: Hymenoptera. \\ Fam. Formicidae. \\ Subfaus. Camponotinae.}

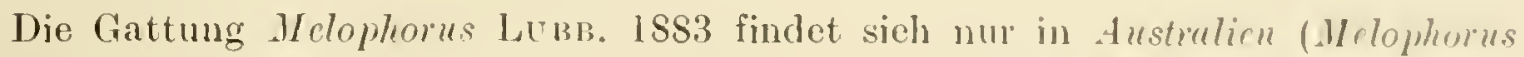
Bagoti LubB. 1853) und in Fenerland, Patagonjen und Chile (.1\%. picinus Roc. 186i3, 1. Sauberi For. 1904).

\section{Ordo: Rhynchota. \\ Fam. Aradidae. \\ Subfan. Isoderminae.}

Die fattung Isodermus Ericıs. 1S42, die cinzige Gattung der Subfamilie Iso. derminae, findet sich nur in Tasmanien (I. plunus ERICus. IS42 und I. rucillrus WaLK. 1873) und in Chile, Patagonien und Fenerland (I. ('ugi SpIx.). Ferner iat Ecpiestocoris aus Chile nahe rerwandt mit Procymbiestus aus Australien.

\section{Ordo: Plecoptera. \\ Fam. Gripopterygidae. \\ Subfan. Antarctoperlinae.}

Interessant ist die V'erbreitung dieser Subfamilie. Antartoperla Exinke. 190.5 hat 2 Arten auf Fenerland, Leptoperle News. 1839) eine Art auf Tasmanien (J. berö Newur. 1839), Parenoloperla Exinerr. 1909 eine Art in Anstralien (P. unstralica Exinert. 1909), Notoperla Experi. 1909 eine Art auf Feuerland und Auchlumdobius Wxin Firt.

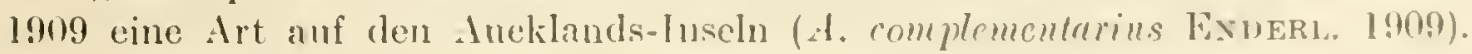

\section{Ordo: Megaloptera. Fan. Mantispidae. \\ Subfinl. Anisopterinae.}

Die Gattung Ditaxis MC Lacul. 1867 mit I Art ans Australien (l). biserinta

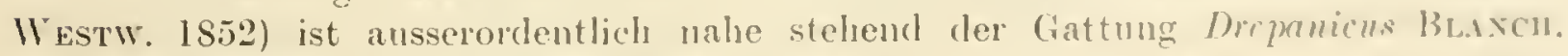
1851 mit 2 Arten aus Chile (I). Guyi Btaxên. 1851 und D). chrysopinus B312. 18s7). 
Ordo: Diptera.

Fan. Limoniidae

(Limnobiidae).

Die Gattung Zulusa ENDERL. 1905 (Z. fallilandica Exdert. 1905) von den Falklands-Inseln steht sehr nahe der Gattung Zaluscodes Lamb 1909 (Z. aucklandicus LАмв 1909) von den Aueklands-Inseln. 


\section{Die Tuseliten der Falkiands-Insoln.}

Die Insektenfama der Falkiands-Inseh war bisher noch wenig bekannt und erst durch die Resultate der schwedisehen Südpolar-Fxpedition ist es ermöglicht, dieselbe in grossen Zïgen festzulegen. wenngleich zweifellos spätere Forsehung noclı viele newe Formen zu Tage bringen wird. zumal Mimutien bisher nur reremzelt gesammelt wrurden. Die beiden Tnseln Ost- und West-Falkland dïnften famistisch ïbereinstinmen, doeh ist die Fauna zu einem sieheren Schluss noeh zu ungenïgend beliannt.

Es sind bis jetrt ron den Falklands-Inseln 67 Arten und 2 Varietäten behannt. ron denen bisher' nur 40 bekannt waren und 27 dureh dic schwedische SiidpolarExpedition nen mitgebracht wurden. Anf die einzelnen Ordumgen verteilen sie sich folgendermassen:

Coleoptera 35 Arten, (laron 20 neu: 12 Lepidouteren (zwei davon unbesehrieben). davon 1 neu: 6 Dipteren, davon 4 neu: I Hymenoptere (neu): I Rhynchote (neu). 1 ('opeognathe (neu), l Trichoptere, 1 Orthoptese (neu) und 9 Collembolen.

Auf Grund des vorliegenden Materiales whrlen von mir 8 nene Ciattumeren aufgestellt. Auffällig ist die grosse Anzahl von Riisselkäferarten. von denen sich 16 Speries anf den Inseln finden.

\section{Ordo Coleoptera. \\ Fam. Carabidae.}

Lissoptern.s W.ATERH. 1843.

Lissopterns W. Ternouse. Ann. Nat. Hist. XI. 184: p. 287.

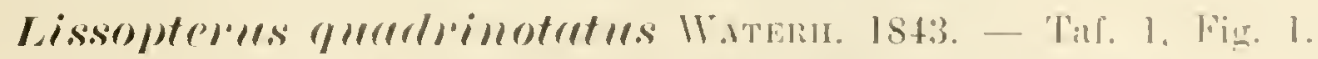

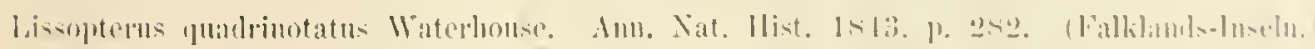

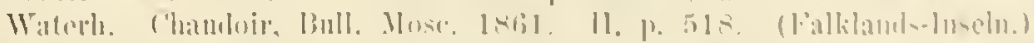

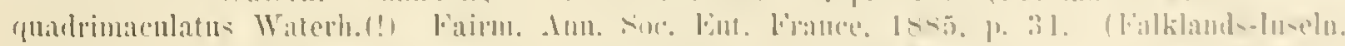

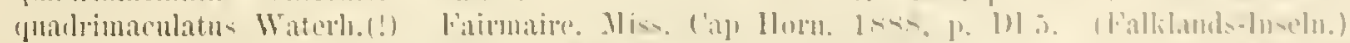

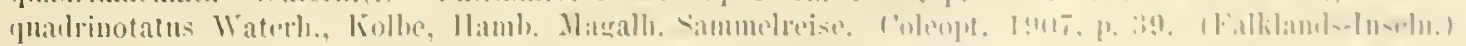

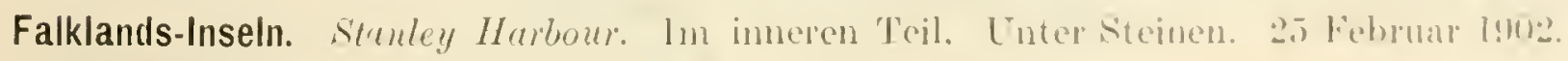

2 Exemplare. Körperlïnge $13^{1} s-16 \mathrm{~mm}$. 
Lissopteres quechleillotetes rar. billotetes nov. - Fig. 1.

Von den 4 Fleeken auf den Elytren sind nur die 2 hinteren erhalten. Körperlänge $12^{1 / 2}-16 \mathrm{~mm}$.

Falklands-Inseln. Port Stamley. Unter Steinen am Ufer. 1. Tanuar 1902. 1 Exemplar. - $\quad$ Port Stanley. Im östlichen Teil. Unter Steinen. 26. Febrnar 1902. 1 Exemplar.

Lissopteress quentionotates var. pirecess nor.

Die 4 Elecke anf den Elytren fehlen völlig. (Körperfarbe sehwarz.) - Körperlänge $12^{1} / 2 \mathrm{~mm}$.

Falklands-Inseln. Port Stantey. Tm östlichen Teil. Unter Steinen. 26. Februar 1902. 1 Exemplar.

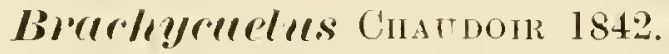

Bull. Mose. 1842. IV, p. S48. 1861. II, p. 512.

Burchycheles virescrus (WATERH. 1842).

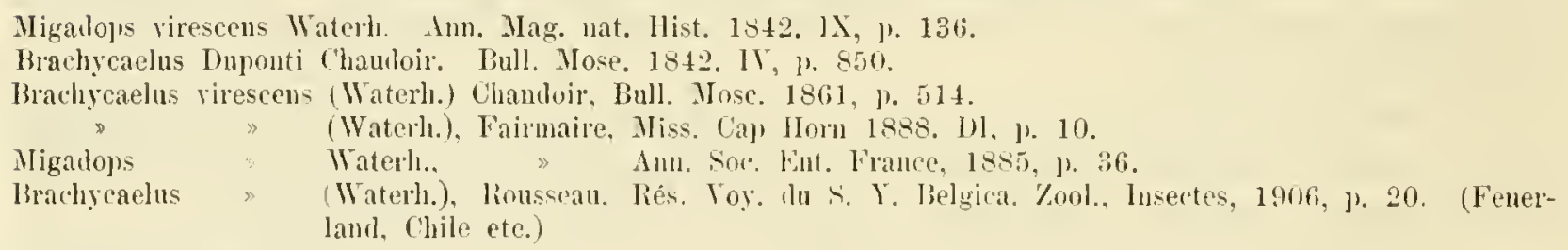

Falklands-Inseln.

Feuerland, Cap Horn.

Migadops. Waterif. 1842.

Waterlouse. Ann. Nat. Hist. TX. 1842, p. 136.

Migredops fallilamdiral Waterh. 1842.

Migadops falklandiens Waterhouse. Am. Mag. IJist. X. 1842, 1. 137. (Falklands-lıseln.)

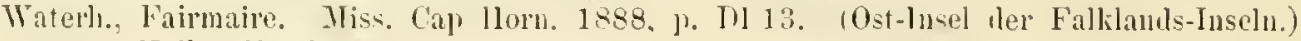
- Kollse. Haub. Magalh. Sammelr. Coleojt. 1907, j) 40.

Metills CurT1S 18:39.

Trans. Linn. Soc. 18. 1839, p. 189.

Metius harpaloirles CuRTts 1839.

Metins harjaloides Curtis. Trans. Linn. Soe. 1839. J. 190. (Falkiands-Inseln.) liolbe, IJanb. Magall. Sammelr. Coleopt. 1907 , p. 45. 


\section{Sulbam. Antarctiinae. \\ Antrerefire DEs, 1828.}

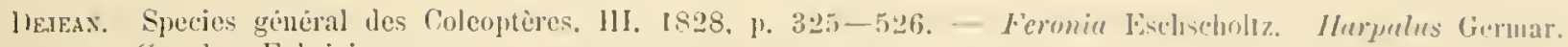
Curabus Fabricius.

\section{Anturetia blumlle DEJEAN 182S. - Taf. I, fig. 2.}

Antarclia blanda Dej. Dejean Spec. 111. 18:8. 1). 529. (Falklaudk-luceln.)

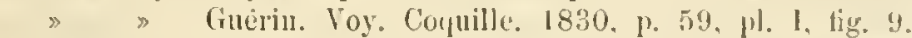

qualricollis Solier, in Gay, Hist. Chile. IV. 1849, 1. 246.

" \$ Gay, Hist. Chile. 1851. IV, 1\%. 2⿺6. (Chile.)

blanda Dej., I’utzeys, Mem. Soc. Se. Liegge. Y. 1873, p. 19.

$\gg \quad$ Fairmaire. Anu. Soc. Ent. Fr, 1885. 1\% 39.

$\gg \gg$ Miss. Cap Holn. 1888 [H, 1\%. 16.

$\gg$, Kolbe. Hamb. Magalh. Sammelr. Col. 1907, p. 46. (Süd-('lile his Fenerland, falklandsliseln.)

$» \gg$, Ronssean. Res. Voy. Belgica. Zool. Ins. Col. 1906, p. 21. (Fenerland.)

Falklands-Inseln. Port Stanley. Marray Highs. Unter Steinen. 22. Februar 1902. 1 Exemplar. - Im östlichen Teil. Unter Steinen. 26. Februar 1902. I Exemplar. - Februar 1904: I Exemplar, ein Übergang zwischen A. blanda nnd var. malachitica DEJ.

Antreretie blemele DE.J. var. melerdhitiren DE.J. 1828.

Aularctia malachitica Dejean. Spee. III. 1824, p, 534. (Falklauds-1uselu.)

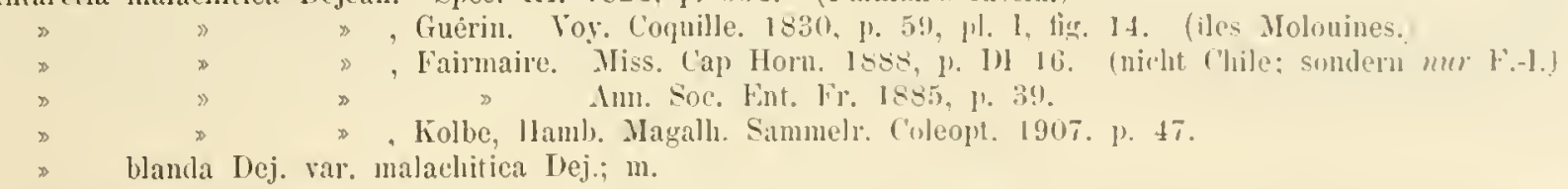

Falklands-Inseln. Port Stanley. Im östliehen Teil. Unter Steinen. 26. Februar 1902. 1 Exemplar. - Februar 19043 Exemplare.

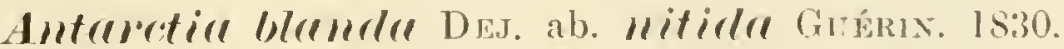

Antarctia nitida Guérin. Foy. Coquille. 1830. 1\%. 59. pl. 1, fig. 90. (l'allilimels-Jusclu.)

$\gg$ Guér., Kiollee. Iamb. Magall. Sammelr. Col. 13117, 1', 46.

b)anda Dej. aberratio nitila Gnér.; m.

Observation Insel. 6. Jammar 1902. I Exemplar.

Anterertia rimoser nor. spec.

Diese Species unterseheidet sich ron Ant. Ulunda DFs. dureh die ausscrordentlich scharfen Längsfurchen auf den Elytren, die mit blossen Augen sehr seharf und auffällig sichtbar sind; zwischen den cinzelnen Fuchen sind die Elytren deutlich gewölbt. Kopf und Thorax schwarz, glänzend, mit schwachem grünlichem Glanz: Elytren etwas weniger stark glänzend und mit ziemlicli stark rütlichem ('Flan\%. Körperlänge $S, 4 \mathrm{~mm}$. Kiörperbreite in der Mitte der Elytren $3{ }^{1}: \mathrm{m} \mathrm{mm}$.

Falklands-Inseln. Port Stanley. liebruar 1904. I lixemplatr. 


\section{Tribus Trechini.}

\section{Dormeyeria nov. gen.}

Typus: D. Audouini (GuÉr. 1830) (Falklands Inseln).

Ǩinnzahn 2-zähnig (Fig. l d); Epilobi (epl) abgesetzt. Über dem Kinnzalm inseriert jederseits unter der Basis des Labialpalpus eine lange Borste. Paraglossen $(p g)$ sehr kur\%, aussen sehr kurz pubesziert. Vorderrand der Zunge (z) gleiehmässig

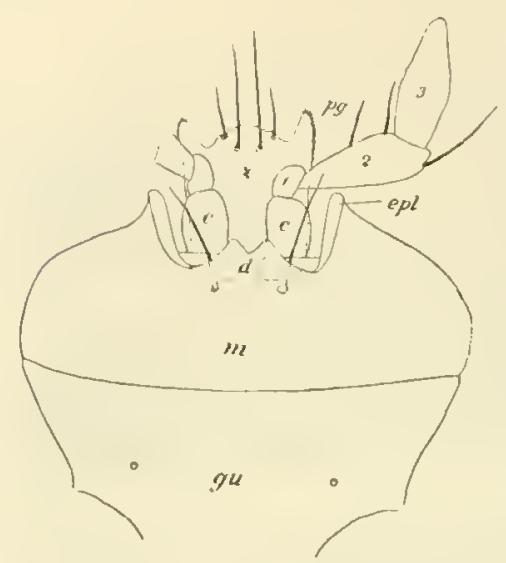

Fig. 1. Dormeyeria dudouini (Guér. 1830). Labium und Zunge von unten gesetien. Vergr. $65: 1$. gu $=$ Gula. $\mathrm{m}=$ Mentun. $\mathbf{d}=$ Krinnzahn. epl $=$ Epilohi, $\mathrm{z}=$ Zunge. $\mathrm{pg}=$ Paraglossen. $\mathrm{e}=$ Stipites (Coxen) des Labium. $1-3$ $=1 .-3$. Labialtasterghied, gewölbt und mit 4 langen Borsten, die 2 äusseren etwas kïrzer.

Der Bau der Zunge ist bei Trechus CraIRv. wesentlich anders, sodass über die Abtrennung kein Zweifel besteht. Trechus hat 10 Vorderrandborsten der Zunge, von denen das 2. Paar (von innen aus gezählt) zehr kurz stummelförmig ist. Paraglossen sehr lang, meist stark einwärts gekrümmt, innen lang und dicht behaart (ef. ENdertein, Deutsche Südp. Exp. Bd. X. Zool. II. 1908, p. 376, Taf. 42, Fig. 36).

Auffällig ist ferner bei Dormeyeria: der Körper ist auffallend glatt; die Elytren sind stark gewölbt und linten etwas mehr heruntergezogen als bei der Gattung Trechus, bei der sie etwas mehr depress erscheinen.

Diese Gattung widme ich meinem Freunde dem Chemiker und Coleopterologen Dr. Carl Dormeykr in Berlin.

Dommegeria Aurlomini (Guḱr. 1830). - Taf. 1, Fig. 4.

Treclus Aulonini Guerin, Yoy. Coquitle. Ins. 1830, 1. 60. Pl. I, Fig. 16. (Falkiauls-Inseln.)

testacens Blanchard, Toyage an pôle Sind. IV. 1853, p. 45. Taf. 3, Fig. 15.

Amlonini (ruér., Putzeys. Stett. Eut. Zeit. 1870 , 1. 22. (Nr. 15.) (Fallilands-Inseln mul Nagellanstr.)

», Fairmaire, Anu. Soc. Ent. Fr. 1885 , p. 42.

, Fairmaire, Miss. Cap Horn. 1888. DI, p. 21.

Dormeyeria Aurlouini (Gnér.) m.

Falklands-Inseln. Port Stanloy. Unter Steinen am Ufer. 1. Januar 1902. 7 Exemplare. - Hookers Point. Unter Steinen und trockenen Erdhöekern. 27. Februar 1902, 4 Exemplare. -- Port Stanley. Februar 1904. 1 Exemplar.

Auf dem 3. Streifen zwischen den Punktreihen vom Nahtrande aus gezählt finden sich jederseits 4 Punkte, die meist dieht am äusseren Punktstreifen liegen.

IDrmmenepia soledlurlima (Guér. 1830). - Taf. 1, Fig. 3.

'Trecluns soledadimus (inér., Guérin, Foy. Gornille. Ins. 1830, p. 60. PI. I. Fig. 15. (Fallitauds-Inseln.)

I'utzeys, Stott. Lnt. Zcit. 1870, pag. 200. (New Zealand) (nu in Verzeichnis an Schluss der Monographie anfgeführt; die Fundortsangahe ist wohl irrtümlich.

Fairmaire, Amm. Soc. Eut. Fr. 1885, 1. 41.

lormeyeria soledaliua (Guér.) m. 
Falklands-Inseln. Östlich ron Port Stumley. Unter einem nassen Stamm. Is. Aurust 1902. I Exemplar. - Febrnar 1!04. I Exemplar. - Senl-Com. Nürdliche Seite. Unter Steinen. 8. März 1904. I Exemplar.

Die 4 Punkte jeder Elytre liegen elenfalls am 3. Punktstreifen, der vordere neigt sich aber meist mehe nach dem 4 . \%wischerranue zu.

Típrllers: Chatr. 1806.

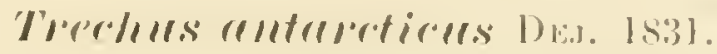

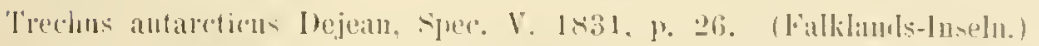

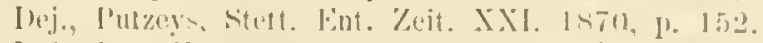

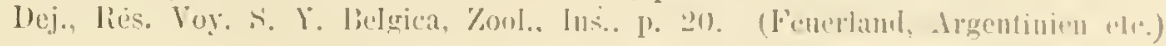

Meriagrles sou. 1849.

Solmer, in GaY, Hist. fis. Chil. IV. 1849, p. Is6. Taf. 3, Fig. 4. (Chile.)

Typus: M. angusticollis. Solive 184!). Chile.

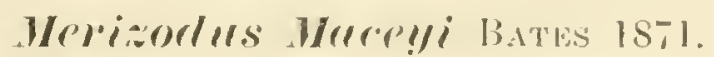

Oopterus Macesi biates. Fint. Mo. Mag. VIII. 1871, 1. I3.

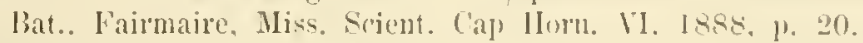

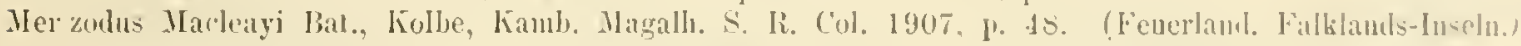

Fam. Dysiscidae.

\section{Lameres Share liseg.}

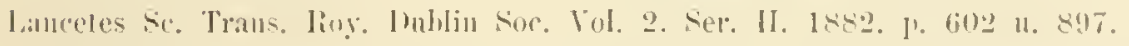

Spitze der Elytren sehräg abgestutzt. Palpen kaum oder nicht ausgerander am Ende des letzten Gliedes. Coxalfortsät\%e verlïngert, tief geteilt und stank divergierend.

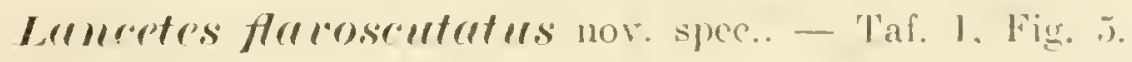

9. Kopf gan\% glatt, gar nicht chagriniert: ehitingelb. Seheitel bramschwar, die Grenze ist seharf, tangiert den Vorderrand der Augen und ist nach vorn ctwas knuknv. Angen gelbbram. Fïhler und Palpen chitingelb. 1)ie eingeritzte linie dicht an jedem Augeninnenrand ist scharf, und deutlich punktiert, sie ist fast his an die vordere obere Angenecke dentlich, beriihrt iln hier und divergiert mit ihm nach hinten zn gleiehmässig. Halssehild glatt. (hitingelb, chenso das Sentelhm die Brustunterseite. Die Vorderecken des Halssehildes sind in sehr lange spitye liontsätze nacl. rorn ansgezogen, die an der Spitze nicht abgertundet sondern schr spitz sind: die Spitze ist nieht nach einwärts gebogen. ['nterscite des Abdomen glatt chitingelb. Metasternalfortsätze am Ende breit gerundet, beide stark divergierend. Jieine chitingelb. Lüngerer Hinterschienensporn ca. ${ }^{3}{ }_{5}$ cles Mletatarsus; dieser fast so lang wie 
die 4 ïbrigen Fussglieder zusammen. Elytren ein wenig matt und sehr fein körnig chagriniert (viel weniger fein chagriniert als bei den verwandten Arten; ehitingelb), die schwarzen dichten zusammenfliessenden Punktreihen lassen an der Aussenseite einen ungewölnulich brciten Randsanm frei, der also ganz gelb ist und ungefähr ${ }^{1 / 3}$ der Breite jeder Elytre einnimmt. Hinten aussen ist jede Elytre schräg abgestutzt, aber nicht konkav (wie z. B. bei L. nigriceps ER.) sondern etwas konvex; die abgestutzte Strecke ist aber dureh eine ziemlich scharfe Ecke nach aussen und vorn von dem ïbrigen Elytrenrand abgesetzt.

Körperlänge $10 \mathrm{~mm}$.

Hintere Breite des Halssehildes 3,5 $\mathrm{mm}$.

Länge der Elytren $7^{1 / 2} \mathrm{~mm}$.

» Hintersehiene 2,5 $\mathrm{mm}$ :

» Hintertarsus $3,4 \mathrm{~mm}$.

Falklands-Inseln. Speer-Well Insel. Halfway-cove. Lagune am Ufer. 13. März 1902. 1 P.

\section{Fam. Staphylinidae.}

\section{Phytosus CurT. 1824.}

\section{P'lytosus Darvini: Waterh. 1879.}

Plytosus Darwini Waterlı., Waterhouse, Journ. Linn. Soc. London. 1879. XIV, 1. 531. (Falklands-Inseln.)

Waterlı., Faimaire, Ann. Soc. Ent. Fr. 1885, 1. 42.

Waterl., Fairmaire, Miss. Cap Jorn. 1888. 1)I, p. 24.

Waterl., Kolbe, IIamburg. Magallı. Sammelr. Coleopt. 1907, p. 52.

\section{Fam. Silphidae.}

Catops Parkut 1798.

Cretops fullilumlirels (Waterh. 1879). - Taf. 1, Fig. S.

Choleva falklaudica Waterh., Waterhonse, Journ. Linn. Soc. I.ondon. XIV. 1878, p. 531. (Falklands-Inseln.)

Waterlı., Fairmaire, Miss. Cap Horn. 1888. II, 1. 26.

Waterlı., Kolbe. Hamburg. Magall. Sammelr. Coleojt. 1907, 1. 56.

Catops falliandicus (Waterl.) Eulderlein, in diesel Abhandlung unter: Insekten rou Feuerland.

Eine Beschreibung nach einem von Feuerland (Gabla Insel) vorliegenden Exemplar findet sich in dieser Abhandlung unter: Insekten von Fenerland.

Soeben erhalte ich ans dem Britischen Musem eine Cotype von WATERHouse aus Ost-Falkland, dic völlig mit dem Stüeke ron Feuerland ïbereinstimmt.

\section{Fam. Byrrhidae.}

\section{Chalciosph(re)illm nov. gen.}

Typus: Ch. solox nov. spec. (Falklands-Inseln).

Körper fast eiförmig gekrïmmt; unten ziemlich flaeh. Clypeus nicht von der Stim getrennt. Labrum guer rechteckig. Fühler 11 -gliedrig, von der Mitte ab 
alluählich verdickt; 1. Glied auffällig dick, etwas länger als das :3. (甘lied. Die scharfen vorderen Seiteneeken des Halssehildes mässig stark zipfelartig vorgezogen, zugespitzt: diese verdecken deckelartig den Hinterrandsaum der Augen. Das Ścutellum fehlt völlig. Elytren hinten nicht klaffend, ohne Spml einer zipfelartigen lirweiterung nach hinten, unten völlig abgerundet. Hinterbrust mit Grube fïr die Hinterschenkel. Hinterbrust sehr lang, hintere Seitenecken rechteckig. 6 Abdominalsternite sichtbar, rom 1. jedoeh nur der Hinterrand (wie bei allen Byrrhiden). Alle Sehenkel imnen mit Rinne zur Aufnalme der Schienen. Alle Sehienen zylindriseh, nicht verbreitert, ohne scharfe Anssenkinnte, alle haben aber aussen cine von zwei sieitenkielen begrenzte Furche am Ende, die bei den beiden vorderen Beinpaaren fast halb so lang wie die Schienenlänge ist, kräftig, breit, poliert glatt und mit kräftigen Seitenkielen: die der Hinterbeine ganz kurz und nieht sehr scharf. Tarsen alle 5gliedrig; 3. Tarsenglied bei allen Fïssen nach innen und hinten in eine lange Spitze ausgezogen; 4. Glied sehr klein, beim Hinterfuss besonders klein und in einer Aushöhlung des 3. Gliedes etwas verborgen, wenn der 'Tarsus etwas gekrïmmt ist. ('Textfig. 2). Chalciosphacrium unterseheidet sich von Morychastes ${ }^{1}$ dureh das Fehlen des Scutellum, durch den Besitz der Aussenfurchen aller Schienen, und durch das Fehlen des Aussenkieles an diesen.

Chalciosphaerillm solox nov. spee. - Taf. 2, Fig. 16 und Textfig. 2 .

Kopf, Halsschild und Elytren intensiv metallisel grïn glänzend. Labrum quadratisch, schwarz. Kopf und Labrum mit kräftig ausgestochenen Punkten ziemlich dieht besetzt. Auf dem Halsschild ist diese Punktierung etwas weniger dicht. Auf den Elytren ist diese Punktierung ebenso dicht wie auf dem Halsschild, aber die Punkte sind klein und seicht und werden nach hinten zu ganz undentlich. Kopf mit Labrum. Halsschild und Elytren mit ziemlich dichter, langer, senkrecht abstehen-

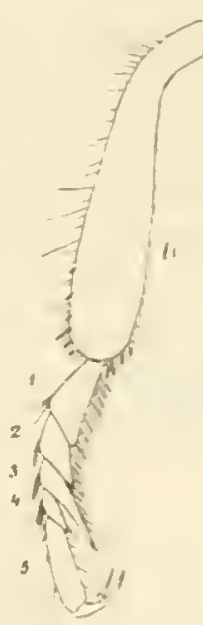

lig. 2 Chalciosphuerium solox Fisneri.. Rechtea Hinterluin Vergr. 43: 1. 13e. hamrungetwasschematisth. der gelbbramer Behaarung. Fïhlel ziemlich klein, selwwabraun. Beine schwarzbraun, mit gelbliehgrauer Behaarung, die ziemlich dielnt und abstehend, auf den Tarsen aussen sehr dicht ist. Tarsen etwas gedrungen, besonders die Vordertarsen. 2.-5. Sternit ziemlich gleieh lang; die Grenze zwischen 5. und 6. Sternit selır fein. Punktierung der Abdominalsternite sehr dicht und ziemlich kräftig, aber weniger kräftig als auf dem Halssehild; ihre Pubeszenz ist ziemlich dicht. sehr fein und mässig kurz; ihre Oberfläehe ist sonst ziemlich glatt. Hinterbrust glatt. mit mässig dichter und mässig feiner Punktierung.

Körperlänge $3^{3} /$ mm. Körperbreite $\stackrel{1}{1}+\mathrm{mm}$.

Falklands-Inseln. Port Louis. I Exemplat an 25. Juli 1902.

1 vergl. unter Iniekten Fencrlands. 


\section{Fall. Tenebrionidae. \\ Subfam. Helopinae.}

\section{Druminella nov. gen.}

Typus: D. amaroides nov. spec.

Antennen auffällig lang und dümn. 2. und 3. Fïllerglied auffällig lang und beide gleichlang. Die ïbrigen Glieder allmählich kürzer werdend, aber alle noch viel länger als breit; das Endglied (11. Glied) etwas länger als das vorletzte.

Halsschild breit, stark gerundet und der Aussenrand breit flachgedriielst und aufgewölbt gerandet, Schildehen klein und dreieckig. Elytren breit, ein breiter stark umgebogener Randsaum auf der Aussenseite. Beine relativ lang und schlank. Die Trochanter aller Beine sind in einen ziemlich kräftigen stark elitinisierten poliert glatten ein wenig abgebogenen spitzen Dorn nach hinten und innen ansgezogen. Klanen lang und schlank, wenig gelirimmt, ungezälnt. Die 5 sichtbaren Abdominalsternite sind nahezu gleichlang, das 2. ist ein wenig länger.

Ich widme diese interessante Gattung dem Andenken C'H. DARwin's, der selbst im Beginn seiner biologischen 'Tätigkeit den relativ starken Gegensatz der Fanna vou Fenerland zu der von Patagonien erkannte.

Dameinelln rmaroirles nov. spee. - Taf. 1, Fig. 10.

Einfarbig, hell braungelb. Der ganze Körper glatt und glänzend. Kopfpunktierung mässig dicht und sehr fein. Punktierung des Thorax fein. Elytren mit ziemlich dichten Längsreihen grosser kräftig eingedrïckter Punkte in ea. 9 Längsreihen. Zwischen diesen Punktreihen hier und da noch eine Längsreihe sehr feiner Punkte. Schildehen klein, fast unpmnktiert. Pubeszenz fehlt anf der Oberseite völlig. Abdomen anf der Unterseite mit mässig kurzer wenig dichter rostgelblicher Behaarung. Vorder- und Mittelcoxen stark aufgeblasen. Beine schlank, Schienen und Tarsen mit sehr kurzer Pubeszenz. Klauen lang, schlank, wenig gekrïmmt. Das Legerohr des + zuweilen weit herausgestreckt. Aus der männlichen Hinterleibspitze ragt häufig ein dünner Chitinfaden herans.

Körperlänge $7,5-10 \mathrm{~mm}$.

Falklands-Inseln. Fox Bay. 23. März 1902. 1 운 unter Steinen. - 25 März 1902. 5 ठ unter Steinen. - 27 März 1902. 1 ơ unter Steinen.

Dieser Käfer hat im Habitus eine gewisse Ähnlichkeit mit einer Carabide.

Proulelops Wateril. 1875.

Waterhouse, Trans. Ent. Soc. London. 1870, p. 333.

Fairmaire, Miss. Cap Horn. VI. 1888. DI, p. 57. 


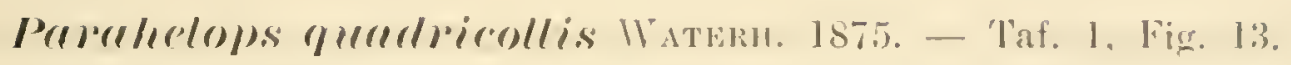

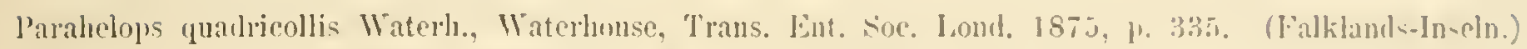

Waterh., Jaimaire, An, Soc. Lint. Fr. 1885, \%, 56.

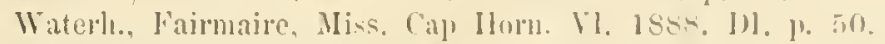

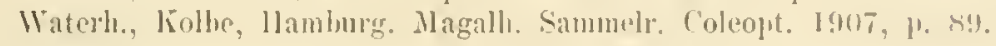

Falklands-Inseln. Port Stanley. Ilarray Hights. 22. Febr. 1902. \& Exemplare unter Sienen. - Cunnilu Creek. 4. März 1902. 12 Exemplare unter Steinen. - Port Darwin. Goose Green. 6. März 1902. T Nxemplare unter Steinen. - Seal C'me. im inneren Teil. 13. Närz 1902. 4 Exemplare unter Steinen. - Port Louis. 31. Juli 1902. I Exemplar unter Steinen. - Seal Core, nördliche Seite. S. März 1904. 5 Exemplare unter Steinen.

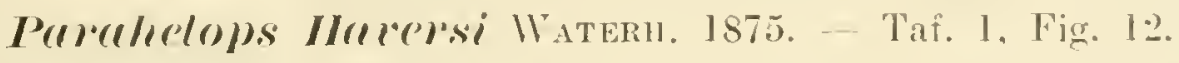

Parahelops Haversi Waterh.. Watcrhouse, Trans. Ent. Soc. Lond. 1875, 1) 336. (Falklands-Inseln).

Watcrl., Fairmaire, Inu. Soc. Ent. Fr. 1885, 1). 57

Waterh., Fairmaire, Niss. Cap Horn. Y1. 1888, 1. 5I. I'l. IJ, Jigr. 4.

Watell.. Kolhe, Ilamburg. Magalh. Sammelr. Colcopt. 1907, 1. 89.

Falklands-Inseln. Fox Bay. 2.5. März 1902. 4 Exemplare unter Steinen. - 26. März 1902. I Exemplar unter Steinen.

Fam. Chrysomelidae.

Subfam. Galerucinae.

Luperus Geofre. I762.

Geoffray, Hist. Ins. I, 1762, p. 230.

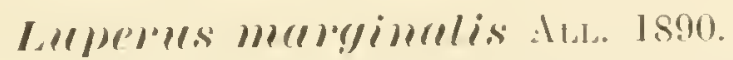

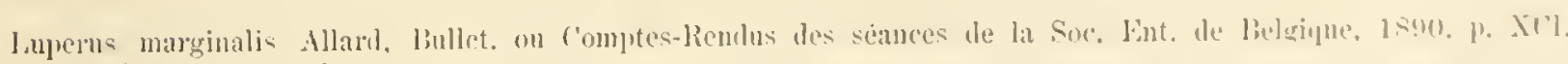
(1'allilands-luseln.)

Fam. Curculionidae.

Sulfam. Cylindrorhininae.

Tribus Cylindrorhinini.

Die Rüsselkïfer der Fallinnts-Inseln gehören nu diesem Tribus an. Die verhältuismässig zahlreichen Arten rerteilen sich anf 3 liattungen, iiber die folgende Tabelle eine Ubersicht gestattet. 


\section{Bestimmungstabelle der : Curculionidengattungen der FalkIands-Inselu.}

1. Rïssel mit meist scharfem Mediankiel. Prothorax mit Augenklappen .

Riissel ohne Mediankiel. Prothorax ohne Angenklappen

\section{2.}

Falklandius EnderL. 1907.

(Typus F. brachyomma

ENDERL. 1907.

Falklands-Tnseln.)

\%. Ober- und Unterseite mehr oder weniger fein punktiert. Prothorax völlig abgerundet. Körperform mehr oder weniger schlank. 3. mnd 4. Abdominalsternit mässig kurz, jedes so lang wie die Hälfte des 2. Sternites, meist aber länger. Trennungslinie zwischen Kopfkapsel und Submentum längs der Rïsselunterseite sehr undentliclı

Listroderes Вснӧмн. 1826.

('Typus L. costirostris

SсHӧNH. Brasilien.

Falklands-Inseln.)

3. Ober- und Unterseite sehr raul grob punktiert. Prothorax mit mehr oder weniger dentlichem Längseindruck. Schulterecken der Elytren mit scharfer kielartiger Seitenkante. Körperform gedrungen; hinten abgestutzt, Elytren steil abfallend. 3. und 4. Abdominalsternit sehr kurz, jedes viel kürzer als die Hälfte des 2. Sternites. Trennungslinie zwischen Kopfkapsel und Submentum längs der Püsselunterseite sehr scharf und tief.

Reichertia nov. gen. ('Iypus R. exsculpticollis

ENDERL. 1907.

Falklands-Inseln.)

Listroderes Sснӧмн. 1826.

(Typus L. costirostris Schönн. Brasilien.)

SCHÖNHERR, Disp. meth. 1826, p. 158.

Gen. et Spee. Curcul. T. II. 1834, p. 277.

Lacordairl, Genera des Coleoptères. T. VI. 1863, p. 344.

Enderleis. Stett. Ent. Zeit. 68. Jahrg. 1907, p. 38.

Syn. Antarctobius Fammare, Ann. Soe. Ent. Fr. 1855, p. 58 und Miss. Cap Horn, 1885.

Submentum mit breitem, kurzen Stiele; Mentum die Maxillen und Labialpalpen nicht verdeckend, aber relativ gross und glatt. Rüssel ungefïhr von Thorax-Länge, 
gerade, relatir sehlank (mässig diek), oben mit Mediankiel, parallelseitig, am Ende merklich verdickt. Angen gross, quer mud liurz eiförmig. Prothorax ohne Spur eines Sternalkanals; Thorax in der Mitte sehwach breiter. Fïhler 12 gliellig: Schaft fast die Mitte der Augen erreiehend, 2. Geisselglied verlängert und etwas kïrzer als das 1. (die in Nordamerika verbreiteten Gattungen Hyperodes JakE. (Ann. France 1sfit, p. 566) mit der Species humilis GYur. und Listronotus JiKEL (1. c. p. 566) mit den

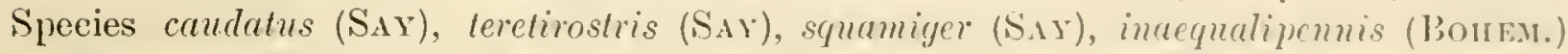
ete. zeichnen sich besonders dadurch aus, dass das 2. Geisselglied mehr als doppelt so lang als das 1. Geisselglied ist; bei diesen ist auch das 7 . Geisselglied ein L'bergang zwisehen Geissel und Keule; diese Formen dïrften eine besondere Gattung darstellen). 3. bis 6. Geisselglied rundlich, 7. C'eisselglied rerbreitert; die Keule hesteht aus 4 Gliedern, die beiden letzten sind aber wenig dentlich isoliert. Angendeckel immer dentlich bis kräftig entwiekelt.

Schienen mit sehr klemem Innendorn am Ende, der des Vorderbeines etwas kräftiger. Vordereoxen dieht gedrängt, Mitteleoxen etwas getrennt, Hintercoxen weit auseindergertiekt. Ein kleines höekeriges dreieckiges Jäppchen des Prosternums dräugt sieh noch ein Stück zwischen die Vordereoxen; zwischen den Mittelcoxen steht rin sehr erhabener Höeker, lı̈ufig auch in Form eines dïnnen Längskiels. Metasternum kurz. Flügel vorhanden. Elytren lang, schmal, hinten und an den Seiten steil abfallend; mit kallösen Auftreibungen in verschiedener Form oder ohme diese. Kürper mïssig dicht behaart, ausserdem mehr oder weniger dicht beschuppt, seltener ohne Sehuppen. 1. 1. 2. Tarsenglied verbreitert, 3-2-lappig, 4. verlängert: die 3 crsten unten mit dichtem sammetartigen Haarbesatz. 1.. 2. und 5 . Abdominalsternit lang. 3. und 4. kurz; von den letzteren beiden jedes so lang wie die Hälfte des 2. Sterniter. meist aber länger. Trennungslinie zwischen Kopfkapsel und Submentum längs der Riisselunterseite selır undentielr.

Die Gattung Anturctobins Furv. 1855 wurde anf Grund ron 3 Species aus

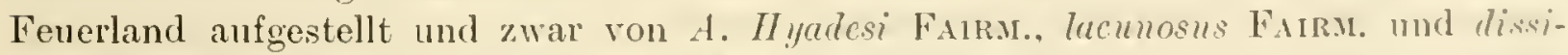
milis FaIru. und der Subfam. Burymotinac eingeordnet. Sowohl die Artheschreibungen und Abbildungen als aneh die Gattungsdiagnose lassen aber keinertei L'ntersehiedr von der Gattung Listroderes Scuöxir. 1826 erkennen. Da num aber die Burynotiden ${ }^{2}$ zu den Adelognalhen, die Cylindrorhinen aber zu den Phancrognathen gehören und die Vertreter der Gattung Listroderes ein für die Adclognalhen (sowohl die Formen von Magellan, Patagonien und Chile, als anch die von (len Falkland-Imseln) mugewihnlich grosses Mentum besitzen, das aber die Maxillen und Labialtaster froi lïsst. so cliirfte sieh FAJRmare ïber die Grösse und Ausdehumg des Mentums getïuscht hahen. Sowohl die völlige Ubereinstimmung des Banes der Fiilnler, als auch die lorm der" Augen und die Anwesenheit eines Mittelkieles des Riussels sprechen fiir dic '/ugehörigkeit zn der Gattung Listroderes. Anch die Anwesenheit der Höcker anf den Elytren bei 2 der Speeies (A. Hyadesi Fanu. und A. lacunosus Farm.) weisen hicranf hin. Aus diesen Griinden und unter Beriieksichtignug der zoogeographisehen Verbreitung

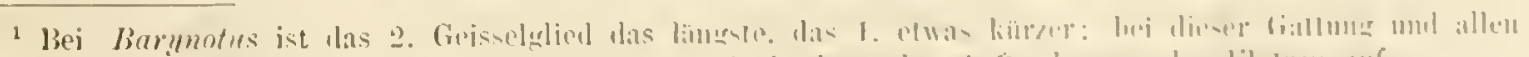

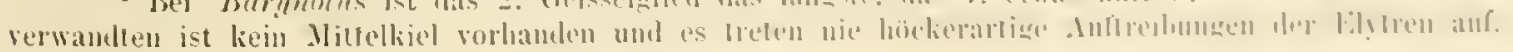

h. Sv. Vet. Akad, Handl. Band $\$ 3$. x: 3. 
hielt ich es 1907 fuir bereehtigt, die Gattung Antarclobius Farrm. 1885 der Gattung Listroderes Scuönı. 1826 einzuordnen. Inzwischen habe ich an Originalstiicken von Antarctobius lacunosus Farru. und A. Hyadesi Falru. im Pariser Musenm mich ïberzengen können, dass es sich tatsächlich so verhält.

Die Anwesenheit oder Abwesenheit von Schuppen ist nicht für die Gruppierung dieser hochentwickelten Insekten zu verwenden, wie dies LAcordarre tut. Es kommen bei allen den ïbrigen Gattnngen der Cylindrorhininen anch einzeln beschuppte Species vor. wie 7. B. bei Adioristus vittatus Pun. (Magellan), Scotoeborus murinus Scnönil, und Gylindrorhinus lateralis PHu. (Magelhan); dagegen kommen anch bei Listroderes Species ohne Schuppen vor, so z. 13. bei Listrod. Iaevigatus Pinu. (Magelhan) und L. glaber Prul. (Chile). Wie bei rielen anderen Gattungen kommen auch in der antarktischen Gattung Ectemnorhinus WaTERII. (Kerguelen und Crozet Inseln) beschuppte und unbeschuppte Species vor. Ubrigens gibt anch Scuösmers in der Originaldiagnose nicht die Anwesenheit eines Schuppenkleides als wesentliches Charakteristikum fïr die Gattung Listroderes an.

Bei der Gattung Adioristus WATERI. 184I ist der Fïhler wie bei Listroderes gebildet, der Riissel kurz und naeh dem Ende verbreitert; bei Scoloeborus Sciönı. ist der Rüssel Kurz und parallelseitig, Ecken abgerundet; Cylindrorhinus Gú́r. unterscheidet sich ron Listroderes durch quer rhombischen Prothorax. Alle diese Gattungen haben wie Listroderes einen Mittelkiel auf dem Rüissel.

Die eigenartige Gattung Empoeotes PAscoe auf Nen Seeland ist Listroderes ausserordentlich ähnlieh, besonders sind aueh die Fühler ron völlig gleichem Ban ebenso treten in gleicher Weise Höeker anf den Elytren und ein Mittelkiel auf dem Rüssel auf; das Mentum deckt jedoeh Maxillen und Labialpalpen völlig zu und haben die für die Phanerognathen charakteristische Entwicklung. Die Verschiedenheit der Ausdehnung des Nentum mag zwar ein für praktische Gruppierung sehr wichtiges Charakteristikum darstellen; das Relative dieses Merkmales ist jedoch sehr auffallend; mir scheinen die auffälligen Beziehnngen zwischen Empoeotes und Listroderes nieht nur zufälliger Natur zu sein, und finden sich aneh in der Auffassung Fairmairs's angedeutet. Listroderes nimmt eben in der Grösse des Submentum eine Mittelstellung zwischen Adelognathen und Phanerognathen ein.

Die Gattung Listroderes hat ihr eigentliches Verbreitungsgebiet in Patagonien, Magelhaen, Chile und anch anf den Falklands-Inseln; hier sind zahlreiche Arten vorhanden. Finzehe Arten gehen nordwärts bis Brasilien nnd Peru. In Nordamerika wird Listroderes durch die nahestehenden Gattungen Listronotus JEKEL und Hyperodes JEkEL ersetzt.

\section{Bestimmungstabelle der auf den Falklands-Inseln vorkommenden Arten der Gattung Listroderes.}

(Unter Körperlänge ist die Länge von Prothorax und Elytren zusammen verstanden.)

1. Elytren glatt, ohne Höcker oder erhabene Streifen.

Scheitel oben mit feiner Querritzung . . . . . ‘.

Elytren mit Höcker, erhabenen Längsstreifen, oder

Querwulsten. Scheitel nur punktiert, ohne Querritzung 4. 
¿. Elytren etwa $13 / 4 m m$ lang, hinten klaffend, dicht besehuppt. Körperlänge 11 mm . . . . . . . d divaricatus lixinliz. 1907. Elytren nicht klaftend, die Abdominalspitze gänzlich bedeckend, dicht besehuppt . . . . . . . . . . .

:;. Elytren hinten nicht seitlich \%usammengedrückt; ron der Seite gesehen hinten allmählich ablallend; die Schuppen erzengen eine grane Sprenkelung. Körperlänge $9^{1 / 2}-10^{1 / 2} \mathrm{~mm}$

Nordenskiöldi

Elytren hinten seitlieh zusammengedriekt; ron der Seite gesehen hinten abgerundet rechtwinklig abfallend und hierdureh einen auffälligen Buckel bildend. Körperlänge $9^{1 / 2}-12 \mathrm{~mm}$.

4. Elytren in der hinteren Hälfte mit 2 sehräg nach innen rechtwinklig konvergierenden Querwiilsten (dahinter je ein kräftiger spitzer Höeker). Körperlänge $8-8 \frac{1}{2}$ mun salebrosus HxDER I94\%. Elytren ohne Querwiilste, hinten nur mit jederseits einem mehr oder weniger grossen Höeker oder mit erhabenen Längsstreifen .

\section{.).}

5. Elytren hinten an der Umbiegungsstelle des Längsstreifens zwisehen 4. und 5. Punktreihe mit mehr oder weniger dentlichem Höeker

Elytren ohne Höcker, nur mit erhabenen Längsstreifen zwischen 2. und 3. sowie 4. und 5. Punktreihe; letzterer weniger deutlich. Elytren und Prothorax pubesziert, ohne Schuppen. Spitzen der Elytren mit je einem winzigen Höckerchen . . . . . . . . . . .

6. Prothorax und Elytren pubesziert, ohne Schnppen. . $;.$

Prothorax mehr oder weniger beschuppt und pubesziert: mit heller Medianlinie. Elytren dicht mit grossen lireisrunden Sehuppen besetzt.

\%. Elytren fein pubesziert; Höeker kräftig. Körperfarbe schwarz, Fühler und Beine dunkehotbraun. Nlle is Rüsselkiele seharf. Körperlänge $S-S_{2}$ z mm . . . . Elytren sehr dicht und kräftig hellgelbbraun pubesziert: Höcker winzig, dureh je einen feinen Haarbiischel deutlicher. Auf dem Prothorax in der Medianlinie eine durch weissliche Haare erzengte schmale helle Längslinie. Körperfarbe liell gelbbraun. Nur der Mittelkiel des Rïssels dentlieh. Körperlänge $4^{1} 4-5 \mathrm{~mm}$. . vulsus binkRL. I!HT.

abditus Exil:ki. 1907.

S. Körper sehlank, gelbbraun bis dunkelbraun. Prothorax mehr pubesziert als beschuppt; die helle Medianlinie aus Haaren bestehend, nur hinten aanz einzelne Sehup-

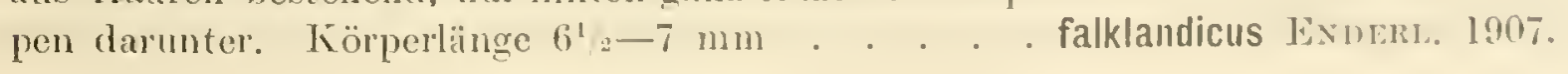


Körper gedrungen, hell gelbbraun. Prothorax mehr besehuppt als pubesziert; die helle Medianlinie aus Schuppen bestehend. Körperlänge $7 \frac{1}{2}-8 \mathrm{~mm}$.

bracteatus ENDERL. I897.

9. Längsstreifen zwisehen 2. und 3. Punktreihe (von der

Naht aus gezählt) besonders hinten vor der Spitze sehr erlaben, der zwisehen 4. und 5. wenig erhaben. Alle 5 Rüsselkiele deutlich. Kööperfarbe schwarz; Fïhler, Beine und Elytren mit Ausnahme der Seitenflächen und je eines Streifehens in der Mitte rotbraun. Körperlänge $9^{3} / 1 \mathrm{~mm}$. . . . . . . . . . • • . gibber ENDERL. 1907.

Längsstreifen zwischen 2. und 3. sowie 4. und 5. Punktreihe mässig erhaben. Innerer Seitenkiel des Rïssels fehlt und wird durch cine Längsfurche ersetzt, äusserer Seitenkiel undeutlich. Körperfarbe schwarz, Fïhler und Beine dunkel rostrot. Körperlänge $13 \mathrm{~mm}$. . . . bicaudatus EnderL. 1907.

\section{Listroderes salebrosus EnderL. 1907. - Taf. 2, Fig. 18.}

listronleres salebrosus linderlein, Stett. Ent. Zeit fis. Jahrg. 1907, p. 44.

Enderl., liolbe, Ilamb. Magalh. Sammelreise. Col. 1907, p. 105.

Sehr lang, schmal. Kopf ziemlich dicht und mässig grob punktiert, mässig dicht und sehr kurz aber kräftig behaart. Mittelkiel des Riissels kräftig, die Vertiefung am oberen Ende derselben in Form einer kräftigen kurzen eingedriickten Längsfurche; äısserer Seitenkiel kräftig, innerer mässig selıarf. Die Rüsselpunktierung ordnet sieh zwischen diesen 5 poliert glatten Längskielen zu Längsreihen an, und zwar finden sieh zwisehen den akzessorischen Kielen und den Seitenkielen je 2, zwischen ersteren und dem Mittelkiel je 3 oder undeutlich 3 Punktreihen. Rüssel mässig diek, nach vorn zu ziemlich gleichmässig verbreitert. 2. Geisselglied fast so lang wie die 3 folgenden zusammen, 1. etwa $1 / 4$ länger.

Prothorax wie der Kopf punktiert, Vorderrand gerade; Augendeckel mässig stark; Mitte des Vorderrandes in Form einer Querbeule erhaben, dicht hinter ihr eine 3-eckige mit der Basis auf ihr ruhende Einsenkung bis zur Mitte des Prothorax, die in der Mitte dureh eine kielartige aber nieht geglättete und breitrüekige Erhebung in 2 Teile zerlegt wird. Grösste Breite des Prothorax ror der Mitte, naeh hinten zu allmählich versehmälert. Elytren von Abdominallänge, sehr lang und sehmal, fast parallelseitig; oben rauh körnig, aber glänzend, Punktreihen sehr weit punktiert, an den Seiten etwas enger; steil abfallende Seitenfläehen ziemlich glatt und glänzend, Punktreihen hier etwas enger; Seitenkanten abgerundet seharfkantig; auf der Oberseite etwa in der Mitte auf jeder Elytre ein wallartiger sehräg nach hinten und innen verlaufender mässig seharfer Querwulst (diese beiden stehen im Winkel von etwa $90^{\circ}$ auf einander), hinter dem 1. Drittel zwisehen diesem und der Elytrenspitze ist ein z.weiter sehr scharfer solcher Querwulst (diese beiden stehen in stumpfem Winkel auf einander). Diese beiden Paare ron Querwulsten erstreeken sieh nicht bis an die 
Naht, sondem nur bis an die 1. Punktreihe (von der Naht aus greziilult) und nach aussen bis an die 4 Punktreihe; diese Anssenenden werden jederseits durelı einen rorn sehwach sich erhebenden und hinten stark entwickelten lä̈ngswulst verbunden, der den Zwisehenraum zwisehen der 4. und 5. Punktreihe ausfült, den hintern Querwulst ein Stiiek iiberragt und in cine kräftige abstehende stmmpfe Spitze endet. Kwiselien dieser und der Elytrenspitze in der Mitte findet sich ebenfalls zwischen 4. und 5. Punktreihe ein kräftiger spitzer kegelfömiger Höeker. Hinten sind die Elytren abgerundet und die Naht kaum eine Spur klaffend.

Tuberkel zwisehen den Mitteleoxen ziemlich breit zungenförnig, glatt. Einselnitt in der Mitte des Hinterrandes des Metasternums winzig, Metasternum fein quergeritz.. Unterseite des Abdomens ziemlich glatt, ziemliclı zerstrent punktiert, 5. Sternit $1^{1} 2$ mal so lang, wie das 3. und 4. zusammen.

Rotbrann; Unterseite des Körpers, die Selienkel und der Prothorax schwarzbrann; Oberrand der Seitenflächen der Elytren mit schwarzen Saum; die Einsenkungen vor und hinter den Querwiilsten häufig schwärzlich. Der ganze Körper mit gelblicher kurzer und mässig dichter Pubeszenz bedeckt.

Länge von Pronotum und Elytren zusammen $8-8^{1}$ : 1 m. Tiopflïnge 21 a mm. Grösste Körperbreite $3 \mathrm{~mm}$. Länge der Hintersehienen ㄹํ' 2

Falklands-Inseln. Stanley Harbour. Im inneren Teil. Unter Steiuen. I Exenplar. - Port Stanley im östlichen Teil. Unter Steinen. 26. Februar 1902.2 2 Exemplare. - Nahe Hookers Point. Unter Steinen und trockenen Firdhöckern. 27. Februar 1902. 2 Exemplare. - Port Dermin. Goosegreen. Unter Steinen. 6. März 1902. 1 Exemplar. - Seal-Cove, auf dem suidlichen Ufer. Auf Sand unter Steinen. S. Mïrz 1902. 1 Exemplar.

Diese Species erinnert durch die Färbung und Gestalt sehr an den Listroderes costirostris Scrönı, bei dieser fehlen jedoch die ? Par Querwiilste auf den Ëlytren und sind nur dureh Zeichung vorgetäuseht.

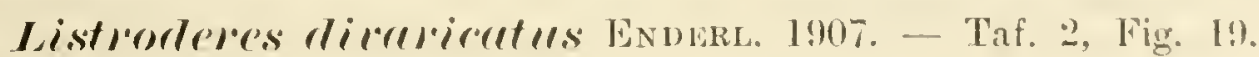

Listroderes divaricatus Finderlein, Stett. Fut. Zeit. 6ะ. Jahrg. 1907, 1). 4h.

Encler., Kolbe. Ilaml. Magalh. Sammeh. Col. 1907. 1. 105.

Lang aber relativ gedrungen. Kopf dieht und ziemlich fein punktiert. Seheitel oben selır fein quergeritzt. Rüssel mit anliegender und nach den Seiten grekïmmt anliegender Pubeszenz, ebenso die Umgebung der Angen. Sclıcitel unbelaart. Rüssel gedrungen, naeh vorn zu sch schwach verbreitert: Mittelkiel kräftig. poliert glatt, cine Vertiefung am oberen Ende desselben fehlt: ïusserer Seitenkiel scharf. imerer wenig scharf und umpoliert, mit ersterem nach vorn zu stark konvergierend. Riisselpunktierung nicht zu Reihen geordnet. 2. Geisselglied kaum so lang wie die ¿ folgenden zusammen, 1. 1'+ mal so lang wie das 2.

Prothorax etwa so lang wie hinten breit; in der Mitte am breitesten, nach rorn und hinten etwas rerengt; gleichmässig walzig; fein körnig und sehr dicht punliert. 
Augendeckel relativ flach und stark abgerundet. Elytren gedrungen, lang, nach hinten allmärlich zugespitzt, Seitenkanten abgerundet. Punktreihen sehr weitpunktiert. Der 'Zwischenraum zwischen 2. und 3. Punktreihe (von der Naht aus gezählt) in fast der ganzen Länge sehr schwach erhaben. Hinten sind die Elytren etwas spitzer oder rechtwinklig zugespitzt, ïberragen den Hinterleib eine Spur und klaffen eine Strecke von etwa $1^{3}{ }_{4} \mathrm{~mm}$ lang, indem sie ein schmales spitzes gleichschenkliges Dreieck vom Abdomen frei und unbedeckt lassen. Die ganzen Elytren gleichmässig mit kreisrunden matt grauglänzenden Schuppen dicht bedeckt, ausserdem mit zerstrent stehenden aufgerichteten gelblichen Haaren besetzt, die nach der Spitze zu sich immer mehr drängen.

Unterseite körnig punktiert, dieht, kurz und gran behaart. Tuberkel zwischen den Mittelcoxen langgestreckt zungenförmig, sehr dicht grau behaart. Hinterrand des Metasternum in der Mitte olme Einschnitt. Metastemum wie die ïbrige Unterseite punktiert. 5. Sternit halbkreisförmig, so lang wie die beiden vorhergehenden zusammen. Dies 3-eckige Feldchen der Oberseite der Abdominalspitze, das durel das Klaffen der Flïgel freibleibt, ist ziemlich dicht grau pubesziert.

Rotbraun, Elytren oben ziemlich dunkel graubraun.

Länge von Pronotum und Elytren zusammen $11 \mathrm{~mm}$.

Kopflänge $4 \mathrm{~mm}$. Grösste Körperbreite $5 \mathrm{~mm}$.

Länge der Hinterschiene $3{ }^{1}, 2 \mathrm{~mm}$.

Falklands-Inseln. Seal-Cove im inneren Teil. Unter Steinen. 13. März 1902. 1 Exemplar.

Listroderes bicundutus ENDFRL. 1907. - Taf. 2, Fig. 20.

Listroderes bieandatus Enderlein, Stett. Ent. Zeit. 68. Jahrg. 1907, 1. 47.

Enderl., Kolbe, Ilamb. Magalh. Sammelr. Col. 1907, 1. 104.

Gedrungen. Kopf ziemlich dicht und mässig fein punktiert. Rüssel besonders vorn ziemlich grob und dicht runzlig punktiert. Rïssel selır fein pubesziert; gedrungen, vorn ziemlich stark verbreitert; Mittelkiel scharf, glatt aber matt, äusserer Seitenkiel von einer undeutlichen Längsfurche ersetzt. Die Vertiefung am oberen Ende des Mittelkieles sehr klein, scharf und halbkugelförmig, die Umgebung hinter ihr spärlicher punktiert. 2. Geisselglied kaum so lang wie die 2 folgenden zusammen, 1. mehr als I $1 / 2$ mal so lang wie das 2.

Prothorax gedrungen, hinten etwas breiter als lang, vor der Mitte etwas höckerartig verbreitet, nach vorn stark, nach hinten allmählich verschmälert; dicht mud fein punktiert. Augendeckel abgerundet. Elytren ziemlich gedrungen, gleichmässig bogrig nach hinten verjüngt; Seitenkanten stark abgerundet; Punktreihen relativ eng punktiert. Die Zwischenräume zwischen der 2. und 3. und zwischen der 4. und 5. Punktreihe sind hinter der Mitte eine ziemlich lange Strecke weit eine Spur ïber die Gesamtoberfläche erhaben. Die Spitzen der Elytren sind nieht klaffend, aber wenig seitlich der Innenecke sitzt jederseits ein winziges kegelförmiges abgerundetes Höekerclıen; die Innenseiten dieser beiden Höekerchen bilden einen kleinen kaum 1/2 $1 \mathrm{~mm}$ langen rechtwinkligen Ausschnitt. Die ganzen Elytren sind mit lebhaft rötlich seiden- 
glänzenden feinen anliegenden Härehen besetzt, die im lindviertel und an den Seiten einen sehr dichten Belag bilden; hier und da besonders an den Seitenfliiehen der Elytren finden sich grössere oder kleinere Partien dieser Haare, die eine blänlich graue Färbung aufweisen.

Unterseite wenig deutlich gelblich grau pubesziert, Seiten des Aldomens granblan pubesziert, Nitte des Abdomens unbehart. 'T'uberkel zwisehen den Vittelenxen selı lang gestreckt und schmal zungenförmig, stark rumzliel punktiert, s]ärlich grau jubesziert. Die ganze Unterseite mässig dieht und fein punkticrt.

Der winzige Aussehnitt in der Mitte des Metasternums lualbkreisfürmig. ‘. Sternit etwas diehter pmnktiert und etwa so lang wie das :3. und 4. zusammen.

Schwarz, Fihhler und Beine rotbrann, Sehenkel dunkel rostrot.

Länge von Pronotum und Elytren zusammen $1: 3 \mathrm{~mm}$.

Kopflänge $4 \mathrm{~mm}$. Grösste Körperbreite $6 \mathrm{~mm}$.

Länge der Hintersehiene $4^{1}, 2 \mathrm{~mm}$.

Falklands-Inseln. Port-Dawin, Goosegreen. Unter Steinen. 6 März 1902. I Fxenjplar.

L. bicaudatus erinnert durch die beiden Höckerchen an den Spitzen der Eilytren an den L. Hyadesi (FArrm. 1885) von Feuerland; letzterer zeiehnet sich aber dureh die Anwesenheit der Elytrenhöekern am Ende der zwisehen 4. und 万. Punktreilie gelegenen Längsstreifen aus.

Listrorleres Nomelemslioïldi Exnert. 1907. Taf. 2, Fig. 221.

listroderes Forlenckiöldi Enderlein, Stett. Ent. Zeit. 68 Jahur. 1907, 1'. 48.

Ender., Folbe, Haml. Magall. Sammell. Col. 1907, 1. 104.

Ziemlich gedrungen bis schlank (ठ). Kopf mässig dicht und mässig fein punktiert, Rüssel ziemlich grob und dicht punktiert, Seheitel oben fein und dicht quergeritzt. Rüssel mässig gedrungen, vom mässig verbreitet. Umgebung der Augen feim anliegend grau pubeszient: Nittelkiel sehr scharf und poliert glatt, die Vertiefung am oberen Ende desselben tief sehlitzartig eingerit»t und kurz. Innerer und äusserer Seitenkiel dicht runzlig punktiert und wenig scharf. 2. Geisselglied etwa ${ }^{3}$ s so lang wie die beiden folgenden zusammen, l. etwa $I^{\prime}$, mal so lang wie das :2.

Prothorax walzig, so lang wie hinten breit, wenig vor der Vitte am breitesten, nach vorn schneller, nach hinten allmählich verschmälert. dielıt und fein punktiert. Augendeckel flach. Elytren gedrungen bis sehlank (o), gleichmässig schwach bogig nach hinten verjüngt; Seitenkanten völlig abgerundet; Punktreilıen weit punktiert.

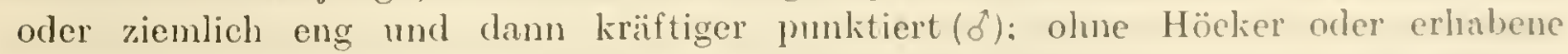
Streifen. Die Spitzen der Elytren sind ahgerundet, Naht durchaus nicht klaffend. beim $\delta$ sind Enden an der Naht spitzwinklig ausgeschnitten und lissen ein kleines 3-eckiges Feld des Abdomens frei durehblieken; die Elytren des ò erreichen ansserden nicht ganz dic Abdominalspitze. Die gesamten Elytren sind sehr dicht mit eiförmigen oder schlankeren Schuppen bedeckt, ehenso die Endhälften der Aussenseite der Hinterschenkel; die meisten dieser Schuppen sind fast farblos und mu mit sehr seharfer 
Lupe erkennbar. Kleine rundliche Partien, die zahlreich sich ïbcr die Seiten und das Enddrittel der Elytren ziemlich dicht verteilen, sind lobhaft weissgrau und erzeugen eine grau gesprenkelte Zeichnung auf den schwarzen Elytren.

Unterseite sehr dicht und fein punktiert, Metasternit 1. und 2. Sternit des Abdomens sehr dicht und undeutlich quergeritzt punktiert. Die ganze Unterseite mässig dicht gran pubesziert. Tuberkel zwischen den Mittelcoxen klein, sehr hoch und etwas langgestreckt. Der winzige Ausschnitt in der Mitte des Hinterrandes des Metasternums kaum angedentet. 5. Sternit halbkreisförmig und so lang wie das 3. ind 4. zusammen.

Tiefschwarz, Fühler dunkelrotbram. Schuppenzeichnung der Elytren siehe oben. Länge von Pronotum und Elytren zusammen $9^{1 / 2}-10^{1}, 2 \mathrm{~mm}$.

Kopflänge $3^{1 / 2} \mathrm{~mm}$. Grösste Körperbreite $3^{3 / 4}-5 \mathrm{~mm}$.

Länge der Hinterschiene $3^{1 / 4}-3^{1 / 2} \mathrm{~mm}$.

Falklands-Inseln. Port Darwin. Goosegreen. Unter Steinen. 6. März 1902. 7 Exemplare. - Seal-Cove im inneren Teil. Unter Steinen. 13. März 1902. 1 Exemplar. - Port Stanley. Febr. 1904. 1 Exemplar.

L. Nordenskiöldi erinnert durch die graugesprenkelten Elytren sehr an L. bicandatus; letzterer interscheidet sich aber leicht durch den völligen Mangel von Schuppen auf den Elytren und von Querritzen auf dem Scheitel.

\section{Listroderes IMlsus ENDERL. 1907. - Taf. 2, Fig. 22.}

Listroderes vulsus Euderlein, Stett. Ent. Zeit. 68. Jahrg. 1907, p. 50.

Enderl, Kolbe, IIaml. Magall. Sammelr. Col. 1907, p. 104.

Schlank. Kopf ziemlich wenig dicht und mässig fein punktiert, Rüssel mit kräftigen etwas in die Länge gezogenen Punkten dichter besetzt. Rüssel gedrungen, vorn schwach verbreitert, völlig ohne Pubeszenz (abgesehen von den Mundborsten). Mittelkiel und äusserer und innerer Seitenkiel (beide stark nach vorn konvergierend) kräftig und scharf ausgebildet und poliert glatt. Die Vertiefung am oberen Ende des Mittelkiels sehr scharf und länglich eiförmig, hinter ihr noch eine winzige, kräftige und rundliche 2. Vertiefung. 2. Geisselglied so lang wie die beiden folgenden zusammen, 1. etwa $1 \frac{1}{2}$ mal so lang wie das 2. Keule langgestreckt, Spitze stark abgermndet.

Prothorax walzig, etwas länger als hinten breit, wenig vor der Mitte am breitesten, nach vorn und hinten gleichmässig verschmälert, ziemlich dicht und fein punktiert. Die ganze Oberflïche des Prothorax ist ausserdem mit einer mikroscopiseh feinen und dichten Punkt-Ziselicrung versehen, die nur einen sehr matten Glanz zu Stande kommen lïsst. Augendeckel sehr flach, von der Seite kaum bemerkbar, nur von schräg unten. Elytren schlank, die Hinterleibsspitze ziemlich weit überragend (so dass der Hinterleib in den Elytren versenkt liegt), parallel, vom Anfang des letzten Drittels ab ziemlich scharf zugespitzt, hinten völlig abgerundet, jederseits der Naht am Ende I winziges sehr flaches Höckerchen; Scitenkanten abgerundet. Punkte der Punktstreifen mässig dicht. Vor der Umbiegungsstelle des 4. Punktstreifens vor der 
Elytrenspitze ein kleiner hinten etwas spitzer Höeker, der an dieser spitzen Stelle ziemlieh dieht pubesziert ist. Naht nicht klaffend. Sehuppen fehlen. Elytren wit ziemlieh dichten, sehr feinen und kurzen grauen Härehen besetzt.

Unten sehr sehwach pubesziert, poliert glatt, kamm hier und da punkitiert, Metasternum und 1. und 2. Abrominalsternit quergerit\%. 5. Stennit etwas länger als dic sehr kurzen 3. und 4. Sternite zusammen. Tuberkel zwisehen den Mitteleoxen wenig hoeh, rauh-und länglich oval. Der wingige Aussehnitt in del Mitte des Hinterrandes des Netastermums dentheh.

Sehwarz; Fïhler, Tarsen. Oberseite der Schenkel und Nahtrand, Aussenrand, Spitze und Seitenkante der Elytren rotbrann. Auf den lilytren dehnt sich die rotbraume Färbung auch zuweilen weiter aus.

Länge von Pronotum und Elytren zusammen $8-8^{1}$ a $\mathrm{mm}$.

Kopflänge $2^{1} / 2 \mathrm{~mm}$. Grösste Kö̈rperbreite $3^{1} \mathrm{~g}-3^{\mathrm{a}}+\mathrm{mm}$.

Länge der Hintersehiene $2^{1 / 2} \mathrm{~mm}$.

Falklands-Inseln. Port Darwin, Goosegreen. Untel Steinen. 6. Mïrz 1902. 3 Exemplare, davon 1 mausgefärbtes gelbbrames Stïek.

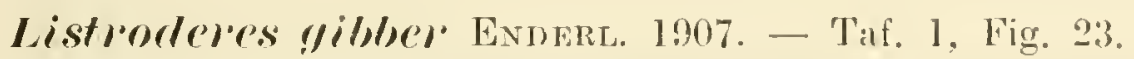

Listroderes gibber Enderlein, Stett. Ent. Zeit. 68. Jalırg. $1 ! 97$, 1. 51.

\$ Enderl., Kolbe, Hamb. Magalh. Sammelr. Col. 1907, p. 105.

Ziemlieh gedrungen. Kopf mässigg dieht und mässig fein punktiert. Riisse] unregelmässig längsrunzlig; gedrungen, vorn schwach verbreitert, sehr spärlich pulsesziert, nur hinter den Augen dentlieher. Mittelkiel scharf, poliert glatt, Verticfung am oberen Ende klein, kräftig eiförmig. Äusserer Seitenkiel scharf, poliert glatt, innerer Seitenkiel wird durch die lä̈ngstmueln etwas weniger dentliel. 2. Cieissclglied wenig länger als die 2 folgenden Glieder zusammen, 1. Geisselglied etwal'za mal so lang wie das zweite Kenle langgestreekt, Spitze stark abgerundet. Sehaft den hinteren Augenrand erreichend.

Prothorax walzig, etwas länger als hinten breit, in der Mitte am breitesten. bogig naeh rom und hinten versehmälert, zicmlich dicht und fein punktiert. Die ganze Oberfläehe des Prothorax ist ansserden mit einer mikroscopisch feinen und dichten Punkt-Ziselierung versehen (wie bei L. vulsus EvonkL.). Augendeckel sehr flach, ron der Seite nur sehwach bemerkbar, dentlich ron schräg unten. Elytren gedrungen. die Hinterleibsspitze ziemlich weit überragend (so dass der Hinterleib in den İlytren versenkt liegt), ziemlich parallel, ron Anfang des letzien Drittels ab zicmlich selıat zugespitzt; hinten völlig abgerundet, an der Elytrenspitze wisehen 1. nnd 2. l'mulitreihe an der Umbiegungsstelle je ein winziger rundlieher Hïeker" Seitenkanten etwas abgerundet. Punkte der Punktstreifen riemlieh dieht. Zwischen 2. und 3. P'unlitstreifen vom Anfang des 3. Drittels ab ein langgestreekter ziemlich erhabener lïingswulst, der sieh sehwach weit nach vorn fortsetzt, \%wischen t. und \%. Punktstreifen ist ein ähnlicher sehr sehwach angedentet. Naht nicht klaffend. Sehuppen fehlen völlig. Elytren ziemlich dicht, sehr foin und kur\% grian pubes\%icrt. 
Unterseite sehr wenig pubesziert, poliert glatt, kaum hiel und da punktiert. Metasternum und 1. Abnominalsternit seicht quergeritzt. Der winzige Ausschnitt in der Mitte des Hinterrandes des Metasternums dentlich. 5. Sternit etwas länger als die 3. und 4. Stemite zusammen. Tuberkel zwisehen den Mlittelcoxen schmal zungenförmig, grob punktiert.

Schwarz, Fühler, Beine (nit Ausnahme der Coxen und Schenkelbasis), Seiten und Hinterrand der Oberseite des Prothorax, Elytren mit Ausnahme der Seitenflächen und je eines Längsstreifens in der Mitte zwischen den 3. und 4. Punktreihen rotbraun.

Länge von Prothorax und Elytren zusammen $9^{3 / 4} \mathrm{~mm}$.

Kopflänge $2^{1} / 4 \mathrm{~mm}$. Grösste Körperbreite $2{ }^{1 / 2}-2^{3} / 4 \mathrm{~mm}$.

Länge der Hinterschiene 21/4 $11 m$.

Falklans-Inseln. Port William, Sparrow-Cove. 2. März 1902. 1 Exemplar.

Listroderes gibber gleicht in Färbung und Habitus sehr dem gleiehfalls schuppenlosen $L$. laevigatus Prin. von Magahhaen; dieser zeichnet sich jedoch besonders dureh den Besitz kräftigej Höcker hinten an der Umbiegungsstelle des Längsstreifens zwischen 4. und 5. Punktreihe aus.

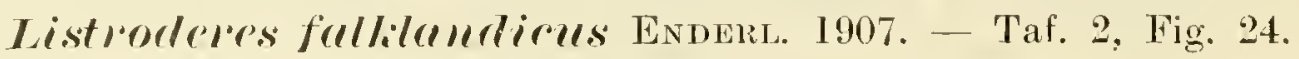

Listroderes falklandicus Enderlein, Stett. Ent. Zeit. 68. Jahrg. 1907, p. 53.

Futlerl, Kolbe, IIamb. Hagalh. Sammehr. Col. 1907, p. 105.

Schlank. Kopf dicht und wenig grob gleichmässig punktiert. Rüssel ziemlich schlank, vorn sehr sehwach verbreitert; von der Seite naeh innen und hinten gekämmt anliegend, ziemlieh dicht gelb pubesziert. Nittelkicl unscharf und runzlig, äusserer Seitenkiel scharf, innerer fast ganz verschwunden. Dic Vertiefung am oberen Fude des Mittelkieles wenig dentlich. 2. Geisselglied fast so lang wie die 3 folgenden zusammen, 1. Geisselglied $I^{1} *$ mal so lang wie das zweite Kenle ziemlich gedrumgen, allmählich nach der Spitze $7 . n$ zugespitzt, Spitze wenig abgerundet. Sehaft den Hinterrand der Augen erreichend.

Prothorax walrig, ziemlich viel länger als hinten breit, oben etwas flachgedriickt, anr Ende des 1. Viertels am breitesten und hier an den Seiten etwas höckerartig verbreitert, nach vorn selır steil, nach hinten bogig verschmälert; sehr dicht und fein punktiert und dicht mit kleinen sehwach gelblich glänzenden runden Schuppen bedeckt; in der dorsalen Mittellinie in einem schmalen Jängsstreifen diese Schuppen lehhaft hellgelb gefürbt, bei dunklen Exemplaren ist diese helle Linie weniger scharf, bei einem dunkelbraunen Exemplar nicht erkembar. Augendeckel stark abgeflacht. Elytren schlank, allmählich bogig nach hinten versehmälert, Ende abgerundet; Naht an der Spitze eine winzige Strecke (etwa $1 / 4 \mathrm{~mm}$ ) klaffend; Seitenkanten stark abgerundet; die Hinterleibsspitze melır oder weniger ïberragend. Punkte der Punktstreifen ziemlich dicht. Zwischenraum zwischen der 1. und 2. Punktreihe (von der Naht aus gezählt) am Ende und der zwischen der vorletzten und letzten Punlitreihe in seiner ganzen länge etwas erhaben. Zwischenraum zwischen 6. und 7. Punktreilıe vom 
Ende des 1. Drittels bis zu seinem Umbiegungspunkt hinter dem Anfang des 3. Drittels ziemlich stark erhaben und in cinen kleinen stumpfen Höeker hinten endend, der mit einem Haarbüschel besetzt ist. Flytren mit längsreihen abstehender gelblichen Börstchen zwischen den Punktreilen und gänzlich nit rundichen grolblich seidenglänzenden kleinen Schuppen sehr dicht bedeekt. Hinterschenkel ohne Selunpen.

Unterseite ziemlich glatt, späirlich und riemlich groh punliticrt, mässig dicht gelblich pubesziert. Tuberkel zwisehen den Mittelcoxen erhaben, gleichseitig dreieckig. punktiert, ziemlich dicht gelblich pubesziert. Der wingige Ausschnitt in der. Mitt. des Hinterandes des Metasternums kräftig und tief. Jetztes Sternit langrestrerlit dreieckig, hinten stark abgerundet, $I^{1}$ " mal so lang als die beiden rorhergehenden (3. und 4.) Sternite.

Gelbbraun bis dunkelbraun: Prothorax neist mit der schon erwihnten Medianlinie aus hellgelbliehen Schupjen; Elytren in der Nitte mit jederseits einem schwärzlichen wenig nach hinten und innen konvergierenden Längsstreifen, dicht dahinter je cin schräg nach hinten und innen convergierender (im Winkel von 90') gelblicher Querfleck (beide berïhren sich in der Mediallinie nicht). Hinter diesem liäufig noch einzelne schwärzliehe Fleckehen. Bei dunklen Tieren tritt diese Zcichnung zuriick, bei einem schwärzliehen Exemplar ist sie nicht zu erkennen.

Länge von Prothorax und Elytren zusammen $6 \frac{1}{2}-7 \mathrm{~mm}$.

Kopflänge $2^{1} \cdot 4 \mathrm{~mm}$. Grösste Körperbreite $2^{1} 2^{2}-2^{3 / 4} \mathrm{~mm}$.

Länge der Hinterschiene $2^{1}+1 m m$.

Falklands-Inseln. Hookers Point. Unter Steinen und troekenen Erdhëckern. 27. Februar 1902. I Exemplar. - Port Irillicm. Sparrow-Cove. 2. März 1902. 1 kixcmplar. - Port Darwin. Goosegreen. Unter Steinen. 6. Mï\% 1902. ¿ Fxemplare. - Seal-Coce in inneren Teil. Unter Steinen. 13. 11:i\% 1902. ¿2 Vxemplare. - Port Strmley. Februar 1904. 1 Exemplar.

L. falklandicus erinnert in Form und Fürbung (besonders anel dureh die gelbe Medianlinie des Prothorax) an L. cinerascens BLANer. von Chile, der sich aber durel, den Mangel ron Höckern auf den (gleichfalls beschupten) Elytren und durch die völige Schuppenlosigkeit des dicht und lang behaarten Prothorax auszeichnet.

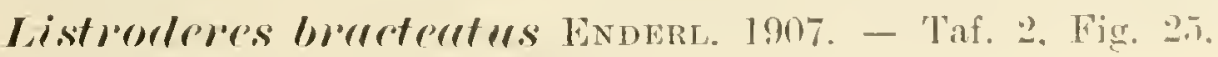

Listroderes bracteatus Enderlein, Stett. Ent. Zeit. 68. Jahrg. 1907. 1\%. 55.

Enderl., liotbe, Hamb. Magah. Sammelr. Crol. 1907, 1. 105.

Ciedrungen. Sliulptur des liopfes ist durch die ziemlich dichte. selur alielie und mässig lange Behaarung nicht erkembar; dic Behaarme ist anf dem Scheitel nach vorn, auf dem Riissel schrüg nach innen und hinten gekïmmut. Mlittelkicl mässig selarf und poliert glatt; innerer Seitenkiel nieht erkonnbar, ïnsserer mnscharf. Ruissel gedrungen, nach dem Ende rerbreitert. Die Verticfung am oberen Ende des Mittelkieles deutlieh aber dureh die Beharmug etwas rerdeckt. 2. Creisselglied fast so Jang wie dic 3 folgenden zusammen. 1. Geisselglied fast längel' als $l^{1}$ a mal so lang wic 
das 2.; Keule ziemlich gedrungen, die beiden ersten Glieder ziemlich abgesetzt, die zugespitze Spitze wenig abgerundet. Schaft fast den Hinterrand der Augen erreichend.

Prothorax walzig, etwa so lang wie hinten breit, oben schwach abgeplattet, an Ende des 1. Viertels an breitesten und hier an den Seiten etwas höckerartig verbreitert, nach vorn steil, nach hinten bogig verschmälert; spärlich abstehend gelb behaart und sehr dicht mit gelblich seidenglänzenden relativ grossen kreisrunden Schuppen bedeckt; in der dorsalen Mittellinie ist ein schmaler Längsstreifen dieser Schuppen lebhaft hellgelb gefärbt, ebenso je ein undentlicher Längswisch nahe der Seiten. Angendeckel stark abgeflacht. Elytren gedrungen; die Abdominalspitze ein wenig überragend; Naht an der. Spitze kaum eine Spur klaffend; Seitenkanten stark abgerundet; nach hinten mässig versehmälert und hinten stark abgerundet. Am Hinterende des Streifens zwischen der 4. und 5. Punktreihe ein kräftiger kegelförmiger Höcker ohne ausgesprochenen Haarbüschel auf der Spitze. Streifen zwischen der 4. und 5. und zwischen der 6. und 7. Punktreihe undentlich in der ganzen Länge erhaben. Elytren mit Längsreihen abstehender gelber Börstchen zwischen den Punktreihen und gänzlich mit kreisrunden gelblich seidenglänzenden relativ grossen Schuppen sehr dicht bedeckt. Hinterschenkel ohne Schuppen.

Unterseite ziemlich seicht punktiert, mässig dicht gelblich pubesziert. Tuberkel zwischen den Mittelcoxen mässig erhaben, schmal zungenförmig, dicht pubesziert. Der winzige Ausschnitt in der Mitte des Hinterrandes des Metasternums rundlich, 3. und 4. Sternit sehr kurz; 5. Sternit relativ lang, dreieckig, hinten ziemlich breit fast gerade abgestutzt und fast doppelt so lang wie das 3. und 4. Sternit zusammen.

Hell gelbbram; Prothorax und Elytren und die Beschuppung, Kiopf und Beine durch die Pubescenz hell bräunlich gelb matt seidenglänzend. Unterseite rötlich braungelb. Thorax mit der erwälmten Schuppenzeichnung.

Länge von Prothorax und Elytren zusammen $7^{1},-8 \mathrm{~mm}$.

Kopflänge $2^{1 / 4}-2^{1} 2 \mathrm{~mm}$. Grösste Körperbreite $3^{1 / 2}-3^{3}{ }_{4} \mathrm{~mm}$.

Länge der Hinterschiene 2,5-2,7 $\mathrm{mm}$.

Falklands-Inseln. Port Stanley. Marray Heights. Unter Steinen. 22. Februar 1902. 2 Exemplare.

Listroderes bracteatus erinnert durch die starken Höcker anf den Elytren an den L. lacunosus (FAIRM. I885) von Magelhaen.

\section{Listoorleves rbrlitus Enderr. 1907. - Taf. 2, Fig. 26.}

Listroderes abditus Euderlein, Stett. Ent. Zeit. 68. Jahrg. 1907, p. 57.

Euderl., Kolbe, IIamb. Magalh. Sammelr. Col. 1907, J. 105.

Mässig gedrungen. Kopf ziemlich grob punktiert, Punktierung durch die zientich dichte und mässig lange Behaarung nicht sehr dentlich erkennhar; die Behaarung ist auf dem Scheitel nach vorn, auf dem Rüssel nach innen zu gekämmt. Mittelkiel wenig scharf aber dentlich, körnig rauh. Innerer und äusserer Seitenkiel nicht erkennbar. Die Vertiefung an oberen Ende des Mittelkieles dentlich. Rüssel lang und ziemlich 
selılank, an Ende kamm verbreitert; über der Fiilılerinsertion mit je einem deutlichen Höeker; der Rüissel ïberragt diesen P'unkt noch nu ein heträchtliches. 2. Cicisselglied etwas länger als die beiden folgenden zusammen, 1. Geisselglied nu wenig länger als das 2.: Keule gedrungen, Spitze abgerundet. Schaft erreieht nicht dic Mlitte der Augen.

Prolhorax walzig, etwas lïnger als hinten breit, oben seluwael abgeplattet, am Ende des 1. Viertels am breitesten mnd hier an den Seiten etwas höckerartig verbreitert. Nach vorn steil, nach hinten allmählich geradlinig verschnälert; dicht mit mässig iangen, dieken, brämulich gelben gelblich seidenglïnzenden Haaren etwas abstchend besetzt; diese Haare sind naeh oben, innen und hinten gekïmmt; völlig olne. Sehuppen. In der dorsalen Mittellinie wird durch hellere Fürbung dieser Haare eine schmale weissliehe Linie erzeugt, die besonders hinten sehr auffällig ist. Augendeckel stark abgeflacht. Elytren mässig gedrungen, die Hinterleibsspitze nicht ranz erreichend (etwa eine ${ }^{1}$ \& mm lange Strecke der Abdominalspitze bleibt unbedeckt); linten und die Seitenkante völig abgerundet; an Hinterende (an der Unbicgungsstelle) des Streifens zwisehen 3. und 4. Punktreihe ein winziger Höcker, der besonders durch den diehten Haarpinsel. der sich senkreeht wenig naeh hinten geneigt auf ihm clheht, bemerkbar sind. Auf ihrer gesamten Oberfläche sind die klytren dicht mit ïhnlichen dicken Haaren besetzt, wie der Prothorax; diese Haare sind zienlich anliegend nach hinten gekämmt, bräunlich gelb und mit ebensolchen Seidenglanz; ausserden stehen auf den Streifen zwisehen den Punktreihen Längsreilien senkrecht abstehend brïunlich gelber Börstehen. Schuppen fehlen völlig. Die unbedeckte Hinterleilsspitze fein und dicht pubeszient. Unterseite ziemlich glatt, seicht punktiert und ziemlich dicht pubesziert. Tuberkel zwischen den Mitteleoxen sehr schmal und lang zungenförmig. Der winzige Aussehnitt in der Mitte des Hinterrandes des Metastemums dentlich. Hinterrand des 2. und noch mehr des 3. und 4. Abdominalsternites mit ciner sehr kräftigen und auffilligen querkielartigen Verdickung; 2. Stemit relativ ku\%. wenn lïnger als das schmale 3. oder 4. Sternit; 5. Stenit langgestreckt halblircisförmig. $1^{1}$ 2 unal so lang, wie die beiden vorhergehenden zusammen, hinten abgerundet.

Hell gelbraun; mit der erwähnten Haazeichmmg. Elytren meist mit je einem ziemlich breiten, parallelen, dunkelbramen Jängswisch, der sich vom Ende des 1. Fïnftels schräg nach innen wenig konvergent bis zur Flïgehnitte erstreekt, und zwar von der 5. Punktreilue bis zur 1. (vom Nahtrand aus gezilhlt). Unterseite rïtlich rostbraun, häufig hier und da, besonders an der Seite, schwäzlich.

Länge von Plothorax und Elytren zusanmen $4^{1}{ }_{4}-5 \mathrm{j}$ m.

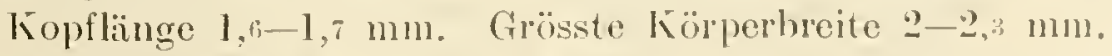

länge der Hinterschiene $l^{1}$ a 1111 .

Falklands-Inseln. Fox Bay. Unter Steinen. 24. und 25. Miir\% 190:2. I Exemplare. 
Listrorteres compressiventris ENDERL. 1907. - Taf. 2, Fig. 27.

Jistrolleres compressiventris Enderlein, Stett. Gnt. Zeit. 68. Jahrg. 1907, p. 58. linder., liolbe, Iamb. Magall. Sammelr. 1907, p. 105.

Schlauk. Elytren hinten stark seitlich komprimiert und von der Seite gesehen abgerundet rechtwinklig abfallend; es entsteht hierdurch ein anffälliger Buckel. Kopf grob und dicht punktiert, besonders der Rüssel, beim $q$ ist der Rüissel sehr grob netzrmnzlig punktiert. Hinterrand des Scheitels dicht und tief quergeritzt. Mittelkiel scharf, beim ơ nur als breit abgeschliffene Kante, beim $q$ scharf und sehr sehmal. Vertiefung am oberen Ende des Mittelkiels oval, aber mur nach vorn seharfrandig begrenzt; hinter dieser ein länglicher Fleck poliert glatt. Ausserer Seitenkiel seharff, innerer nur an der Basis scharf. Rüssel lang und kräftig, am Ende wenig verbreitert. Ziemlich spärlich gelb nach innen gekämmt behaart. Scheitel kaum, hinter den Augen mässig dicht behaart; beim $\delta$ ist die Kopfbehaarung wenig deutlich. 2. Geisselglied etwa so lang wie das 3. und die Hälfte des 4. zusammen; :3. langgestreckt etwa ${ }^{2 / 3}$ vom 2. und $1^{1 / 2}$ so lang wie das 4.; 1. nur eine Spur länger als das 2. Schaft erreicht ungefälar die Augenmitte.

Prothorax gedrungen, hinten etwas breiter als lang, in der Mitte sehr wenig verbceitert; grob und dicht runzlig punktiert, $q$ in der Medianlinie mit einem poliert glatten, schmalen, seln wenig crlabenen Längsstreifen, bis an das Ende des 3. Viertels, der beim ơ nur selıwach angedentet ist; gänzlich dicht beschuppt, Schuppen an der Seite gross und kreisrund, nach der Medianlinie zu (und besonders nach rorn) immer kleiner und spärlicher werdend. Angendeckel deutlich aber flach. Elytren vorn mehr oder weniger gewölbt und mässig sehmal, hinten stark seitlich komprimiert von anfangs erwähnter Form; die Hinterleibsspitze ïberdeckend oder ein weniges ïberragend; ohne irgend welche Höcker oder Auswïchse; Aussenrand an Ende des 1. Drittels ziemlich stark eingedrückt und flach ausgeschnitten; Punkte der Punktreihen ziemlich weitstehend; die gesamte Oberfläche sehr dicht mit grossen kreisrunden Schuppen bedeckt. Zwischen den Punktreihen mit je einer Längsreihe gelblicher knrzer Börstehen. Unterseite mässig dicht gelblich pubesziert, ziemlich glatt, sehr seicht punkticrt, Metasternum seicht und dicht quergeritzt, 1. Abdominalsternit undentlich dicht quergeritzt. Tuberkel zwischen den Mittelcoxen in Form eines schmalen kräftigen punktierten Längskieles. Der winzige Ausschnitt in der Mitte des Hinterrandes des Metasternums deutlich. 5. Sternit fast halblieisförmig, ziemlich schmal, so lang wie das 3. und 4. Sternit zusammen und dichter pubesziert.

Schwarz; Fühler und Tarsen dunkelrotbraun. Enddrittel der Schienen, besonders der Mittel- und Hinterschienen lebhaft goldgelb pubesziert. Schienen rötlich schwarz bis schwarz. Beschuppung des Prothorax grünlich grau bis matt golden, der Elytren hinten mehr oder weniger golden bis rötlich golden vorn düster kupfern glänzend; die Besehuppung des Aussenrandsaunes und ein schräg nach innen und hinten verlaufender vom Aussenrand vom Anfang bis Ende des 2. Drittels der Elytrenlänge reichender Keilfleck grünlichgrau. 
Läinge von Prothorax und Elytren zusammen $9^{1} \mathrm{~g}-12$ mm.

Kopflänge $: 3^{1 / 4}-4^{1} 2 \mathrm{~mm}$. Grösste Körperbreite :3 -51, mm.

Länge der Hintersehiene $3-31 / 2 \mathrm{~mm}$.

Falklands-Inseln. Seal-Core im inneren 'Teil. Unter Steinen. 1:3. März 1902 (1 แnausgefärbtes Exemplar). - Port Louis. 7. August 1902. 2 lixemplare.

Die Farbe des unausgefärbten Exemplares ist hell sehmutzic rostbraun. Der linke Oberkiefer trägt noeh den larvalen Mandibularanhang, dessen Vorkommen schon von einer Reihe friseh ausgesehlïpfter Riisselkäfer bekannt geworden ist; er sitnt an der Anssenseite der Oberkieferbasis in Form eines mässig diinnen Plättchens in Rechleckform, das etwas länger als die doppelte Breite ist. Seine länge ist kanm ${ }^{1 / 3} \mathrm{~mm}$.

lieirlertire nov, gen.

Typus: R. exsculpticollis EvDERL, 1907 (Falklands-Inselu).

Die Gattung steht der Gattung Listroderes nahe, unterscheidet sich aber durch folgendes:

Ober- und Unterseite selu ranh und grob punktiert. Prothorax mit melı oder weniger dentliehem Längseindruek. Sehultereeken der Elytren mit seharfer kiclartiger Seitenkante. Körperform gedrungen; hinten abgestutzt, Elytren steil abfallend. 3. und 4. Abdominalsternit sehr kurz, jerles viel kïrzer als die IJälfte des 2. Sternites. Trenmungslinie zwisehen Kopfkapsel und Submentum längs der Rïsselunterseite sehr scharf und tief.

Diese Gattung sei meinem Fremde ALEx RkicherT in Leipzig gewidmet, dem ieh so viele ausgezeichnete Abbildungen antarktiseher und subantarktischer Insekten verdanke.

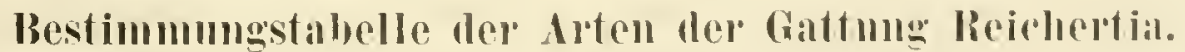

1. Vorderrand des Prothorax in ter llitte schwach eingedriiekt. Sehulterecken der Elytren mit \%iemlieh langer seharfer Seitenkante. Elytren gänzlich unheschuppt oder hauptsäichlieh zwisehen 5. und 6 . Punktreihe besehuppt . . . . . . . . . . Vorderrand des P'rothorax in der Nitte gerade (niclat eingedriickt) oder fast gerade. Sebulterecken mit kurzer Seitenkante. Elytuen gänzlieh beschuppt.

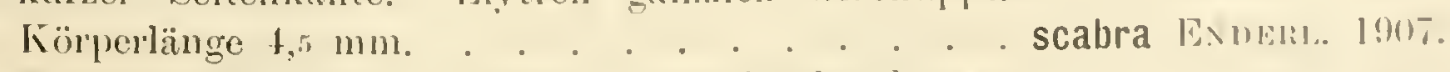

?. Elytren zwischen 5. und 6. Punktreihe heschuppt. Innere Seitenkicle des Riissels dentlieh. Kürperlänge $5 \%$ - $7111 \mathrm{~m}$. exsculpticollis Fxintis. 1907. Elytren völlig unbeschuppt, gïnzlich puhesziert. In-

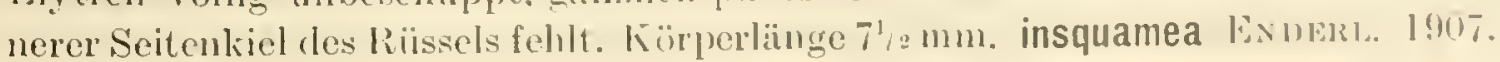


Reirhertid exsordpticollis (ENDERL. 1907). - Taf. 2, Fig. 28.

Listroleres exsculpticollis Enderlein, Stett. Eut. Zeit. 68. Jahrg. 1907, p. 60.

Enderl, Kolbe, Hamb. Hagall. Sammelr. Col. 1907, 1. 105.

Sehr gedrungen, hinten stark abgestutzt, Seiten der Elytren parallel. Kopf sehr grob und dicht runzlig punktiert, auch der Rïssel. Riissel mässig lang, kräftig; Mittelkiel kammartig erhölt, sehl scharf und sehmal, etwas skulpturiert (schwach runzlig); äusserer Scitenkiel sehr scharf, sehwach runzlig; innerer Seitenkiel mässig scharf aber in der ganzen Länge ausgebildet, stark runzlig. Vertiefung am obcren Ende des Mittelkicles stark verbreitert und almählich verlanfend, nach hinten in der Mitte mehr oder weniger als seichter Längseindruck auf den Scheitel fortgesetzt. Kopf mit mässig zerstreuten abstehenden kräftigen gelbbraunen Börstchen besetzt, besonders anch dic Kämme der äusseren und inneren Seitenkiele; Scheitel kurz und spärlich behaart, unbeborstet. 2. Geisselglied etwa so lang wie das 3. und 4. zusammen, 3. etwas verlängert, 1 . etwa $1 \frac{1}{2}$ mal so lang wie das 2. Schaft erreieht ungefähr die Augenmitte.

Prothorax gedrungen, ungefähr so lang wie breit, von oben gesehen fast gleichseitig S-eckig; in der Medianlinic eine vorn verschwindende Längseinsenkung, die meist scharf, selten weniger deutlich ist; unbeschuppt, mässig dicht mit abstehenden gelbbramen Börstehen besetzt; schr dicht und grob runzlig punktiert. Vorderrand oben etwas vorgezogen und allmählich erhöht, in der Mitte seicht und flach ausgebnehtet. Augendeckel seharf eckig (stumpfwinklig) rorspringend. Elytren gedrungen, mässig breit, parallelseitig, hinten gerade abgestutzt und sehr steil und abgerundet abfallend, ein schmales Querstreifehen der Hinterleibsspitze unbedeckt lassend; Punkte der Punktreihen kräftig und mässig dicht; Seitenecken seharf, abgerundet, an den Schulterecken eine kurze Streeke sehr scharfkantig und kielartig erweitert; Seitenflächen etwas eingedriickt. Am Hinterende des Streifens zwischen 4. und 5. Punktreihe (von der Naht aus gezählt), - etwa an der hinten steil abfallenden Kante ist auf jeder Elytre ein ziemlich kräftiger Höcker; ein wenig weiter nach vorn liegt zwischen 2. und 3. Prnktreihe ein weiterer sehr kleiner und meist wenig deutlicher Höeker. Die Elytren sind ziemlich dicht und kurz gelbbraun behaart, der Längsstreif zwisehen 5. und 6. Punktreihe in seiner ganzen Länge sehr dicht bis mässig dicht mit hell braungelben runden Sehuppen besetzt, die in dem hinten abfallenden Teil auch in den Iuängsstreifen zwischen 4. und 5., sowie zwischen 6. und 7. Punktreihe ïbertreten und an den Vorderenden der Flytren häufig allmählich in Haare ïbergehen; auch scitlich werden die Schuppen immer kleiner und sehmäler un endlich sieh in der Haarform zu verlieren. Seitenflächen und sonstige Partien der Elytren völlig unbesehuppt. Anf den Längsstreifen zwischen den Punktreihen ausserdem noch Längsreihen abstehender gelbbratucr Börstchen. Unterseite dieht und sehr grob rmnzlig bis querrunzlig punktiert, Spärlich gelbbraun pubesziert, Hinterrand des 2. Abdominalstemites und das 3. und 4, ziemlich dicht pubesziert. 'Tubcrkel zwischen den Mitteleoxen gross und breit, sehr erhaben, fast kreisrund. 3. und 4. Sternit sehr kurz; 5. Sternit halbkreisförmig, etwas länger als dic beiden vorhergehenden zusammen. 
Schmutzig sehwarzbram; Fihhler, Schienen und 'T'arsen dunliel intlurann; die Sehuppenstreifen an den Seiten der Elytren innerhalb der Ścitenkante sind schmutzig gelbbraun bis braun.

Länge von Prothorax und Elytren zusammen $5^{3}{ }_{4}-7 \mathrm{~mm}$.

Kopflänge $2-2^{1 / 2} \mathrm{~mm}$. Grösste Körperlänge $3-3^{3}+m m$.

Länge der Hinterschiene 2-2' 2 mm.

Falklands-Inseln. Port Damin. Goosegreen. Unter Stcinen. fi. März 19n2. - Porl s'unley. Februar 1904.

\section{Reirhertill illsermullel (ExDERL. 1907).}

Listroderes insquamens Enderlein, Stett. Ent. Zeit. 68. Jahıณ. 1907, 1. 62.

listroderes insquamea Eurlerl., Ko folbe, Hamb. Magall. Samulelr. Col. 19(17. p. 105.

2 Ende März gefundene etwas grössere Exemplare unterseheiden sich von $L$. exsculpticollis nur dureh folgende Punkte: Innerer Seitenkiel des Rïssels felılt völlig und ist nur durch einige Höckerchen angedentet. Der Scheiteleindruck scheint sich etwas mehr nach hinten zu erstrecken. Auf dem Längsstreifen zwischen 5. und 6. Punktreihe wie iiberhaupt auf der ganzen Oberfläche der Elytren finden sich keine Sehuppen; sie sind durehaus nicht abgerieben, sondern an ihrer Stelle finden sich hell gelbbraume Haare.

Jänge von Prothorax und Elytren zusammen $7^{1 / 2} \mathrm{~mm}$.

Kopflänge $2^{1}: 2 \mathrm{~mm}$. Grösste Körperbreite $3^{3}{ }_{4} \mathrm{~mm}$.

Länge der Hinterschiene $2 \frac{1}{2} \mathrm{~mm}$.

Falklands-Inseln. Fox Bay. Unter Steinen, 25. März 1902 (1 Fxemplar) und 27. Mä̈r 1902 (1 Exemplar).

Ein weiteres Exemplar von gleicher Grösse weicht wieder von $L_{\text {. }}$ insquaneus dadureh ab, dass der innere Seitenkiel des Riissels in seiner rorderen Hälfte entwickelt ist, in seiner hinteren aber völlig fehlt. J)ie Elytren sind ebenfalls behart. aber es finden sich in der Umgebung des grossen Höckers auf jeder Elytre eine Anzahl von Schuppen. Dieses Stiick steht also in der Mitte zwischen L. exsculplicollis und L. insquameus. $\mathrm{Ob}$ es beide Formen verbindet, oder nur eine Aberration ron L. insqumeus, oder eine dritte Spezies darstellt, kann ieh an der Hand rorliegendes Stückes nicht entscheiden. Bestimmt ist aber dieses Stïck, wie L. insqurmens nicht das $q$ zu L. exsculplicollis, da mir von dieser Spezies ônd q vorliegen.

Falklands-Inseln. Fox Brty. Unter Steinen. 2:3. März 1902 (1 Fxemplar).

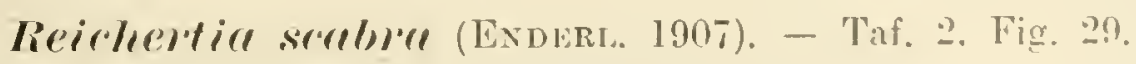

Listroderes scaber Enterlein, Stett. Ent. Zeit. Gs. Jinn. 1907, p. fia.

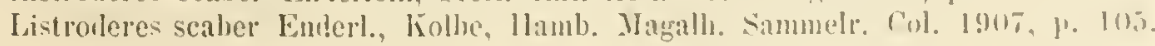

Gedrungen, hinten stark abgestutat, Seiten der Elytren parallel. Kopt grob mul dicht runzlig punktiert, der Rïssel sehr grob; Mittelkiel des Riissols sehart und foin. k. Sv. Vet. Akad. Haudl. Band 4S. X:o 3. 
etwas runzlig, äusserer und innerer Seitenkiel scharf und etwas runzlig. Am oberen Ende des Mittelkiels eine seichte Einsenkung, die nicht anf den Scheitel verlängert ist. Kopf mässig dicht mit braunen abstehenden kräftigen Börstehen besetzt, besonder's auch die Kämme der äusseren und inneren Seitenkiele; Scheitel kaum beborstet. 4.-6. Geisselglied kugelig, 7. etwas verbreitert, 3. etwas verlängert, 2. ungefähr so lang wie die 2 folgenden zusammen, 1. etwa $1 \frac{1}{2}$ mal so lang wie das zweite. Schaft etwas weiter als bis an den vorderen Augenrand reichend.

Prothorax gedrungen, ungefähr so lang wie breit, von oben gesehen abgerundet 8-eckig; in der Medianlinie eine ziemlich scharfe vorn verschwindende Längseinsenkung; sehr grob und dicht runzlig punktiert; unbeschuppt, mässig dicht mit abstehenden bramen Börstchen besetzt. Vorderrand oben etwas vorgezogen und allmählich erhöht, in der Mitte meist gerade abgeschnitten, oder kam etwaz eingedriickt. Augendeckel scharf eckig (stumpfwinklig) vorspringend. Elytren gedrungen, mässig breit, parallelseitig, hinten gerade abgestutzt und sehr steil und abgerundet abfallend und ein sehr schmales Querstreifchen der Hinterleibsspitze unbedeckt lassend. Punkte der Pmktreihen selır kräftig, grob und etwas quer verbreitert und ziemlich dicht; Seitenecken ziemlich scharf, abgerundet, Schulterecken scharfkantig und eckig erweitert; Scitenflächen etwas eingedrückt. Am Hinterende des Jängsstreifens zwischen 4. und 5. Punktreihe (von der Naht aus gezählt), - etwa an der hinten steil abfallenden Kante - auf jeder Elytre ein ziemlich kräftiger abgerundeter Höcker; wenig mehr nach vorn liegt zwischen 2. und 3. Punktreihe ein weiterer kleinerer Höcker, der sich nach vorn in den eine kürzere Strecke weit etwas erlabenen Längsstreifen fortsetzt. Die ganze Oberfläche der Elytren sind dicht mit mässig kleinen runden grauen und wenig vortretenden Schuppen bedeckt, die Längsstreifon zwischen den Punktreihen ausserdem mit Längsreihen gelbbrauner abstehender Börstchen. Nur bei 1 Exemplar sind diese Börstchen dunkelbraun. Sind die Schuppen abgerieben, so ist nirgends eine feine Pubeszierung zu sehen; in diesem Falle sind aber meist noch Reste an den etwas konkaven Seitenflächen zu erkennen (hier fehlen sie bei L. exscrlpticollis stets). Unterseite ziemlich dicht und sehr grob punktiert, fast netzpunktiert; mässig dicht und kurz gelbbraun pubesziert. Tuberkel zwischen den Mittelcoxen gross langgestreckt dreieckig zungenförmig, punktiert und gelbbraun pubesziert. 3. und 4. Sternit sehr kurz, 5. halbkreisförmig und fast doppelt so lang wie die beiden vorhergehenden zusammen.

Schmutzig schwarzbraun; Schienen, Tarsen und Antennen dunkel rotbramn.

Länge von Prothorax und Elytren zusammen 4-5 $\mathrm{mm}$.

Kopflänge $1^{3 / 4}-2 \mathrm{~mm}$. Grösste Körperbreite $2-2^{3} / 4 \mathrm{~mm}$.

Länge der Hinterschiene $1 \frac{1}{2} \mathrm{~mm}$.

Falklands-Inseln. Port Stamley im östlichen Teil. Unter Steinen. 26. Februar 1902. Porl Damwin. Goosegreen Unter Steinen. 6. März 1902. - Seal-Cove im inneren Teil. Unter Steinen. 13. März 1902. - Port Stanley. Februar 1904.

L. scaber unterscheidet sich von dem nahestenden L. exsculpticollis leicht durch die Roschuppung der ganzen Elytren; durch den langgestreckten Tuberkel zwisehen 
den Mitteleoxen, die kurze Schulterecke der Elytren und den in der Mitte nicht cingedriickten Vorderrand des Prothorax.

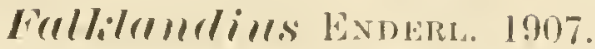 \\ (Typus: Falkiandius brachyomma ExDERL. 1907.)}

Falklandius, Enderlein, Stett. lint. Z.eit. Jalırg. 1907, 1\%.65.

Diese Gattung steht der Gattung Listroderes sehr nahe und untersehciclet sich von ihr dureh folgende Punkte: Riissel röllig ohne Mittelkiel, rorn mit mehr oder weniger rimnenförmigem Eindruck, der mehr oder weniger flach oder tief mul mehr oler weniger breit ist (bei Fulklandius suffodens ist dieser Eindrnck äusserst flach und scicht. bei den übrigen Arten mehr rimnenfömig, bei $F$. Imbificalus sind die Seiten cler breiten und seharfen Rinne kielartig). 1. Geisselglied etwas verlängert, mehr orler weniger aufgetrieben; 2.-7. Geisselglied kugelig oder fast kugelig. Prothorax villig ohne Augenklappen. Augen bei Falklandius brachyomma kreisrund, bei den ïbrigen Spezies etwas quer eifömig. Elytren mit 10 Punktreihen, ohne Höcker orler Iuswiichse. Pubesziert oder besehuppt.

Sehr kleine Formen.

\section{Bestimmmmgstabelle der Arten der Gathumg Falkimdius.}

(Unter Körperlänge ist die Länge ron Prothorax mal Elytren zusammen verstanden.)

1. Tuberkel zwischen den Mittelcoxen stark entwickelt und sehmal. Riissel rorn mit sehr undentichem seiehten Längseindruek. Prothorax und Elytren dicht beschuppt (Sehuppen sehr klein). Elytren gedrungen. Körperlänge $2^{3}-3,1 \mathrm{~mm}$. . . . . . . . . suffodens EXDERL. $190 \%$.

Tuberkel zwischen den Mitteleoxen fehlt. Rïssel rorn mit tiefer und scharfer Rinne. Völlig mbeschmpt. Elytren sehlank. . . . . . . . . . .

2. Augen klein und rund. 2. Geisselglied kugelig und etwas grösser als die folgonden. Körperlänge $21 / 4-$ $2^{1} 3 \mathrm{~mm}$.

brachyomma lixplis. 1907.

3. Augen gross und kurz queroval. 2). (ieisselglied nicht kugelig, etwas gestreckt. Körpertänge $3^{3 / 4} \mathrm{~mm}$. . turbificatus ExnERL. I90\%.

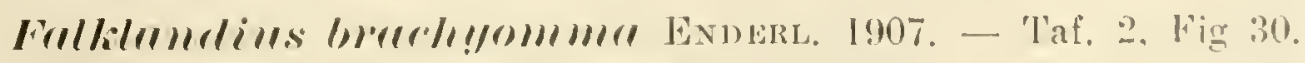

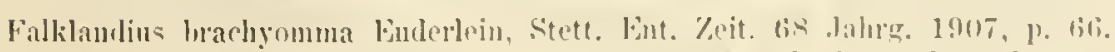

Finderl. Kolloc, llanls. Magallı. Sammelr. Col. l!107, p. I

Schlank. Rïssel kurz und gedrungen, am linde ziemlich stark rerhreitert. D)ic 2 seitlieh stehenden Kiele in der Vorderhälfte des Rïssels scitheh allmählich ïbergehend, so dass es sich mehr $u$ cine mediane ansgegrabene Rimne handelt: diese 
ist riemlich schmal und scharf. Scheitel glatt, fein und spärlich pmmktiert, Rüssel ziemlich grob nnd dieht punktiert, hinten sind die Punkte öfters lang ansgezogen. Scheitel ohne Eindruck. Kopf äusserst fein und sehr spärlich pubesziert (Mundgegend beborstet). 1. Geisselglied fast lingelig aufgetrieben, mit Ausnalume des stielförmigen Basaldrittels; so lang wie das 2., 3. und 4. Geisselglied zusammen; Kenle eiförmig.

Prothorax sehr schlank, ungefähr $1^{2}{ }_{3}$ mal so lang wie hinten breit; stark walzig, in der Mitte wenig verbreitert; mit grossen groben Punkten mässig dicht besetzt, nahe der Medianlinie fast zn Längslinien angeordnet; Vorderrandzone glatt. Elytren ziemlich lang oval, den Hinterleib gänzlich ïberdeckend; Punktreihen selır grob und sehr dicht. Auf den Längsstreifen zwischen den Punktreihen je eine Längsreihe winziger gelblicher abstehender Börstchen, dazwischen sehr spärlich mit winzigen Härehen. Oberfläche der Elytren glänzend glatt. Unterseite poliert glatt, sehr spärlich fein punktiert; 3. und 4. Abdominalsternit zusammen so lang wie das 2., 5. etwas kiirzer. Mitteleoxen relativ weit getrennt, zwischen ihnen kein Tuberkel bemerkbar, sondern ganz glatt.

Dunkelbraun; Kopf und Thorax schwarz; Vorderrand des Prothorax, Fiihler und Beine rotbraun.

Länge von Prothorax und Elytren zusammen $2^{1 / 4}-2^{1 / 2} 11 m$.

Kopflänge ea $3 / 4$-fast $1 \mathrm{~mm}$.

Grösste Körperbreite $1 \mathrm{~mm}$. Länge der Hinterschiene ca $1 \mathrm{~mm}$.

Falklands-Inseln. Port Stanley im östlichen Teil. Unter Steinen. 26. Februar 1902. 2 Exemplare.

Fallilamaims tubificatus ENDERL. 1907. - Taf. 2, Fig. 31.

Falklandius turbificatus Fnderlein. Stett. Eut. Zeit. 68. Jahrg. 1907, p. 67.

Enderl., Kolbe, Hamb. Magall. Sammelr. Col. 1907. p. 103.

Sehr schlank. Rüissel mässig lang, gedrungen, an Ende verbreitert. 2 seitliehe Kiele anf der Endhälfte des Rüssels lassen eine ziemlich breite, tiefe und poliert glatte Rinne zwischen sich frei. Kopf sonst rauh und spärlich seicht punktiert. Scheitel ohne Eindruek. Kopf sehr spärlieh punktiert. Angen schwach queroval. 1. Geisselglied etwas aufgetrieben, mit Ausnahme des stielförmigen Basaldrittels; etwas länger als die 2 folgenden Glieder zusammen, 2. Geisselglied sehr wenig verlängert, die ïbrigen kugelig; Keule etwas gestreckt eiförmig.

Prothorax sehr schlank, mngefähr $1^{2} / 3$ mal so lang wie hinten breit; stark walzig, in der Mitte wenig verbreitert; mit grossen groben Punliten ziemlich dicht besetzt; in der Medianlinie zwei dicht neben einander laufende feine eingeritzte Längslinien bis zur Mitte, das sehmale Feld zwisehen ihmen mpmktiert. Vorderrandzone nicht geglättet. Elytren sehr lang ausgezogen, naeh hinten lang und stark zugespitzt, den Hinterleib gänzlich ïberdeckend; Punktreihen grob und ziemlich dicht; Längstreifen zwischen den Punktreihen mit Längsreihen abstehender gelblicher Börstchen besetzt; Oberfläche der Elytren glatt und glänzend. Unterseite poliert glatt selır spärlich und 
scicht punktiert; 3. und 4. Abdominalstemit zusammen etwas kïrzer als das 2., 5. ungefähr so lang wie das 3. und 4. zusammen. Mittelcoxen ziemlich weit getrennt, zwischen ihnen kein Tuberkel.

Schwarz; dunkelrostrot sind: Fühler, Beine, Vorderrand des Prothorax und Schulterecken der Elytren.

Länge von Prothorax und Elytren zusammen $: 3^{3} \& \mathrm{~mm}$.

Kopflänge $1^{1}+\mathrm{mm}$. Grösste Körperbreite $1^{1 / 3} \mathrm{~mm}$.

Länge der Hinterschiene $I^{1 / 4} 111 m$.

Falklands-Inseln. I'ort ITilliam. Sparrow-Cove. 2. Mär"z 1902.

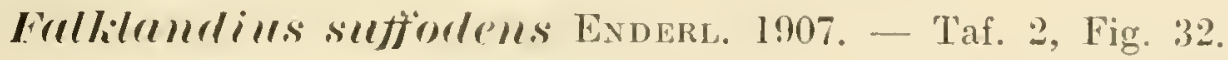

Falklandins suffodens Enderleiu, Stett. Eint. Zeit. 68. Jalng. 1907, 1. 68.

Enterl., Kolbe, Hamb. Jagalh. Sammelr. Col. 1907, p. 103.

Relativ gedrungen. Rüssel ziemlich kur\% und gedrungen, am Ende verbreitert; oben abgeflacht kaum mit Spuren einer rinnenartigen Einsenkung. Scheitel mit winzigem ovalen Eindruck. Kopf rauh und sehr kurz pubeszicrt. Augen queroval. 1. Geisselglied mit Ausnahme des Basaldrittels kugelig anfgetricben, etwa ron der Länge der 3 folgenden Glieder zusammen; 2. bis 6. Glied kugelig, 7. quer-oval. Keule länglich eiförmig, Ende etwas zugespitzt.

Prothorax schlank fast $\mathrm{I}^{\prime}{ }_{2}$ mal so lang als hinten breit, walzig, ror der Mitte schwach verbreitert, nach vorn stark, nach hinten allmählich verschmälert; rauh mit grossen groben Punkten zerstrent besetzt, behaart und dicht mit sehr liteinen undeutlichen Schuppen besetzt. Elytren gedrungen, abgerundet, eiförmig, das Abdomen gänzlich bedeckend; Punktreihen mässig weit; dicht mit sehr kleinen rundlichen Schuppen von hell gelblich brauner Farbe besetzt, die wenig deutlich als solche erkembar sind. Unterseite fein und mässig dicht punktiert und pubesziert. 2. Abdominalsternit etwa ${ }^{3}+$ der Länge rom 3. und 4. Sternit zusammen, 5. cin wenig liirzer als diese beiden. Tuberkel zwischen den Mittelcoxen hoch und sehr schmal zungenförmig.

Schmutzig gelbbraun; Kopf schwarz; Fïhler und Schenkel dunkel rotbraun; Sclienen und Tarsen hell gelbbraun, roströtlich angehancht.

Länge von Prothorax und Elytren zusammen $2^{3}{ }_{4}-3.1 \mathrm{~mm}$.

Kopflänge $1-\mathrm{l}^{1}+\mathrm{mm}$. Grösste Körperbreite $\mathrm{l}^{1} \mathrm{l}^{1}: \mathrm{mm}$.

Länge der Hinterschiene ca. $1 \mathrm{~mm}$.

Falklands-Inseln. Nahe Hookers P'oint. Unter Steinen und troekenen Eidhöckeru. 27. Februar 1902. 2 Exemplare. 


\section{Ordo: Lepidoptera. \\ Fam. Nymphalidae. \\ Subfam. Nymphalinae. \\ Aryymmis F. 1807. \\ Argymmis Cytheris (Drury 1773).}

Papilio Cytheris Hrury, lllustr. exot. Entom. II. 1773. Pl. IV. Fig. 3, 4. (Chile.)

Argymuis siga Hübner, Samml. exot. Schmetterl. Zntr. 1832. Fig. 677, 678.

Cytheris (Drury), Mabille, Miss. Cap Horn. Hépidopt. 1888, p. 5. (Fenerlaud: Beagle Canal n. Orange Bai.)

siga IIübn., Butler, Ann. Mag. Nat. Hist. Vol. XIl. 6. ser. 1893, p. 207. Nr. 1. (Falklands-Inseln.)

\section{Fam. Noctuidae.}

Subfam. Agrotinae.

Alfrotis Ocusenu. 1816.

Typus: Agr. rectangula (SCHIFF. 1776).

\section{A!lotis hispialula Guen. 1852.}

Agrotis hispidula Guence, Noet. 1. 1852, 1. 293. No. 476. (Chile.)

» Guen., Butler, Ann. Mag. Nat. Ilist. 6. ser. Vol. 12. 1893, 1. 207. Nr. 2. (Fatklands-Inseln.)

Guen., Hampson, Cat. Lepid. I'halaenac Brit. Mus. Vol. IV. 1903, 1. 289. Taf. 66, Fig. 3.

(Patagonien, Magellan, Chile, Falklands-Inseln.)

Euxol HüвN. 1827.

Typus: E. decorr (SсHгFF. 1776), Europa.

Euxore falchumlicre Hanps. 1903.

Euxoa falclauliea Hampson, Cat. Lepid. Plalaen. Brit. MIns, Vol. IV. 1903, p. 224. I'l. 62, Fig. 22. (Falklands-Inseln.)

Feltia, WALK. 1856.

Typus: F. ducens (WaLk. 1856), Nord Amerika.

Feltia mralefida (GuEN. 1852).

Agrotis malefida Guenée, Noct. I. 1852, p. 267. (Nord Amerika.)

$\gg$ Guen., Smith, Cat. Noct. N. Am. P. 84.

¿ inspinosa Guenée, Noct. I. 1852, p. 269. (Brasilien.)

" consueta Walker, X., p. 334 (1856).

Feltia malefida (Guen.) Hampson, Cat. Lepid. Phalaen. Brit. Mus. IV. 1903, p. 353. I'l. 68, Fig. 15. (Vereingte Staaten, Mexico, Cuba, Ilaiti, Bahamas-Inseln, Costa Rica, Venezuela, Brasilien, Argentinien, Falklands-Inseln.)

\section{Feltive clevicre. (BuTL. 1882).}

Agrotis clerica Butler. Trans. Ent. Soc. 1882, p. 129. Nr. 27. (Chile.)

carbonifera Mabille, I3ull. Soc. Philom. (7.) IX. 1885, p. 60.

Mabille, Miss. Sci. Cap Horn. 1888, p. 16. Pl. Il, Fig. 3, (Fenerland: Uschuaia u. Beagle Canal.)

Peridroma clerica (Butl.) Butler, Ant. Nag. Nat. Itist. ser. 6. Vol. 12. 1893, p. 208. Nr. 5. (Falklands-Inseln.) Agrotis punta-arenae Staulinger, Ilamb. Nagalh. R. IV. 1899, P. 53.

Feltia cleriea (Butl.) Hampson, Cat. Lepid. Phalaen. Brit. Mus. Vol. IV. 1903, p, 356. PI. 68. Fig. 19. 


\section{Ejisilen Hüßx̃. 1827. \\ 'Typus: Le. lnlens Hĩ̛is. 18:7. Enropa.}

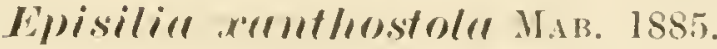

Agrotis xanthostola Mabille, Bull. Sor. I'lilom. (7.) 1X. 1885, 1\%. 61. (Patagonien.'

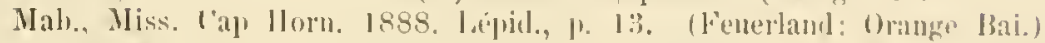

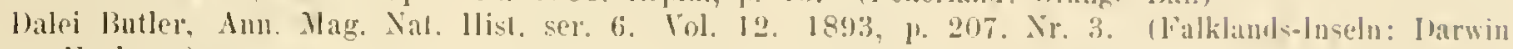
Harlour.)

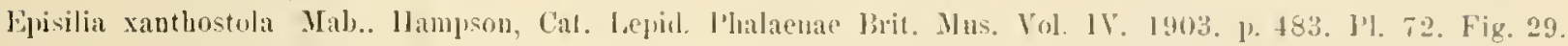

\section{Ejpisilirl birololor (.11a r. 185.)).}

Agrotis bicolor, Mabille, Bull. Soc. Jhilom. (7). 1855. IX, 1). 59. Feuerland.

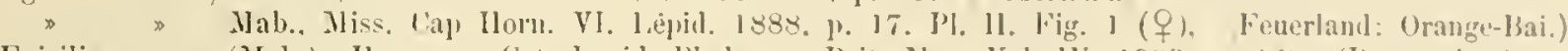

Fpisilia , (Mab.), Ilamplson, Cat. lepicl. Phalaenae Bril. Mus. Vol. IV. 1903, 1).464. (I'atagonien.)

Falklands-Inseln. Hookers Poinl. 1. o tot am Ufer gefunden. 27. Februar 1902.

Das Exemplar ist im Bram des Vorderfligels etwas dunkler als das von $11 \mathrm{~A}$ BILle abgebildete ․ Der blasse Samm nahe am Aussenrand ist viel weniger dentlich und eigentlieh nur an Innenrand deutlieh erkennbar. Körperlünge $107 \mathrm{~mm}$, Flïgelspannung $41^{1 / 2} \mathrm{~mm}$.

\section{L!!(ro)pllotill HüBN. 1827.}

\section{L!/(O)/lotill llostilis (WAL. 1857).}

Agrotis hostilis Walker, I.epicl. IInt. X]. 1857, 1. 737.

Jeridnoma hostilis (Walk.) Butler, Aum. Mag. Nat. llist. ser. G. Vol. 12. 1893, 1. 209. Nr. 4. (Falklands-luseln.) l.ycophotia 》 (Walk.) m. (fehll im llampson!.

Subfan. Hadeninae.

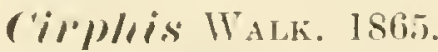

Hampon, Catal. Noct. 13rit. Mus. 1905. 1, p. 478.

Typus: ('. costulis WALK. IS6:5 ('T'asmanien).

Cilollis fullollulirol (Burt. 1893).

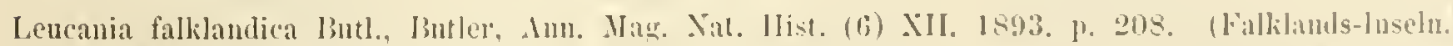

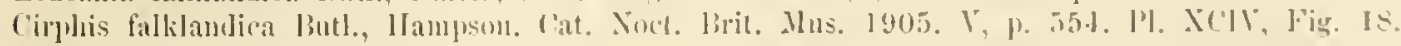

Falklands-Inseln. Porl Stanley. l'ebrual 1904. 1 d. Sism Birara.

Fam. Geometridae.

Subfam. Larentiinae.

Enllitherinl Curt. 18:5.

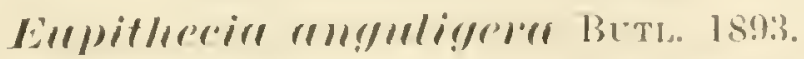

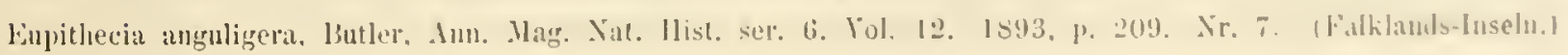




\section{Fam. - - - \\ Apurima WatKer 1863. \\ Apmrima spee.}

Apurima spec., Butler, Ann. Mag. Nat. Hist. ser. 6. Vol. 12. 1893, p. 210. Nr. 10. (Falklands-Inseln.)

\section{Fam. Pyralidae. \\ Subfam. Scopariinae. \\ Scoprerial Hw. 1803.}

Sroparia glaureulalis Hampson 1897. - Taf. 3, Fig. 37 und Textfig. 3. Scoparia? spec., Butler, Ann. Mag. Nat. IIist. ser. 6. Vol. 12. I893, p. 210. Nr. 8. (Falklands-Inseln.) Scoparia glauculalis IIampson, Trans. Ent. Soc. London. 1897, pag. 233. (Falklands-Inselu.)

Kopf, Thorax und Abdomen mit blass bräunlich graner, seidenglänzender Beschuppung besetzt. Kopf und Thorax sind bei dem vorliegenden Stïck stark abge-
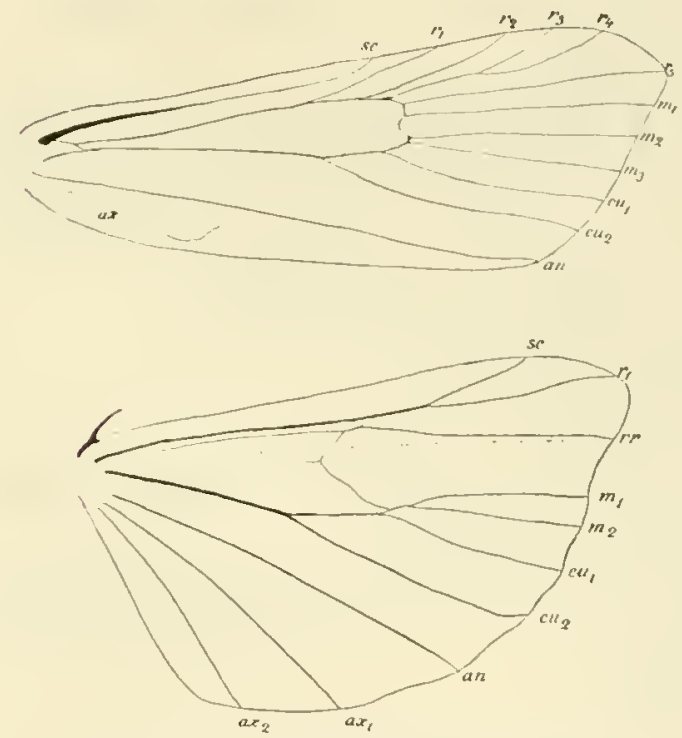

Fig. 3. Scoparia glauculalis HAMPs. જ Geäder des Vorder- und Hinterflïgels. Vergr. 8:1.

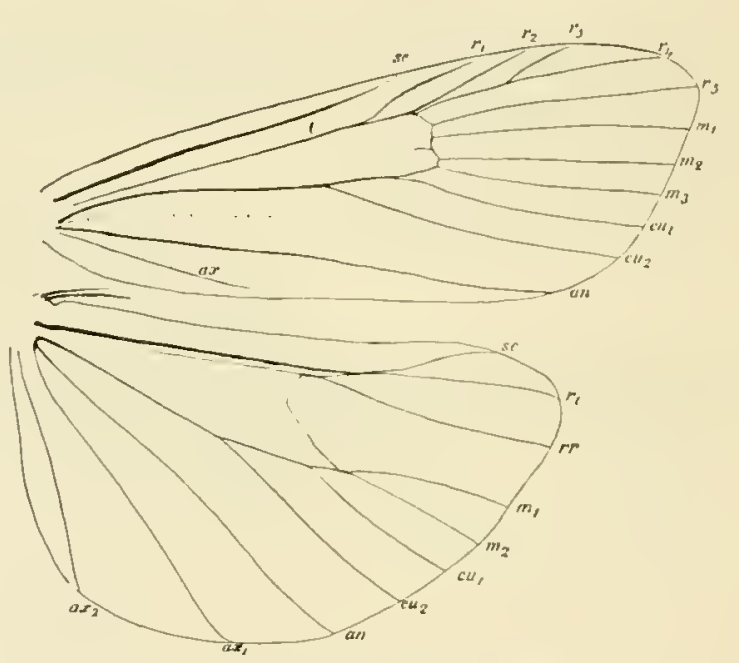

Fig. 4. Scoparia truncicollella STT. 9 . Ceäder des Vorder- und Hinterflügels.

rioben und es ist so zu erkennen, dass der Chitinpanzer des Kopfes glänzend sehwarz und der des Thorax hell rostbraun ist. Fïhler dünn, wenig verjüngt, hellbräunlich, ea. ${ }^{2 / 3}$ der Vorderflügellänge; die Geisselglieder in der Basalhälfte ea. $1^{1}{ }_{4}$, in der Endhälfte ea. $1^{1} \frac{1}{2}$ mal so lang wie diek. Angen dunkelbrann, mit bronze-artigem Glanz, Beine hellbräunlich. Besehuppung blass bräunlieh grau und seidenglänzend. Längerer Hintersehienenendsporn kaum halb so lang wie der Metatarsus.

Vorderflïgel blass bräunlieh weissgrau, seidenglänzend, ein sehr schmaler Vorderrandsaum etwas mehr blassbräunlieh; die Aussenrandschuppen mehr weisshieh. \%wischen den Adern des Apicaldrittels je eine scharfe konkave Längsfalte, die aber den Aussenrand nieht erreieht. Hinterflügel ähnlich gefärbt, aber mit etwas mehr bräunlieh gelbem Ton. Die Randschuppen am Hinterrand sehr lang. 
Das Geäder ist in Textfignr' 3 abgebildct: zum V'ergleich dazu das Geäder von Scoparia truncicollella STT. aus Dentsehland in wigur 4. Im wesentlichen ist das Geäder beider sehr ïhnlich. Nur wendet sich bei s. glunculalis $r_{4}$ in Vorderflügel mehr dem Vorderrande zu und die Entfernung zwischen den Enden von $r_{4}^{*}$ und $r_{s}^{*}$ ist mehr als doppelt so lang wie dic zwischen $r_{5}$ und $m_{1}$ (bei $S$. Iruncicollella sind bejule Strecken ungefähr gleichlang). Ferner ist im Hinterfliigel die zelle $\mathrm{M}_{1}$ selır sehmal (bei S. trunc. ziemlich breit).

Körperlänge ca. $7^{1}$ z mm. - Vorderfliigellänge ca. 9 mm. - Flïgelspannung $19^{1} \mathrm{a} \mathrm{mm}$. - Länge der Hinterschiene $3 \mathrm{~mm}$. - Länge der Hintertarsen $3 \mathrm{~mm}$.

Falklands-Inseln. Port Stunley. Marray Highs. 22. Februar 1902. 1 o unter Steinen.

Um späteren Bearbeitern umnötiges Nachschlagen zu ersparen. füge ich die Butler'sche Notiz an:

Butrer 1, e.: A s single example in worn eondition.s

Eine gelbbraune Puppe ron $7^{1}+4 m$ Körperlänge mit riemlich dïnn z.ngespitztem Hinterleibsende scheint zu Scoparia gluncululis zu gehören. An der Abdominalspitze stehen jederseits ca. 4 am Ende spiralig anfgerollte Haare.

\section{Subfam. Crambinae.}

Cormlnus F. 1798 .

Corambus fallilandirellus H.umes. 1895.

Crambus spee., Butler, Amm. Mag. Nat. Hist. ser. 6. Yol. 12. 1893, p. 210. Nr. 9. (Fillilands-Incelu.

('rambus falklandicellus IIampson, Proc. Znol. Soc. Tomdon, 1395. pag. 930. (Falliamls-Inseln).

\section{Ordo: Hymenoptera.}

Subordo: Apocrida.

Fam. Ichneumonidae.

Subfam. Ophioninae.

\section{Oplliom F. 1798.}

Ophion Lanseni nov. spec. - T'af. 3, Fig. 36, 'Textfig. 5. 6.

Kopf hinter den Augen ein wenig länger als bei $O$. luteus und nieht verengt. Ocellen selır gross; Angenabstand der hinteren Ocellen ca. ' acellendurchmesser. des vorderen Ocellus ca, I Ocellendurehmesser. Fïhler mässig dïn, fast ron Vorderflïgellänge. Die Angen erreichen nicht ganz die Oberkieferbasis. Der ganze Kopf mit dichter graner Pubeszenz, anch Sehlïen und Hinterkopf. Parapsidenfurehen etwas sehärfer als bei $O$. luteus, der zwischen ihnen gelegene 'Teil in der hinteren Hälfte mit nicht selı dentlichem Längseindruck. Mlittelsegment (Fig̣. j) mit kräftigen l.eisten. die ein 6-eckiges Mittelfeld bilden, vor und seitlich davon à wabenartige Felder: an den Seiten etwas den Seitenrindern genähert je eine schwach gebogene Liingsleiste: der hintere Teil bis fast an die Seitenleisten heran mit etwas gewellten Laingshleisten. 
4. bis 6. Abdominalsegment relativ kurz, fast doppelt so hoch wie lang.

Im Vorderflügel (Fig. 6) ist Nervus basalis (nb) und Cubitus (eu) etwas konvergierend. Der Ramellus (ra) ist nur als winziger Stummel angedentet. Das innere Fenster (fi) ist sehr lang, das äussere Fenster (fe) fast die Hälfte des Nervus recurrens (nr). Der Nervulus ist interstitial. In Hinterflügel ist Cubitus und Braehium fast parallel und beide sind ziemlich genähert. Der Nervellus (ne) ist in der Mitte gebrochen.

Ziemlich dunkel rostbraun, Kopf sehwärzlich rostbraun, Ocellen und Augen selıwarz, Fühler und Beine wie der Körper gefïrbt. Flügel grau hyalin, Adern schwarz. Costa mnd Stigma hell branngelb, letzteres in der äusseren des Hinterrandes fein schwärzlich gesäumt. Nembran schwach grün bis rot irisierend. liörperpubeszenz graugelblich, Beimpubeszenz glänzend gelb.

Körperlänge $16-18 \mathrm{~mm}$. - Vorderflügellänge $15-15^{1 / 2} \mathrm{~mm}$.

Hintersclıenkellänge (incl. basalem Schniirstiick) $6 \mathrm{~mm}$ )

Hintertibienlänge $5^{1 / 2} \mathrm{~mm}$

Hintertarsuslänge $6,2 \mathrm{~mm}$

beim grösseren Exemplar.

Falklands-Inseln. Port Stunley. Februar 1904.

2 ?.

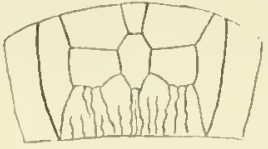

Fig. 5. Ophion Larseni ENDERL. Mittelsegment in die Ebene ansgebreitet. (Umriss und Leistenverhuf.) Vergrössert.

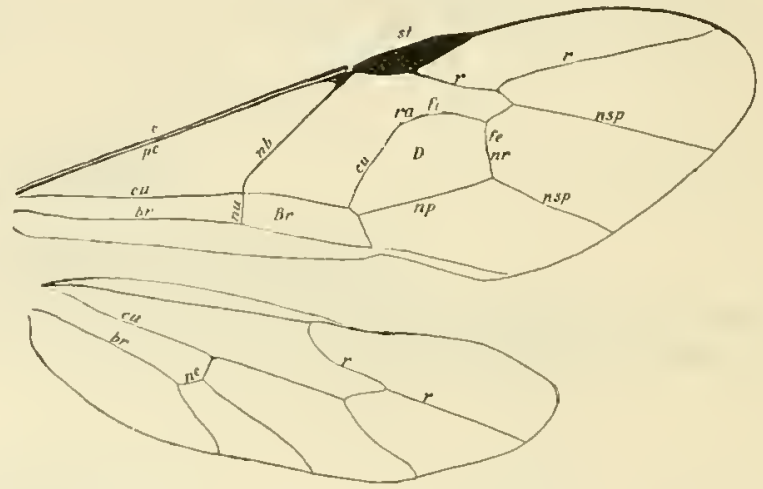

Fig. 6. Ophion Larseni EnderL. Flügelgeäder. Vergr. 5:1 $c=$ Costa. $\quad p c=$ Postcosta. $\quad$ st $=$ Stigma. $\quad c u=$ Culjitus. f $\mathrm{r}=$ Brachium. $\mathrm{nb}=$ Nervus basalis. $\mathrm{r}=$ Radius. $\mathrm{nr}=$ Nervus recurrens. nsp = Nervi spurii. np $=$ Nervus paral lelus. $r a=$ Ramellus, $n u=$ Nervulus $n e=$ Nervellus.

Diese interessante Species, die ich Herrn Cart Anton Larsen, dem Kiapitän der *Antarctic anf der schwedischen Südpolar Expedition widme, nimmt durch das genetzte Mittelsegment eine sehr extreme Stellung in der Gattung Ophion ein; der europäische Ophion Mocsaryi Brauns 1889 nähert sich in dieser Beziehung ihm etwas.

2 im Stettiner Zolog. Museum mir vorliegende Stücke einer Ophion-Art ans Chile nit der Körperlänge von 15-16 mm, gehören dem Ophion intricatus LEP. 1846 an; ihre Körperfarbe ist hell rostgelb, auch der Kopf, die Skulptur des Mittelsegments ist ähnlich, aber das lintere Drittel zeigt nur 6 Längsleisten. Ein weiteres Stück aus Chile scheint Ophion chitensis Sprs. 1851 zu sein; dieses Stück hat eine viel geringere Skulptur des Mittelsegmentes und der Nervus basalis und Cubitus im Vorderflügel divergiert sehr stark nach hinten und letzterer bildet einen stark einspringenden Winkel. 
Orio: Diptera.

Fan. Dryomyzidae.

Arelorede's nov. gen.

Typus: A. abscondila nov, spec., l'alkiands-luseln.

Untergesieht ohne Mediankiel; die Fïlılergruben jederseits als sehr flache lü̈ngsmulde. Die Backenvorderecke fehlt, ganz flach abgermelet. Backen sehr breit: Subgenalsaum (unbehaarter Saum am unteren Rande der Backen) schr schmal: Backenleiste (Leiste am oberen Rande des Sulhgenalsaumes) fehlt. Leiste des ïnseren Fïhlergrubenrandes schr scharf; Zahnhöcker am unteren Ende der z̈̈ısseren Fïllergrubenleiste etwas kräftig. Backenbehaarung kurz und dieht, beim ơ länger; Kinelse. borsten fehlen. Clypens (Epistoma) klein und schmal. Fïhor ziemlich kur. umpubesziert, ihre beiden Basalglieder lang und ziemlich dick. Eingedriickte thorakale Längslinien fehlen. Pubeszenz des Scutellum mässig dicht; mit 4 Makrochaeten, die 2 vorderen sehr kurz. Plenralpubeszenz, des Thorax fehlt. Randmakrochaeten an der Seite des sehr dicht und fein behaarten, in der Mitte längsgefurehten Mesosternum fehlen bei beiden Geschlechtern; Pubeszenz beim of sehr lang, beim $f$ lang. Die Abdominaltergite umfassen den Körper nieht. Beim of 6 Tergite, von denen das 6. nach unten herumgebogen und ron oben kaum sichtbar ist; beim $q . \bar{g}$ grosse Tergite, die ïbrigen als Legerohr in das 5. cingestiilpt und nur die schmale Spitze des Legerohres ragt ein wenig hervor, Abdominalpubeszenz des of sehr dicht. sehr lang und sehr fein; beim of dieht, knrz und fein. Beinpubeszenz des of abstehend. sehr fein, oder dicht und sehr lang; des $q$ abstehend, sehr fein, sehr dicht und lang. Makrochacten an Hinterrande des 4. und $\overline{5}$. Tergites beim $q$ rorhanden, beim d fehlend. Metatarsus der Vorderbeine des o innen am Ende mit dickem, kräftigem. kurz abgerundetem, dunkel ehitinisiertem Dorn. Metatarsus der Vorderbeine des c und of mit einer Reihe dichter, lkurzer und senkreeht abstehender schwarzer Borsten. Anzahl der Spornen des Hinterendes der Mittelschiene beim o ea. 6 und bein $q$ ea $S$. Dic Subcosta ist stark an $r_{1}$ genähert. Auf der Costa fehlen ansser der Puheszenz. Borsten; nur am Rande des Pterostigma sind bei starker Vergrössermng einiqe die Pubeszenz nicht ïberragende Borstenhaare erkenmhar. Pterostigma sehr sehmal, mit langem Vorderrand. Sehenkel des of verdickt, die der Vorderbeine schr stark. Subapicalborste der Oberseite der Hintersehiene beim of fehlend, beim $f$ lang und diunn. Erstes Hintertarsenglied des o am Ende unten, etwas an cler Anssenseite mit einem kurzen, stumpfen, zapfenartigen, schwar\%cn Dorn. Prosternaldreieck mässiur grow. hinten schmal; Seitenränder hinten hoch anfgeworfen; mur hinten und an den hinteren Seiten pubesziert. Medianfurehe sehr scharf. Dornenreilıe der L'nterseite des Metatarsus der Mittelbeine beim or verdiekt.

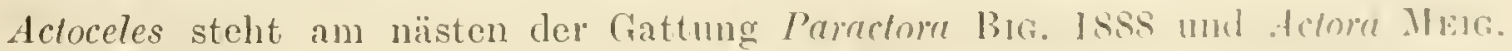
Actora unterseheidet sich ron ihr dureh folgendes:

$1 \dot{\gamma}_{i} \dot{x} \% \dot{r}=$ steile Küuste, $; \% \dot{s} \lambda_{r_{j}}=$ Schnellsegler. 
Dornen ausser der Pubeszenz an der Costa kräftig und lang. Untergesicht nieht eingedrückt. Die 4 Makrochaeten des Sentellum fast gleichlang. 4 Randmakrochaeten bei $\delta$ and ${ }^{\circ}$ an der Aussenseite des Mesosternum. Der Dorn am Ende des Metatarsus der Vorderbeine des $\delta$ fehlt. Anzahl der Spormen am Ende der Mittelschiene bei of und o ca. 10, ringsgestellt. Pterostigma gross. Subapicakalborste der Oberseite der Hintersehiene beim of lang und dünn, bein + lang und kräftig.

\section{Actoreles abscomdita nov. spee. - Taf. 3, Fig. 33, 34.}

Stirn matt grau rostgelb, mit Ausnahme schmaler Streifen am Augenrand und eines schmalen nach hinten verbreiteten Streifens in der Mitte meist mehr sehwärzlich grau. Scheitel mehr rostgelb. Die Begrenzung der Färbung der Stirn und des Seheitels ist nie scharf. Stirn und vorderer Teil des Scheitels bilden eine Ebene; Behaarung sehr kurz, nur hinten und am Augenrand einige längere Borsten. Untergesicht steht zur Stirn reehtwinklig; rostgelb mit granem 'Ton, ebenso Backen und Schläfen. Fïhler rostgelb.

Thorax mit Ausnahme der rostgelblichen Suturen matt schwärzliel. Behaarung sehr kurz und ziemlich dicht. An den Seiten und hinten einige mässig lange Borsten. Abdomen schwärzlich, das 우 mit feinem gelblieh granem Hinterrandsaum an jedem Tergit. Abdominalpubeszenz des ơ auffällig lang, dicht und abstehend; beim + kurz und nur auf dem 4. und 5. Tergit etwas länger. Beine hell braungelb; die Pubeszenz gelbbraun, beim ơ auffällig lang. Halteren blass gelblich.

Flügel grau hyalin, Adern braun mit ziemlich breiten, wenig dentlichen, sehr blass bräunlichen Säumen; die Radiomedianquerader schwarzbraun, von einem sehwärzlichem Saum umgeben. Der Endabschnitt von en ungefähr halb so lang wie die Nediocubitalquerader.

Körperlänge ơ $6,5-10 \mathrm{~mm}$, o $S-9^{1}+1 \mathrm{~mm}$.

Flügellänge $\delta 5,5-\$, 51111$, $+6,5-7^{1}+4 \mathrm{~mm}$.

Falklands-Inseln. Port Stanley. 31. Dezember 1901. 1 ô. I ㅇ. - Seal-Cove an Sïdliehen Ufer. Unter Steinen auf Sand, \& März 1902. 8 o. 1 ㅇ.

Wenn MacQuart in seiner Diagnose der Gattung Actora bei Beschreibung der Actora flavipes MACQ. 1843 von Falklands-Inseln nieht besonders die Beborstung des Flügelvorderrandes erwähnt hätte, und anch die Abbildung diese Beborstung nieht zeigen wïrde, würde die Diagnose auf die vorliegende Species Actoceles abscordita anmähernd passen, und zwar auf ein $\delta$, wie besonders die 6 Mittelschienenendborsten zeigen; dieses Gesehlecht giot ja anch MACQUART an.

\section{Prr)(retorr. Brgot 1S9I.}

Paractora, Bigot, Miss. Cap IIorn, Zool. Insect. 1888. 1) V. (Diptera), P. 38. Pl. IV, Fig. 5 , 5 a und 5 l).

Die Gattung Paraclora Bra. steht der Gattung Actoceles Enderu. und Aclora MEIG. nahe.

Von Actoceles unterseheidet sie sich dureh folgendes: 
Die Dornen anf der Costa sind vorhanden; sie sind kräiftig und lang und finden sich von der Basis bis zur Mündıng von $r_{2+3}$. Die 4 Makiochaeten des Sentellum sind fast gleichlang. Die Domenreihe der Unterseite des Metatarsiss der Mittelbeine beim of stark verdickt. Makrochacten am Ausserrand des Mesosternum finden sich beim $\delta 2$ merklieh von der langen Beharming unterschieden, beim of sehr mudeut. lieh von der langen Behaarung untersehieden. Beinpubeszenz des $q$ sehr fein, sehr dicht, und mässig kum, wenig abstehend. Auf der Unterseite des Metatarsus der Vorderbeine bei $\delta$ und + eine sehware Harreihe. Pterostigna mässig schmal. Simb. apiealborste der Oberseite der Hinterschiene beim ơ unter den langen Haaren fast verschwindend, beim of lang und ziemlich kräftig.

Von Actore unterscheidet sie sich durch folgendes:

Die Domenreihe der Unterseite des Metatarsus der Mittelbeine beim of stark verdickt (bei Actora nicht verdickt). Untergesicht jederseits mit sehr flacher lïngsmulde (Fïhlergrube) (bei Actora nicht eingedlïckt). Subgenalsamm sehmal (bei Actora seh. breit). Makrochaeten am Aussenrand des Mesosternmm finden sich beim o ? merklich von der langen Behaarung untersehieden (bei Actore 4 lange und diinn), beim 9 l sehr undeutlich von der langen Behaarung untersehieden (bei Actora 4 lange). Malirochacten des Hinterrandes des 4. und 5. Tergites beim f fehlend, beim 2. vor. handen (bei Actora bei of und $q$ fehlend). Endspornen des Mittelschiene nur imnen. beim o 6 , beim + ea. $\$$ (bei Actora ca. 10 ringsgestellte). Pterostigma miassieg schmal (bei Actore gross und zicmlich breit).

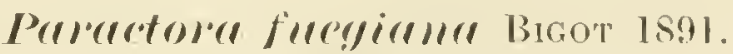

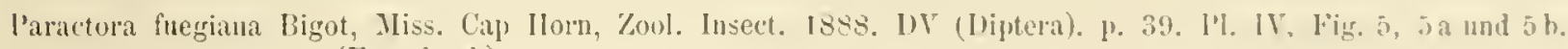
(Feuerlanel.)

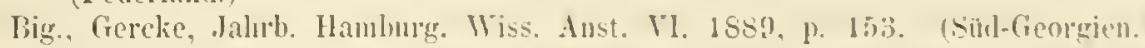

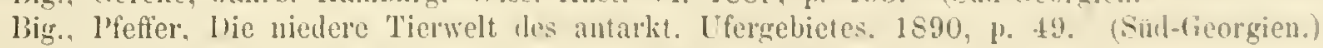

Big., Enderlein, Deutsed. Sirlpol. Exped. Bı. X. 1:108 1909, 1. 499.

Ausser 3 Exemplaren von Sïd-Georgien liegen mir : Exemplare von den lalklands-Inseln vor, die aber von ersteren und ron der Original-Diagnose und Abbildung dadureh abweichen, dass die blassbrannen lä̈ngsadersäume so verbreitert sind, dass die Ränder zum grossen 'Teil sieh berïhren.

Körperlänge $\delta 9 \mathrm{~mm}$, 우 $6,2 \mathrm{~mm}$.

Fliigellänge $\delta 7 \mathrm{~mm}$, 우 $5 \mathrm{~mm}$.

Falklands-Inseln. Nahe Hookers Point. Unter Steinen und trockenen lindhückern. "27.

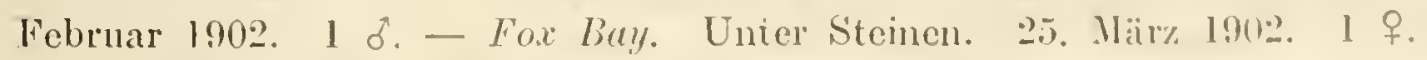

Das vorliegende $q$ stimmt in der Stimzeichnmng mit dem ö überein. die Färbung ist nur sehr dunkel. Dagegen ist eins der fon Siicl-(ieorgien sowolil in ilel Zeichnung als auch in der Färbung völlig mit dem ; ïbereinstimmend, cin ‥ f dagegen stark ergraut und mit ctwas verwischter \%eichnungsgrenze des stim-zickracks. Wenn Paractora flaripes (1]ACQ.) (num das of ist besehrieben) wirklich cine besonelere Species ist, so liegt daher die llöglichkeit vor, dass die von Buict hesehriehemen + 
zu dieser gehören. Das eine der vorliegenden $q$ von Süd-Georgien mit ergrauter Stim gehört dagegen sicher zu Paractora fuegiana BIG. und es erscheint daher wahrscheinlich, dass Paractora flavipes (MACQ.) nur eine Form mit grauer Stirn von P. fuegiana ist. In diesem Falle muss die Speeies $P$. flavipes (Macq.) heissen, zu ihr gehören als typische Formen die Stüeke mit graner Stim (ơ von MaCQART besehrieben, $q$ von BıGoT besehrieben), während die Formen mit der lebhaft gelblieh braunroten Stirn nnd scharfer Zeiehnungsbegrenzung als var. fucgiana B1G. geführt werden muss. Beide Formen dürften ïberall zugleich vorkommen (Feuerland, Falklands-Inseln, SüdGeorgien).

Bei den ô sind iiłrigens die Tergite ungesäumt; bei den ${ }^{\top}$ ist das 5. Tergit hinten immer fein gelblich gran gesäumt, bei einem der $q$ von Süd-Georgien sind die Hinterränder aller 5 Tergite fein gelblieh grau gesäumt. Der Hinterrand des 5. Tergites des $q$ hat eine Querreihe sehr langer dïnner Borsten, die bei dem Stüek vou Falklands-Inseln rom Hinterrande ziemlich stark abgeriekt ist, bei den 2 q von SiidGeorgien dagegen - allerdings verschieden - stark nahe gerïckt ist.

\section{Prrerroforer Alripes (MACQ. 1843).}

Actora tlavipes, Macpuart, Iiput. exot. Tom. 2. 1'. 3. 1843, P. 264. Tal. 33, Fig. 5 und 5 a. (Fallilands-Inselu.)

Sowohl in der Gattungsbesehreibnng pag. 263 als anch in der Abbildung sind lange Borsten in der Mitte des Flügelvorderrandes erwähnt.

Die Beschreibung passt aueh auf Paractora fuegiana Bigot, nur wäre die scharfe zackige Begrenzung der Stirnfärbung hinten nicht erwähnt. Das eine Stück der vorliegenden Bigot'schen Art von Falklands-Inseln hat sehr dunkle fast rötlich schwarzbraune Stirnfärbung, aber der graue Reflex fehlt. Dagegen hat wieder eins der vorliegenden $q$ von Süd-Georgien eine stark ergraute Stirm, bei der die scharfe Zeichnungsbegrenzung ziemlieh verwiseht ist. Ieh lasse diese Frage ror der Hand unentschieden, stelle aber diese Speeies vorläufig zur Gattung Paraclora.

\section{Fam. Helomyzidae.}

\section{Heloparia, nov. gen.}

Typus: H. Ekelöfi nov. spee. (Falklands-Inseln.)

Untergesicht gerade und ziemlich eben, ohne Mediankiel; die Fühlergruben kanm eingedrïckt. Backen sehr breit, der obere Teil bis zur Backenleiste nngefähr $2 / 3$ des Durchmessers der rundlichen Angen. Backenleiste sehr seharf, wendet sieh an der Stelle der Backenvordereeke, ohne aber eine Eeke zu bilden, ziemlich sehnell nach oben herum und endet, wenig schwächer werdend, an der Fühlerbasis. Der Subgenalsanm (unbehaarter Saum unter der Backenleiste) sehr breit, fast mehr als halb so breit wie der Durchmesser der Backen. Leiste des äusseren Fühlergrubenrandes sehr fein, unten ohne Zahnhöcker. Ein schmaler unterer nach hinten verbreiterter Backensaum ist mit einer ganzen Anzahl rou mehr oder weniger langen liäftigen 
Borsten besetzt, einige davon seln lang; in der Mitte des oberen Teiles am Angenrande noch einige kleinere Borsten. 3. Fihlerglied rund scheihenförmig, Borste unpubesziert, Rüssel wie bei Helonyza.

Thorax oben ziemlich dicht mit kumen bis langen borsten besetzt. Scutellum jederseits mit 3 Makrochaeten und an jeder Seite einige kurze Härchen. Plenren ohme Pubeszen\% min olne Borsten.

Mesosternum sehr dicht mit langen sehr feinen Haaren beset\%t, hinten aussen mit einzelnen Borsten. Die Abdominaltergite lassen die Sternite breit sielitbar. Abdomen des länglieh eirund, vom breit abgestutzt; nit 6 Tergiten, von denen das 6. sehr schmal und nach nuten herumgebogen ist, sollass es von oben kaum noch eine Spur sichtbar ist. Abdomen des $f$ mit 7 Tergiten; das 1. kurz, das 3., 4. lind 6. ziemlich kurz und gleichlang, das 2. ea. $2^{1}$ a mal so lang und das 7 . fast doppelt so lang, stark abgeplattet, selumal und nach hinten verjïngt; das weibliche Abromen verjüngt sich rom Hinterrainde des 2. Tergites ab. Männliches Abdomen sehr dicht mit sehr langen und sehr feinen Haaren besetzt, gan\% ohne Borsten. Weibliches Abdomen mässig dieht mu ziemlich kurz und fein pubesziert, in der hinteren Hälfte mit einigen Makrochaeten und zwar 3. Tergit mit 2, 4. mnd 5. mit 4, 6. mit 6 Borsten.

Sehenkel des fo wenig verdickt, des of stark verdickt, besonders die Hinterschenkel. Beine des ơ: Hinterschenkel naeh allen Seiten lang, sehr dieht und sehr fein behaart, die Praeapicalborste ist aussen sichtbar; Mittel-und Vorderschenkel nach hinten ebenso behaart, nach rorn 7.1 knrz und dieht pubesziert; Torderschenkel am Ende nach oben mo mach unten mit einigen Borsten; Sehienen kurz und dicht pubesziert; Hintersehienen etwas abgeflacht verbreitert und etwas gekrummt. Beine des $q$ : Schenkel knrz und dicht behaart; Hintersehenkel mit kräftiger und langer Praeapicalborste aussen; Vordersehenkel in der Endhälfte oben und unten mit je einer Längsreihe von ca. 6 sehr langen Borsten; Schienen sehr kurz pubesziert. Hinterschiene nicht verdickt, nieht verbreitert und gerade. Klanen schlank. gekrimmt und ungezähnt. Schienen und Tarsen ohne Zähne oder Dornen. Sehicnen ohne Borsten, aber mit kleinem Endsporn, der beim Mittelbein des o ziemlich lang ist.

Geäder wie bei Helomyza FaLL. 1820. nur fehlen die 1)ornen des Torderrandes völlig. Vorderrand kurz und dick pubesziert. Hinterrand kurz und fein pubesziert. Heloparia steht unter den Helomyziden am nächsten der Gattung Heteromyza FALL. 1820. Durch die dichte Wollige Behaarung und andere Eigentiinlichkeiten scheint mir aber trotz der zahlreiehen Kunebelborsten vicl Verwandtschaft zu den Dryomyziden zu bestehen, zumal nach meiner Ansicht die Anwesenheit oder das Fehlen von Knebelborsten nnmöglich zu einer 'Trennung in Unterfamilien oler gar Familien verwendet werden kann.

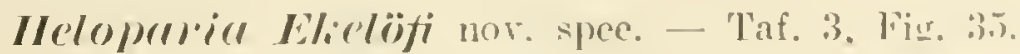

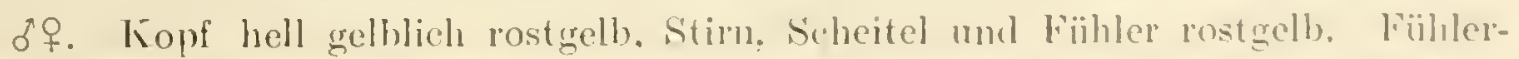
borste sehwar\%. Borsten schwar\%. Stim mässig dicht mit ziemlich kumon, borstenartigen Haaren besetzt. Scheitel ohne Hare. jeclerseit mit:3 langen Borsten, :2 hinter 
den Ocellen und joderscits 2 zwischen vorderen und hinteren Ocellen. Schläfen kurz. behaart. Hinterhaupt in der Mitte mit dichtem Haarpinsel.

Thorax dunkel rostgelb. Riickenschild mit Ausnahme der Seitenränder und des Vorderrandes, die dunkel grau rostgelb sind, dunkelgrau, beim $q$ mehr hellgrau, nahe der Nedianlinie mit 2 mässig breiten schwärzlichen Längsstriemen, die aber wenig anffällig sind, und zuweilen etwas undeutlich. Borsten und Haare schwarz. Scutellum hell rostgelb. Hinterricken rostgelb. Abdomen des ơ dunkelbram bis schwarzbraun, Behaarung schwarzbraun. Abdomen des 을 glänend schwarz mit schwach bläulichem Glanz; das glänzende Schwarz wird aber fast ganz verdeckt durch einen sehr dichten hellgramen Reif; Behaarung schwarz; Endhälfte des 7. Segmentes rostgelb. Beine hell rostgelb; Behaarung und Klauen schwarz. 1. Hintertarsenglied des $\delta 3$ mal so lang wie dick, 2., 3. und 4. jedes so lang wie dick; 5. doppelt so lang wie dick; 1. Hintertarsenglied des 우 4 mal so lang wie dick, 2. ca. $1^{1 / 2}$, 3. ca. 11/3 so lang wie dick, 4. so lang wie dick, 5. doppelt so lang wie dick. Halteren blass gelblich.

Flügel schwach gelblich grau. Adern einschliesslich Costa blass rostgelblich; Costalpubeszenz schwarz. Membran sehr schwach grün bis rot irisierend.

Körperlänge ơ $5,3-7 \mathrm{~mm}$. क + $5^{1 / 2} \mathrm{~mm}$.

Flïgellänge $\delta 6-8 \mathrm{~mm}$. ㅇ $6^{1 / 2} \mathrm{~mm}$.

Falklands-Inseln. Nahe Hookers Point. Unter Steinen und trockenen Erdhöckern. 27. Februar 1902. 2 o, 1 ㅇ.

Gewidmet wurde diese Species Herrn Dr. Frik Ekeıöf, dem Arzt und Bakteriologen der schwedischen Siidpolar-Expedition.

\section{Fam. Empididae. \\ Subfam. Empidinae.}

Hillre METG. IS22.

Hilura maluinemsis nov. spec. - Textfig. 7.

․ Kopf schwärzlich gran mit granweissem Reif; Stirn schmal, etwas länger als breit, Seitenränder parallel. Kopfpubescenz kurz, am Mundrand etwas länger. Untergesicht etwa so lang wie breit, Seitemänder nach vorn schwach divergierend. Rüissel etwa so lang wie die Kopfhöhe, ziemlich dick. Fühler sehwärzlich, fast so lang wie die Kopflänge; 1. Glied $1^{1 / 2}$ mal so lang wie breit, 2. so lang wie breit; 3 . etwa $1^{1 / 2} \mathrm{mal}$ so lang wie die beiden ersten zusammen, an der Basis etwas keulig verdickt, und nach dem Ende allmählich zugespitzt. Die Jiihlerborste besteht aus 2 Teilen, der Basalteil (4. Fïlnlerglied) ist ein relativ kräftiges gliedartiges Stïck, das etwa 3 mal so lang wie dick etwas länger als das 2. Fühlerglied und etwa halb so dick wie das 3. Fühlerglied in der Mitte ist; an Ende dieses Stückes sitzt einc knrze diinne Borste (5. Fïhlerglied), die nicht ganz halb so lang als das Basalstiick ist.

Thorax schwärzlich grau, mit grauweissem Reif; oben mit 4 graubraunen Längsstreifen, die etwa in gleichen Abständen sind; dic seitlichen gehen nicht weiter nach 
vorn als bis in die Höhe des Quereindruekes hinter der Sehulterbeule. Behaarung ziemlich lang und abstelıend, sclirarz; auf den Lïngsstriemen finden sich keine Haare; die Spitzenteile der Haare glänzen in gewisser Richtung gelblich. Scutellum gerundet, fast halbkreisförmig, Hinterrand mit ea. S lïngeren Haaren. Abrlomen laṇ̨. fast gleichdick, Endviertel stark zugespitzt, fast ohne P’ubeszenz, schwärzlich griau mit stark silberweissem Reif, der an der melır qraubraunen Spitze folilt. Beine nieht sehr dunkel braun mit schwach rötlichem Ton; Pubeszenz sehr fein; Schienen anssen mit einzelnen längeren Haaren, die Hinterschienen mit ea 6. Coxen etwas dunkler, und etwas grau bereift. Halteren sehr blassbräunlich, fast weisslich. Flïgel (Fig. 7) hyalin, mit schwach rostbräunlichem Ton. Adern hell rostbraun. Gabel ron $r_{4}$ und $r_{5}$ relativ liurz. und breit, $r_{4}$ relativ steil. Membran rot bis grim irisierend.

Körperlänge 4,1 $\mathrm{mm}$.

Flïgellänge $4 \mathrm{~mm}$.

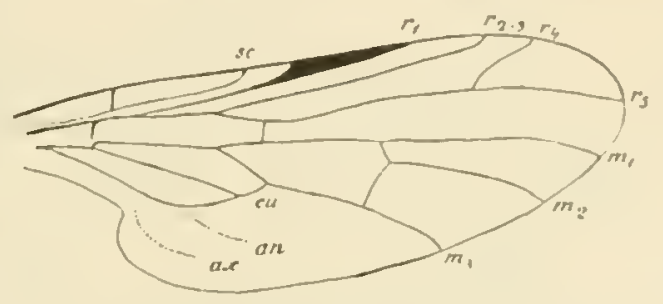

Falklands-Inseln. Port Stanley. 1. Januar 1902. 1 \%.

Fig. 7. Hilara maluinensis ExDERL. \&. IRliged. Vergr. $15: 1$.

Von den europäischen Arten unterseheidet sich Hilara muluinensis durch dic relativ kurze und breite Cabel $r_{4}+r_{5}$, von der $r_{4}$ ziemliel steil und relatir kur\% ist. Von den Arten von Fenerland und Patagonien ist leider nichts ïber diese Gabel angegeben.

Fam. Limnobiidae.

Subfam. Limnobiinae.

Zulus( ExDERL. 1905.'

Zalusa, Enderlein, Zoolog. Auzeiger. Bd. 29. 1905, 1). 70-71. Fig. 1 uml 2.

Antennen 14-gliedrig, nicht gesïgt. Proboscis kïrzer als der Kopf. 'Tibien ohne Spornen. Flïgel stark verkïrzt, etwa von der Lïnge des Thorax. Radialramus :ästig (nur 1 Submarginalzelle). Media z-ästig. Cubitus, Analis und Axillaris sehr undentlieh, besonders die Analis. Klanen mit 4 Kähnen (die lange Spitze nicht mitgezählt). Halteren lang und dïmn. Die Adern des Vorderrandes und der Flügelspitze dicht beborstet.

Labialpalpus 1-gliedrig. Hypopharynx rom mit emem liurzen dornartigen Fortsatz, Paraglossen zapfenförmig, behart und dentlich die Unterlippe ïberragenul. Mentum mit 2 grossen Borsten. Maxillarpalpus 4.gliedrig: letztes Gílied an der Innenseite des vorletzten inserierend: Palpiger als dentliches (ilied ausgebildet, mit : kräftigen Borsten. Maxillarlade dïnn und spitz. Eine abgeschlossene Diozoidalzelle fehlt, ebenso eine Querader zwischen Media und Cubitus.

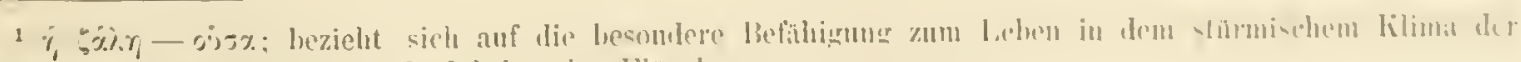

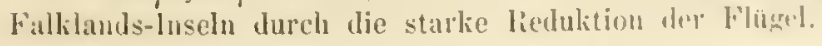

K. Sv. Tet. Akru. Mandl. Baud 48 . N:o 3 


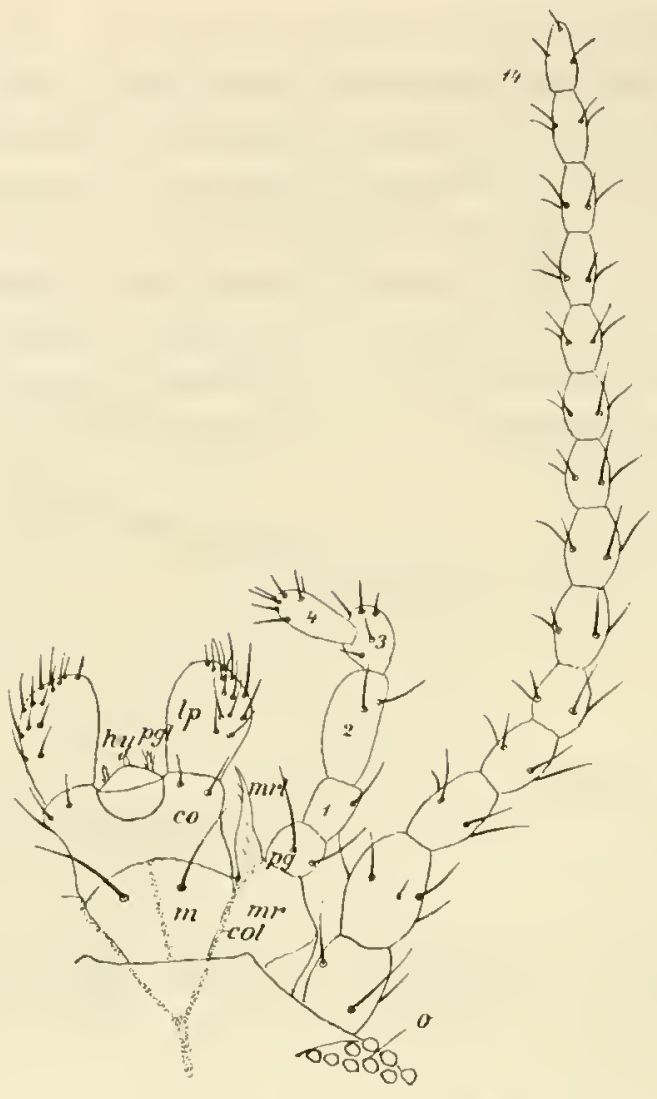

Fig. 8. Zalusa falklandica ENDERL. Mundteile und Fühler. Verg. $100: 1$. $m=$ Mlentum. $c o=$ die ver. schmolzene Coxen des Labium. lp = Labialpalpus. $\mathrm{mx}=$ Maxille. $\quad$ col = Coxalleiste der Maxille. pg $=$ Palpiger. $\mathrm{mxl}=$ Maxillarlade. $\quad \mathrm{l}-4=1 .-4$. Maxillartasterglied. $\quad 14=14$. Fühlerglied. $0=$ Stïck vom Auge.

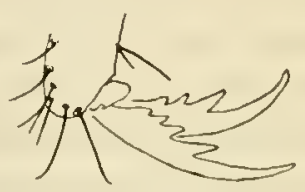

Fig. 9. Zalusa falklandica FNDERL. O?. Klaue. V'ergr. 160:1

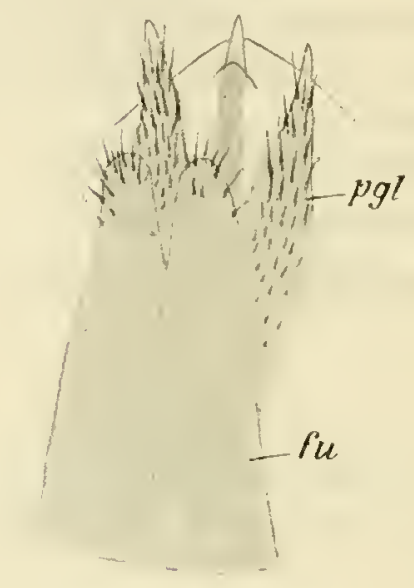

Fig. 10. Zalusa fallilantica ENDERL. O'. Vergr. $400: 1$. Hypopharynx (Maxillulae) von innen. $\mathrm{pg}=$ Paraglosien. $\mathrm{fu}=$ Fulturae.

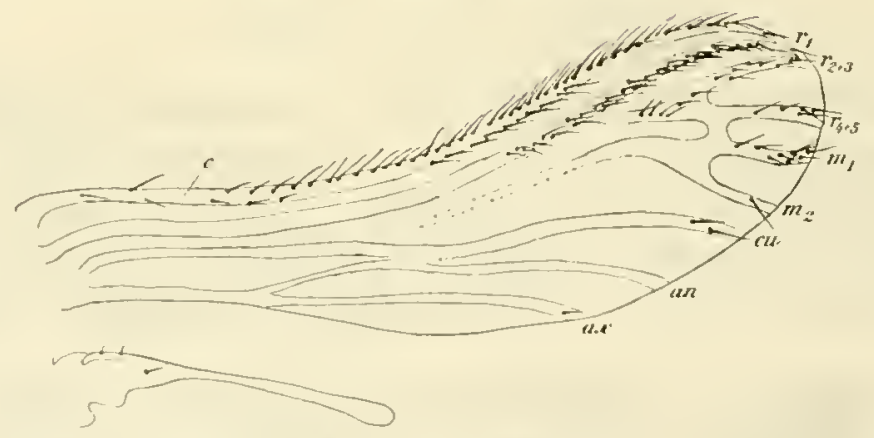

Fï. 11. Zalusa falklandica Enderl. $0^{7}$. Flügel und Haltere. Vergr. $80: 1 . \quad c=$ Costa. $r=$ Ralius. $m=$ Media. $\mathrm{cu}=$ Cubitus. an = Analis. ax. = Axillaris.

Von allen bisher besehriebenen Limoniinen (Limmobiinenj-Gattungen ${ }^{1}$ weieht Zalusa durch die nur 2-ästige Media und dureh die starke Reduktion der Flügel ab.

1 Dicranomyia Steph. 1820, Thrypticomyia Skuse 1890, Geranomyia Halid. 1833, Triphama Skuse 1890 , Tetraphana SkUse 1890, Rhipiltia MeIg. 1818, Goniodincura v. 1. Wulp. 1895, Peripheroptera Schin. 1866, Limonia MEIa. $1803(=$ Limnobia MEIG. 1818), Discobola Ost. Sach. 1865 (Trochobola Ost. SaCk. 1860), Jupanoptera Westw. 1881, Libnotes Westw. 1876. 
Zaluser follillurlica Exderd. 1905. - Textfig. S-12.

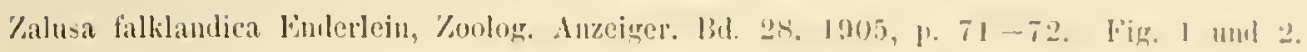

Blass bräunlich gelb, Kopf bräunlieh. Thorax oben hellbran, chenso die Beine. Schenkel gelbbram, Klanen und Fühler braun. Flïgel farblos, durch die dichte schwarze Beborstung der Adern des Vor" derrandes und der Spitze erscheint eine scharfe streifige schwarzbraune Zeichnung; c und $r_{1}$ trägt anch auf der $\mathrm{U}_{n}$ terseite Borsten. Fühlerglieder etwa doppelt so lang als dick, anf jedem Glied ea. 4 relativ kurze Haare. Angen gross, schwarz, mbehart. $\delta$. Genitalsegment stark erweitert. Penis ( $p$ ) lang, an der Basis einige Borsten. Valvulae (v), morphologiseh vielleicht die Gonopoden. in einen sehr langen dïnnen, nach aussen

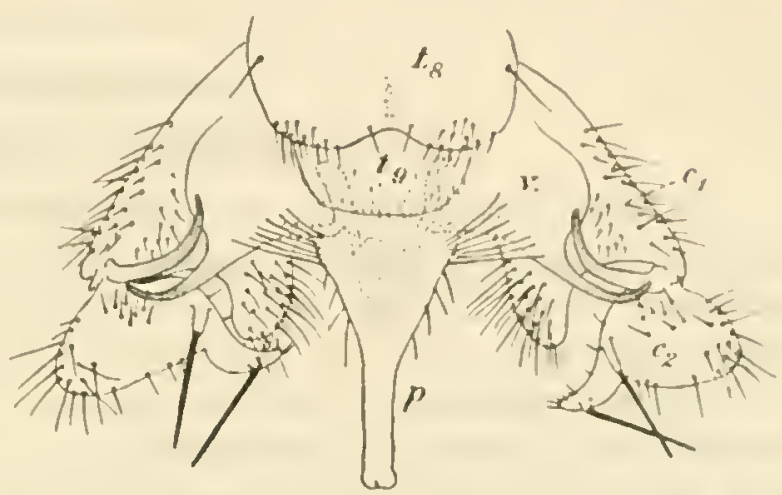
gebogenen Chitinzahn verlängert. Cerci

l'ig. 12. Zalusa falklandica Linelerl., Sexualapparat des Mänchens. Vergr. $50: 1$.

2-gliedrig, das Basalglied $\left(c_{1}\right)$ an Ende mit einem grossen langen dïnnen nach innen gebogenen Chitinzahn, das 2 Glied $\left(\mathrm{c}_{2}\right)$ mit dem ersten gelenkig verbunden, rundlich innen mit einem kräftigen fleisehigen 'aapfen, der 2 lange krïftige Dornen trägt (den einen an der Basis, den anderen in der Nähe der Spitze).

Ühorsicht über die Jänger der Beinglieder in mus.

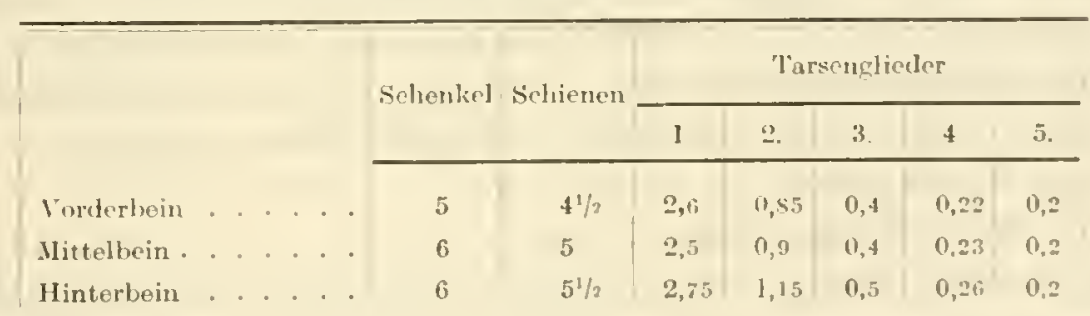

Die Klanenlänge beträgt etwa $0,15 \mathrm{~mm}$.

Körperlänge $5 \mathrm{~mm}$. Flügellänge $1 \mathrm{~mm}$.

Iänge der Halteren $0,45 \mathrm{~mm}$. Fïhler wenig lïnger wie $1 \mathrm{~mm}$.

Falklands-Inseln. Port Darwin. 3. IIïr, 1902. 2 $\delta$. Sehwedische Südpolar-Expedition 


\section{Ordo: Rhynchota. \\ Subordo: Andonorhyncha. \\ Homoptera.}

Fam. Jassidae.

Subfam. Acocephalinae.

Acocepleculus Gerr. 1833.

Acocephalus(?) fallilandicus nov. spec.

2 Nymphen stimmen im wesentlichen so auffällig mit der Nymphe der europäischen Acocephulus stratus F. überein, so dass kein Zweifel vorliegt, dass sie Acocephalinen sind. Ob sie der Gattung Acocephalus angehören, lasse ich zweifelhaft, aber sie scheinen unter den deutschen Formen diescr Gattung am nächsten zu stehen.

Körper matt und fein chagriniert. Kopf, Thorax, Flïgelanlangen und Beine ziemlich hell gelbbraun; Abdomen schmutzig gelbbram. Stirn etwas gewölbt, ein Saum dicht längs des Scheitclrandes eingedrïckt; mit ca. 10 feinen unscharfen bräunlichen nach den IIundteilen zu konkav gebogenen Querlinien. Scheitelrand scharfkantig. Scheitel etwas spitzer als rechtwinklig, rorn stark und flach abgerundet. Occllenanlagen in der Mitte zwischen Augenvorderrand and Scheitelspitze in einem tiefen runden punktartigen Eindruck, der sich nach vorn in einen flacheren ovalen nach der Scheitclspitze zu gerichteten Längseindruck fortsetzt; die Ocellenanlage ist so weit vom scharfkantigen Scheitelvorderrand entfernt wie der Durchmesser der punktartigen Vertiefung lang ist. Hinterschicne aussen mit 2 kantigen Längsleisten, die untere mit 7 kräftigeren, dic obere mit ea. 10 kïrzeren und schwächeren Dornen besetzt. Abdomen etwas lateral zusammengedrïickt; die Tergite bilden oben eine scharfe Kante, die letzten Tergite und besondcrs das letzte eine messerartig scharfe Kante. Das letzte Segment ist von der Seite gesehen halbkreisförmig. Vorderflügelanlagen etwa doppelt so lang als breit, am Ende mässig schmal gerundet; Hinterflügelanlagen breit, hinten breit abgestutzt und ganz flach gerundet.

Körperlänge $3,1-3,2 \mathrm{~mm}$.

Länge der Vorderflïgelanlagen $\mathrm{I}, 1 \mathrm{~mm}$.

Falklands-Inseln. Hookers Point. Unter Steinen nud trockenen Erdhöckenn. 27. Februar 1902. 2 Nymphen.

Ordo: Trichoptera.

Fam. Limnophilidae.

Limmophilus (Leacii 1815) Burm. 1839.

Limmophilus menidionalis ULM. 1905.

Limnophilus spec. Mc Iachlan, Ent. Mo. Mag. Vol. VIII. 1872. pag. 273 (Falklands-Inseln). merilionalis, Ulmer, Anu. Soc. Ent. Belg. Vol. 49. 1905, p. 18. Fig. 2, 3, 4. (Patagonien, FalklandsInseln.

Ulm., Ulmer, Notes Leyden Mus. Vol. 28. I906, p. 9. Fig. S, 9. 
Einige undeterminierte larven stammen yon folgenden Lokalitiiten:

Falklands-Inseln. In einem Teiche nordöstlich ron Port Sitruley. 31. Mär\% 1902. \& Larven. - In einem Teiche östlich von P'ort Skmley. 18. Augrust 1902. I Larre.

\section{Orthoptera.}

Fam. Phasgonuridae.

Subfam. Rhaphidophorinae.

Tribus: Ceuthophilini.

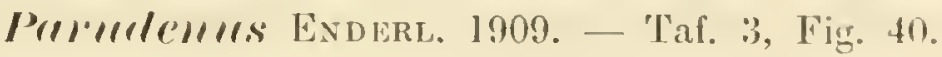

P'arudenus, Enderlein, Zool. Auz. Bil. 35. 1909. 1. 157.

Kopf kurz. Stirnhöeker dureh eine tiefe Furche in 2 zerlegt, beide likein und sehr hoch und spitz, jeder scheint mit einem Ocellus versehen zu sein. Fïigel fehlen völlig. Vorder- und Mittelschenkel ohne jeden Dorn. Die beiden Seitenleisten der Furehe der Unterseite des Hinterschenkels im Enddrittel mit kleinen wahnartigen Dornen. Die Seitenleisten der Oberseitenfurche der Hinterschienen mit kräftigen Dornen, mit denen kleine Dörnehen regelmässig alternieren, nur zwischen den 3 letzten Dornen fehlen diese Dörnehen; die 2 letzten Dornen länger und kräftiger. 1. und 2. Hintertarsenglied oben mit kleinen zu 2 Reihen angeordneten Dornen, 3. und 4. ohne Dornen. Mitte der Anssenseite der grossen Vordereoxe allmälbieh lı̈̈gelartig erhoben und in eine scharfe Spitze ausgezogen. Die Cerei gerade und behart. Oripositor breit, zusammengedrüickt, glatt, schwach aufgebogen, zugespitzt, Medianlamelle im Endviertel fein gesägt, Sägezähne basilwärts gerichtet.

Parudenus gehört zu der Phasgonuriden-Subfamilie Rhaphidophorinae und zwar in die Tribus Ceuthophilini und ist am nächsten verwandt mit der Gattung Hcleromallus BRUÑxer ISSS, von der 2 Species aus Chile bekannt sind (H. nolabilis Bruxx. Is8s und H. spina BRUNx. 1888) und mit Udenus BRUxxer 1900 mit 1 Species aus Patagonien ( $U$. w-nigrum BRUvy. 1900). Erstere unterscheidet sich vor allem durch die bedornten Vorderschenkel, letztere durch das Fehlen der Dornen an allen Schenkeln. Parudenus nimmt somit eine Mittelstellung zwischen beiden Gattungen ein. Alle 3 Gattungen stehen einander sehr nahe.

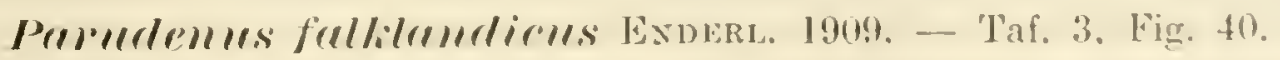
Parudenus falklandicus Euderlein, Zoolog. Anz. 131. 3is. 1909, J. 15\%.

Braungelb, Abdomen braun mit braungelben Flecken. Augen und letztes Ahdominaltergit schwarz. Oripositor im Spitzendrittel rostbraun.

Augen nach der Fïhlerbasis zu gerade (kaum merlich konkav), abgestutzt. Grösster Augendurchmesser ungefähr ron der Läinge des Fühlerschaftes. 5. Maxillar- 
palpalglied das längste, nach dem dem Ende zu verbreitert und gerade abgestutzt. Längs der Seitenränder der Unterseite der Vorderschiene jederseits bis an die Spitze mit 5-6 Dornen, ebenso die Mittelschiene. Innere Seitenleisten der Unterseitenfurehe der Hinterschenkel im Enddrittel mit 6-8 kleinen zahnartigen Dornen, äussere mit ca. 7 sehr kleinen zahnartigen Dörnehen. Hintersehienen oben bedornt wie die Gattungsdiagnose angibt, unten am Ende jederseits ein schwächerer Dorn. Cerei stark zugespitzt. 1. Hintertarsenglied in der Endhälfte oben mit 2 Seitenreihen von 3 Dornen, die vorderen beiden Paare kurz, die beiden Enddorne kräftiger. 2. Hintertarsenglied mit 2 Enddornen und vor jedem ein kurzer Dorn. Grösste Länge der

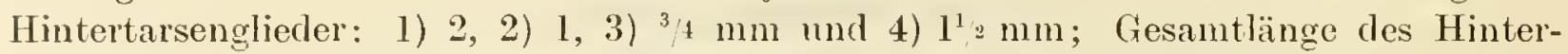
tarsus $4^{1}+\mathrm{mm}$. Oberrand des Ovipositor sehwaeh gekrümmt, Unterrand schwach, im Enddrittel stark gekrïmmt. Olme Spuren von Rudimenten der Vorder- und Hinterfliigel.

Körperlänge $11^{1 / 2} \mathrm{~mm}$.

Länge des Pronotum in der Medianlinie $4 \mathrm{~mm}$.

\&Vorderselienkels $5^{1}, 4 \mathrm{~mm}$.

, Mittelschenkels $4^{1 / 2} \mathrm{~mm}$.

» Hinterschenkels $9^{1 / 2} \mathrm{~mm}$.
Länge der Vorderschiene $4^{3}+1 \mathrm{~mm}$. - Mittelschiene $4^{1} / \mathrm{g} \mathrm{mm}$. ఎ Hinterschiene $9^{1}, \mathrm{~mm}$. des Ovipositor $8^{1 / 2} \mathrm{~mm}$.

Grösste Kopfhöhe $5^{3}+\mathrm{mm}$.

Falklands-Inseln. Port Stanley im östliehen Teil. 26. Februar 1902. 1 q inter Steinen.

Superordo: Haplognatha.

(BöRNER 1904.)

Ordo: Copeognatha.

(Enderlein. Zoolog. Anzeiger. Bd. 26. 1903, p. 423-437.)

Heterotecnomera.

Cryptoderata.

Fam. Mesopsocidae.

Subfam. Mesopsocinae.

Copeognathen sind bisher weder von Patagonien, noeh von Feuerland und den Falklands-Inseln zu uns gekommen. Bei dem Waldreichtum dieser Gebiete ist es wohl zweifellos, dlass eine ganz beträehliche Anzahl von Formen dort heimisch ist. Ihre Kleinheit und Zartheit ist hier, wie überall, der Grund ihrer Vernaehlässigung gewesen. Eine Speeies von den Falklands-Insehn gelangte mit dem Material der sehwedisehen Südpolar-Expedition in einigen Str̈eken in meine Hände. 


\section{PMilotursus Kiolbri 1880.}

Pllilotursus follolumalirus Exinert. 1905. - Taf. 4, Fig. 44, 4.); Textfig. 13. Philotalsus falklandicus Finderlein, Zoolog. Anz. Bd. 2!. 1905, p. 126. Falkiauds-Inselu.)

Körper grau gelbbraun, Thorax oben rötlich braun, Abdomen blass. Scheitel braun gefleekt. Antennen blass bräunlich gelb, mit riemlich langen struppigen Haaren ziemlich dieht besetzt; etwa von ${ }^{3}{ }^{4}$ der Vorderfliigellänge; Endglied zugespitr.t, am Ende etwas knöpfehenartig erweitert. Angen klein, schwarz. Clypens gross, gewölbt, mit feinen blassen Längslinien. Maxillartaster sehr blass, Endglied hellbraun; Irorhältnis der Glieder etwa $1^{1}: 2: 1^{3}{ }_{4}: 1: 2$.

Beine sehr blass, graulieh, distales Ende der Sehienen und die Tarsen hellbraun. Klauen braun, Spitze blass; ror der Spitze ein ziemlieh kräftiger Zalm. 1. Hintertarsenglied mit 17 braumen Ctenidien. Verhältmis der Hintertarsenglieder $5^{1}: 1: 1^{3}{ }_{4}$.

Fliigel grauweisslich hyalin. Adern braun bis gelblich braun, im Vorderflïgel von brïunlichem Hanclı gesäumt. Der 'Wwischenraum zwischen dem Scheitel der Areola postica und m im Vorderflügel von graubrauner Fïrbung ausgefïllt, ebenso das distale Ende der Zellen An und Ax, sowie der proximale Teil der Zelle $A x$ im Vorderflïgel und das distale Ende von An im Hinterflügel. Areola postica mit abgerundetem Seheitel. Rand des Vorder- und Hinterflügels mit Ausnalume der Basalhälfte des Vorderrandes, letzteres dicht und lang, meist vielreihig pubesziert. Adern des Vorderflïgels mit nur einer Reihe re-

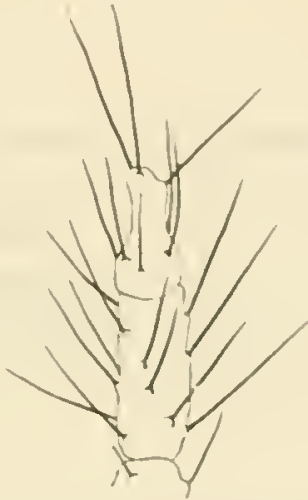

Fig. 13. Philotarsus falk-lan. dicus linderL. Fishlirspitze 12. und 13. Glied. Vergr. $270: 1$. lativ langer Haare, nur der ausserhalb der Abzweigung des Radialramus gelegene Teil von $r_{1}$ zwei- bis mehrreihig pubesziert. an ist olne Pubeszenz. Pterostigma mit Ausnahme einer selmmalen Zone am Hinterrande ziemlieh dicht pubesziert. In Hinterflïgel sind die Enden ron $r_{1+5}$, $m$ und cu fein $z$ weireihig pubesziert. Membran zienlich lebhaft rot, grïn und gelb irisierend.

Vorderflïgellänge $3 \mathrm{~mm}$. Flïgelspammung $7 \mathrm{~mm}$.

Falklands-Inseln. Port Jrilliam. 2. IIärz 1902. 9 ․ Schwedisehe Siidpolar-Expedition.

Der europäische philotarsus flaviceps (STEPIr.) untersehcidet sich leicht durch folgendes: Adern der Vorderflügel grösstenteils zweireihig pubes\%iert, Pterostigma meist sehr spärlich pubesziert, 1. Hintertarsenglied mit nur 1:2-1:3 Ctenidien. Fiihler viel kürzer pubesziert, Flïgelzeiehmung wesentlieh anders und stärker. Verhältnis der Hintertarsenglieder 4:1 : 1. Philotursus fraterme ExDERL. 1901 aus lbolivia ist we-

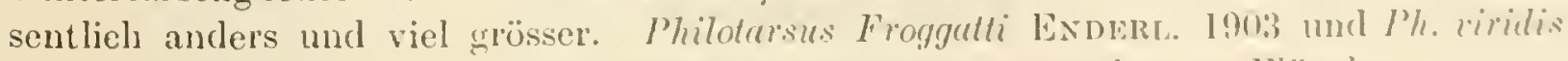
ENDERL. 1903 aus Australien sind grösser mod mit mgezeicheten liageln. 
Ordo: Collembola.

Fam. Poduridae.

Subfam. Onychiurinae.

T'ullberginl LuBB. 1876.

Trullbergier imsuldris WaHLGR. 1906.

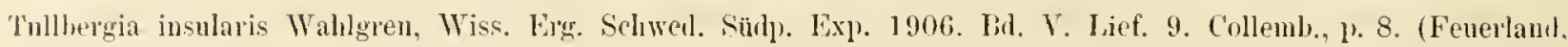
Ost-Falliland, Süid-Georgien.

\section{Subfam. Achorutinae CB. \\ Tribus: Pseudachorutini CB. \\ Choudrachorutes WaHLGR. 1906.}

Wahlgren, Wiss. Ergelm. Schwed. Südpol. Exp. 1906. Bd. V. Lief. 9. Collemb, p. 5.

Chomdrarluormtes tuberenlatus WAHLGR. 1906.

Chondrachorutes tuherculatus Wahlgren, Wiss. Ergeln. Schwed. Südpol. Exp. 1906. Bd. V. 1,ief. 9. Collemb. p. 5. (Ost Falklaud.)

Fam. Entomobryidae.

Subfam. Isotominae.

Tribus: Isotomini CB.

Isotoma BOURL. 1839, CB. s. str. 1906.

Isotomer malvinemsis WAHLGR. 1906.

Isotoma malvinensis Walılgren, Wiss. Erg. Schwed. Südnol. Exp. Bd. V. I,ief. 9. 1906, 1. 13. Taf. 2, Fig. 22 -28. (West-Falklanit.)

Isotoma pmomctertu WaHLer. 1906.

Isotoma pronctata Wahlgren, Wiss. Erg. Schwed. Sïdpol. Exp. Did. V. Lief. 9. 1906, p. 14. Taf. 2, Fig. 29 -32. (Feuerland, Ost- und West-Filliland.)

Isotomer ti!minellel WAHLGR. 1906.

Isotoma tigrinella Wrahlgren, Wiss. Erg. Schwed. Südnol. Exp. Bd. V. Lief. ?. 1906, p. 14. (Ost-Falkland.)

Isotomll ormorte WAHLGR. 1906.

Isotoma ornata Wahlgren, Wiss. Erg. Selıwed. Südpol. Exp. Bd. Y. Lief. 9. 1906, p. 15. Taf. 2. Fig. $33-35$. (Ost-Falkiani.)

T'ribus: Anurophorini CB.

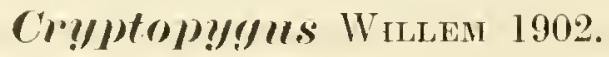

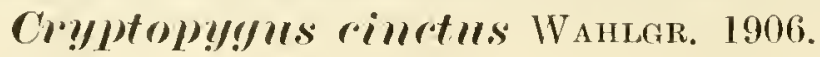

Cryptopygus cinctus Wahlgren, Wiss. Erg. Schwed. Südpol. Wxp. Bo. V. Lief. 9. 1906, p. 11. Taf. 2. Fïg. 19. (Feuerland, Ost-Falkland.) 


\section{Subfam. Entomobryinae sonärlers. \\ Tribus: Isotomurini C'l3.

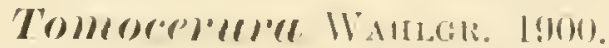

Tomocerura, Wallgren, lint. Tilskr. 1900.

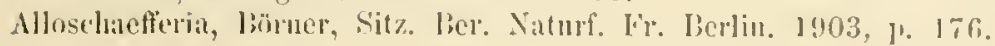

\section{Tommorenemer rem,jum!rms (Scrär. 1897).}

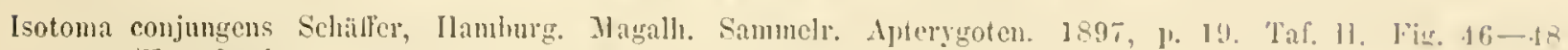
(leurland.

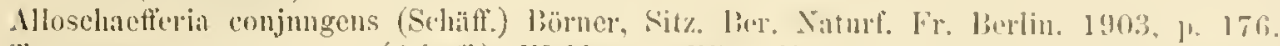

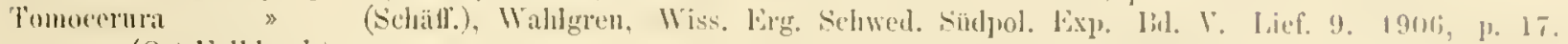
(Ost-l'alkland.)

Ptemura, Templ.

Tribus: Entomobryini CB.

Sira, lubbock.

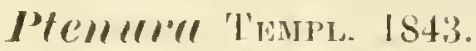

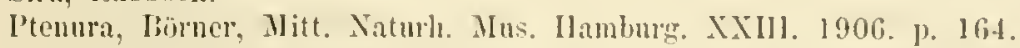

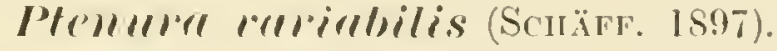

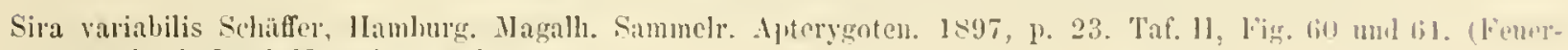
lant, lusel Navarin, Inkel I'icton.)

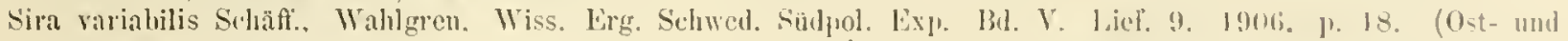
West-Falkiand.)

Ptcuura variabilis (Schïff.) $m$.

\section{Die hauptsächlielsste Literatur iber die Inseliten der Fallibuls-Inseln.}

Alsamd, Troisième note sur les Galérucides. Iiulletin on comptes-liendus das séances de la socicte. Iint. de liclgique. 1890, P. 1.XXX-XCT.

Bates. Totes on Carabidar, and iescriptions of new species. Linfomol. Montly Magazinc. 1112. 1871. 1) $11-11$ (1)ag. 13 ).

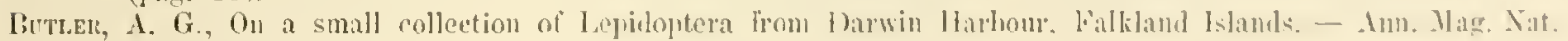
Ilist. 6) XII. 1893, 1. $207-210$.

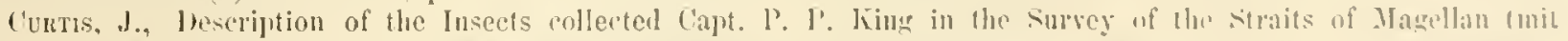

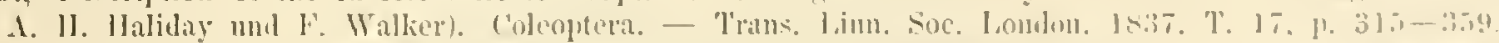

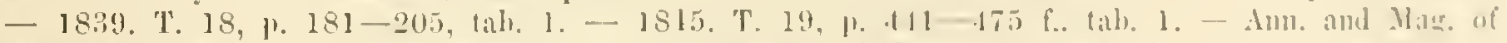

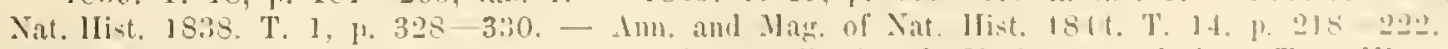

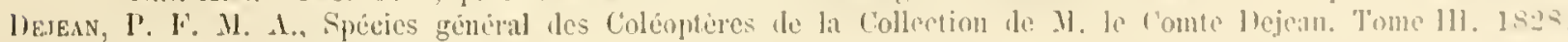
(1). 529,534$)$.

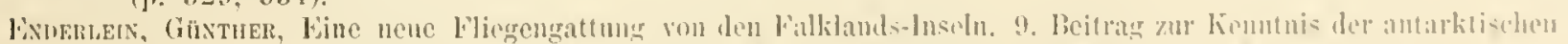

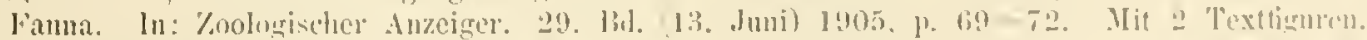

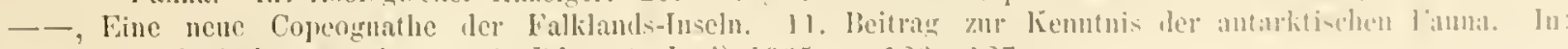
Zoologischer Anzeiger. 29. 131. (10. Juni) 1905, 1). 126-127.

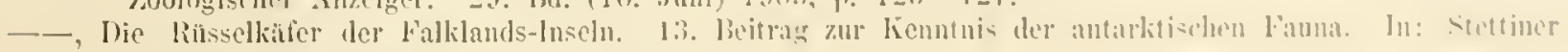

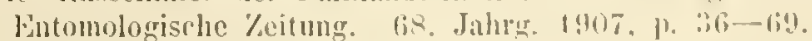

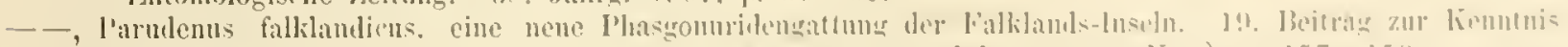

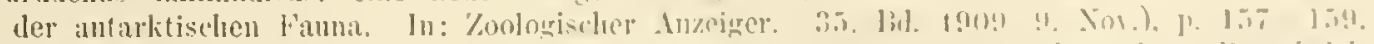

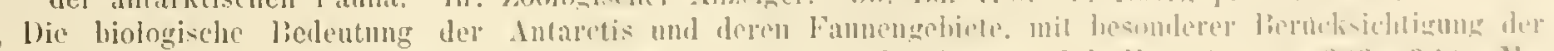

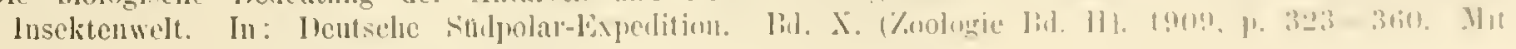
Tafel 39 und 2 Ablothmugen im 'Text.

K. Sv. Vel. Akad Ilandl. Band 45 . N: 3. 
Falranke, L., Jiste des Coléoptères recucillis à la terre de Feu. Ann. Soc. Ent. de France. 1885, p. $33-62$.

-_. Coleoptéra. Mission Scientifique du Cal IIom. 1882-1883. Tome VI. Zoologie. Insectes. Paris 1888. DI, Colcoptères, 1. 3-63. Tafel 1 und 2.

__, Tenebrionidae, Cantharidae, Oedemerilac. Résnltats du Voyage ılı S. Y. IRelgica en $1897,1898,1899$. 1906, pag. $41-43$.

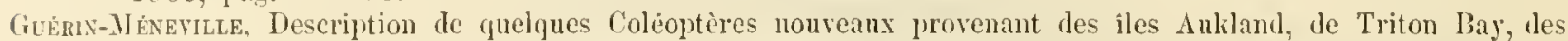
îles Salomon et rlu I'ort Famine, dans le létroit de Nagellan. - Revue Zool. 1841. 1\%. 213-217.

- - Deserijtion de quelques Coléopteres des côtes du détroit de Magellan. - Tievue 70ol. 1839, p. 295 - 303.

- - in: L. I. Dupereer, Foyage autour du Monde, cxécute par ordre dn Roi, sur la Corvette le Sa Majeste, La Coquilie, pendant les amces 1822, 1823, 1824 et 1825 etc. (Zoologie par M. I.tsuN). Paris 1830. Tome I1, 2. I'artie.

Insecten. Cap. XII, 1. 57-302. „luhalt» an Inseliten, p. 304-312. - Coleoptera, p. 57. - Orthoptera, p. 152. - Hemiptera, p. 154. - Neuroptera, p. 194. - Ilymenoptera, 1. 197. - Lepidoptera, 1. 271. Iiptera, r. 286.

Inspsox, G. F., On the classification of the Schoenobinae and Crambinac, two families of moths of the family Pyralidae. - Pr. Zool. Soc. London 1895, p. 897-974.

- - On the Classification of two sulfimilies of moths of the family Pyralidac: the IIydrocampinae and Scopariinae. In: Trans. Ent. Soc. London. 1847 (pag. 127-240), p. 233.

_- Catal. Lepirlopt. Plialaen. British Museum. Vol. IV. 1903 (p. 224, I']. 62, Fig. 22).

Kízise, II. J., Coleoptera. Hamburger Hagalhaensische Sammelreise. Ilambmrg 1907, p. 1-125. 3 Karten.

Malile, Lepidoptera, in Miss. Scientif. du Cap Horn. 1882-1883. Tome VI. Zoologie. Insectes. Paris 1888. IIV, pag. $1-35$. Taf. $1-3$.

Macquart. Diptères cxotiques. 'Tome H. I’art 3. 1843 (1. 264. Tah. 33, Fig. 5 und 5 a).

Résultats du Voyage du S. Y. Belgica en 1897-1898-1899 sous le commendement de A. de Gerlache de Gomery. Piapports scientitipues publiés anx frais du Gouvernement lielge. sons la direction re la commission de la Belgica. Zoologie. Inscetes. Anvers 1906, P. 1-92. 5 Tabl.

Hierin: Introdnction: Severin. Orthoptères: Brunner von Waltenwyl; Hemiptères: Bergrotì. Coleoptères: E. liousseau, A. Grouvelle, H. Selouteden, E. Brenske, H. Toilcau, J. Bourgeois, E. Olivier, L. Fairmaire, G. Stierlin, A. Bovie, A. Lameere; Hyménoptères: J. Tosquinet, C. Emery, E. Antré, J. Vachal; Dipteres: J. Ch. Jacobs, Th. Becker, E. II. Iiübsaamen.

Ulamer, Ann. Soc. Entom. Belg. Vol. 49. 1905, p. 18 (Fig. 3, 4).

- - Totes Leydeu Museum. Tol. 28. 1906, 1). 9 (Fig. 8, 9).

TaLiextix, in: Mem. Manchester Soc. Xl ViII. 1904. No. 23, p. 20-22.

Wallugen, Eivar, Antarktische und subantarktische Collembolen. Mit 2 Tafeln. - Wissensclı. Ergehnisse der schwelischen Sudpolar-Fxpedition 1901-1903 unter Leitung von Dr. Otto Fordenslijoll. 1906,22 pag.

Waterhouse. G. R., Descriptions of some now Colcopterous Insects from the sonthern parts of South America. - Amn. and Mag. Yat. Ilist. 1842. X, P. 13I-147; 1. $217-224$.

- Descriptions of a new gems of Carabidons Insects hraghit from Falklands-Islands by C. Darwin (Lissopterus quadrinotatus! - Ann. and IIag. Nat. Hist. 1843. XI, ). $281-283$.

Wateknense, F. I1., Trans. Entom. Soc. London 1875, p. 335.

- Descriptions of new Coleoptera of Creographical interest, collected ly Clarles Darwin, Iss!. in: Jommal of the linucan Socicty. London. Vol. XIV. 1879, 1) 530-534. 


\title{
Die Insekten Fenerlands.
}

Eine zusammenfassende Arheit ïber die Insekten Fenerlands, abgesehen von dem Namensverzeichnis der Käfer ron KozBF, existiert bisher noch nicht. Dic schr zerstreute Litteratur ist z. 'T. schwer auffindbar und schwer zugänglich. Die zahlreichen kleinen Inseln südlieh der Hauptinsel, sowie auch die Staaten Insel gehören faunistiseh zu Fenerland. Die Anzahl der bis jetzt ron Feuerland nachgewiesenen Insekten beträgt 286 Arten, und zwar 85 Coleopteren, 69 Lepidopteren, $6 \mathrm{Hymeno-}$ pteren, 65 Dipteren, 23 Rhynchoten, 2 Odonaten, 7 Trichopteren, 5 Plecopteren, 1 Agnathe und 23 Collembolen. Von Fenerland sind dureh die schwedische SiidpolarExpedition nur wenige Arten nitgebracht worden, die aber biogreographiseh ron grossem Interesse sind und 11 nene Species enthielten (3 Coleopteren, 5) Dipteren, 3 Plecopteren).

\author{
Ordo: Coleoptera. \\ Fan. Carabidae. \\ Subfan. Carabinae. \\ Ceronglosstrs Solder. 1849.
}

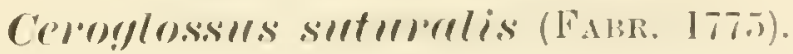

Carabus suturalis, Fabricius, syst. Fint. 1775, 1. 238. Ir. 13.
F., Fobrioitus, Spec. Ins. 17s1. 1. 1. 301. Ni. 16.

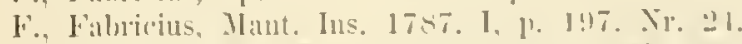

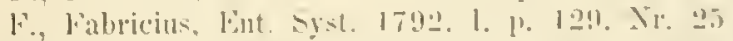

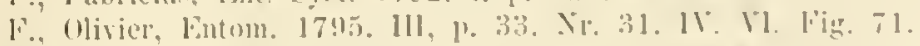

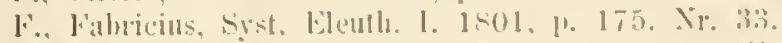

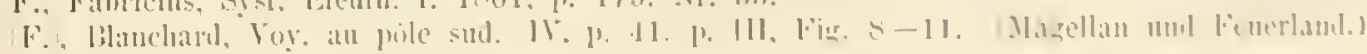

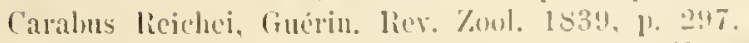

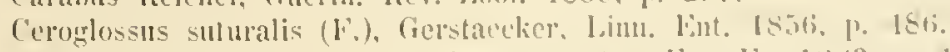

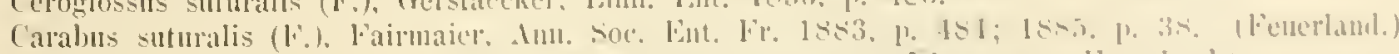

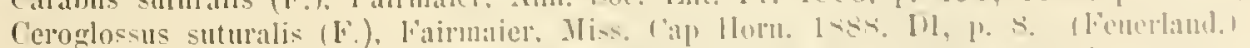

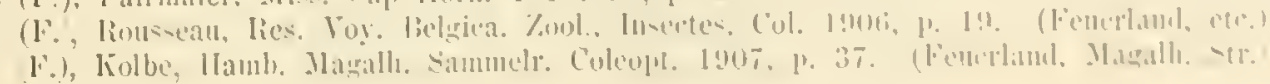


Lissopteme Waternouse. Ann. of nat. Hist. 1843, p. 281.

\section{Lissopterus II!norlesi HaIRM. 1885.}

Lissopterus IIyadesi, Fairmaire, Ann. Soc. Ent. Fr. 1885, p. 35. (Feverland: Orange-Bai.) Farm., Fairmaire, Miss. Se. Cap Horm. VI. 1888. MI, 1. 6. Pl. 1, I.ig. 1. Fairn., Kolbe, Ilamb. Magall. Sammelr. Coleopt. I907, p. 39.

Subfam. Migadopinae.

Burch!rcoelus Ciraudorr. 1842.

Bull. Mosc. I 842 . IV, 1. 848; 1861 . II, 1). 512.

Buelleroehes vivescens WATERII. 1842.

Migadolns virescens Watcri., Waterhouse, Nn1. Mag. Nat. IIist. 1842. IX, p. 136. Pl. IIl, Fig. 2. Brachyeoelus Duponti Chaudoir, Bull. Mosc. 1842. IY, 1. 850.

virescens (Waterh.) Claudoir, Mull. Mose. 1861, 1. 514.

Migadops virescens Waterl., Fairmaire, Ann. Soc. Ent. Fr. 1885, 1. 36.

Brachycoelus virescens Waterh., Fairmaire, Miss. Cap IIorn. 1888. 1)I, 1. 10. (Feuerland, Orange-Bai.)

Waterh., liousseau, Iies. Voy. du S. Y. Belgica. Zool. Insectes. 1906, p. 20. (Fenerland, Cliile ete.)

Waterl., Rousseau, Ries. Voy. Belgica. Zool. Ins. 1906. Coleopt., p. 20. (Fenerland und Falkilands-Inseln.)

Waterh., Kólbe, Hamb. Magall. Sammelr. Coleopt. 1907. p. 39. (Fenerland.)

Burchyroelus comerolou C. O. WATERII. 1881.

Brachycoelia concolor, C. O. Waterhouse, Proc. Zool. Soc. London 1S81, p. 80. (Fenerlanu.)

Bracliycoelus » C. O. Waterlı, Kolbe, IIamb. Magall. Sammelr. Colcopt. 1907, p. 40.

Antriotomomiles Chaudotr 1861.

Bull. Mose. 1861. I1, p. 518. Fairm. Miss. Cap IIorn 1888. D1, 1. 7.

Antareromomms Peromi Chaud 1861.

Antarctonomus P'oroni, Chaudoir, Bull. Mosc. 1861. Il, l. 519. (Magalh. Str.)

Chaud., Fairmaire, Anl. Soc. Ent. Fr. 1885, p. 35.

Chaud., Fairmaire, Miss. Cap. IJorn. 1858. DI, p. 8. (Feuerlaud, Orange-Iaai.)

Chaud., Kolbe, IIamb. Magall. Sammelr. Coleojt. 1907, 1) to. (Fenerland und Magallı. Str.)

Migarlops Waterit. 1842.

Migarlops ocelis WATERII. 1842.

Migadops ovalis, Wateriouse, Am.. Nat. Ilist. 1842, 1. 139. Taf. 3, Fï. 3. (Fenerland.)

Clraudoir, Bull. Nose. 1861. II, 1'. 522.

Waterls., Faimaire, Mnı. Soc. Ent. Fr. 1885, p. 37.

Waterh., Fairmaire, Niss. Cap Horn. 1888. DI, 1. 11. P'l. I, F'ig. 5.

Waserh., Lolle, Hamb. Magahl. Sammèr. Colropt. 1907, p. 40.

Feuerland. Orange-Bay, auf dem Krater-Pik, Kermite-Insel.

\section{Migadops migrocoemled WATERH. 1842.}

Migalops nigrocoerulens. Waterhouse, Ann. Nat. IIist. 1842, p. 138. (Feuerland.)

Waterl., Faimaire, Am. Soc. Fint. Fr. 1885, 1. 37.

Waterh., Fairmaire, Niss. Cap IIorn. 1888. DI, p. 12.

Waterlı., Kollse, IIamb. Magall. Sammelr. Coleopt. 1907, p. 40. (Fenerland.) 


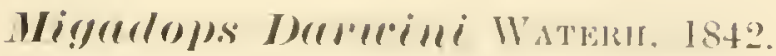

Migadops Danwini, Waterhonse, Amm. Nat, Ilist. 1842, 11. 138. Magalh. Str.)

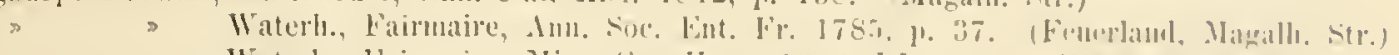

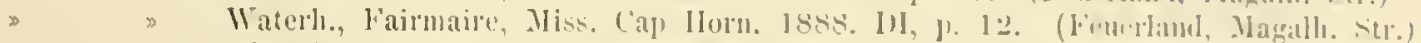

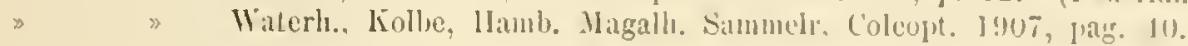

\author{
Conscelins Curtis 1839. \\ Trans. Linn. Soc. 18. 183!', 13. 181 (- C'reobius Guẻr.).
}

Corseclies mitides WaTERH. Istl.

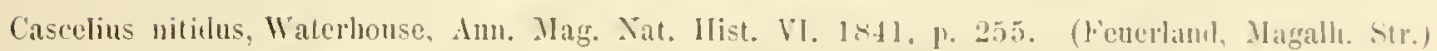

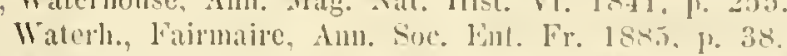

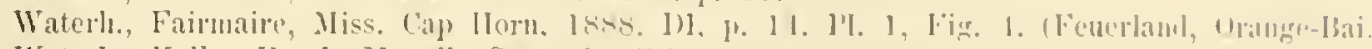

Waterh., liolbe, Ilamb. Matgalls. Sannelr. Colcopt. 1907, 1\%. 10.

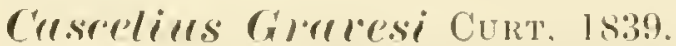

Cascelius Gravesi, Curlis. Trans. Lim. Soc. 1839, 1). 123. Tal. 15, ling. 13.

Curt., l'ut\%ap, Slent. Ent. \%eit. 29. Jalurg. 1slis, 11. 53:2.

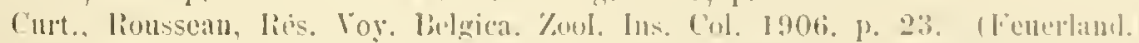

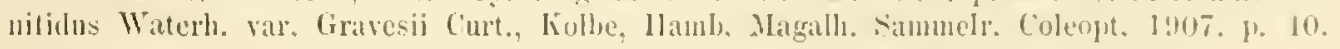

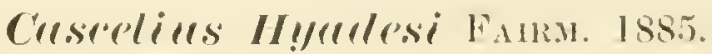

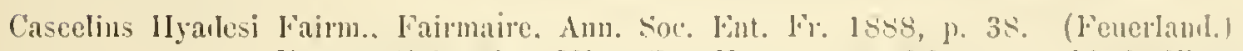

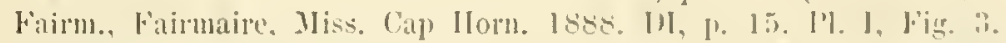

Fairm., Lolbe, Itaml. Magall. simmolr. Coleopt. 1907, p. 11. (leuerlanil.)

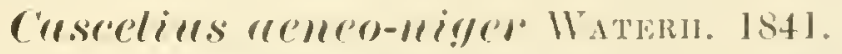

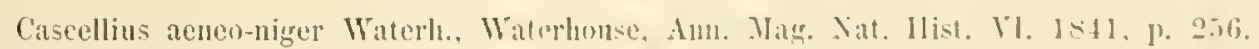

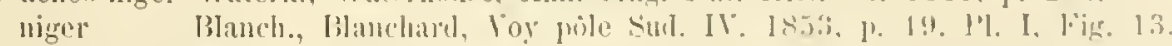

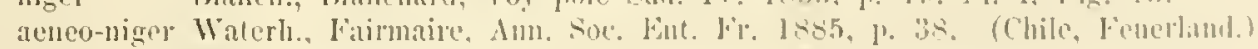

Waterh. Fairmaire, Miss. Cap Morn. 188s. M. 1\%, I1.

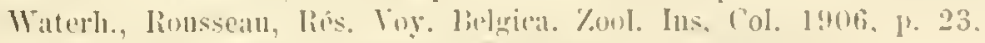

Waterlı., Kiolbe, Ilaml. Ilagalh. Simmell. C'ol. 1907, 1) \&1.

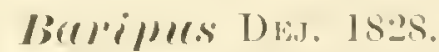

1)EJEM, Splec. III. I $828.1 \% .24$.

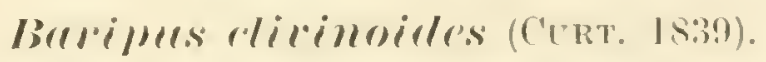

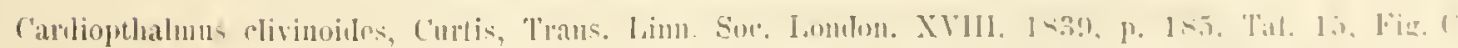

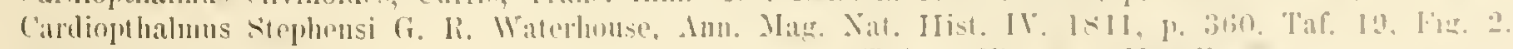

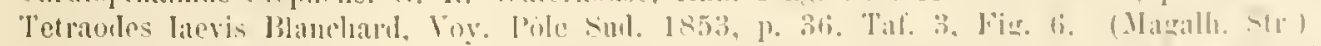

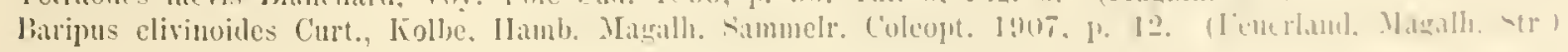

Subfam. Antarctinae.

Aleterertin Drs. IsLs.

Solder, Gay. Ilist. fis. pul. Chile. 1819. I1, I?. 213. 


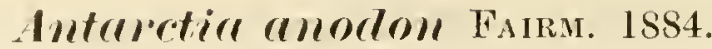

Antarctia anodon, Fairmaire, Ann. Soc. Ent. Fr. 1884, p. 485.

Fairm., Faimatre, Ann. Soc. Ent. F. 1883 , 1. 485. 1885, p. 39.

Fairm., Fairmaire, Miss. Cap IIorn. 1888. II, 1) 16.

Fairu., liolbe, Ilamb. Magalh. Sammelr. Coleopt. 1907, 1. 45. (Fenerland, Magallı. Str.)

\section{Anteretia caerellen Solite 1851.}

Antarctia "aerulea, Solicr, Gay. Ilist. Chile. 1851. IV, 1). 241. (Chile.)

Solier, Fatmaire, Am. Soc. Ent. Fr. I8s5, 1\% 39.

Solier, Fairmaire, Miss. Cap. Horn. 1888. WI, p. 16. (Fenerland.)

\section{Autaretire falsicolor FAIRM. 1884.}

Antaretia falsicolor, Fairmaire, Ann. Soc. Ent. France. 1884, 1. 487.

» Jairm., Líolbe, Ianh). Magalh. Sammeh. Coleopt. 1907, p. 46. (Fenerland, Magalh. Str.)

\section{Anterertia Iatigastrira, DEJ. 1828.}

Antaretia latigastrica, Hejean, Spce. Gen. III. 1828, p. 528.

Dej.. Irullè, des Insectes dans le voyage d'Urbigny dans I'Amérique méridionale. Paris $1837-1843$, p. 31 .

Iej., Gay, Ilist. fis. 1851. IV, p. 250.

Dej., Kiolbe, Hamb. Magalh. Sammelr. Colcont. 1907, 1. 46. Chile, Uruguay, Patagonien, F'enerland.)

Anterectia blamde Des. 1828. - Taf. 1, Fig. 2.

Antarctia lokanda Dejean, Spec. Gen. IH. 1828, 1. 529.

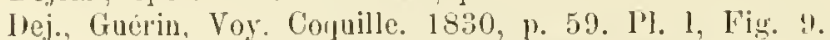

quadricollis Solier, Gay, Hist. Chile. I85 L. IV, p. 246. (Chile.)

blanda Dej., Faimaire, Ann. Soc. Eut. Fr. 1885, p. 39.

Dej., Fairmaire, Miss. Cap Horn. 1888. 01. Col., P. 16.

Dej., Rousseau, Rés. Toy. Belgica, Zool. Ins. Col. 1906, p. 21.

Dej., liolbe, Hamb. Magaht. Sammeli. Col. 1907, p. 46. (Chile bis Feuerlaud, Falliands-Inseln.)

\section{Anterertial Rarovitall Rouss. 1900.}

Antarctia Racovitzai, Rousseau, Anu. Soc. Ent. Belg. Vol. 44. 1900, p. 108. (Feuerland.)

Rouss, lioussean, Res. Voy. Belgica. 1906. Zool. Ins. Col., 1. 22. Pl. 1, Fig. 3, 5, 7.

Kouss., Kolbe, Hamb. Magalh. Sammetr. Col. 1907, 1) 46.

Feromiola Tschitscin ERINe 1900.

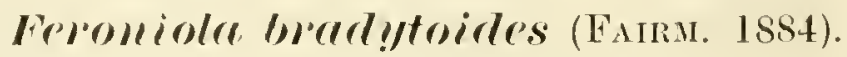

Antaretia bradytoides, Fairmaire, Amn. Soe. Ent. France. 1884, 1. 487.

Fairm., Faimaire, Anm. Soc. Eut. Fr. 1885, p. 39.

Fairm., Fairmaire, Miss. Cap Horn. 1888. Coleopt. II, 1. 17.

Feroniola bradytoides (Faim.), Kolbe, Iamb. Magall. Sammelr. 1907, p. 47. (Feuertand, Magalh. Str.)

ITUl) OPJels Waterh. 1842.

Alropus, Wh'terhouse, AmI. Nat. Hist. IX. 1842, 1) 134. 


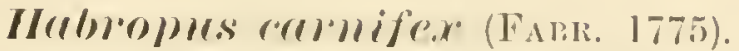

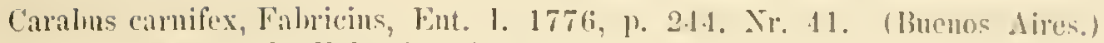
$\gg \quad$ F., Fabricius. Spee. lns. 1781.1. 1\% 308.
$\bowtie$ 1., labricits, Mant. Ins. 1787. I. W. 301,
» $\quad$ F.. Falricins, Ent. Syst. 17!2. 1, 1\% 15:3.

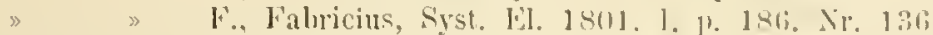
" $\$$ F., Olivier, Ent. 1745, 11. 71. Nr. !7. 'T'af. 7. l'ig. 2a.

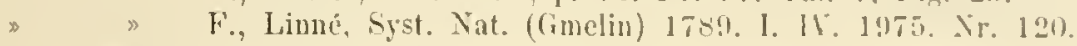

llarpalus Mollbergii Gyllhall. (Buenos Aires.)

pallipes Sturn. (Brasilien.)

Metius splendilus (inérin, liev. \%ool. 1839, 1\%. 297. (Magellan.)

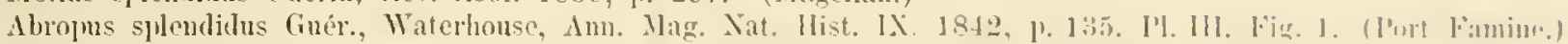

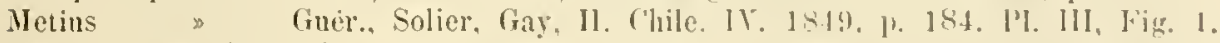

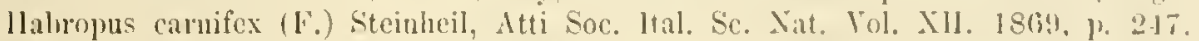

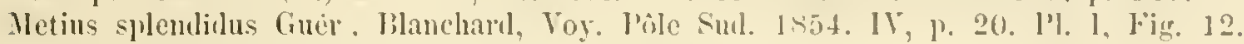

- - - - Seliaum, Siett. Lut. Zeit. 18.18, p. 33.1.

IIabropms earnifex (F.), Faimaire, Ann. Soc. Fint. Fr. 1885, p. 39.

$\gg$ (F.), Fairmaire, Miss. (ap Horn. 1888. 11. p. 9. Fencland: Orange-13ai.)

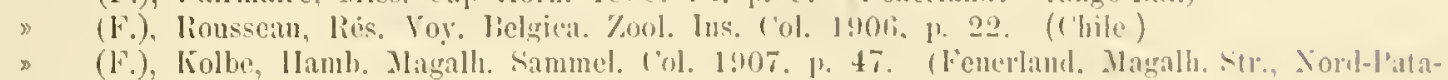
gonien, Argentinien, lirasilicn.)

\section{Meriaglus Solter 1849. \\ Merianders Murengi (Bates 1871).}

Oopterns Maccyi, Bates, lint. montlı. Magaz. VIIt. 1871, 1. 13. (liallianıl.)

Merizodus Maeleyi(!) (Bat.), Faimaire, Ann. Soc. Ent. Fr. 188.5. 1\% to.

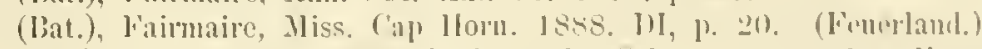

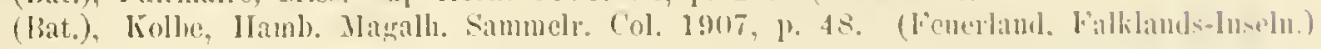

\section{THerll1.S CLAHRY 1806.}

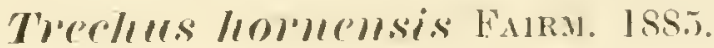

Trechus hornensis, Fairmaire, Amm. Soc. Ent. Fr. 1885. 1) 11. (1*enerlant.)

" Fairm., Fanmaire, Miss. ('ap 110rn. 188s. II, 1. 22.

» Fairm., Lolbe, Hamb. Magall. Sammelr. Col. 1!07, 1). Is.

\section{Trechus IViemrlieri Rouss. 1900.}

Trechus Wienckei, Ronssean, Inn. Soe. Fint. lielg. Vol. 1.1. 1900, 1. 108. (Frmerlamel.)

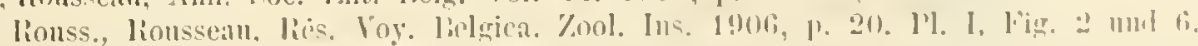

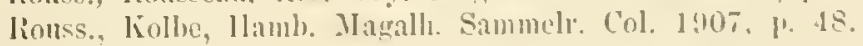

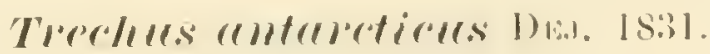

Treclus antareticns, Dejean, Spec. Col. У. 1831, p. o․ (Filliands-Inselı.)

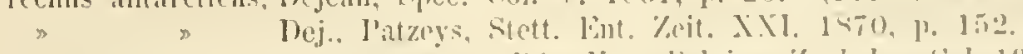

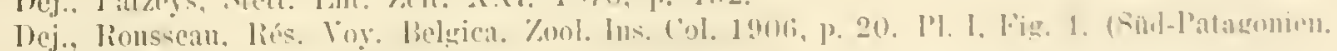

lenerlami, Argentinien.)

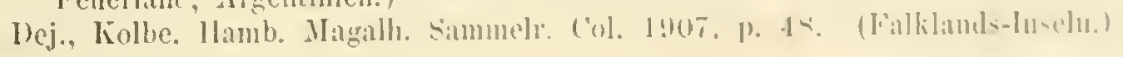




\section{Subfam. Lebiinae. \\ IIOIJalodera SoLien 1849.

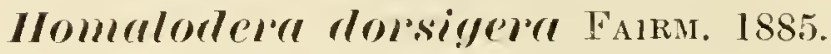

Homalodera dorsigera Fairm., Fairmaire, Ann. Soc. Ent. Fr. 18s5, r. 39. (Feuerland.)

Fairm., Fairmaire, Miss. Cap Hor'u. 18ss. II, p. 18. I']. I, Fig. 4.

Fairm., Kolbe, Ilamb. Magah. Sammelr. Col. 1907, 1. 49.

\section{Homerlorleme sutulletu FAIRM. 1885.}

Homalodera suturata Fairm., Faimaire, Ann. Soe. Fnt. Fr. 1885, p. 40. (Fenerlant.)

Fairm., Faimaire, Miss. Cal IIorn. 1888. I1, 1) 19.

Fairm., liolbe, Ilamb. Magaht. Sammelr. Col. 1907, 1) 49.

\section{Fam. Dytiscidae. \\ Rhallut LACORDAIRE 1835. \\ Rlentus Dalleimi (Bablngton 1841).}

Colymbetes (Hiantus) Tarvinii Babington, Trans. Fut. Soe. 1II. 1841, p. S.

Darwini (Bab.), Sharp., Trans. Roy. Dubl. Soc. Tol. 2. Ser. Il. 1882, p. 758, Nr. 1219. (Patagonien.)

Rhantus $\gg$ (liab.), Kolbe, Hamb. Magah. Sammehr. Col. 1907, p. 51. (Magall. Str., Feuerland.)

\section{Truncetes SuARP 1881.}

Sunrp, Se. Trans. Roy. Dublin Soc. Tol. 2. Ser. II. 1882, pag. 602 minl 897.

\section{Lrllucetes morgellanirus (BAB. 1841).}

Colymbetes magellanicns, Babington, Trans. Ent. Soc. IlI. 1841, p. 10.

Agalms $\gg$ (liab.), Gemminger und Ilarold, Cat. Col. II. 1868, p. 455.

Colymbetes „ (Bab.), Sharl, Se. Trans. Roy. Dublin Soc. Tol. 2. Ser. II. 1882, p. 762. Nr. 1238 (Fenerland.)

I ancetes (Bab.), Kolbe, Iamb. Hagalh. Sammeh. Col. 1907, p. 52. (Magalh. Str.)

\section{Lancetes reticmlates (BaB. 1841).}

Colymbetes (Rhantus) reticulatus, Babington, Trans. Ent. Soc. Iondon. Vol. I1I. 1841, 1). 4. (ठ’). nigro-rematus, Babington, 'Trans. Fut. Soc. london. Tol. I1l. 1841, 1. 5. (q).

Rhantus praemorsus (Wrichs.), Tairmaire, Miss. Cap Horu. Col. I)I. 1888, 1\%. 24. (nee praem. Frichs.) Lancetes reticulatus (liab.), Kolhe, Ilamb. Magalh. Sammelr. Col. 1907, 1. 51. (Magalh. Str., Fenerland.)

Lullcetes mixtlls (C. O. WATERII. 1881).

Rhantus mixtus, C. O. Waterhonse, Froe. Zool. Soc. London. 18S1, 1). 81. (Fenerland.)

lancetes » (C. 0. Waterh.), liolle, llamb. Nagalh. Sammely. Col. 1907, p. 52. (Fenerland.)

Fam. Staphylinidae.

O.x?Inorla MLanneirit. 1830.

Maxiertielar, Brachèl. $1830,1 \% 69$.

1 ber edhte Lancetes pracmorsus Encus, kommt nicht in Fenerlanl ror, sondern hanptsäehlich in ("hile etc. 
KUNGL. SY. VET. AKADRMIENS IIANDLIFGR. BAXD 48. N:o 3.

O.x!lporla rim!guletu Boir. 1858.

Oxypuna cingulata, lioheman, lingeiens liesa. 1858, p. 2.5. (l'atagonicm.)

Boh., Kolhe, llamh. Magall. Sammell. Col. 1!07, p. 53. (Fucrlam.)

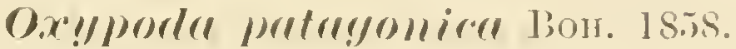

Oxypora patagonia, boheman, lanenies Resa. 1858, 1. 25. (1'atagonien.)

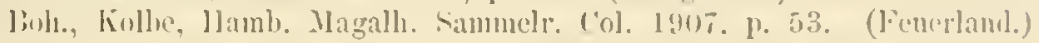

Ot/lils STEPHENS 1832 .

Stepuexs, Ill. IBrit. Ent. V. 1832, 1). 253.

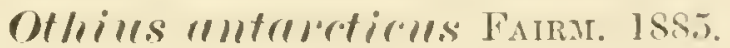

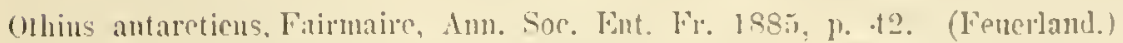

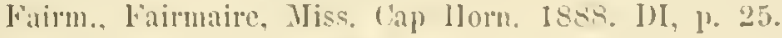

Fairu., liolbe, llamb. Magall. Sammelr. Col. 1907, 11. 54.

\section{Subfam. Aleocharinae.}

Norrlensli;jïldelle nor. gen.

Typus: N. flarilarsis nov. spee. (Fenerland.)

IIentum quer trapezfömig, vorn gerade (Fig. 14 m) Labialpalpus (Fig. 14 1. 2,3) 3-gliedrig; Endglied unbehaart, sehr dünn und etwas länger als das 2. Glied. Hypopharynx (Fig. 14 hyp) ziemlich lang. vorn in etwa 1/5 seiner Länge eingespalten. Paraglossen (Fig. 14 pgl) wenig rorgezogen, etwa in der Mitte der Oberseite mit einer Längsreihe von mässig langen Haaren, die sich nach hinten fortsetzt. Maxillarpalpus

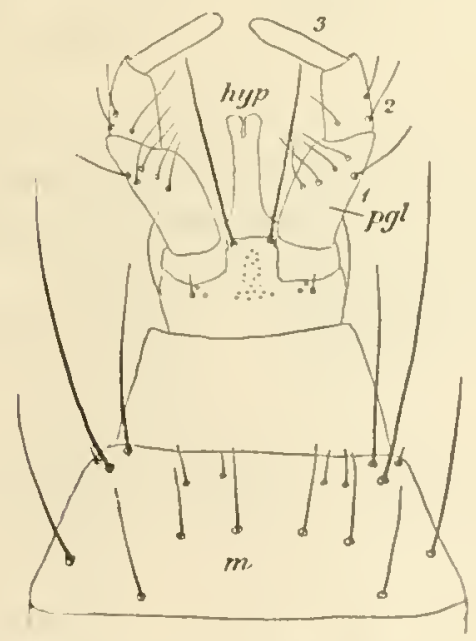

Fig. 14. Nordenskjoldella flavitarsis liNDERL. Labium und Mentum von

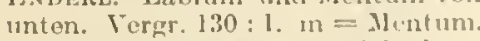
$1-3=1 .-3$. Glioul des Latialpalpus. l'gl = Paraglosson. lugl = IIypor pharyns.

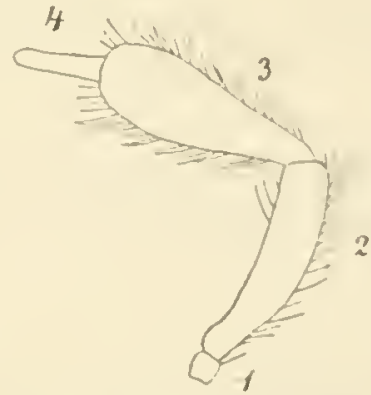

Fig. Ji. Nordenakjuldelln

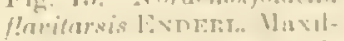
lnipulpus. Vergir. I(II): 1 .

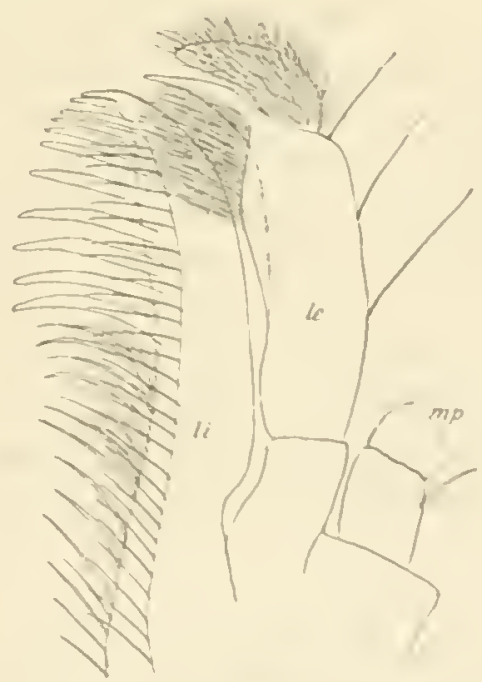

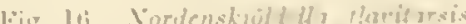

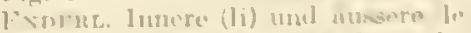

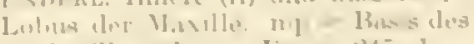
Javillarpolpus, Vergr. atis: 1 .

K. Sr. Vet. Akad. II 
(Fig. 15) viergliedrig, das Endglied sehr dünn, kurz, stiftförmig und unbehaart; das 3. Glied kräftig, naeh dem Ende zu verdiekt und nicht ganz 3 mal so lang wie das vierte. Der 3-gliedrige Lobus externus der Maxille (Fig. 16 le) trägt am mittleren Teil aussen 3 lange Borsten; Endglied clieht behaart. 2. Glied am Ende in eine einwärts geriehtete Spitze ausgezogen, hinter der eine Längsreihe sehr diehter, langer, feiner mud einwärts geriehteter Haare inseriert; Lobus internus (li) innen mit einer Reihe dieker und langer Zähne, dazwisehen im hinteren 'Teil lange, feine Haare, etwas answärts davon gerïekt oben eine Reihe ebenfalls einwärts geriehteter Borsten. Mandibeln (Fig. 17) hinter der gekrümmten Spitze nit einem kräftigen Zahn und vor der Mitte mit einem kleinen Zahn; beide sind bei der rechten Mandibel ziemlieh spitz und abstehend, bei der linken Mandibel (Fig. 17) flach, breit und abgermndet.

Kopf so breit, wie das Halssehild, nach hinten versehmälert

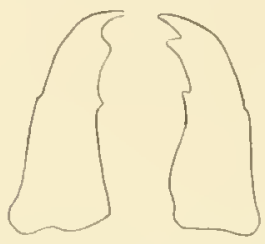

1Nig. 17. Nordenshioldella flavitarsis ENDERL. Linke und rechte Mandibel. Vergr. $58: 1$. und abgerundet; hinten nicht eingesehnürt. Fïhlerglieder churchsehnittlich fast doppelt so lang wie breit,. das erste etwas länger und ein wenig dieker; die Geissel nach dem Ende zu allmählieh und sehr wenig verdickt; Endglied stumpf konisch zugespitzt und am Ende abgerundet. Angen pubesziert.

Halssehild etwas sehmäler, als die Elytren zusammen; rorn und hinten gerundet, Seiten parallel; so lang wie breit. Seutellum mässig gross, dreieckig. Flügeldeeken an den Seiten stark gerundet umbiegend und ohne Seitenliante; die Aussenspitze etwas vorgewölbt, aber gleielmässig germndet; der übrige Hinterrand jeder Elytre etwas flach gerundet.

Abdomen oben flach. 3. Abdominalsternit nahe der Basis mit einem undentlichen Quereindruek. Tarsen sämtlich 5-gliedrig (bei den vorderen nach mikroskopischem Präparat!); innen in der ganzen Länge mit längeren Borstenhaaren. Das 1. Hintertarsenglied so lang wie das Endglied.

Dureh den Zahn hinter der Mandibelspitze hat Nordenskjöldella zn der enropäischen Gattung Dasyglossa KraAtz 1956 Beziehungen.

Blepharymenus SoLiter 1850 (mit einigen Arten aus Chile), von dem die Anzahl der Vordertarsenglieder nieht genügend bekannt ist, kommt nieht in Betracht, weil der Kopf hinten eingesehnürt, das Halssehild vorn verengt und oben mit 2 tiefen Längsfurehen versehen ist; diese Gattung seheint aber Phytosus nahe zu stehen.

Phytosus Curt. 1824, Gyrophaena Mannerr., Placusa Ericris. ete., die im Ban des Labium ähnlich sind, sehalten für nähere Verwandtsehaft dureh die viergliedrigen Vordertarsen aus.

Gewidmet wnrde diese Gattung dem Leiter der sehwedischen Sïdpolar Expedition Herrn Professor Dr. Otтo Nordensкjöld.

Tometenstajüldella flavitursis nov. spee. - Taf. 1, Fig. 7; Textfig. 14-17.

f. Sehwarz, mit rostgelben Schienenendspitzen und Tarsen.

Kopf sehwarz, ziemlich dieht und fein punktiert. 
Pubeszenz gelbbraun, dicht und sehr kurz. Schläfen etwas länger als die Augenlänge. Zwisehen der Fühlerbasis eine sehr deutliche kielartige K̈nickungr der Stirn, - die etwas geglättet ist. Mandibel rostrot. Labrum kurz und breit, in der Mitte jeder Hälfte vorn etwas eingedrückt; schwarz, Vorderrandsaum schmal rostgelb, Behaarung gelblich. Clypeus an den Seiten etwas gewölbt. Kiefertaster schwarz; Behaarung dicht, ziemlich lang, gelblich; 4. Glied rostrot. Fïhler ziemlich lang (ca. 2,2 mm), fast gleichdick, schwarz, Pubeszenz kurz; Endglied nur selı wenig dicker; 1. Glied ca. 21 mal so lang wie dick, 2. und 3. Glied 3 mal so lang wie dick, 4. Cilied (loppelt so lang wie dick, 5.-9. Glied ca. $1^{2 / 3}$ mal so lang wie dick, 10. Glicd $1 \frac{1}{2} 2$ mal so lang wie dick, 11. Glied (Endglied) doppelt so lang wie dick.

Prothorax nur schr wenig länger als breit, abgerundet rechteckig; etwas glatt, Punktierung fein und dicht, Pubeszenz sehr dicht, kurz und braun. Elytren mit feiner und sehr dichter Punktierung, Pubeszenz sehr dicht, kurz und braun; der nach unten herumgeliappte Seitenrandsamm ist ziemlich breit und stark abgerundet rechtwinklig nugebogen; Hinterrand ziemlieh gerade, aussen innerhalb des ungebogenen Randsammes ziemlieh kräftig, flael und breit eingedrückt. Hinterleib breit, oben eben, Seitenränder ziemlich stark in die Höhe gehoben; Unterseite kräftig gewülbt; iiberall glatt, Punktierung sehr fein, Pubeszenz dicht, kurz und braun, an der Spitze mehr rostgelblieh. Beine schwarz, Endspitzen der Sehienen und die T'arsen rostgelb. 'Tarsen sehr schlank und dïnn; Klanen sehr schlank, dünn, wenig gebogen und rostgelb.

Körperlänge ea. $5^{1 / 2} \mathrm{~mm}$.

Abdominalbreite $1,4 \mathrm{~mm}$.

Feuerland. Lapalaia. 9. Oktober 1902. I f. Schwedische Suidpolar Lxpedition.

Fam. Silphidae.

Catops Parket, 1798.

Catops, P’arke, Faun. Suce. I. 1798. p. 342.

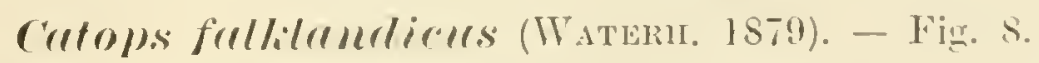

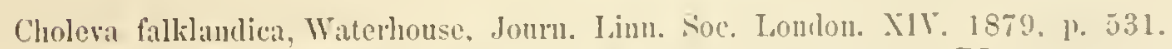

Waterlı., Farmuire, Miss. Cap 1101m. 1s8s. DI, 11. 26.

Waterh., Kolle, Ilanb. Hagilh. Sammels. Col. 1907, 1. 56.

Catops falliandicus (Waterh., m. Vergl, in diescl Abhandlung, 1'. 12,

Körpergestalt etwas länglich oval, nicht stark gewölbt. Schwarzbaun, etwas glinzend. Kopf hinten breit, vor den Augen stark versehmälert. Jabrum rostrot.

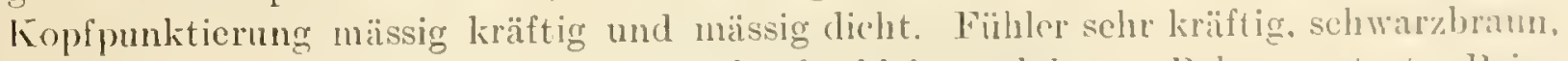
die beiden Basalglieder rostrot; S. Glied sehr kiein und kurz. l'alpus rostrot. Beine gedrungen, dunkel rötlieh braun, 'Tarsen rostrot; 1. Tordertarsenglied kiirzer als lureit und fast breiter als die Sehiene; I. Mitteltarsenglied so breit wie die Sehiene mul wenig länger als breit: 1. Hintertarsenglied halb so dick wie die sichicne mnd ea. 4 mal so lang wie dick. 'llorax viel breiter als der Kopf. Seiten nach voln gerundet konvergierend, Hinterrand gerade; Punlitierum wie beim liopf, loch nicht 
ganz so dicht. Elytren ohne jede Spur von Längslinien; nur nalıe dem Nahtrancle eine scharfe eingedrückte Furehe, die hinten sich stark dem Nahtrande nähert und im vorderen Elytrendrittel versehwunden ist. Punktierung etwas weniger kräftig als • beim Thorax. Kopf, Thorax und Elytren mit ziemlich diehter, mässig langer brauner Pubeszenz. Sehildehen klein.

Kiörperlänge $3 \mathrm{~mm}$.

Elytrenlänge $2 \mathrm{~mm}$.

Feuerland. Gable-Insel. 28. Oktober 1902. I Exemplar.

Nachträghich erhalte ich noeh eine mir vom Britischen Mnseum freundlichst geliehene Cotype von WATERHouse, die völlig mit dem vorliegenden Stüeke übereinstimmt. 3 weitere Stücke aus Fenerland im Britisehen Museum, die mir gleichfalls zum Vergleich vorhegen, sind etwas anders gefärbt. Ein Exemplar daron ist fast schwarz, etwas länglieher und sehmaler und seheint ein $\delta$ zu sein. 2 Exemplare mit rostbrauner Färbung sind $q$. Die Fundorte sind:

Feuerland. 1 오. R. Crawshay. - San Sebastian Settlement. Oktober 1904. 1 오. R. Crawshay. - Rio Mac Clelland. November-Dezember 1904. I J. R. Crawshay.

Die vorliegende Art gehört sieher nieht zu Choleva LATR. 1796 sondern zu Catops PAYKuL 179S, wenn sie auch innerhalb dieser Gattung sehr isoliert stelit. Durch das aufällig stark verkleinerte 8. Fühlerglied erinnert sie etwas an Catops chrysomeloides Panz. der europäischen Fanna.

\section{Hypermecrodles Kíratz.}

Subgen. Katanecrodes Scirout. 1905.

\section{Iypernecronles bigmttatus (R. A. PniL. 1859).}

Necrodes biguttatus, li. A. Ihilipli, Anal. Univers. Chile. XVI. 1859, p. 664. (Chile.)

Silpha biguttula, Faimaire et Gelunin, Rev, et Mag. Zool. 1859(2). XI, 1. 350. (Magalh. Str.)

Fairm., lieed, Ann. Uuiv. Chile. 48. 1876, 1. 275.

Fairm., Philippi, Anal. Univ. Chile. 71. 1887. p. 668.

Necrodes biguttulus Fairm. et Germ., Faimaire, Miss. Caj IIorn. YI. 1888. Col. MI, p. 27. PI. I, Fig. 6. (Fenerland, Patagonien bis Cliile.)

Hypernecrodes biguttatus (1'hil.), C. Berg, Comun. Mus. Tac. Buenos-Aires. I. 1901, 1. 325.

(Kiatanecrodes) bigntatus (I'hil.). Schonteden, Anı. Soc. Ent. Belg. 49. 1905, 1\% 196 und 199. biguttatus (Phil.), Schouteden, Iiés. Voy. Belgica. Zool. 1906. Ins., p. 27.

Fam. Scarabaeidae.

Subfam. Lucaninae.

Srlerogllatlens Hore 1845.

Catal. Lucan. 1545, 1\%. 26.

Sclemorguthers femomelis GuÉR. 1839.

Scleroguathus femonalis Guér., Gnérin, Rev. Zool. 1839, p. 303.

barwini Hope, Hopre, Trans. Ent. Sue. London. III. 1842, p. 279.

IIope, Ann. Nat. Hist. 1843, 1. 302. 
Sclerognathus rufolemoralis Curtis, Trans. Lim. Soc. London. 1515. H. 156.

Burm., Hope, Cat. Iac. 18.5, P. 26.

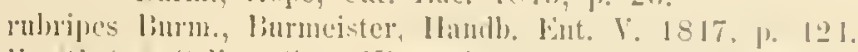

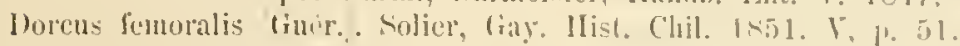

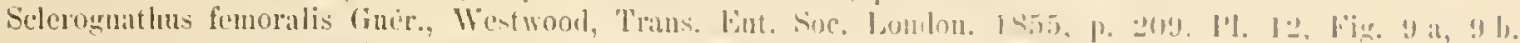

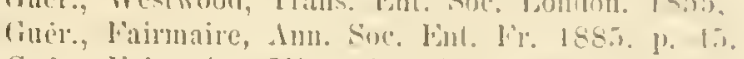

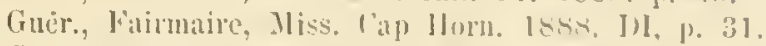

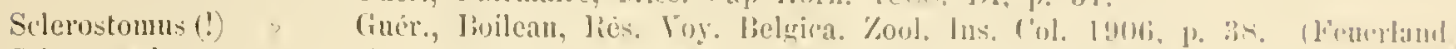

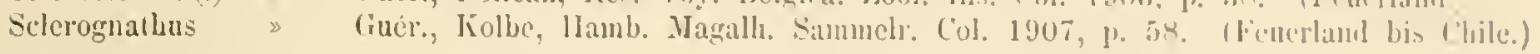

Subfam. Melolonthinae.

MU(C)OSOOIIIC HOPE 1837.

Mareposoma glariale (F, 1775).

Jedolontha glacialis, l'abricius, Syst. Lint. 1. 1775, 1\% 35. Xir. 15.

\begin{tabular}{|c|c|c|}
\hline 》 & $t$ & F., Fabricius, Species Ins. I. 1781, 1) 34. N. 18. \\
\hline$\$$ & » & I., Fabricius, Mautissa lns. I. 1787, 1. 20. Xi. 23. \\
\hline » & $\$$ & 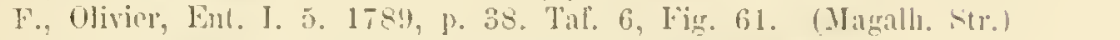 \\
\hline$»$ & » & F., Hlliger, Olivier, Lnl. II. 1789-1808, 1\%. 61 . N1. 16. \\
\hline$»$ & 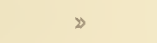 & F., IIerbst, Natursyst. Kïfer. III. 1789-1806, 1. 76. Nr. 25. \\
\hline$m$ & $\gg$ & F.. Fabricius. Fintom. Syst. I. 2. 1792, 1. 162. Nr. 30. \\
\hline " & 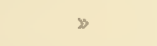 & F., Falnicius, Syst. Elcuth. II. 1801. 1\%. 168. Nr. 40. \\
\hline 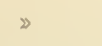 & " & F., Schönherr, Syn. Ins. 1. 3. 1806, 1) 19s. Xr. 169. \\
\hline rosoma & a $\quad 》$ & F.. IIope, Coleojiterisl's Manual. 1. $1>37$, p. 109. \\
\hline coides & licichei, & Gucrin, lier. Zool. I1. 1839, 1\%. 301. \\
\hline 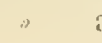 & atricapilla & Curtis, Trans. Linn. Soce lonl. X1X. 1S45, p. tin. Tab. 41 , Fig. 1. \\
\hline & glacialis & (F.), Blancharcl. Catalogue, 1850, p. 114. Nr. 913. \\
\hline lontha & a & F., Gay, Jist. Chile. V. 1851, p. 112. Taf. 17. Fig. 6. (Eür-chile.) \\
\hline rosoma & . & (F.), Burmeister, IIandl,. Ent. IV. 1855, 1. 215. \\
\hline coides & $\gg$ & (F.), Lacordaire, Gencra dles Coleopt. III. 1856, p. 239. \\
\hline 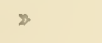 & 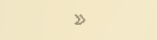 & (F.) Philippi. Ent. Keit. Stettin 1864, 1). 326. Note. \\
\hline rosoma & $\triangleright$ & (F.), Fairmaire, Inn. Suc. Lint. Fr. 1885. p. 45. \\
\hline coides & 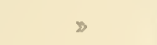 & 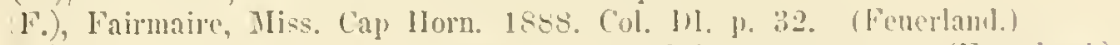 \\
\hline 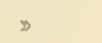 & $\triangleright$ & (f), Jrenske. lies. Voy liclgica. \%ool. Ins. Col. 1906, 1. 31. (Fenerland.) \\
\hline$\triangleright$ & $\gg$ & (F.), Kolbe, llamb. Magalh. Sanmelr. Col. 1907, p. 63. (leuerlanel.) \\
\hline
\end{tabular}

Macrosoma " F.. IIope, Coleopterist's Manual. 1. 1s37, p. 109.

Sericoides licichei, Guerin, lier. Zool. II. 1839, 1.301.

glacialis (F.), Blanchard. Catalogue, 1850, p. 114. Nr. 913.

(F.) Lacordaire, Gencra des Coleopt. III. 1856, p. 239.

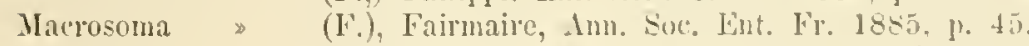

Sericoides \$ F.), Fairmaire, Miss. Cap Horn. 18ss. Col. H. J. 32. (Fenerlant.)

(F.), Kolbe, llamb. Nagall. Sanmedr. Col. 1907, p. 63. (l'eucrland.)

\section{Listurm! Ge GLER. 1839 . \\ Listion! !ex testurerus (F. 1775.)}

Mclolontlua testarea, Fibricius, syst. Fint. 1755. 1. 35.

$\$ \quad$ F., Fabricius, species Ins. I. 1781. 1. 39.

\ F., Fabricius, Mantisa Ins. I. 1787. P. 20,

fusca L.. Limi, Syst. Nat. el. (imel. 1. 1, 178s-17!3, 1. 1569.

lestacea F., Olivier, dutom. T. 1. 1789 gemre. 5, p. 39. I'l. 5, lig. 4!1.

$\gg$ IF., llliger, Olir., lint. II. 1789-180s, 1. 62.

\$ F., llerbst, Natursystem, lialer. Ill. 1789-1806, 1. 78.

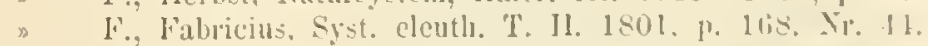

F., Schönlien, sym. Ins. I. 1806. 1. 198.

Listronyx nigrieces Gucrin, Rey. \%ool. Sor. T. H. 183!, 1\%, 302.

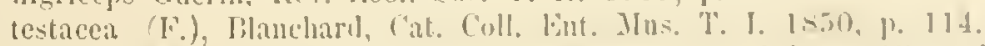

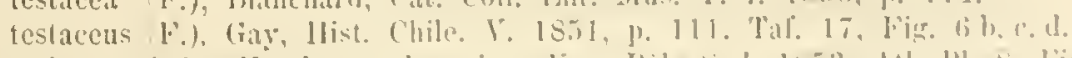

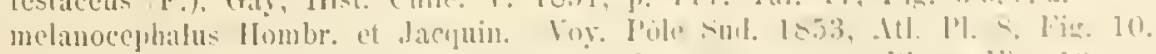

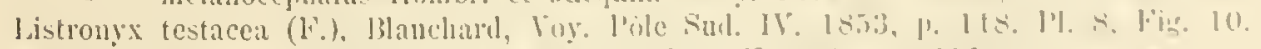

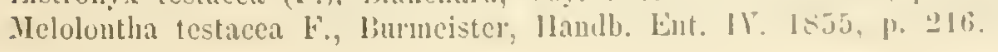


Melolonta testacea I4., Isacordaire, Genera. III. 1856, P. 240.

F., Germain, Am. Soc. Ent. Fr. $1862,1 \% 741$.

F., Philipi, Ent. Zeit. Stett. 1864, I. 325, Note.

listronyx testaceus (F.), Fairmaire, Inn. Soc. Lnt. Fr. 1885, p. 45.

(F), Fairmaire, Miss. Cap IIorm. 1888. Dl, r. 32.

(F), Birenske, Riés. Toy. Belgica. Zool. Ins, Col. 1906, p. 33. (Magall. Str.)

(F.), Kiolbe, Ilamb. Magall. Sammeh. Col. 1907, 1. 64. (Magall. Str., Feucrlaud.)

\section{Listrom?x famimari (Blanch. 1850).}

Listronyx faminaei, Llanchard, Cat. Coll. Ent. 1850, p. 114. (Magall. Str.)

Solier, Gay, llist. Chil. V, p. 111. T. 17, Fig. 6. (Fencrlaud, Cap Horn.)

Blanch., Fairmaine, Miss. Cap llorn. 1888. DI, 1) 32.

Blanch., Kolbe, Ilanb. Magall. Sammelr. Col. 1907, P. 65.

\section{Listrom?x antarcticus BRENSKE 1900.}

Iistronyx antarctiens, Brenske, Anlı. Soc. Eut. Belg Vol. 4t. 1900, p. 109. (Fenerland.)

Lirenske, Brenske, Rés. Voy. Belg. Zoul. Ins. Col. 1906, 1. 32. Pl. II, Fig. 1, 3. (Fenerlaud.)

Accia Curt. 1845.

Curtis, Trans. Linn. Soc. 1845, P. 453.

Acrice picer Kolbe 1907.

Accia picea Kolbe, Hamb. Magalh. Sammelr. Col. 1907, p. 65 und 111. (Sül-I’atagonien: Magallı. Str., Feucrland.)

Fam. Lampyridae.

Photimus Castelnau 1833.

Aim. Fr. 1833, 1). 141.

Pllotimus obscullus (F. 1775).

Lampyris obsenrus, Fabricius, Syst. Ent. 1775, p. 200. Nr. 3.

Fabricius, Spee. Ins. T. I, 1781, p. 251, Nr. 4.

F., Olivier, Ent. I1. 1789-1808, 28, 1. 18. Taf. 2. Fig. 13. (Feuerland.)

(= nigricans Stum. Cat. 1826, p. 159.) (Brasilicn.)

Pyractomena rhododerum Solier, in Gay, Hist. Chile. IV. 1849, p. 449 .

Ingubre, Solier, in Gay, Hist. Chile. IV. 1849, p. $449 . \delta$.

binotatum, Solier, in Gay, Hist. Chile. IV. 1849, p. 449. ․․

fissicolle, Solier, in Gay, IList. Chile. IV. 1849, p. 449. (Anomalie.)

Chandiognatus bioculatus lilanch., Toy. Pole Sud. IV. 1853, 1\%.70. Taf. 5, Fig. 7.

Jyractomena $》$ (F.), Fairmaire, Ann. Soc. Ent. Fr. 1885, [1. 47.

(Solier) obscura (F.), Fain'maire, Miss. Cap IIorn. 1888. II, 1. 36. (Fenerland.)

(!) obseurum (F.). Olivier, liés. Yoy. Bolg. Zool. Ins. Col. 1906, 1. 40. (Fenerland.)

I'lotinus obscurts (F.), líulbe, Ilamb. Magalh. Sammelr. Col. 1907, P. 67. (Fenerland.)

\section{Fam. Cantharidae.}

IIt) louls FaIRMAIRE 1885.

IIt)lous segmenturiurs FAIRM. 1885.

Haplous segmentarius Fairm., Fairmaire, Ann. Soc. Ent. Fr. 1885, 1. 47 . (Feuerlanl.)

Fairm., Fairmaire, Miss. Cal Horn. 18s8. Dl, p. 37. I'l. I, Fig. 11.

Fairm., Kolbe, Hamb. Magalh. Sammelr. Col. 1907, p. 68. 
Fam. Dascillidae.

Helocles Latr. 1796.

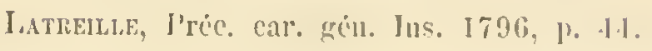

IIelodes antareticus Faris. ISS4.

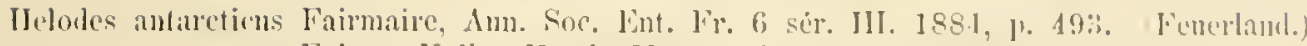

Fuirm., Kolbe, IJamb. Nagall. Sammelt. Col. 1907, 1) 71.

\section{ITelodes mallimolor (Famm. 1885).}

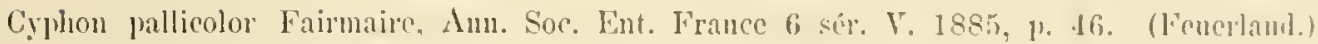
Fairm., Fairmaire, Miss. Cap 1lorn. ('ol.. 1). 35.

lfelutes " (Fairm.), liolbe, Itamb. Magalh. Sammelr. Col, 1907, 1. T1.

\section{Helodes patugomirus Curt. 1839.}

Ilelodes palagonicus Curtis, Tr. limn. Soc. I.ond. X'TIIl. 1839. p. 199.

Curt., Waterlouse, l'roc. \%onl. Soc. Lond. 1881, p. 82.

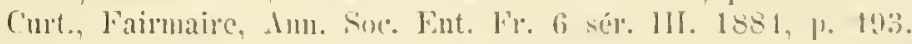

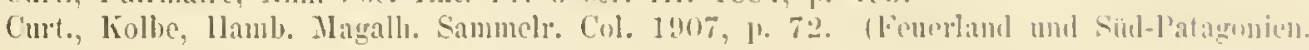

Mirmorara Thoms. 1855.

Mirmorrede fuergensis Boura. 1900.

Microcara luegensis Tommenis, Am. Sor. Lint. Belg. Vol. 44. 1900, 1. 111. (leucrlanl.

lonrgenis, lies. Voy. lieler. Zool. Ins. ('ol. 1906. 11. 37. 'Taf. J, Jïg. 10.

Homogenis, liolbe, liaml). Magall. Sammell. Col. 19107, 1) 72.

Fam. Elateridae.

Deromecuss SOLIER 1S5I.

Sozıkl: in Gir, Ilist. Chile. Y. 1851, I. 11.

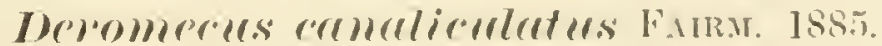

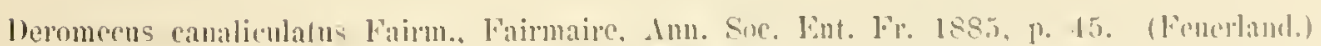

Famm. Fammaire, Mis. Cap llum less. 11, 1. 33.

Fairn., liolbe, Ilaml. Magallı. Sammetr. Col. 1907, p. 73.

Cor!mmbites Tatr. 1834.

LATReille, Ann. Fonance. 183., 1). 150.

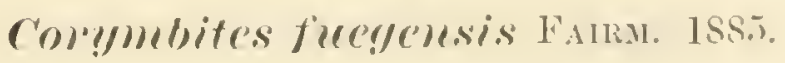

Corymbites fuegencis Fairmaire, Amm. Sue. lint. Fr. 1885, p. 46. (Fenerlaml.)

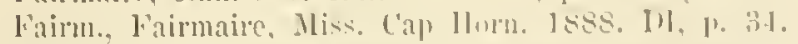

laimm., Kolbe, Itamb. Magalb. Sammell. Col. 190\%, 1) 73. 
Fam. Byrrhidae.

Morychastes FaIRM. 1885.

Typus: M. australis (Branch. 1853).

Morychastes Fairmaire, Ann. Soc. Ent. Fr. 1885, p. 43.

Faimaire, Hiss. Cap Ilorn. Col. 1888, p. 27.

Körper oben fast eiförmig gekrümmt; unten ziemlich flach. Clypeus nicht von der Stirn getrennt. Labrum fast quadratiseh. Linke und rechte Nandibel am Ende 3-zälnnig. Fühler 1l-gliedrig, klein, von der Mitte ab allmählich verdiekt; 1. Glied wenig verdickt und ungefähr so lang wie das dritte; die beiden vorletzten Glieder ein wenig kïrzer als breit; letztes Glied kurz konisch zugespitzt. Die seharfen vorderen Seitenecken des Halsschildes wenig zipfelartig vorgezogen, zugespitzt; diese verdecken deckelartig den Hinterrandsaum der Augen. Das Scutellum ist dreieckig, sehr klein. Elytren ganz hinten ein wenig klaffend, und eine Spur zipfelig aber abgerundet ausgezogen. Hinterbrust mit flacher Grube für die Aufnahme der Hinterschenkel. Hinterbrust sehr lang, hintere Seitenecken rechtwinklig. 6 Abdominalsternite sichtbar, vom 1 . jedoch nur der Hinterrand (wie bei allen Byrrhiden). Alle Schenkel innen mit Rinne zur Aufnahme dor Schienen. Alle Schienen fast zylindrich, nicht verbreitert, aber mit charfer Aussenkante; nur die Vorderschiene hat aussen am Ende eine nicht sehr deutliche Furche, die ziemlich kurz ist. Tarsen alle 5-gliedrig, 3. Tarsenglied bei allen Füssen nach innen und hinten in eine lange Spitze ausgezogen; 4. Glied sehr klein, beim Hinterfuss noch kleiner (Fig. 18).

Momyrhastes rustralis (Blandr. 1853). - Taf. 2, Fig. 15; Textfig. 18. Byrrhus australis Dilanch., Blanclard, Yoy. Pöle Sud. Entom. 1853, p. 52. J'l. IV, Fig. 7. (MIagallı. Str.) Moryclastes australis (Blanch.), Fairmaire, Amll Soc. Ent. Fr. 1885, 1. 43.

(Blanch.), Fairmaire, Miss. Cap Ilorn. 1888. D1, p. 28. (Feverland.)

(Blanch.), Kolbe, Hamb. Magalh. Sammelr. Col. 1907, p. 77.

Feuerland. Ushuctia. In Fagus-Wald unten Rinde, 1 Exemplar am 6. Märs 1902.

Das vorliegende Stiicke hat eine Körperlänge von $5^{1 / 2} \mathrm{~mm}$ und die Färbung ist selıwarzbraun mit rötlichbraunem ehernen Glanz; die kurze Pubeszenz ist gelblich.

\section{Purhymm?s Fatru. ISS8.}

Braclymus Fairm. 1885. Ann. Soc. Ent. Fr. 1885, p. 44. (praeocc.)

J'achymys Fairm. 1888. Miss. Cap Horn. 1888. DI, p. 29.

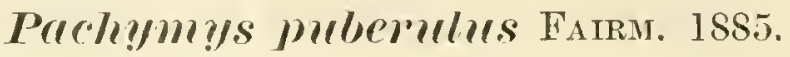

Brachymys puberulns Faimaire, Amn. Soc. Ent. Fr. 1885, p. 45. (Fenerland.)

Pachymys " Fairn., Fairmaire, Miss. Cap Horn. 1888. D1, 1. 30. J'l. I, F'jg. 7.

Fairm., Kolbe, Iamb. Nagalh. Sammelr. Col. 1907, 1. 77. 


\section{Fam. Coccinellidae. \\ ENiol)is MuLSANT 1851 .

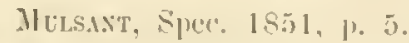

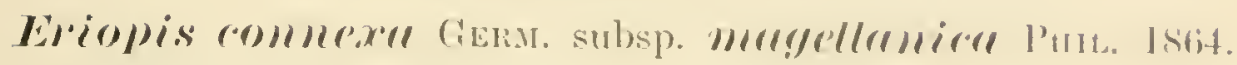

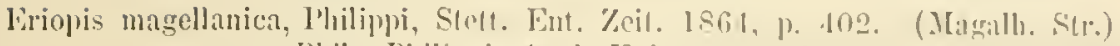

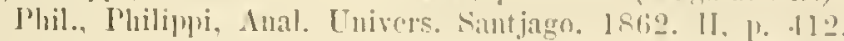

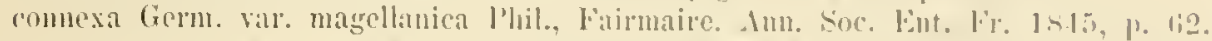

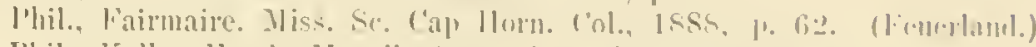

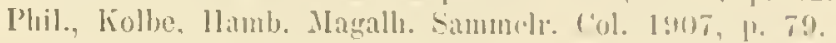

Corcincller 1. 1758.

Syst. Nal. cd. X. 1758. 1) 34i-1.

\section{Corriuella Allplaris C. Berg 1899.}

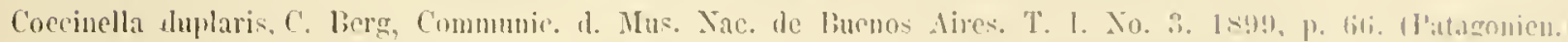

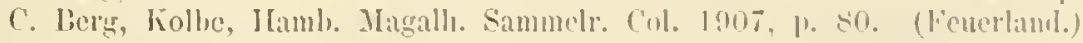

Fam. Tenebrionidae.

Subfam. Pimpeliinae.

\section{Eummalorleva Solier 1851.}

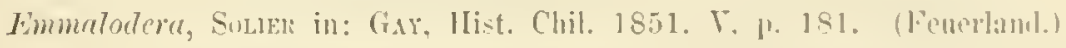

\section{Emmalodera obesa (Góner. 1841).}

Scotobius obesa, Guérin, Kiév. Zool. 1841, 1. 215. (Magalh. Str.)

Emmalodera obesa Solier, Gay. Ilisl. ("lit. 1851. V, 1). 18\%. T'al, 19. Fir. 7.

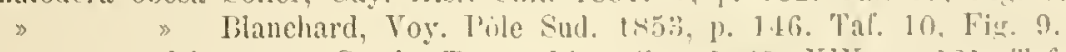

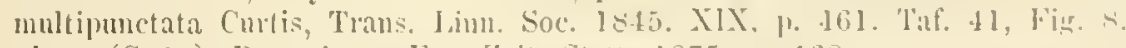

Eimmalodera obesa (Guer.), Bumeister. Ent. Zeil. Stett, 1875, 1\%. 168.

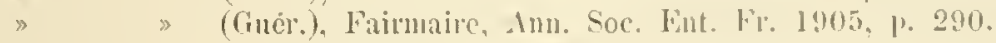

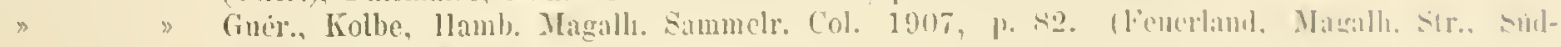
Patagonien.

\section{Nyrtelie Latr. 1825.}

Fam. แat. 1825. 1). :175.

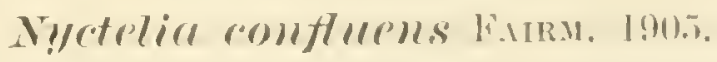

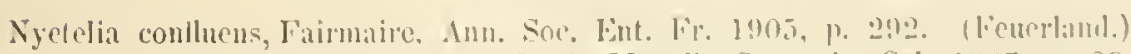

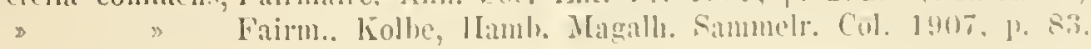

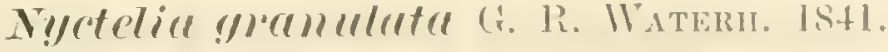

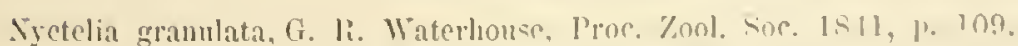

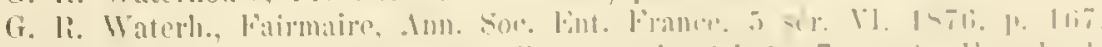

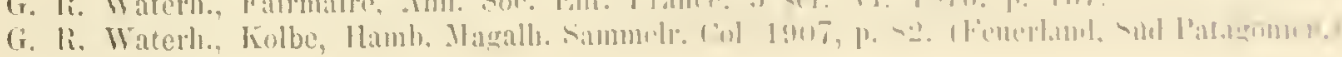

ふ. Sv. Het. Akad. Uandl. Band 48 . x:0 3. 


\section{Subfam. Helopinae. \\ Chitomiscus: WATERII. 1875.}

Waternouse, Trams. Ent. Soc. London. 1875, 1) 331-332.

Fammare, Miss. Caj Horn. 1888. Dl, p. 38-39.

» Anm. Soc. Ent. Fr. 1885, 1. 48-49.

Chitomiscus brevipenmis WATERH. 1875.

Chitoniseus brevipennis Waterlı., Waterlonse, Trans. Ent. Soe. Lonton. 1875, 1. 332. (Fencrlanl.)

Watcrl., Faimaire, Ann. Soc. Ent. Fr. 1885, 1) 49.

brevissimus Watcrh., Fairmaire, Miss. Caj Horn. 1888. TH, p. 39.

brevipennis Waterll., Kolbe, Hamb. Magalh. Sammelr. Col. 1907, p. 88.

\section{IIydromedion WATERII. 1875.}

Mygdromedion Waterhouse, Trans. Ent. Soc. London. 1875, p. 333. Mylops Faramare, Ann. Soc. Ent. Fr. 1883, p. 499.

IIyclrometion Fallimaine, Ann. Soc. Ent. Fr. 1885, p. 50-51.

\section{Hydromedion elongatum WaterH. 1875.}

llydromedion elongatum Waterl., Waterhouse, Trans. Ent. Soc. Lond. 1875, 1. 333. (Fenerland.)

Waterlı., Fairmaire, Miss. Ca]) Ilorn. VI. 1888. IH, p. 43.

Waterh., Fairmaire, Ann. Soc. Ent. Fr. 1885, 1. 51.

Waterh., Kolbe, Hamb. Magalh. Sammelr, Col. 1907, 1. 88.

\section{Hyjllomerlion magellamicum FaIRu. 1883.}

Mrlops magellanicus, Fairmaire, Ann. Soc. Ent. Fr. 1883, p. 500. (Fenerland: Orange Pai; Süd-Patagonien.) llydronedion magellanicum Faim., Fairmaire, Miss. Cap Horn. VI. 1888. DI, p. 43.

Fairm., Fairmaire, Am. Soc. Eut. Fr. 1885, 1). 52.

Fairm., Kolbe, Hamb. Nagal. Sammelr. Col. 1907, p. 88.

Feuerland. Uschuaia. März 1902. 2 Exemplare.

\section{M!jolromealiom variegatmm WATERH. 1875.}

Hydromedion variegatum, Waterliouse, Trans. Ent. Scc. Lon\}. 1875, 1. 333. (Fenerland.)

Waterlı., Faimaire, Anm. Soc. Ent. Fr. 1885, p. 53. (Feuerland, Sür-Patagonien: Magalh. Str.)

Waterl., Fairmaire, Niss. Cap IIorn. VI. 1888. Dl, p. 45. Pl. Il, Jig. 1.

Waterl., Kolbe, Hamb. Magall. Sammelr. Col. 1907, p. 88.

\section{Ilydromerlion distin!nemalum FA1RM. 1885.}

Ilylromedion distinguendum, Fairm., Ann. Soc. Ent. Fis. 1885, p. 53.

Fairmaire, Miss. Cap Jorm. 1888. DI, p. 45. (Fenerland: Orange Hay.)

Fairm., Kolbe, Hamb. Magalh. Sammelr. Col. 1907, p. 88.

\section{IIyderomertion amomoremm Fann. 1885.}

Hycisomedion anomocerum, Fairm., Fainmaire, Ann. Soc. Fnt. Fr. 1885, p. 54.

l'airmaire, Mliss. Cap IJorn. 1888. 1)1, 1. 47. (Fenerland: Perricr-lnsel.)

Fairm., Kolbe, IIamb. Magalh. Sammelr. Col. 1907, p. 89. 


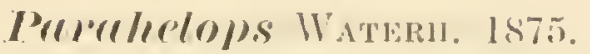

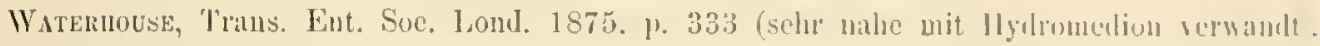

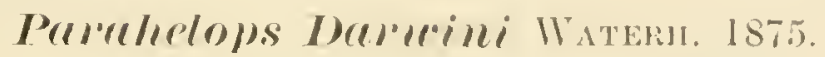

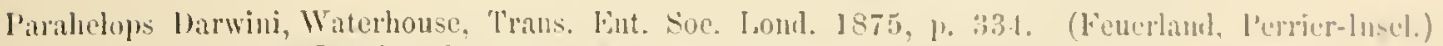

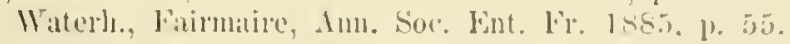

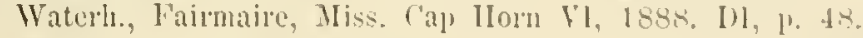

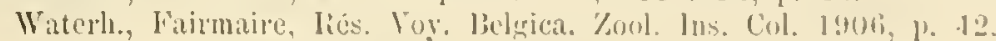

Walerh, Kolbe, IIamb. Magalh. Sammely. Col. 1907, 1\% 89.

Pareledons mobescens Watera. 1875. - Figg. It.

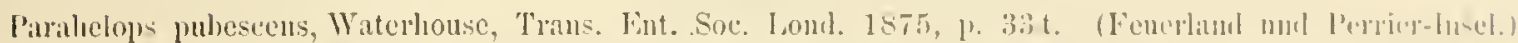

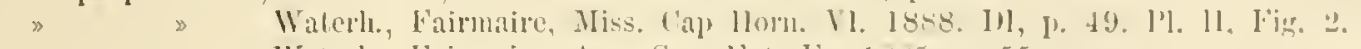

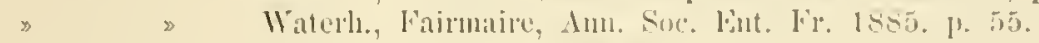

Waterl., Kolbe, IIamb. Magall. Sammelr. Col. 1907, 1'. S4.

Feuerland. Uschuaia. Fagns-Wald, an Rinde. 6. März 1902. I Exemplia.

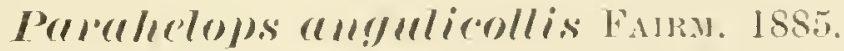

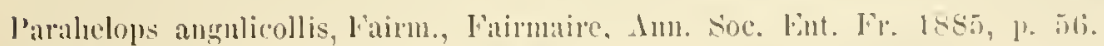

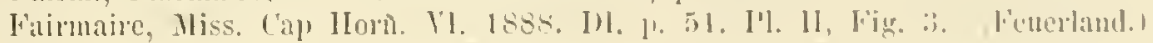

f'arm., Lolle, Ilamb. Magall. Sammelr, Col. 1907. 1. s!?.

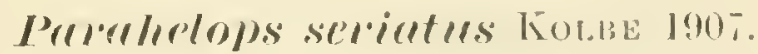

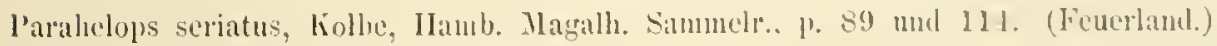

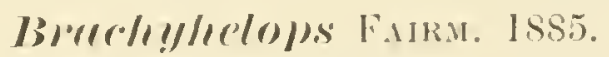

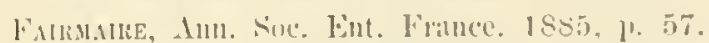

Fammolie, Miss. Cilp Horn. V1. 1888. 11. 1) 52.

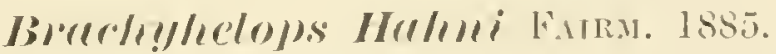

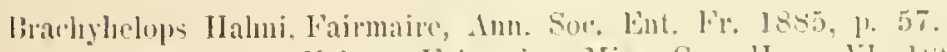

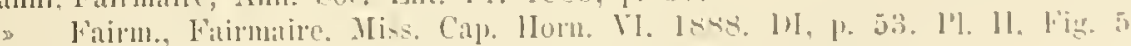

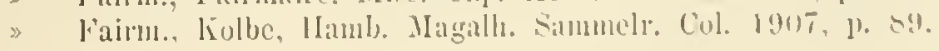

\author{
Fam. Pythidae. \\ P!ftlopplesills ko1,13: 1!007.

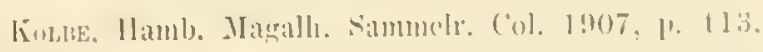

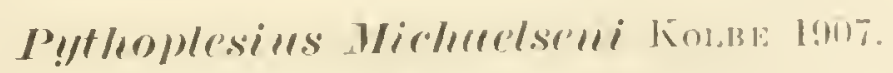

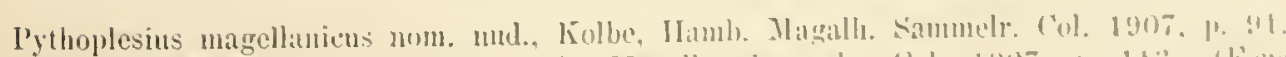

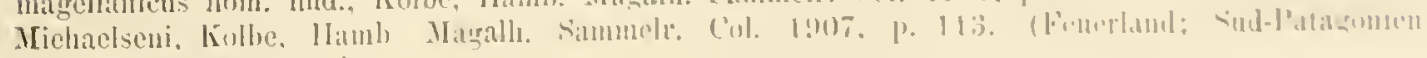

Magallh. Str.) 


\section{Fam. Melandryidae.}

Tolmemle FaIRM. 1900.

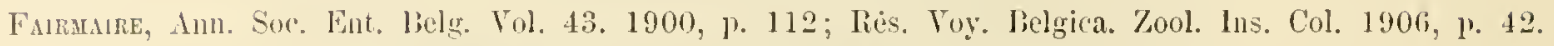

\section{Tolmeme lomgipemis Fams. 1900.}

Tolmerus longipennis, Fairmaire, Ann. Soc. Ent. Belg. Vol. 44. 1900, 1. 112. (Feuerland: Beagle-kanal.) l'airm., Firirmaire, liés. Voy. Bolg. Zool. lns. Col. 1906, p. 42. Pl. I, Fig. 13.

Fairm., Kolle, Hamb. Magallı. Sammelı. Col. 1907, 1. 92.

\section{Fam. Cerambycidae.}

Subfam. Prioninae.

Microplophollls Blanch. 1851.

Jihavchard, Gay, Hist. Chil. V. 1851, p. 454.

Mirmolophomes celstumeus Buanch. 1851.

Microplophorus castanens, Bhanclard, in: (Gay, Ilist. Clible, 1851, 1. 456. 'Taf. 27, Fig. 6. (Sül-Chile.)

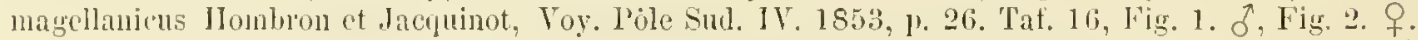

1Hauch., Fairmaire, Am. Soc. Ent. Fr. 1855, p. 61. (Fenerland, Sül-1’atagonien.)

lilancl., Fairmaire, Miss. Cap 1lorn. VI. Col. 1888. LI, 1) 60.

("astaneus 13lanch., Kulbe, Hamh. Magalh. Sammelr. Col. 1907, 1. 93.

Subfam. Cerambycinae.

IIoloptemels Buanch. 1851.

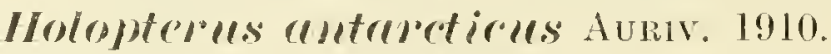

Ilolopterns antarcticus, Aurivillins, Arliviv l. Zool. V1L: 3. 1910, 1., 6.

\section{Sybilla.}

S!Jbilla Dancoi Lam. 1900.

Sybilla Dancoi, Lameere, Ann. Soc. kint. liclg. Vol. 44. 1900, p. 112. (Fenerlanul.)

Laun, lameere, lies. Yoy. Jielg. 1906. Zool. Ins. Col, 1. 49. I'l. I, lig. 9.

Lam., liolbe, IJamb. Magalh. Sammelr. Col. 1907, 1. 95.

\section{Callispllymis Newn. 1840.}

The Entomol. 1840, 1\%. 1.

Callisple!ris semicaligatus Fanm. 1859.

Callisphyris semicaligatus Faim., Farmaire. Ann. Soc. Ent. Fr. 1859, 1) 196.

seluythei l'hilipli, Ann. Iniv, Chil. 1862, 1) 212.

I'lil., l'hilini, Ntett. \%eit. $186 \%$, 1) 380.

semicaligatus fairm., l'lilipli, Anales de la [universilad de Chile. 1878, ]. 38.

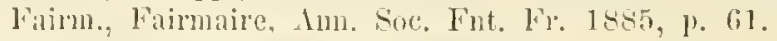

Jairm., Fairmaire, Miss. Cap Hor.1. 111. 1888. DI, p. 60. 1'l. 11, Fig. 10. (Fenerland: Orange liai.)

Fairm., Kolbe, Lamb. Magalh. Sammelr. Col. 1907, p. 95. 


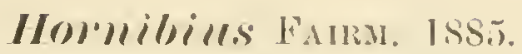

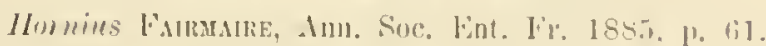

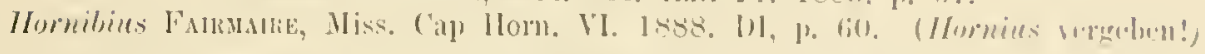

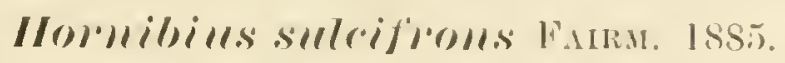

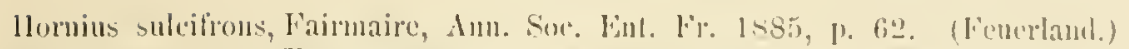

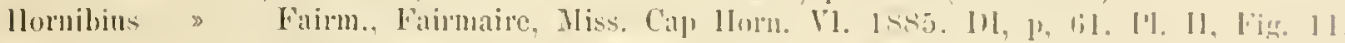

Fainu., Kolbe, lJamb. Magalls. Summel. col. 1907, 11. 9i.

Fam. Chrysomelidae.

Subfam. Galerucinae.

Preltobothrills nov. gen.

'Typus: P. Ohtinianus nor. spee. (Feucrland.)

Vordereoxenhöhlen hinten offen. Fïhlerinsertion zwischen den Augen ungefähı in der Mitte des Augeninnenrandes, etwa die halbe Länge des ersten Giliecles von ihın entfernt. Die Schläfen etwa so lang wie die grösste Augenlänge. Augen küz oral. Pronotum hinten nicht verschmälert; hintere Seiteneeken mit einer rechtwinkligen Spitze; etwas einwärts von der hinteren Seitenecke des Halssehildes beginnt nahe am Hinterrande je eine sehräg nach vorn und innen gelagerte ovale grubenartige Vertiefung, die etwas vor der Mitte der Länge des Halssehildes endet und vorn besonders scharf eingedrïekt ist. Elytren mit dichten, undentlichen Längsreihen dichtgestellter feiner Punkte, ungefähr jede zweite längscihe leigt auf einer nur ganz schwach eingedrückten Längsfurche, die zum Teil verschwindend flach sind. Etwas einwärts der Vordereeken der Elytren findet sieh ein etwas bogiger (nach imnen offen) längseindruck ron der Breite der Halssehildgrube und in ihrer l'ortsetzmug, etwas iänger als dieser aber flacher. Epipleure seharf begrenzt. Erstes Hintertarsenglied zicmlich diek, so lang wie die zwei folgenden zusammen. Alle Tibien mit Sporn. Kilanen nicht gespalten, an der Basis nur mit höekerartigem Anhang. Alle Schienen anssen mit sehr scharfen längskiclen.

Bei einem nicht völlig ausgefärbten Exemplar sind die beiden Gruben des Halssehildes weniger seharf und die Längsfurehen der Elytren ziemlich auffällig scharf.

Peltobothrus steht der Gattung Malacosoma Cherk. 1846 (D) Oritgi.. Diet. unir. VII. 1846, p. 605) sehr nahe, und unterscheidet sich im Wesentlichen dureh die " ovalen Gruben des Halssehildes.

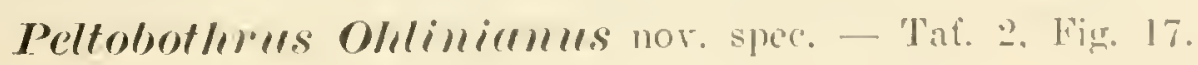

Kopf, Thorax und Elytren glänzend schwarz. Scheitel und Schläfen polient glatt, unpunktiert. Zwischen der Fühlerbasis ein krïftigen schmaler Lä̈ngskiclo der in der Mitte der Augen zwisehen zwei flachen Benlen endet: dicht daren schliesst sieh nach hinten eine feine Lähgsfurche an, die mitten zwischen de'n Auecuhinterrändern 
in einer kräftigen Punktgrube endet. Pubeszenz am Kopfe nur ganz voru. Fübler bramnsehwarz, spärlich und sehr fein behaart. 1. Fühlerglied ziemlich dick, kenlig, doppelt so lang wie am Ende breit; zweites Fühlerglied kaum dünner als die iibrigen, so lang wie am Ende breit; die ïbrigen Fühlerglieder nach der Basis zu etwas verjüngt und etwa $1 \% \mathrm{mal}$ so lang wie breit; Endglied (11. Glied) lang oval und fast 2 mal so lang wie breit. Vorletztes Glied des schwarzen Maxillarpalpus nach dem Ende zu stark verbreitert, von der Seite gesehen 3-eckig, ea. $1^{1 / 2}$ mal so lang wie am Ende breit; Endglied an der Basis halb so breit, wie das vorletzte Glied am Ende, kurz koniseh, und $1 \frac{1}{2}$ mal so lang wie an der Basis breit.

Halssehild poliert glatt, sehr fein punktiert; an der Seite fein aber scharf gerandet, hinten sehr fein gerandet; an der Seite unterhalb des Seitenrandes fein und dicht quergerieft. Die Gruben im vorderen Ende mit einigen groben Punkten. Elytren glänzend glatt, völlig unpubesziert; die dichte Punktierung mässig fein, ziemlich dicht und zu ganz unregelmässigen und oft undentlichen Längsreihen angeordnet, ron denen ungefähr die zweite in einer sehr flachen Längsfurche steht. Aussenrand der Elytren sehr fein gerandet; ein mässig schmaler nach hinten allmählieh zugespitzter Aussenrandsaum ist seharfkantig nach unten umgebogen. Nahtrand der Elytren äusserst fein gerandet; hinten abgerundet, daher die Elytren hinten etwas klaffend. Scutellum klein, rechtwinklig dreieckig, poliert glatt, völlig mpunktiert. Hinterbrust hinten und an der Seite fein gerandet, fein und ziemlich dicht punktiert.

Beine schwarz, Schienen in der Basalhälfte hell rostgelb. Bei einem nicht ganz ausgefärbten Exemplar sind die Schienen und das erste Tarsenglied aller Beine hell bräunlich gelb. Alle Schienen aussen mit einem sehr scharfen Längskiel. Hinterschenkel etwas dicker als die Mittelschenkel. 2. Tarsenglied so lang wie am Ende breit, 3. kürzer; 4. selı dünn und schlank. Abdominalsternite dicht und fein punktiert, mit feiner granen anliegenden Pubeszenz; 1. dentlich sichtbares Sternit in der Witte ca. 21/2 mal so lang wie das 2., das 2., 3, und 4. Sternit gleichlang, das 5. Sternit doppelt so lang wie das vierte.

Körperlänge ea. $4^{1} / 2 \mathrm{~mm}$.

Breite der beiden Elytren in der Nitte ca. 1,8-2 $1 \mathrm{~mm}$.

Feuerland. Uschuaia. März 1902. 5 Exemplare, daron eine nicht ganz ausgefärbt.

Gewidmet wurde diese Species dem Andenken des 1903 rerstorbenen Zoologen der sehwedisehen Südpolar Expedition Herrn Dr. Axes Ohlıs.

Das nicht ganz ausgefärbte Exemplar hat alle Schienen und ersten 'Tarsenglieder hell bräunlich gelb und die Elytren mit relativ sehr seharfen Längsfurchen. 


\author{
Fan. Curculionidae. \\ Subfam. Otiorrhynchinae. \\ Otiom rhyurellus Germ. 1824. \\ (iemulR, Ins. Spece nov. 182.1, 1). 313.
}

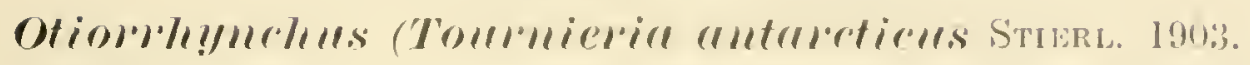

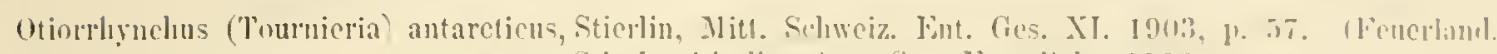

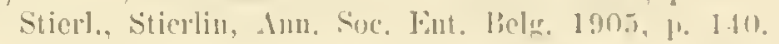

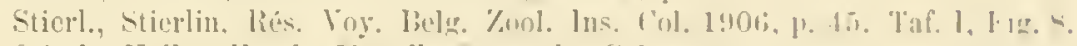

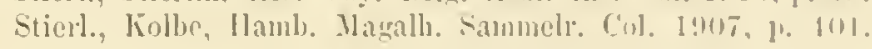

Subfam. Cylindrorrhininae.

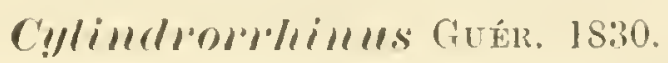

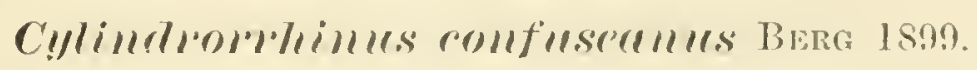

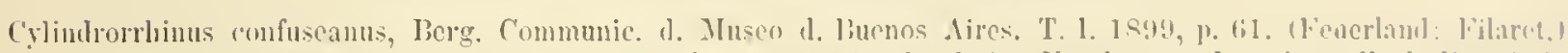

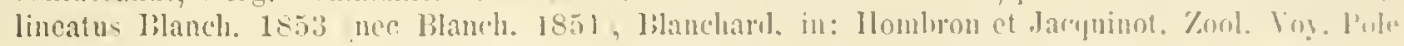
sul. Ins. 1853. 'Taf. 13, Jig. 19.

confuseanus lierg, liolbe. Ilaml. Magall. Sammelr. 1'ol. 1907. 1. 102.

Arliomistus Watrenl. $18+1$.

Maternotse, Proc. \%oo]. Soc. I.nulon. 1811, p. 124.

Adionistus sulcatus linas. 1855.

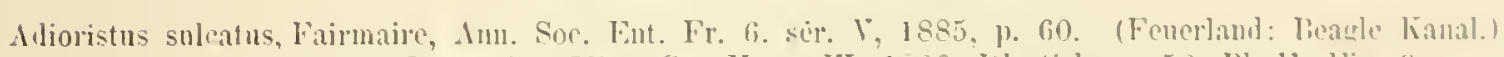

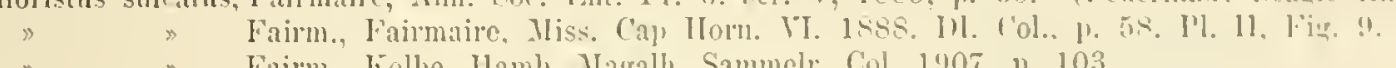

» Farm., lolhe, Haml. Matralh. Sammelr. Col. 1:107, 1) 103.

\title{
Adionistus fuegirmulls Barg 1899.
}

hetioristus fuegianus, Berg, Communic. Mus. Nac. de Buenos Aires. 'T'ome 1.

lierg, Kollo, Ilamb. Magalh. Sammely. Col. 1907. p. 103.

Scotoeborles ScHösu. $18+3$.

Trpus: S. murinus (Boh.). Argentinien.

Schosuerr. licn. Cure. VIr. 1. 1813. p. 97.

scotoeboleles Interenlis Bare 1899.

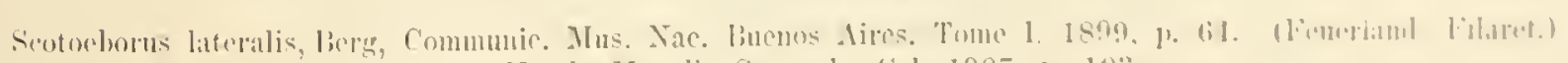

lHerg, Kolbe, ILamb. Magall,. Samulls. ('ol. 1907, p. 10:3.

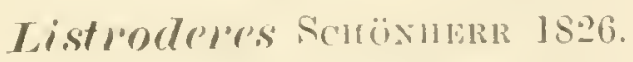

Typus: L. costirostris Ścü̈rn. Brasilien.

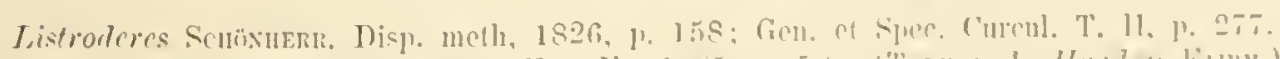

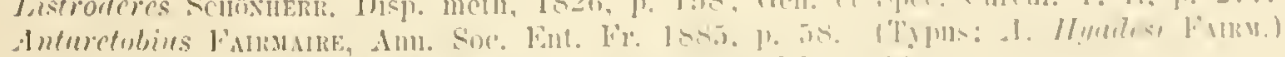

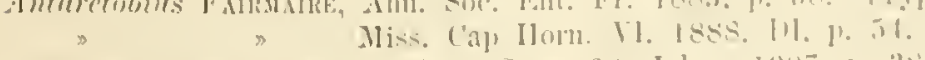

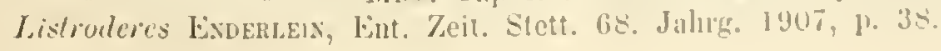




\section{Listroderes Hydulesi (FA1RM. 1885).}

Intaretolyus Iyadesi Faim., Fairmaire, Ann. Soe. Ent. Fr. 1885, p. 58. (Fcuerland.)

Faim. Faimuane, Miss, Cap Horn. VI. 1888. DJ, p. 54. Pl. II, I'ig. 6.

Listroderes IJyalesi (Fairm.), Eulerlein, Ent. Zeit. Stett. 68. Janıg. 1907, 1. 39.

(Fairm.), Kolbe, Hamb. Magallı. Sammelr. Col. 1907, p. 104.

(Famm.), Enderlein, in diesem IIeft, p. 17.

\section{Listroderes lacmuosus (FAlRM. 1885).}

Antaretobius lacmosns Fairm., Fairmaire, Ann. Soe. Ent. Fr. 1885, 1. 59. (Feuerland.)

l'airm., Fanmaire, Miss. Cap. IIorn. VI. 1888. DI, p. 56. P'l. II, Fig. 8.

listroderes $》 \quad$ (Fairm.), Enderlein, Ent. Zeit. Stett. 68. Jahrg. 1907, p. 39.

(Fairm.), Kolbe, IIamb. Magall. Sammelr. Col. 1907, p. 105.

(Faim.), Enderlein, in diesem Heft, p. 17.

\section{Iistrorleres dissimilis (FAIRH. 1885).}

Antarctolius dissimilis Fairm., Fairmaire, Ann. Soc. Ent. Fr. 1885, p. 60. (Fenerland und Perrier Ins.) laim., Faimaire, Miss. Cap Horn. VI. 1888. I)1, 1. 57. Pl. 11, Fig, 7.

Iistroderes $\gg$ (Faim.), Enterlein, Ent. Zeit. Stett. 68. Jahrg. 1907, p. 39.

Fairm., Kolbe, IIamb. Magalh. Sammelr. Col. 1907, p. 105.

\section{Subfam. Aterpinae.}

\section{Lophotıs ScHönil. 1834.}

Lophotus Schönuerr, Gen. Curc. II. 1834, 1. 314.

Aeyorhinus Enenson,

Cerapsis Sollel.

Fubleplurus SOsiser,

Leucolopus Dejean,

Lophodus DEJEAN.

\section{Lophotus vitulus (F. 1775).}

Curculio ritulus Fabricius, Syst. Ent., 1775, 1. 152. leprosns Olivier, Ent. V. 1789-1808, 83, p. 395. Taf. 25, Fig. 360.

lophotus excavatus Dejean, Cat. 3. ed. 1837, p. 284. vitulus F., Jilanrhard, Gay, Hist. Chile. T. 1851, 11. 329,

Lophotns $\gg$ (F.), Fairmaire, Ann. Soe. Eut. Fr. 1885, p. 61. (Feuerland, Süil-Chile. Magalh. Gehict.)

F., Fairmaire, Miss. Cap Horn. VI. 1888, p. 60. (Fenerland: Orange liai.)

F. Bovie, Kés. Voy. Belg. Zool. Ins. 1906, p. 47. (Staaten Jusehn.)

F., Kolbe, IIamb. Magall. Sammelr. Col. 1907, p. 106.

Feuerland. Uschuaia. 6. März 1902. I Exemplar im Buchenwald.

\section{Lophotus strmmosus (OLIV. 1789-1808).}

Curculio strumosus Olivier, Entomologie. T. 83, 1789-1808 p. 394. Taf. 4, Fig. 36.

Lophotus longipes, Waterhouse, Amn. Mag. Nat. Ilist. T. 1840, p. 330. strumosus (Oliv.), Kolbe, IIamb. Magall. Sammelr. Col. 1907, 1. 106. (Sücl-Chile, Feuerland.) 


\author{
Śubfam. Apioninae. \\ I Jirnll HuRlsst 1797. \\ IIminst, Naturgesell. Kaffer. VII. 1797, j. 100.
}

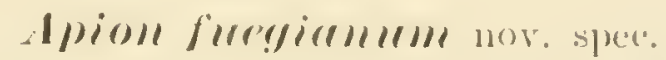

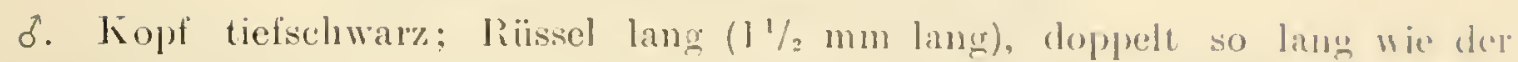
ïbrige Kopf, gleiehmässig dick, ziemlich diinn, nicht zugespitzt, glatt, mit gan\% kurzen eingeritzten Länısstricheln ziemlieh dicht beleckt; nur ganz vereinzelte, abstehende kurze Hare. Fïhler dunkelhrann, in der Riisselnitte insericrend; 1. Gilied nicht ganz so lang wie lie halbe Rüssellïnge, an Ende mit einer kurzen keuligen Verdickung, 2. Glied 2\% 11 al so lang wie breit, 3. ca. doppelt so lang wie breit, an der Basis stark gestielt, 4. und 5. so lang wie breit (die iibrigen abgebrochen). J)ie hintere Hälfte der Scheitelstrecke hinter den Augen poliert glatt mit dichten mikroskopisch feinen Querritzen. Der übrige Kopf rauh dicht und groh pmbtiert und mit mässig dichten und mässig kurzen anliegenden nach vorn zu gekïmmten grauen Haaren besetzt. Augen grau, kreisłund, Durelumesser gleiclı dem des Riissels.

Thorax schwarz, gleichmässig nach vorn zu verjüngt. Iänge eire Spur kïrzer als die hintere Breite und etwas lïuger als die vordere Breite: Punlitierung groh. dicht und rauh, Behaarung mässig dicht, mässig kur\%, anliegend und grau: dicht vor dem Hinterrande eine kurze eingedrïckte glatte Furele von kinum 1/5 fler Halsschildlänge. Schildehen winzig klein, rauh. Elytren schwarz, rauh, mäissig dicht und mässig klein punktiert, Pubeszenz mässig dicht grau, anliegend, Selunltern beulig gewölbt und etwas poliert. Die Punktreihen selır scharf eingedriickt, die Punkte sehr gross, selur kräftig und mässig weit von einander getrennt. (Entfernung von einander ca. doppelt so gross als der Punktdurchmesser.) Elytrenform eiförmig. Unterseite des Abromen selur raul, dicht und grob punlitiert: 1. und 2. Sternit lang, das erste etwas länger, das 3.-5. fast gleichlang und zusammen so lang wie das zweite.

Beine schwarz mit graner behaarung. Schenkel ziemlich gleichartig verdickt.

Tarsus relativ dick. 2. 'larkenglied ca. $1 / 2$ des ersten.

Körperlänge $4.4 \mathrm{~mm}$.

länge der Elytren 2,6 $\mathrm{mm}$.

Feuerland. Lapalaia. 1 o an 9. Oktober 1902.

\title{
Ordo: Lepidoptera.
}

Fam. Pieridae.

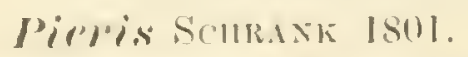

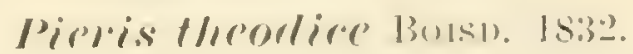

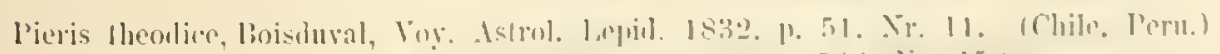

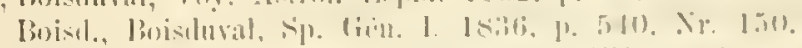

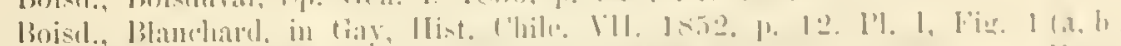

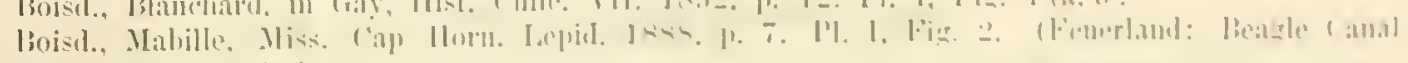
mul (1rame-liati.)

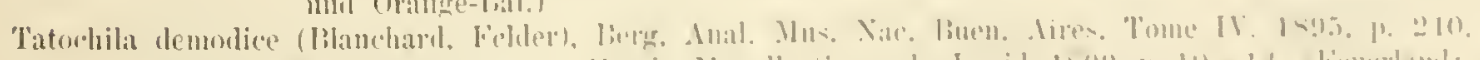

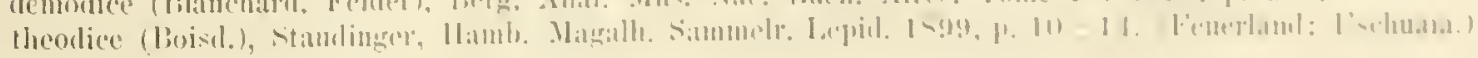

k. Sis. Viet. Akad. IIandl. lsand ts. X:o 3 . 


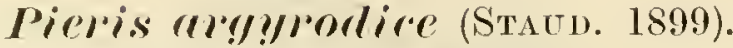

Tatochila argyrodice, Staulinger, IIamb. Magalh. Sammelr. 1,eprid. 1899, 1. 14-17. Fig. 11. (Fenerłamt: Uschuaia.)

\section{Piemis mirmolice (BLanch. 1852).}

l'ieris microdice, E. Hanchard, in: Gay, Hist. Chile. Znol. VII. 1852, p. 11.

I'ieris xanthodice, Mabille, Miss. Scient. Cap. Horn. Lepiul. IY. 1888, J. 6. I'l. I, Fig. 2 (non 1). (Punta-Arenas.) Tatochila microulice (Blanch.), lierg. in: Anal. Mus. Nac. Buenos Aires. 1895, p. 245.

Tatochila microdice (Blanch.), Staulinger, Hanb. Magalh. Sammelr. Lepid. 1899, J. 17-23. (Fenertand: Uschuaia.)

Fam. Nymphalidae.

Subfam. Nymphalinae.

Ar!! !m!lis F. 1807 .

Ary!mmis Cytheris (Drury 1773).

Papilio Cytheris, Drury, llustr. exst. Entom. H. 1773. F'l. TY, Fig. 3, 4. (Chile.)

Argynis siga, llüner, /utr. exot. Schnetterl. 1832. Fig. 677, 67s. (Chile.)

Anna, Fincharl, in Gay, llist. Chile. VIl. 1852, 1. 23. (Chile.)

» Banch. Mahille, Miss. (ap, Horn. Lepid. 1888, p. 4. (Fenerland: Beagle Canal u. Grange Bai.) Cytheris (1)rury), Mabille, Miss. Cap Horn. Lepid. 1888, J. 5.

siga Hübn., Butler, Ann. Mag. Nat. Ffist. Tol. X11. 6 sér. I898, p. 287. Nr. 1. (Falklanis-Inseln.) lathonioides, lianchard, in: Gay, Hist. Chile. TT\}. 1852, J. 22. (Chile.)

Cytheris (Drury), Staulinger, Hamb. Magall. Sammelr. Lephil. 1899, p. 28-31. (Fencrimul: Rio Grande, Insel Navarin.)

\section{Aly!mmis Drmmini Staud 1899.}

Argynis Darwini, Standinger, Famb. Magalh. Sammedr, Lepitl. I899, p. 32-35. (Fenerland: Rio (irande.)

\section{Fan. Satyridae.}

Ereldic DaLM. 1816.

\section{everbir plormbeola (BuTL. 1868).}

Tetraplilebia? IIfunbenla, Eutler, Cat. Dinrn. Leje. Satyr. 1868, 1. 95. Pl. 2, Fig. 11.

" lintl., lieed. Marip. Chilen. 187t, p. 59.

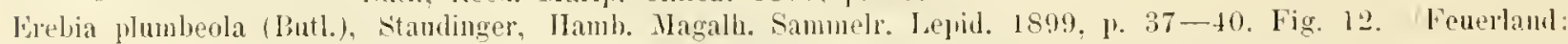
lin (imale; ('liile.)

Fam. Limantriidae (Liparidae).

Das?grhive Stepit. 1829.

Ders!rllivere plat!)

Hasyohira platyptera, Malille, Bull. Soc. philom. 1885, p. 58. (Fenerland.)

Mab., Mal,ille, Miss. (ap Horn. Lepicl. 1888, J. 9. Pl. 1, Fig. 5. (Fenerland: lieagle ('anal.)

Mab., Stantinger, Hamb. Magall. Sammelr. Lejiıl. 1s99. p. 46. 


\section{Fam. Saturnidae. \\ Jilllirl HÜßs. 1826.

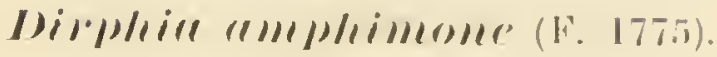

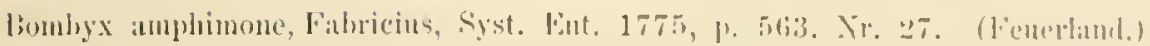

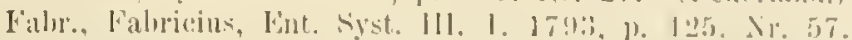

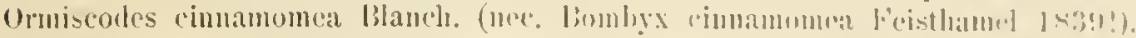

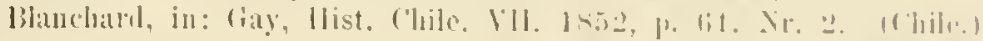

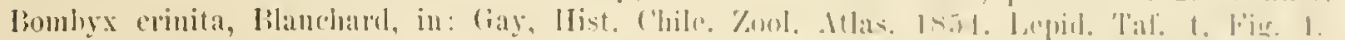

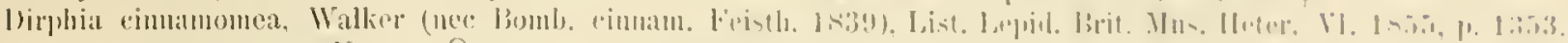
Nir. S. Q.

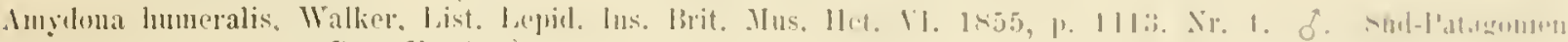
P'ort. I':aninc.)

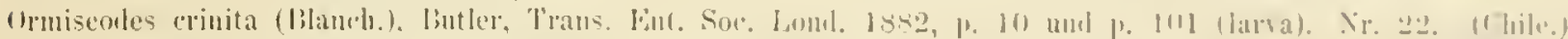

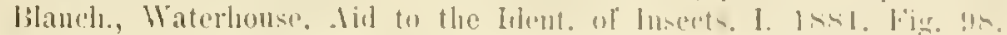

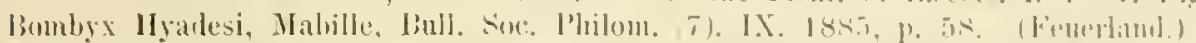

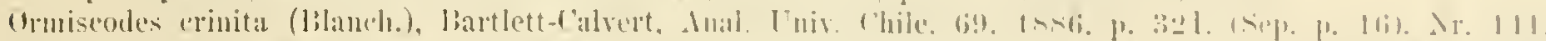

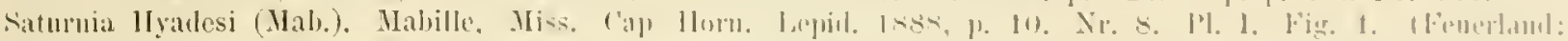

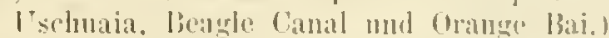

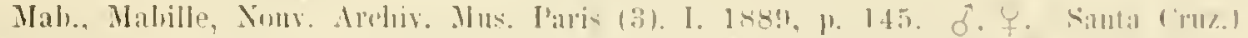

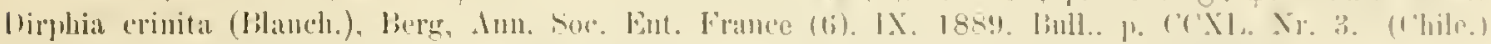

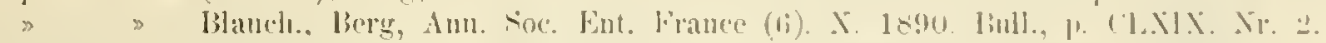

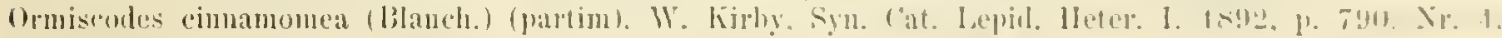

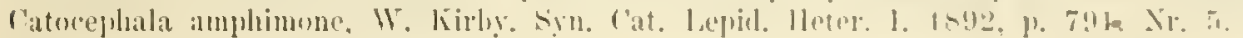

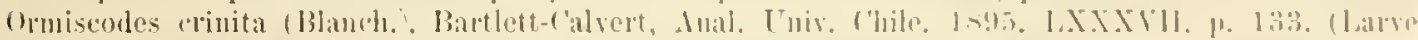

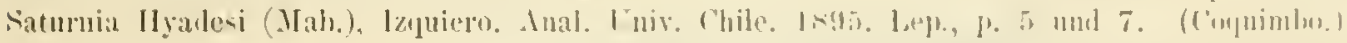

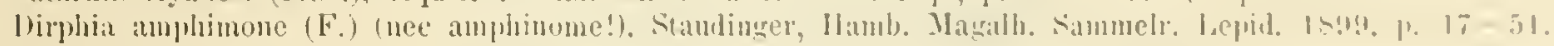

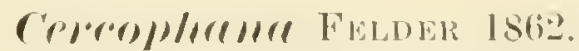

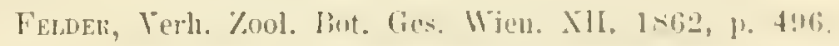

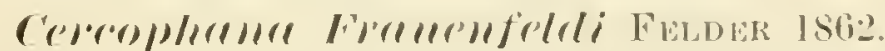

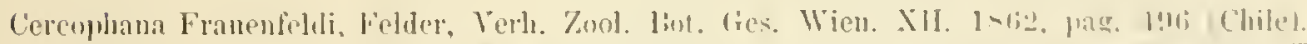

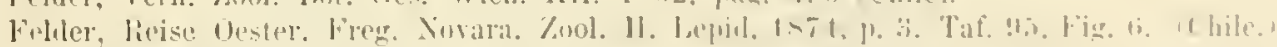

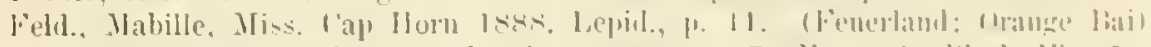

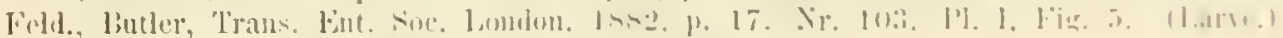

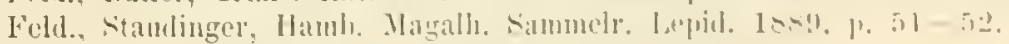

Fam. Noctuidae.

Sulfam. Agrotinae.

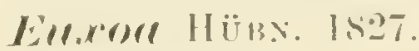

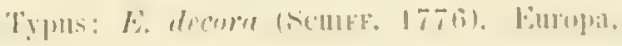

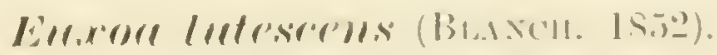

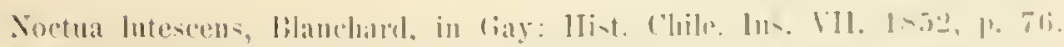

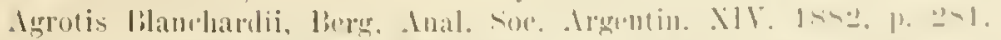

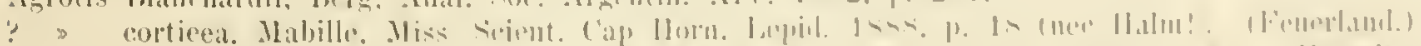

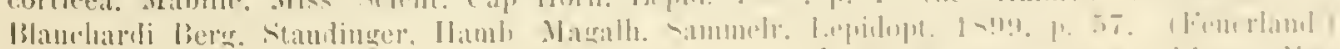

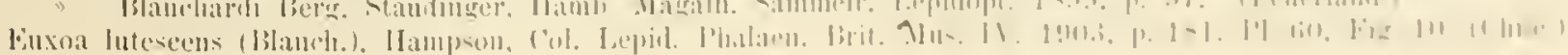


Feltir WAL. 1856.

Typus: $F$. ducens (WaLK. 1856). Nord Amerika.

\section{Freltia releriral (BuTt. 1852).}

Agrotis clerica, Butler, 'Trans. Ent. Sor. 1882, p. 129. (Chile.)

Igrotis carbonifera, Mabille, Inull. Soc. I'lilom. 1885, 1). 60.

Mab., Mabile, Miss. Cap IIorn. 18s8. Lẹid., 1. 16. I’l. I1, Fig. 3. (Fenerland: Ischuaia und lieagle ('anal.)

Peridrona clerica (Butl.), Butler, Anu. Mag. Nat. Iist. (i.) Vol. 12. 1893, p. 205. Nr. 5. (Falklands-Inselı: Iarwin-Harbour.)

Igrotis punta-arenae, Staulinger, Jlanb. Magall. Sammelr. Lepid. 1894. IV, l. 53. (Süd-Patagonien.)

Feltia clerica Int1.), Ilanpson, (at. Lepid. Ihalaenae. Lrit. Mus. Yol. IV. 1903, p. 356. Pl. 68, Fig. 19. Agrotis carbonifera Mab., Standinger, Ilamb. Magah. Sammeh. Lepid. 1899, 1. (i2. (Fenerland.)

Feuerland. Ischuriu. 1 우 in einem Hause am 7. März 1902.

\section{Feltirl perele (BERA 1877).}

Agrotis pexa, Berg, Anal. Soc. Argent. IT. 187\%, P. 199.

» Ingoufii, Mabille, Isull. Soc. I'hilom. 7. (IX.) 1885, p. 59.

» Mab., Mabille, Nour. Areh. Mus. Paris. (3) 1. 1889, 1. 146. PI. 10, Fig. \%. (Fenerland, 1'atagonicu.)

» pexa Rerg, Staudinger, Il:mb. Magalh. Sammels, Idepid. 1890, 1) 56.

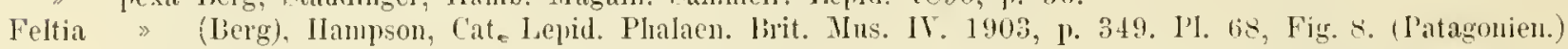

\section{Episilia. HüBN. 1827.}

Typus: E. latens Hïrs. 1827. (Europa.)

Episilia, IIübner, Verz. 1\&27, 1. 210.

Episilir !)・llirll (MAB. 1SS5).

Agrotis gravida, Mabille, Buil. Soc. Philom. IX. 1885, p. 59.

Nab., Mabille. Miss. Scient. Cap Horn. 1884. V1. Lep., p. 15. Pl. II, Figr. 4. Fenerland: Orange Bai.)

Mab., Staudinger, Naml. Magalh. Sammelr. Lepid. 1899, \%. 54.

Episitia ” (Mab.), Llampson, Cat. Lepid. Phalaen. Brit. Mus. Vol. IV. 1903, 1) 469. (Suil-Patagonien.)

\section{Episilia bicolo) (MAR. 1885).}

Agrotis bicolor, Mahille, Iinlt. Soc. I'hilom. 7.) 1855. IX, p. 59. (Fenerland.)

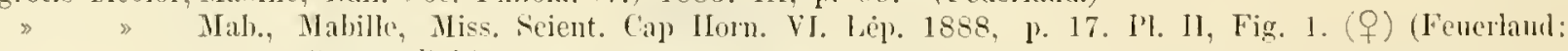
Orange Bai.)

Episilia » (Mab.), llampson, (at. Lepid. Phalaen. Brit. Mus. Vol. IV. 1903, 1. 469. (Patagonien.)

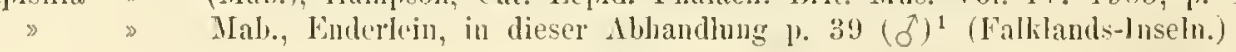

\section{Episilie flerirosta (WALIGR. 1860).}

Noctua flavicosta, Wallgreen, Hintom. Monthl. Mag. IV. 1860, 1. 169.

Ochropleurn magellanica, IButler, J'roc. Zool. Soc. Lond. 1881, p. 83.

Agrotis lisplubula lierg (nee (inene), Anal. Soc. Cient. Argent. 1882, 1\% 282.

?" Havicosta (Wallgr:), Staulinger, Ilamb. Magall. Sammelr. Lepid. 1899. 1. 52.

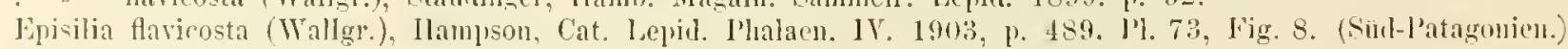

1 Nicht , wic pag. 39 angegeluen. 
Ob diese Species in Fenerland vorkommt, ist nicht sicher, da es mnsicher ist. ob Staudxatr wirklich diese Species vorlag.

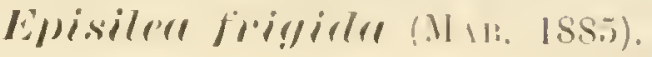

Anrotis lrigida, Malrille, Bull. Soce l'hilom. Kssi, 11. (i).

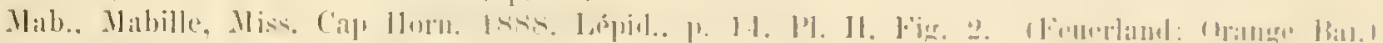

,

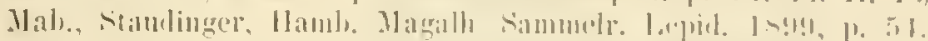

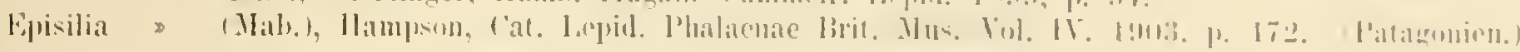

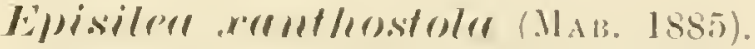

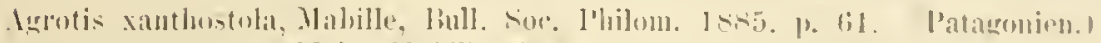

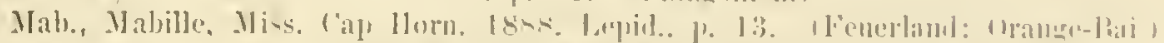

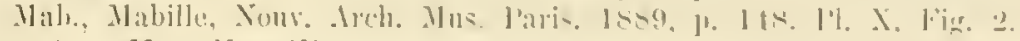

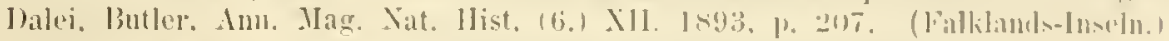

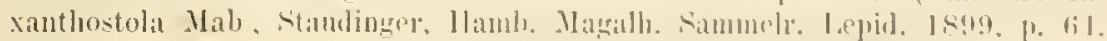

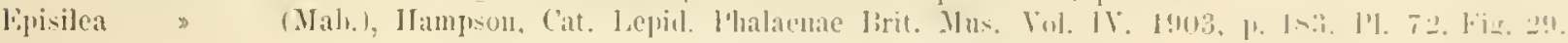

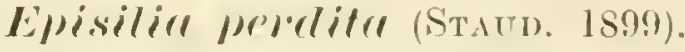

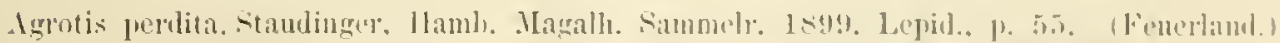

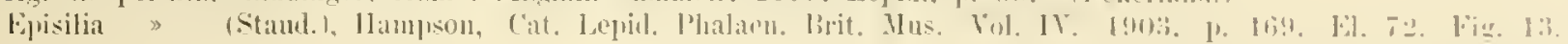
(lenerlind.)

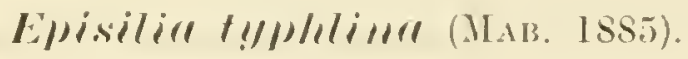

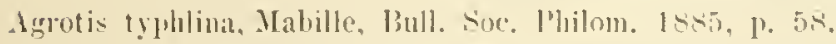

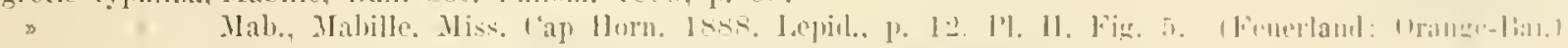

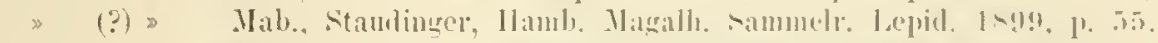

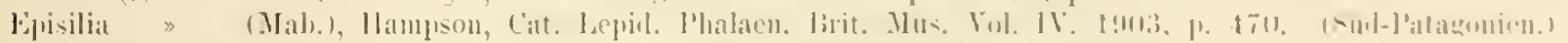

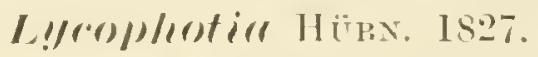

Typus: A. porphyea (Scure, 1776). Luropa.

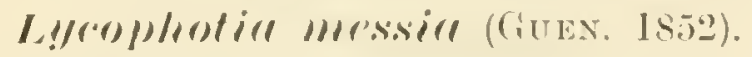

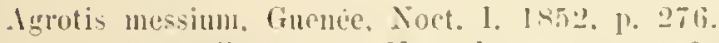

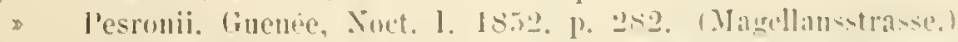

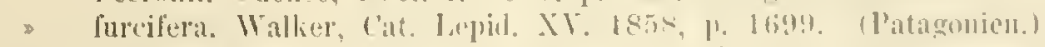

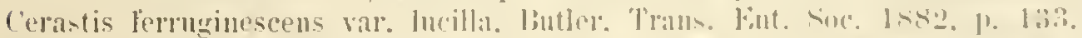

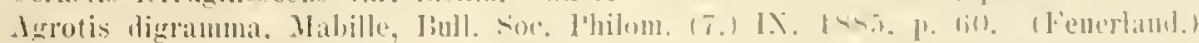

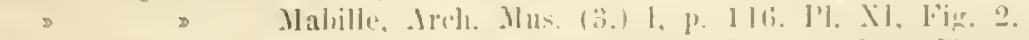

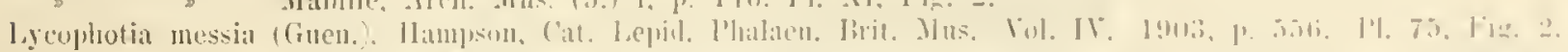
(c'luile, sul-l'atagonien, Fenerlaul.)

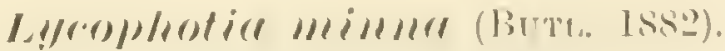

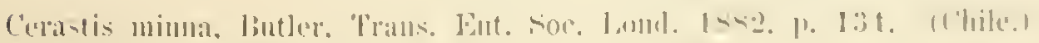

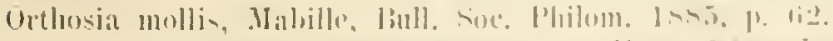

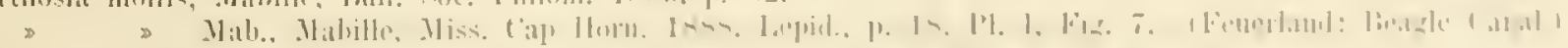

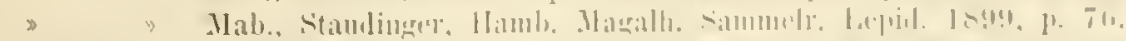

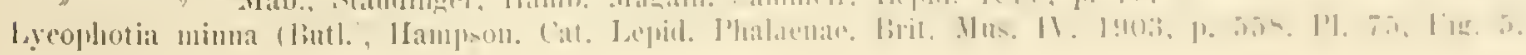




\section{Lycophotia molibcloirla (Staud. 1899).}

Igrotis molibdoida, Standiuger, Mamb. Magalh. Sammelr. Lepicl. 18!19, 1. 61, Fig. 14. (Feuerland.)

Lycophotia molibdoida (Staud.), llanpson, Cat. Lepid. Plalaen. Brit. Mus. IV. 1903, p. 576. P'l. 75, Fig. 30. (Süd-l'atagonien.)

\section{Subfam. Hadeninae.}

Harlem! SCHRANK 1802.

'Typus: H. reticulata VILL. 1789. (Europa.)

IIarlema. tetrongoma. MaB. 1885.

Hadena tetragona, Mabille, Bnll. Soc. Pliilom. 1885, 1. 63.

» Mab., Mabille, Miss. Caj Horn. 1888. Lẻpil., p. 19. Pl. I, Fig. 8. (Fenerland: Beagle Canal.) Manestra tetragona (Mab.), Staudinger, Hanb. Magalh. Sammelr. Lepid. 1894, 1. 67.

\section{Amarta Ociss. 1816.}

Typus: A. myrtilli L. 1746.

Mugellana, Staudnger, Llamb. Magalhaens. Sammell. IV. 1899, p. 77. (Typus: An. Trisemu.)

\section{Amcertu trisemer. Mab. 1885.}

Anarta trisema, Mabille, Bull. Soc. Philom. (7.) IX. 1885, p. (64.

$»$ » Mab., Mabille, Miss. Scient. Cap Horn. V1. 1888, 1. 20. P'I. 1, Fig. 9. (Fenerlaur.)

Magellana trisema (Mab.), Standinger, Hamb. Magall. Sammelr. IV. 1899, 1. 77.

Anarta trisema Mab., Ilampson, Cat. Lepjd. P'halaen. Brit. Nus. Vol. V. 1905, 1. 37. Fig. 11.

\section{Feuerland.}

\section{Scriptania Hanes. 1905.}

S. Michaelseni (StruUd. 1899).

\section{Srroptemin Mirhrelsemi StTaud. 1899.}

Agrotis Michaelseni, Stamlinger, Mamb. Magalh. Sammelr. IV. 1899, p. 60. Fig. 13. Fenertand, Uschunia.)

Seriptania Michaelsenj (Staud.), Inampson, Cat. Lepiel. Phahen. Brit. Mlus. Yol. V. 1905, p. 465. Fig. 135.

\section{Leucamir. HüBN. 1818.}

\section{Lencenid antarertira STAUD. 1899.}

Leucania antaretica, Standinger, IIamb. Magall. Sammelr. Lepid. 1899, p. 70. Fig. 16. (Fenerland: Usehuaia, sudd-Patagonien: P'unta Arenas.)

\section{Lemrermire memotr. Staud. 1899.}

Lencania remota, Staudinger, Hamb. Magalh. Sammelr. Lepid. 1899, p. 71. Fig. 15. (Fenerland: Uschuaia mnd Paramo.)

Psemalemermia Staud. 1899.

Staudnagr, Ilamb. Magall. Sammelr. Lepjil. 1899, p. 73.

\section{Psemrlolemramir igmirola Staud. 1899.}

I'sendolencania ignicola, Staudinger, llamb. Magalh. Sammelr. Lepid. 1899, p. 73. Fig. 25. (Fenerland: Rio Grande.) 


\section{Orthrosirl O. 1816. \\ Orflorsin (:) IMrlmini Staun. 1899.}

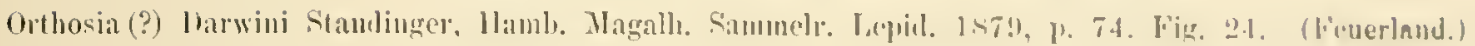

Subfam. ?

Jist(l!)!III STAUT). 1899.

IDistre!/mull alesolntu Staun. 1899.

Distagma desolata Stamlinger, Maml, Magalh. Sammolr. Lepid. 1S!!, p. Sn. (Fenerland.)

Fam. Geometridae.

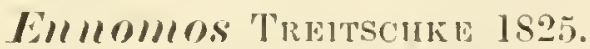

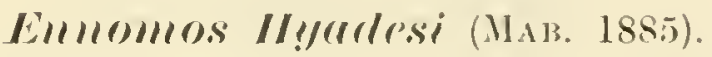

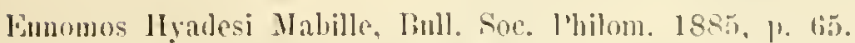

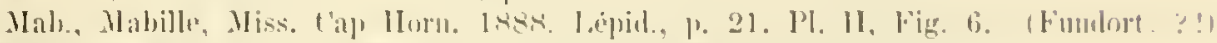

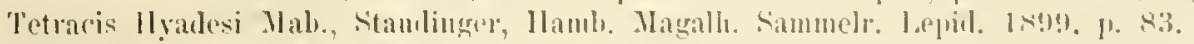

Emonos II yatesi (Mab.).

Salpis Mar. 1885.

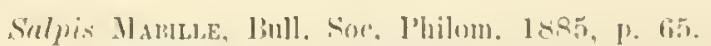

Miss. Cap Horn. I.epild. Isse, p. 20.

Sulpise centrullutu Mar. 1855.

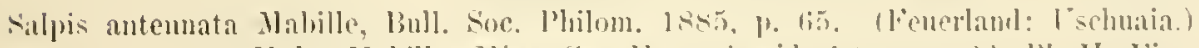

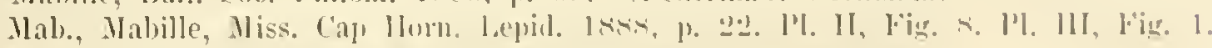

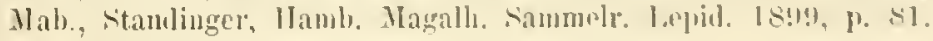

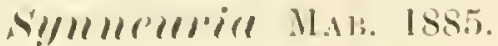

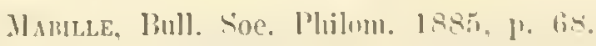

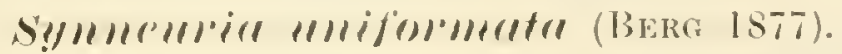

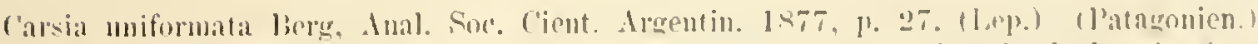

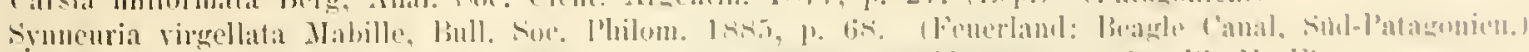

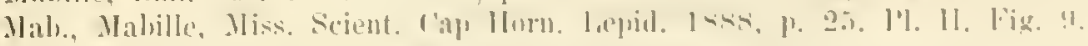

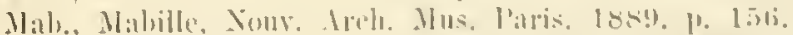

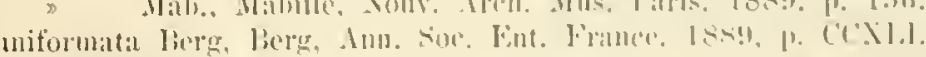

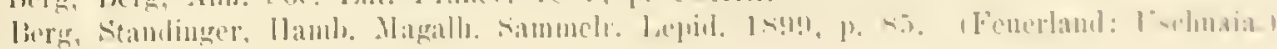

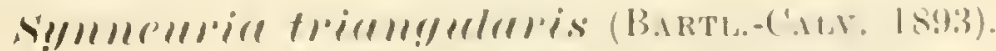

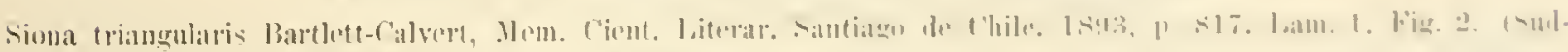
latagonien: l'muta Aremaso.

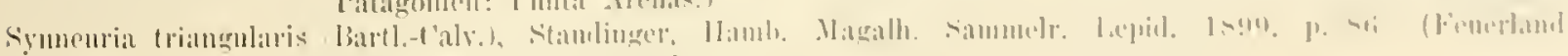

Uschmaia mud lion (iramele.) 


\section{Aspilates Treitschike 1825. Aspilutes merriferoura BERG 1877.}

Aspilates cruciferaria Berg. Anal. Soc. C'ient. Argentin. 1877, j. 25. (Separat.)

glyphicarins Mahille, Bull. Sue. l'hilom. 18s5, p. foti. (Fenerland.)

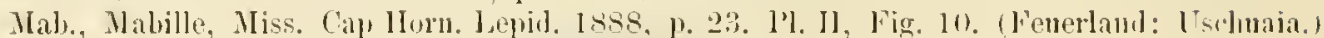
arueiferaria lierg. Standinger. Hamb. Magall. Sammelr. Lepid. 189!!, p. s.t.

II!) proplertis HüBN. 1822.

II!)

Hypoplectis distictaria Mabille, BuII. Six. Philom. 1885, p. fi. (Fenerland.)

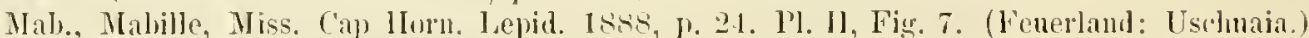

Mab., Staudinger. Hamb. Magall. Sammetr. Lepii. 1899, P. 8.8.

Psorlos Treitschic 1828.

Psorlos quarliniserefrirl MaB. 1885.

Psodlos unadrisectaria Mabille, Bull. Soe. Philom. 1885, 13. (is.

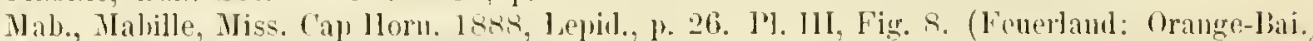

Milb., Staulinger, Mamb. Magall. Sammelr. l,epid. 18!9, p. \&4

\section{Lobopl/ome CURT. 1825.}

\section{Lobophorel stemopterata МАв. 1885.}

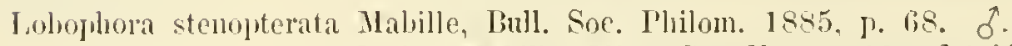

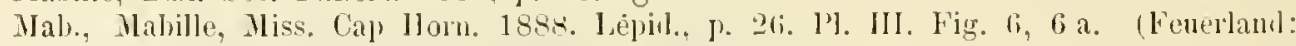
Orange Bai.)

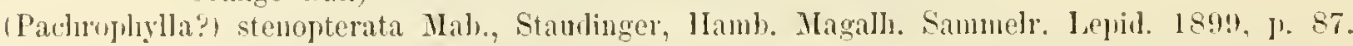

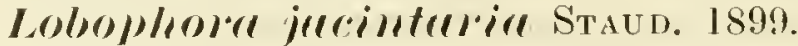

Lobophora (Pachophÿla) jacintaria Standinger. Jamb. Magall, Sammelr. Lepid. 1899, 1. 88, Fig. 6. Fenerland: lajpataia.)

\section{Lolonpllorel lepterill STAUD. 1899.}

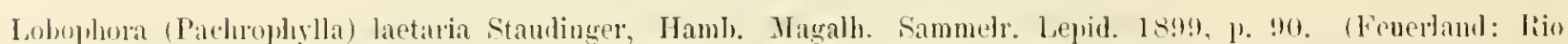
Grande.)

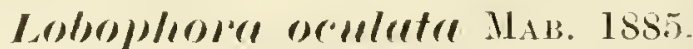

Lolophliora oenlata Mabille, Thll. Soc. l'hilom. 1885, 1). $70 . d$.

Mall., Mahille, Miss. (ay) Iorn. 1884. Lépid., p. 28. J'. III, Fig. 7. (Fenerland: Orange-Jai.)

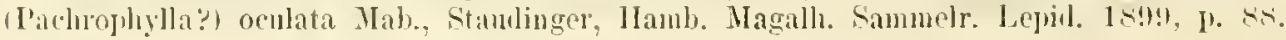

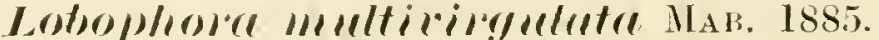

Larentia multivirgulata Mabille, Bull. Soc. Phiłom. 1885, J. 70.0 .

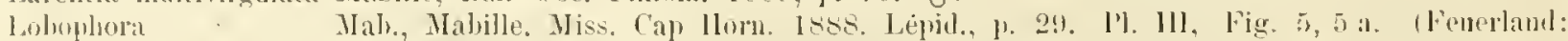
(range-Pai.)

Mal., Standinger, Ilamb. Magall. Sammelr. Jejpid. 18!!!, J. !l. 


\section{Eurosmir S'T:Pli. 18:?.

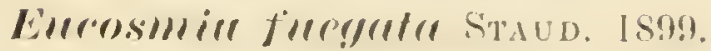

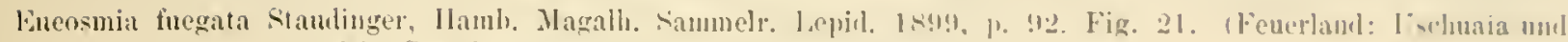
liiu Frande.)

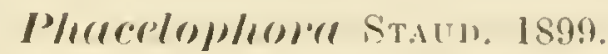

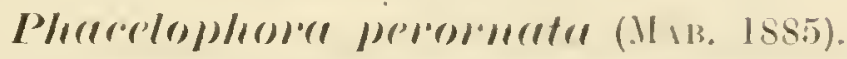

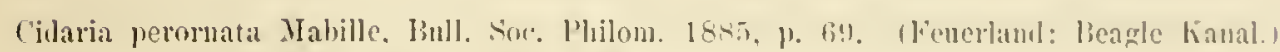

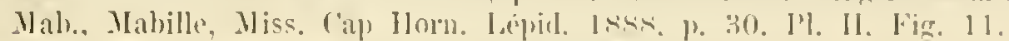

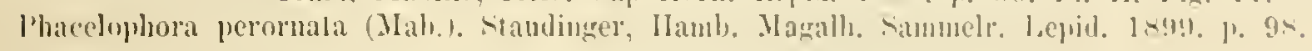

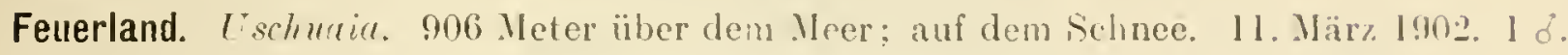

\section{Asprilloill Staun. 1899.

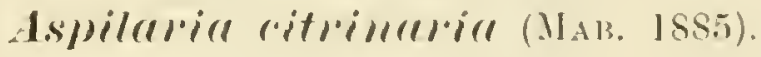

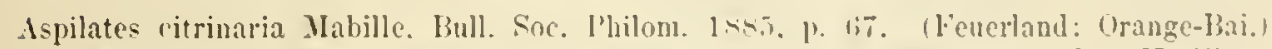

Cidaria " Mab., Malille. Miss. Cap Ilom. Tépid. 1sk8, p. 30. PI. III, Fig. 3.

Aspilaria " Mab., Staudinger, Hamb. Jagall, Sammelr. l.epid. 1S99. p. 93. Fig. J. (Feueriand: I'schuais, lion Cirande: Insel Navariu.)

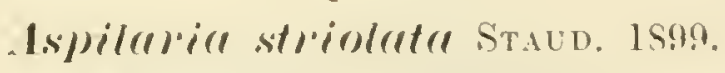

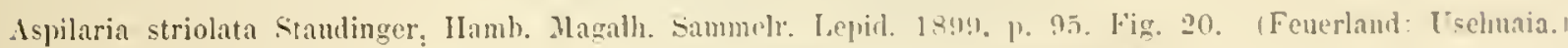

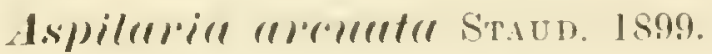

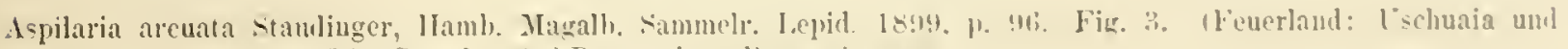
Rin Frande; Sind-Patagonien: l'mnta drenas. I

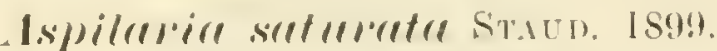

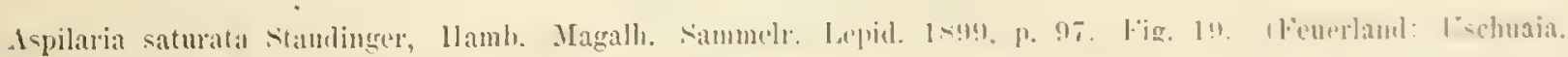
siid-P'atagonicus: l'unta . Aremas.l

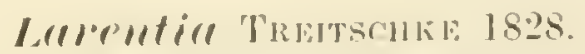

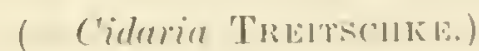

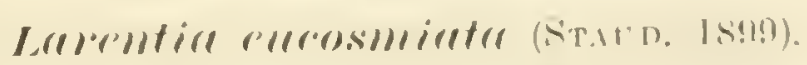

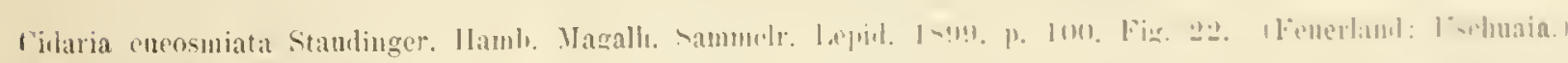
l.arentia 1. - taut.) $\mathrm{m}$.

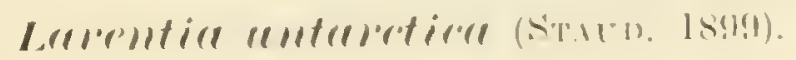

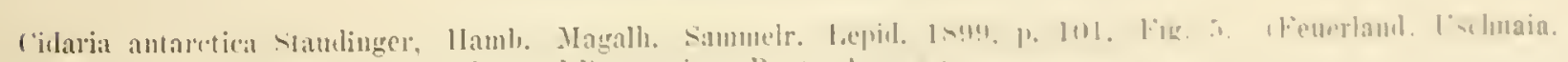

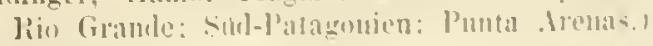

Latrentia $>$ (Stand.) 11.

h. Sv. Vet. Aknt, Handl. Band 48, Xiv 3 , 


\section{Laremtia obsoletmia (STaud. 1899).}

(idaria ohsoletaria Standinger. Iamb. Magahl. Sammelr. Lepicl. 189!, p. 102. Fig. 23. (Fenerland: I'sehuaia.) Larentia (Stand.) m.

Vysipetes Steph. I829.

Ipsipetes mentubilis (Mab. 1885).

Cidaria mutabilis Mabille, Bull. Soc. Philom. 1885, p. 69.

Ypsipetes mutahilis (Mab.), Mabille, Miss. Cap ILoru. 1888. Lépid., 1. 31. I'l. Ill, Fig. 2, (Fenerland: Orange-Bai.) Cillaria

Mal., Staudiager. Ilamb. Magall. Sammelr. Lejil. 18!!!, j. 102.

Ëlpitherill CuRT. 1825.

(Tephroclystia Нüвх. 1826.)

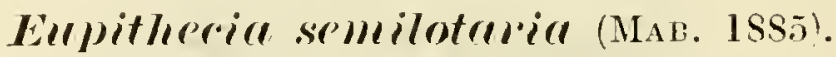

Larentia semilotaria Mabille, liull. Soe. Philom. 1885, p. 70. (Fenerland: Orange-lai.)

Mab., Mahille, Miss. (a) ILor. Lépirl. 1888. 1. 32. Pl. IlI, Fig. 4.

Eunithecia 》 (Mah.). Staudinger, Ilamb. Magalh. Sammelr. Lepirl. 18!!!, 11. I0\%.

Eerpithereill elltererticel Staud. 1899.

Empithecia antarctica Standinger. Jaml). Magalh. Sammelr. Lepid. 1896. p. 105. Vig. 18. (Fonteland: Uschuaia.)

Pserrllllir Staud. Is99.

Psemderial drbilis Staud. 1899.

Psendaria debilis Standinger, Hamb. Magall. Sammedr. lepid. 1899. p. 104. (Fenerlant: lion (irande.)

\section{Microlepidoptera.}

Fam. Hepialidae.

Hepiolers F. 1775.

Hopialus fuscers Мав. 1855.

Ilepialus fusens Mahille, Bull. Soe. Thilom. 1885, p. 56.

Mab., Mabille, Miss. Caj Ilorn. Lepid. 1888, 1. 8. P’l. 1. Fig. li. (Fenerland: Orange-Bai.)

Mah.. Staudinger, Haml. Magall. Sammelr. Icepid. 1899. p. 44.

\section{Hepirlus letteirom'lls.s (BERG IS82).}

I'jelus luteicomis Berg, Farrago Fepirl., in: Anales Sor. Scient. Argentina. XHI. 1882, 1. 218. (Patagonien.)

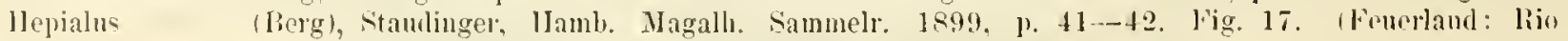
Grande: Süd-latagonien: Punta Irenas.)

\section{II'pialls antardicus STAUn, 1899.}

Hepialus antarctious Stamlinger. Haml,. Magall. Sammels. 1899, p. 42-44. (Finerland: Parano.) 


\title{
Fam. Pyralidae. \\ Subfant. Crambinae. \\ Ciromblus li. 1798.

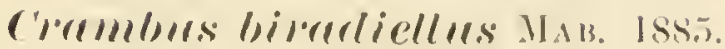

C'rambus biradiellus, Mabille. Bull. Soc. ['hilon. 1885, 1. 70. (F'enedtude Mrange-liai.)

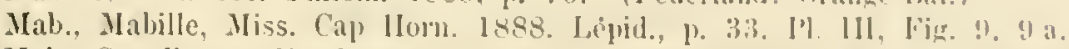

Mab., Staudinger, Hamb. Magall. Simmelr. I.epint. 1s99, 1. 10\%. IFeurlanul: l'veluaia.।

Crommbus igmirolll Staun. 1899.

Crambus ignicola, staulinger, Hamb. Magalh. Sammeln. I.epiol. ]s99, p. 108 (lenerland: I schuaia.)

\section{('101mlills spee.}

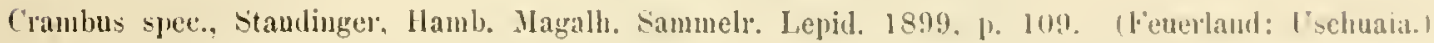

\section{Subfam. Scopariinae.}

scroprerill Hw. IS03.

Sropmerill anturecticulis Staun. 1899.

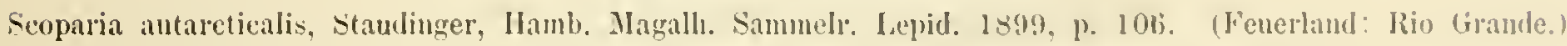

$$
\begin{gathered}
\text { Fam. Tineidae. } \\
\text { Subfam. Tineinae. } \\
\text { Till'll L. 175s. }
\end{gathered}
$$

Tillen gulentelln Мав. 1888.

Tinea galeatella, Mabille, Miss. (ap) IIorn. Iepid. 1888, p. 34. I'l. 111. Fig. 10. (lenerland: Orange-l3ai.) Mab., Staulinger, Hamb. Magall. Sammelr. Lepid. 1899, 1\% 110.

\section{Tilner pellimmelln L.}

Tinea pellionella L., Staulinger, Hamburg. Magall. Sammelr. Lepuil. 1899, 1. 110. (Feuerland: I"sehuaia.) Aus Europa eingeschleplut.

\section{Timeolle H. N. 185i3. \\ Timeolle hisellielle Hall.}

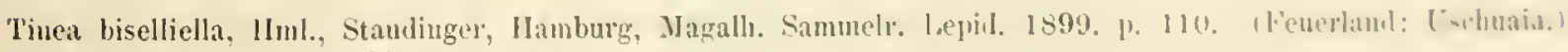
Aus Europa eingeschleppt.

\author{
Fan. Gelechiidae.

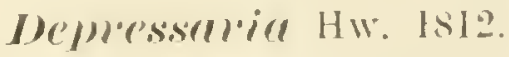

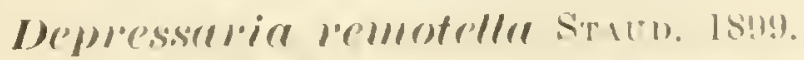

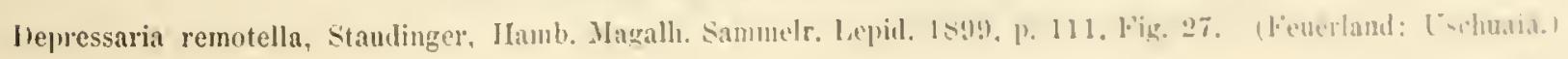


(r)!ntolerhia. \%. 1853.

Creyptolechice tortricella STaud. 1839.

Cryptolechia tortricella, Staudinger, Hamb. Magalh. Sammelr. Lepid. 1899, p. 111. Fig. 10. (Fenerland: Usc.huaia.)

Oecopholll LATR. 1806.

Oerophower sper.

Oecophora? spec., Standinger. Hamb. Magah. Sammelr. Lcpiul. 1899, 1. 112. (Feuerland: Uschuaia.)

Pseurloccophom Straud. 1899.

Psendoecoplerole ritellimellu Staud. 1899.

l'seudoecophora vitellinella, Staudinger, IJamb. Magalh. Sammelr. Lepidl. 1899, p. 112. (Fenerland: Uschnaia.)

Endrosis Нв. 1818.

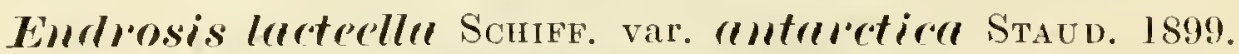

Eudrosis lacteella Schiff. var. antarctica, Staudinger, Haml, Magallı. Sammelr. Lepid. 1899. p. 113. F'jg. 26. (Feuerland: Uschnaia.)

Fam. Pterophoridae.

Mimcreseoptilus Wallengr. 1861.

limaeseoptilus antaricus STAUD. 1899.

Uimaeseoptilus antareticus, Staudinger, Hamb. Magalh. Sammelr. I.epid. 1899, p. 114. (Feuerland: Uschuaia.)

Ordo: Hymenoptera.

Fam. Formicidae.

Subfam. Camponotinae.

Melophor\%ls. LuвB. 1883.

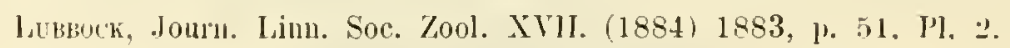

Melophorus picimlss Pog. 1863.

Lasius picinus, Roger, Berlin. entom. Zeitschr. VII. 1863, 1) 163. (Chile etc.)

Melophorus (Lasiophanes) picinus, Rog., Emery, Rés. Yoy. Relgica. Zool. Ins, 1906, 1. 57. (Magellau Str. und Fenerland: Beagle Canal.)

\section{Melophorus sumberi Forec 1904.}

Melophorns Sauberi, Forel, IIamb. Magalh. Sammelt. Formiciden. 1904. 1. 4. (Sud-Feuerland: Lago Jacinta, Insel Nararin, Puerto Pantalon; Süd-Patagonien: Punta Arenas.)

Feuerland. Insel Navarin. 4. März 1902. 2 Arbeiter.

\section{MoHOMONOUIII MLYYR 1855.}

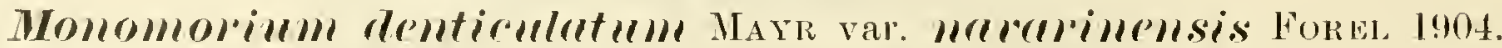

Monomorium denticulatum Mayr var. navarinensis Forel, Iamb. Magalh. Sammelr. Formic. 1904, 1. 7 . (SürFeuerland: Insel Navarin.) 


\title{
Fam. Ichneumonidae. \\ Subfim. Hemitelinae.

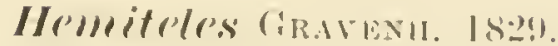

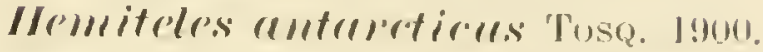

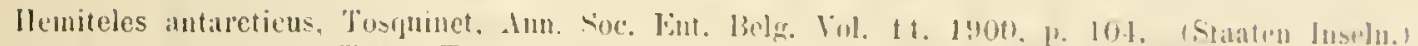

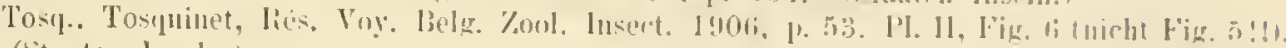
(Stiaten Inseln..

\section{Fam. Braconidae.}

Subfum. Meteorinae.

Metrollls. HaLio. 1835.

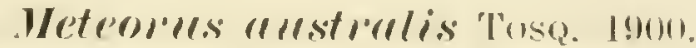

Meteorus anstralis, Tosquinet. Ann. Soc. liut. Belg. 44. 1900. 1. 104. Jenetand: Ireagle Canal.

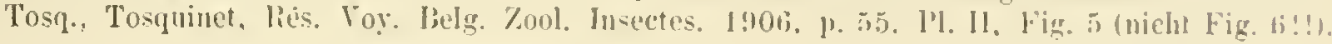

\section{Fan. Chalcididae.}

Arlitrorleles Rübs. 1902.

Rúbsanex. Hamh. Magalh. Sammelt. I'ternmaliden. 1902, 1. 3-7. Taf. . lig. 1-1:.

Irliturorlens forgirollus RüBs. 1902.

Arlitrochus tagicolus, liubsanuen, Hamb. Magalh. Sammelr. I’terom. 1902, 1\% 3-7. Taf., l"io. 1-12. IFenelland: ('schuaia.)

\author{
Ordo: Diptera. \\ Pan. Ephydridae. \\ Subfan. Agromyzinae. \\ . 1 !)

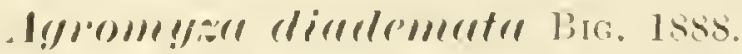

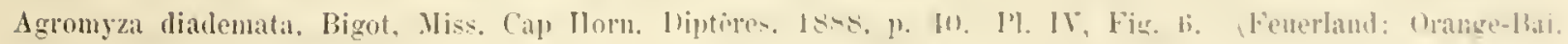

Subfim. Notiphilinae.

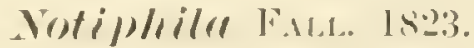

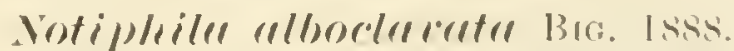

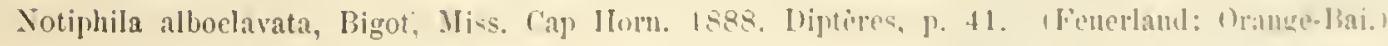

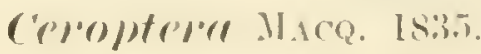

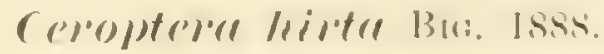

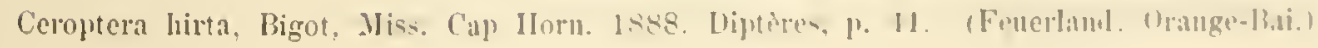




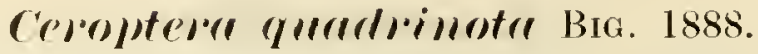

Ceroptera quadriunta, Bigot, Miss. Cap IIoru. 1888. Diptères, p. 42. (Fenerland: Orange-Bai.)

Srortophill, Веск. 1896.

BEckel, Berlin. Ent. Zeitsch1. 41. 1896, P. 237.

Scatophill roltipenthis Beck. 1905.

Scatophila rurtipennis, Becker, Amn. Soc. Ent. Belg. 49. 1905, 1. 192. (Staaten Inselu.)

Berk., Becker, Rés. Voy. Belg, Zool. Insectes, 1906, 1. 73. Pl. III. Fig. 1 mil 2.

Fam. Sapromyzidae.

Prllopterer FALL. 1820.

Palloptern guettipenmis Bia. 1888.

Palloptera guttipemis, Bigot, Miss. Cap Iom. Diptères. 1888, 1. 36. Pl. IV, Fig. 3. (Feuerland: Orange-Bai.)

Fam. Helomyzidae.

ITelom!!a! FALL. 1830 .

Helomeyal reneris Big. 1888.

Helomyza. veneris, Bigot, Miss. Cau, Horn. 1888. Diptères, pag. 34. Pl. IV, Fig. 2. (Fenerland: Orange-Bai.)

Leria Rob. Desv. 1830.

Levire rufifinols Big. 1888.

Leria ruffrons, Migot, Miss. Cap, IIorn. Dipt. 1888, p. 35. (Fenerland: Orange-Bai.)

Die 2 Typen konnte ich im Pariser Museum einsehen. Sie sind schmutzig braungelb. Die rötlich gelbbraune Stirnzeichung ist sehr scharf begrenzt und sammetartig; die beiden Zipfel sehr lang und spitz ausgezogen. Am Augenrand sind vorn je 2 Borsten, hinten je 2 neben einander. Die 2 vorderen und die 2 hinteren Ocellenborsten ziemlich klein. Zwischen ihnen ziemlich viel winzige Bürstchen. Die 2 Hinterhauptsbürstchen klein. Scutellum ausser den 4 Borsten oben jederseits seitlich mit 5-11 kurze Härchen, aussen seitlich je circa 1-3 solche Härchen. Abdomen oben kurz und mässig dicht behaart; 4. Tergit hinten mit 3 sehr langen Borsten, 5. mit 5 sehr langen Borsten. 2. Tergit sehr lang. Beine mit ziemlich dichter mässig kurzer bis mässig langer Behaarung. Schienen aussen am Ende mit ca. 3 Borsten.

Körperlänge $6-61 / 2 \mathrm{~mm}$.

Vorderflügellänge $7-7^{1 / 2} \mathrm{~mm}$.

Feuerland. Orange-Bai. 2 i (Typen).

Lepir pirtiromis Bag. 1888.

Leria pieticornis, Bigot, Miss. Cap Horn. Dipt. 1888, p. 35. (Fenerland: Orange-Bai.) 
Levirl menirillibes nor. spec. - Textfig. 19.

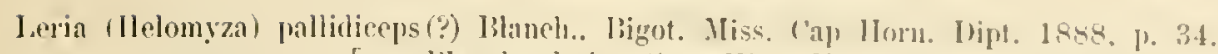

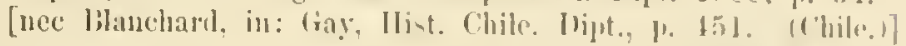

ठ์?. Kopf, Thorax, Abdomen und Beine hell, schwach bräimlich ockergelh, beim $q$ etwas meln rötlich, Stirn rostfarben. Fïhler schwarzbran, Fühlerborste nackt. Knebelborste sehr lang. Pubeszenz sehr kur\%, Borsten lang und schwarz (4 bei den Oeellen, je 5 an dem Augenand). Hinterkopf mit 2 schwarzen Harbïrstehen dicht neben einander.

Thorax mit sehr wenig dichter schwarzer mässig knrzer Pubeszenz. Borsten lang und schwarz. Seutellum ohme Pubeszenz, die 4 Borsten lang und schwar\%. Abdomen mit kurzer Pubeszenz, an Hinterrand jedes Segmentes eine Querreilie Haare. die an den Seiten beim ? lang, beim of sehr lang und kriftig sind. Letrtes Segment des $\delta$ glatt, fast kugelig gesehwollen und mit dichter selır langer und sehr diinner blasser Behaarung. Pleuren olne Pubeszenz und olme Borsten. Mesosternum nur in der Mitte dicht und lang behaart, an den Seitenteilen nur je 2 lange Borsten. Schenkel beim $q$ dick, beim ó sehr diek. Pubeszenz kurz; Pracapikalborste an allen Sehienen. Mittelschenkel und Mittelschienen des ơ auf der Unterseite mit einer sehr dichten, sehr langen und diimnen struppig abstehenden schwarzen Behaarung, die

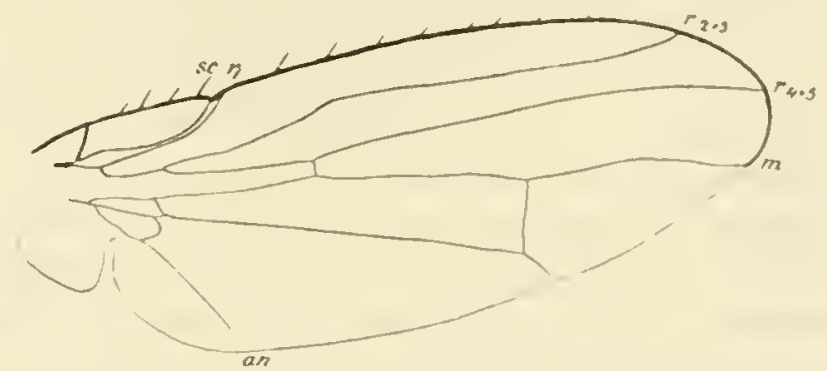

Fig. 19. Leria penicillipes Exnert. $\sigma$. Flügel. Vorgr. 14: 1. auf der Sehiene ungefähr halb so lang wie die Schienenlänge ist und sich auch auf den Metatarsus erstreckt.

Flügel (Fig. 19) blass bräunlich ockergelb, Adern bräunlich oeliergelb. Costa wenig dicht mit langen schwarzen Dornen besetzt (ca. It auf der ganzen Iänge bis zur Nündung von $r_{2+3}$ ). Adern unbehaart. se und $r_{1}$ stark genähert. $r_{2+3}$ macht iiber der kleinen Querader eine starke eckige aber abgerundete Biegnng nach unten und verläuft dann fast völlig gerade. $r_{4+5}$ ist von der kileinen Querader ab gleichuässig mässig seluwach nach hinten konkar gebogen. $l^{\prime} a+3$ nnd $r_{t+s}$ dirergieren anfangs, dann konvergieren sic und nahe an Ende divergieren sie wieler. Membran rot his griin irisierend.

Körperlänge $q 5,3 \mathrm{~mm}$.

Fliigellänge $\delta 6^{1}{ }^{1}+\mathrm{mm}$.

Feuerland. Uschuaiu. Augrust 1902. I o. Tn Walde (Fehwedische Siidpolar-bxpedition). - Orange-Bai. 1 f (Cap Horn lixpedition: das Originaletiick Bucotra. das ieh in Paris mit dem vorliegenden of vergleichen lionnte). 


\section{Fam. Dryomyzidae.}

Actorrl Mvig. 1826.

Artomer rimereasrens Big. 1888.

Actora cinerascens. IBigot, Miss. Cap Horn. Dipt. 1888. p. 37 (nicht: I'l. IV, Fig. 4; gehört zu Art. rufina!!). (Fenerland: Orange-Bai.)

Artora rufinn Big. 1888.

Actora (?) rufina, Ligot, Miss. Cap Ilorn. Dipt. 1888. p. 37. Pl. 1V, Fig. 4. (Feuerland: Orange-Bai.)

Nach den Typen im Pariser Nuseum habe ich folgende Notizen gemacht:

Die beiden Bürstchen ganz unten am Hinterhanpt dichtgedrängt. Macrochaeten sehr lang; am Seitenrand der Angen je eine, hinten jederseits 2 neben einander. Wangen und Schläfen mit mässig dichter, kräftiger Behaarung. Dicht hinter dem vorderen Ocellus 2, ziemlich weit hinter den 2 hinteren Ocellen 2 weitere Borsten; zwischen beiden Borstenpaaren mit ziemlich dichter mässig feiner und kurzer Pubeszenz. Pubeszenz bram, Behaarung schwarz.

Thorax mit ziemlich dichter Behaarung, seitlich der undentlichen bräunlichen Medianlinie je eine Längsreihe von 4 Macrochaeten, die vorderste ziemlich kurz; Hinterrand mit jederseits 4 grösseren und 2 kleineren Macrochaeten (unregelmässig gestellt). Seitenrand mit je circa 6 grossen Macrochaeten und einigen kleineren. Scutellum mit 4 Macrochaeten, die seitlichen ziemlieh weit vorn; zwisclien je einer vorderen und einer hinteren Macrochaete 4 kleinere aber ziemlich kräftige Borsten; auf der Oberseite seitlich einige (je 5-7) Härchen. Metanotum relativ sehr gross, in der Mitte durch starken Qnereindruck in 2 gleichmässig gewölbte Teile zerlegt, deren vorderer 'Teil unter dem Scutellum liegt. Abdomen mit dichter und ziemlich langer Behaarung ( $q$ ) oder mit sehr dichter, langer und dünnhaariger Behaarung, die sich am Ende etwas kränselt $\left(\sigma^{*}\right)$. Schenkel des $q$ normal, des $\delta$ (besonders des Hinterbeines) starls verdickt.

우: Sehenkel mit kurzer und dichter Pubeszenz, Vorderschenkel unten anssen mit Längsreihe von circa 8 langen kräftigen Borsten, Mittelschenkel ohne Borsten, Hinterschenkel am Ende des 2. Drittels aussen unten mit sehr langer Borste, oben mit einer kurzen und einer sehr kurzen Borste.

o: Schenkel mit langer und sehr dichter Pubeszenz, die Borsten der Vorderund Hinterschenkel sind wenig dentlich und haarartig verdïnnt, aber länger als die ïbrigen Haare.

Dunkelbraunrot, Sentellum rötlich gelbbrann, Abdomen dunkelrotbraun. Beine gelbbrann.

Vorderflïgellänge $\delta 7^{1 / 2} \mathrm{~mm}$, 우 $7 \mathrm{~mm}$.

Körperlänge $\delta 7 \mathrm{~mm}$, 우 $6^{1} / 2 \mathrm{~mm}$.

Feuerland. Beagle Canal. 1 d, 1 ㅇ. Französiche Cap Horn Experlition. - OrangeBai. 1 o, 1 ㅇ Französiche Cap Horn Expedition.

Typen im Pariser Musenu. 
var. IIIII) nov.

Ein $\delta$ ist wesentlich kleiner. Dic Borsten der Vorder- mol Hinterschenkel sind hier kräftig. Die Härchen zwischen den 4 Ocellenborsten sind schr rerburiert und spärlich.

Körperlänge $5 \mathrm{~mm}$.

Fliigelläinge $5 \frac{1}{4} \mathrm{~mm}$.

Feuerland. Orange-Bai. 1 d. Französische Cap Hom Expedition. 'Type in Pariser' Museum.

\author{
Prüretorir Big. 1888. \\ [Briot, Miss. Cap Horn, Wiptères. 1858, p. 38.
}

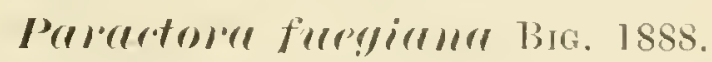

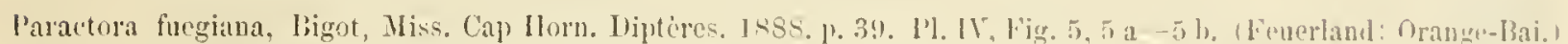
Big., Gercke. Jahrl. Hamh. Wiss. Aust. 1\%. 1879, \%. 153. (Süul-Feorgien.)

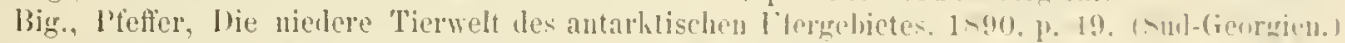

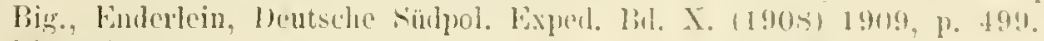

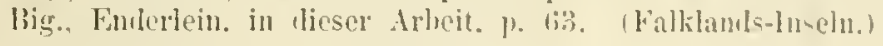

\title{
Fam. Borboridae.
}

Int)ops lixnerir. 1909.

Pteremis. Bigot. Miss. Cap Ilorn, Zool. Insect. 1888. 11 (1)iptera), p. 43. M. M․ Fig. 7. 7 it.

Antrops. Enderlein, \%ool. Anzeiger. IB. 34. 190!, 1. 225. Textfigur.

Kopf langgestreckt und oben ziemlich abgeplattet. Gesicht (Untergesicht) ansserordentlich tief höhlenartig oder tasehenartig eingesenkt; Vorderrand der Stim (Obergesicht) halbkreisförmig und scharfkantig und ïberdeckt, von oben gesehen, auch noch die Basalteile der Fühler, die aueh etwas mit eingesenkt stehen. Untergesicht mit geradem Vorderrande, der in der Mitte kaum merklich eingedrüekt ist : cin . leediankiel feht, auch von einer medianen Erhebung ist kaum zu spreehen. Epistoma (Clypens) gross und weit schaufelförmig vorragend, Vorderrand fast halbkireisförmig. Ingen relatir klein, längsoval, unpubeziert. Kopfoberseite gleichmilsig nit gleichlangen. senkreeht abstehenden, sehr kurzen Borstenhaaren zienlich dicht besetzt: cinzelne längere Borsten finden sich dazwischen, und zwar je eine seitlich des Mittelkicls an der Stelle der Oeellen, je eine in der IItte zwischen dieser und dem Himterrande der Augen und zwei hintereinander am lnnenrande der Augen: beim $\delta$ ist die Konfhehaarung noch kiirzer und aneh diese Borsten stark rerkïrzt und weniger dentlich.

Backen zicmlich breit; oberhalb des Epistoma (Clypens) und etwan pinwärt= von der Grenze zwisehen Obergesicht (Stirn) und Schläfen geht wour Vorderrand eine Furehe aus, die die ganze Länge des Unterrandes der Backen hinzicht mel einn nach hinten sich verbreiternden Saum ron etwa ${ }^{2}{ }_{3}$ der Backenbreite abgrengt. der in vorderen Viertel sehr sehmal ist. Diese Furehe ist aber nur im rorteren Viertel sehr tief und seharf, im übrigen Verlanfe sehr undentlich. Der obere 'Teil der Backen Ii. Sr. Vet. Akal. Handl. Band 48. $x: 03$. 
oberhalb dieser Linie ist bis an die Stirngrenze glatt nnd unbehaart, der untere Saum nuterhalb dieser Linie trägt ziemlich dichte und kurze - beim o sehr kurze - abstehende Behaarung und nahe am Vorderrande zwei kräftigere Knebelborsten, von denen die rordere sehr lang (fast von der Länge der Fühlerborste), die hintere etwa halb so lang ist. Dicht hinter dem Hinterende der Angen geht ein Quereindruck senkrecht bis zum Unterrand der Backen, der schmale Teil der Backen hinter diesem Quereindruck ist wie die Schläfen gleichmässig mit kurzen (o) bis sehr kurzen ( $\left.\sigma^{*}\right)$ Borstenhaaren besetzt. Ton Ocellen ist keine Spur vorhanden. An ihrer Stelle ist ein sehr kurzer, mehr oder weniger deutlicher Längsliel. Rüssel kurz und versteckt. Fiihlergeissel pubesziert.

Thorax rorn gerade abgestutzt, Schulterecken durch unscharfe, schräge Eindrïcke abgesetzt. Die ganze Oberseite ähnlich wie die Kopfoberseite behart. Seutellum kurz nnd breit, hinten nur wenig abgerundet, vom Thorax durch einen nieht sehr dentlichen Quereindıuck abgesetzt; nur mit wenigen sehr liurzen abstehenden Borstenhaaren besetzt; Borsten scheinen völlig zu fehlen, Macrochaeten fehlen sieher. Abdomen oval, ziemlich stark dorsorentral zusammengedriekt, oben ziemlich glatt und

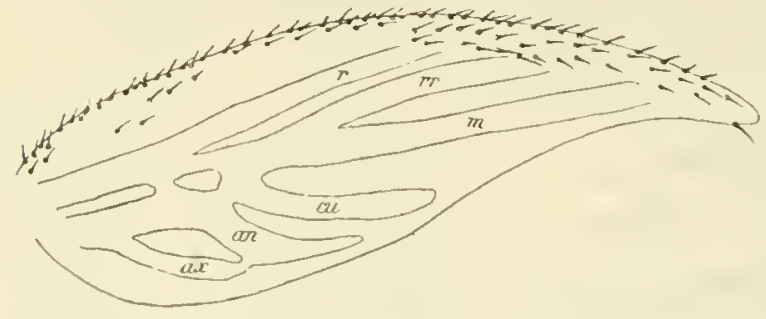

Fig. 20. Antrops truncipennis nov. gen. nov. spec.
Rechter Flügel. Vergr. 45: 1 . spärlich mit selır kurzen Härchen besetzt; an der Spitze, besonders an der Seite, mit einer Anzahl längerer Haare; beim $q$ tragen die Hinterränder des 2. bis 4. Segmentes besonders auch an der Seite zerstreute längere Borstenhaare; - 0 mit 5 Segmenten, von denen die rier ersten von oben sichtbar sind, das fünfte ist fast halbkugelförmig nach unten herumgebogen, 1 . Tergit $1^{1 / 2}$ des zweiten; - o mit vier deutlichen Segmenten, in der IIitte des gerade abgestutzten Hinterrandes des 4. Segmentes ragt jedoeh (ähn]ich wie bei Malacomyza HaL. 1839 [= Phycodroma Stexн. 1S55], Orygma Meig. usw.) ein sclimales, an der Spitze behaartes Zäpfehen hervor, das das Legerohr darstellt; aus wieviel Segmenten dies besteht ist am trocknen Stiick nicht festzustellen, doch erkennt man noch ein deutliches schuppenförmiges Basalstück, das somit ein fünftes sichtbares Tergit darstellt. Alle Tergite schlagen sicl am Rande weit $m$, so dass die Sternite ziemlich schmal sind.

Beine knrz behaart: Schenkel bein on ziemlich, beim $q$ weniger verdickt. Vorderschiene beim $\delta$ mit einer ziemlich kräftigen, beim + mit zwei sehr feinen Präapicalborsten. Mittelschiene ( $\delta q)$ am Ende mit einem Kranze liräftiger sehwarzer Borsten und hinten mit 2 Präapicalborsten, ron denen die obere weiter naeb der Spitze zu geriickt ist. Hinterschiene mit zwei kïrzeren Apicalborsten, beim of mit einer, beim $q$ mit zwei ziemlieh langen Präanicalborsten nahe der Spitze. 1. Hintertarsenglied etwa so lang wie am Ende breit, zweites sehlanker und nur Weniges länger als das erste. Klanen dïnn und zart, einfach und gebogen. 1. Vordertarsenglied des $\delta$ unten am Ende mit einem nach unten schräg abstehenden kräftigen, am Ende abgestutzten und abgerundeten dornartigen Fortsatz, der dem $q$ völlig fehlt. 
Flügel (s. Figuc 20) stark rerkürzt. Wenigg lïnger als die Thoraslïnge; nach cler Spitze zu zugespitzt, Vorderrandzone sehr ku\% belornt; Ardern sind nicht sehr dentlich erhalten, und die einfachen Adern sind anch noch als liadius (r). liadialramus $(r r)$, Media (m), Cubitus (cu), Analis (an) und Avillaris $\left(n x^{\circ}\right) \%$ denten. Halteren scheinen zu fehlen.

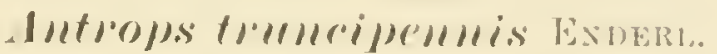

(lï. 20.)

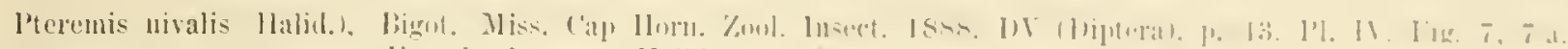

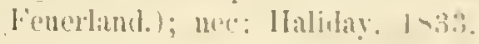

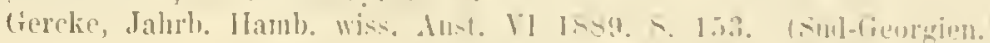

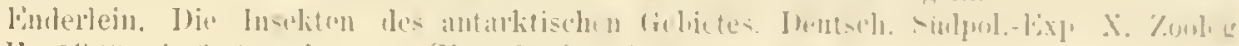

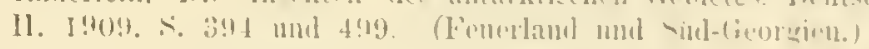

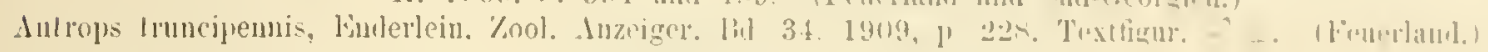

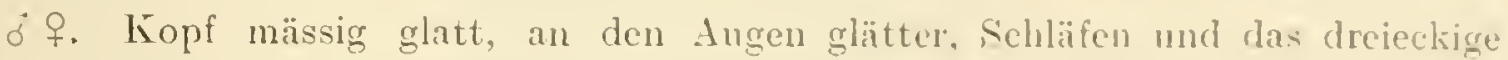
Feld auf den Backen poliert glatt. Unterer Angenrand ziemlich geradlinig und etwas sehräg ron vorn unten nach hinten oben. Bewimperung der Fühlergeissel ziemlich lang und deutlich, jedoch nicht dicht. Backen ror den Augen kaum halb so lang wie die Augen, unter den Augen jedoch stark backenartig verbreitert. Tuterrand fast halbkreisfömig: Backenfläche ziemlich eben. Die rordere Knebelborste an dem Vorderende der Backen nur wenig kïrer als die Fïhlerborste und etwas geliüumt.

Thorax ron oben gesehen fast quadratiseh, wenig lïnger als breit. 1. Abehminal. segment vorn breit abgestutzt. Die Tergitlängen verhalten sich bei alen vier von oben dentlich sichtbaren Segmenten beim of wie $1^{1} / 2: 1:{ }^{3}:^{1}{ }_{2}$, beim o wie $I^{1} a: 1: 1:{ }^{3}$.

Beine ziemlich lang und kräftig. 1. und 2. Hintertarsenglied innen mit einem sehr dichten Polster feiner langer Haare, die sehräg mach hinten geriehtet sind, das des 1. Gliedes ziemlich langhaarig. 1. Hintertarsenglied mit diesem Polster fast dielien als die Schiene. Hinterschiene des ó innen mit sehr langen dünnen. mäsvig dieht stehenden Haaren in der ganzen Länge. Auch in der Nitte der Hinterseite des Hintersehenkels sind die Haare ähnlich verlängert. Alle 'Tarsen, besonders die j. Tarsenglieder, mit ziemlich langer, nicht dichter l'ubeszenz.

Das ganze Tier, auch Flügel und Hinterleib, etwas speckig glämend. Kopnt und Thorax oben gelblichbran bis braun, Abdomen schwarbian. Kopf an der Seite und unten beim $q$ rostgell, beim of braun und nur der unbeharte Wingenteil rostgelb. Thorax an der Seite und unten rostgelb, chenso the Beine und ilure Pubeszenz, aber ohne die Borstenhare. Borsten und Klanen, die sehwar sind: dunlielbraun ist die äusserste Spitze der Schenkel. Augen rostbraun, in der Mitte dunliler. Rostgelb sind anch die Fühler. Fiuhlerborste, das hohle Gesicht (Lntergesieht) und der Clypeus (Epistoma). Flügel hraun, dic borstenhare der Vorderrandzone schwarz.

Körperlïnge $4 \mathrm{~mm}($ o $)-t^{1}=1 \mathrm{~mm}$ (d).

Abdominallänge $2^{1}: \operatorname{lnm}(q)-2^{3}, \mathrm{~mm}\left(0^{\circ}\right)$.

Abdominalbreite $I^{1} a m m(q)-l^{3}+m m(\delta)$.

Kopflänge fast $\mathrm{I}^{3}$ \& $\mathrm{mm}$. 
Flügellänge $1,5 \mathrm{~mm}(q)-1,65 \mathrm{~mm}\left(\delta^{\pi}\right)$.

Hinterschienenlänge $1 \frac{1}{2} \mathrm{~mm}$.

Feuerland. Arehipel von Kap Horn. Orangebai. 1885. 1 o und 1 q. Französisehe Kap Horn-Expedition. Gesammelt ron Hyades und HaHN.

Nach Gercke 1. c. kommt diese Fliege anch auf Süd-Georgien vor.

Von den vielen Differenzen zwischen Antrops truncipennis ENDERL. und Pteremis nivalis (HALID. IS33) hebe ich nur die mehr als doppelte Körpergrösse und das tief ausgehöhlte Gesicht der ersteren hervor. Letztere steht der Gattung Limosina nahe und lıat wie diese nur ein schwach ausgehöhltes Gesicht; ausserdem scheint nach der Angabe von CuRTIS das Geäder nur sehwach reduziert zu sein, da derselbe nur angibt, dass die 4. und 5. Ader nicht vereinigt sind.

Borborus Meig. 1803.

Borbormes reripes Big. 1858.

Barborus varipes, Bigot, Miss. Cạ Horn. 1888. Iiptères, p. 43. (Fenerland Orange Bai.)

\section{Fam. Sciomyzidae.}

\section{Schoenom!zal HaLid. 1833.}

Schoenomyar fenestrute Bia. 1888.

Schoenomyza fenestrata, Bigot, Miss. Cap Horr. Diptères. 1888. p. 30. (Feuerland: Orange Bai.)

Nach der Type habe ich mir im Pariser Museum einige Notizen gemacht:

Der ganze Scheitel dunkel sammetbraun. Das ganze Gesicht mit der Stirn und die kleinen Backen dunkel golden (erzeugt dureh microscopiseh feine und dichte Pubeszenz); diese Färbung zieht sich längs der Augen ein Stiick nach hinten. Längs des Angeninnenrandes je 3 grosse und eine kleine Borste; hinten je 2 neben einander sehr lang. Hinter dem vorderen Ocellus 2 sehr lange Borsten, die hinteren 2 (weit hinter dem hinteren Ocellus) sehr klein. Schläfen auf den Hinterkopf gedrängt, fast fehlend, mit je einer Reihe kurzer Haare parallel zum Augenrand. Thorax schwarzbraun, vorn zwei dunkel sammetbraune mässig breite Längsstreifen in der Mitte, die dieht gedrängt sind. "Scutellum relativ lang, die 4 Borsten sehr lang, die vorderen ziemlich weit vorn, seitlich (nach aussen) von diesen je 2 kleine Härchen, sonst unpubesziert. Abdomen relativ sehlank und flach, Seiten fast parallel, hinten zugespitzt; Pubeszenz relativ spärlich und kurz, nur an den Seiten und hinten einzelne lange Borsten.

Flügel bräunlich, Hinterrand und Aussenrand hyalin, ebenso der Zwischenraum zwischen den Adern in der Mitte nach dem Aussenrand zu.

Feuerland. Orange Bai. 1 (die Type Brgot's). Fränzösische Cap Horn Expedition. 


\author{
Fam. Muscidae. \\ Subfam. Muscinae.

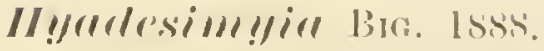

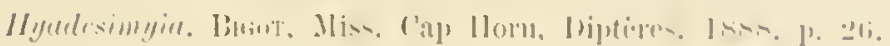

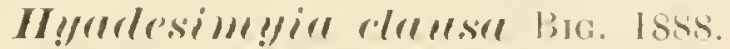

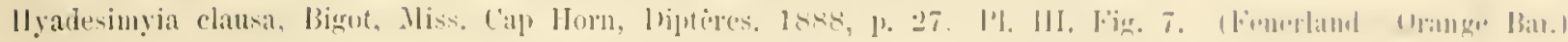

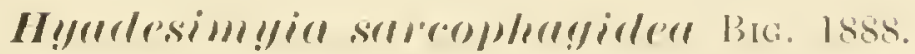

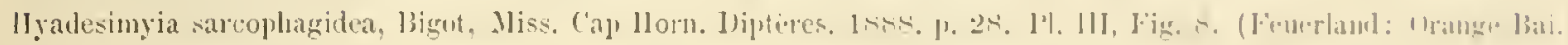

Subfan. Anthomyinae.

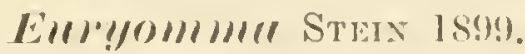

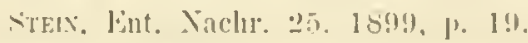

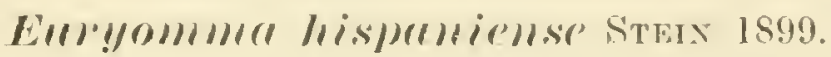

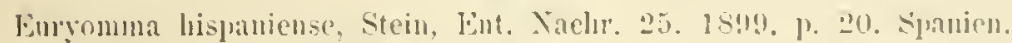

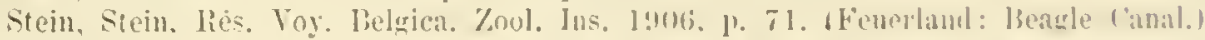

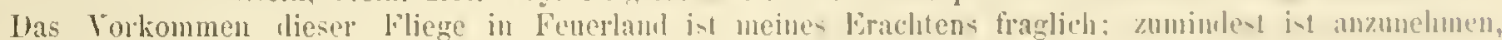
dass sie eingescleeppt ist.

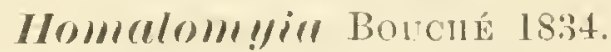

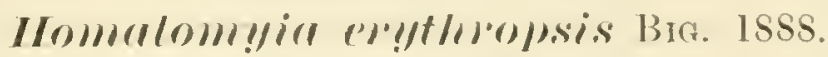

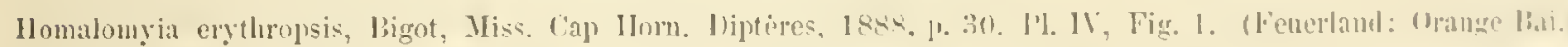

Feuerland. Uchuair, im Walde. 1 ․ Mïrz 1902.

Fam. Tachinidae.

Subfam. Tachininae.

PMrnorerer Ros. Dess. 1s:30.

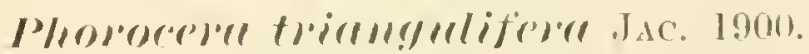

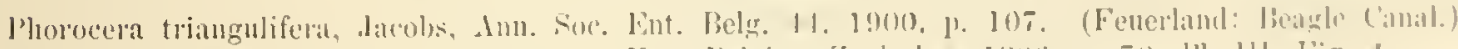

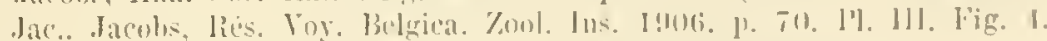

Fan11. Syrphidae.

Subfam. Syrphinae.

Helamostomm Scmix. 1860.

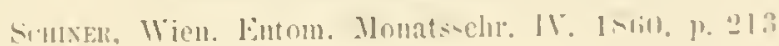

Aus dieser Gattming sind bisher Arten aus dem Arehiplata-Ciebiete (Chile. Argentinien, Patagonieu. Feuerland ete.) ausser der. M. stegmum nieht besehriehen worden.

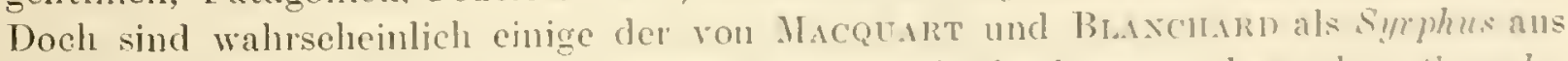
Chile beschriebenen Arten hier cinzuoldnen; vielleicht kommen hesonders s. melanostoma MaCe. und S. sermuculalus Mace. hierfiir in Botrachat. 


\section{Melamostoma lomgigena nov. spec.}

․ Kopf poliert glatt, schwarz mit schwach bläulichem Glanze; und - besonders im Untergesicht - mit einem grauen Reif; dicht, sehr fein und mässig lang behaart. Augen queroval, hinten geradlinig gerandet. Schläfen relativ breit, Länge ilnrer Breite so lang wie die Länge des 3. Fühlergliedes. Backen sehr lang (ca. 0,8 $\mathrm{mm}$ ). Untergesicht dementsprechend sehr lang; Mundrand schmal halbkreisförmig, an den Seiten dieses Ausschnittes je ein kleiner fast zapfenförmiger Höcker, am hinteren Rande des Mundausschnittes ein dritter solcher Höcker, der dicht ror dem Gesichtshöcker, der ziemlich kräftiğ, ziemlich stark abgesetzt und fast halbkugelig ist. Püssel glatt, ca. $1 \mathrm{~mm}$ lang. Der Kopf ist sehr gross, und wesentlich breiter als der 'Thorax. Fühler schwarz, 3. Glied dunkel rostbraun. Borste unpubesziert in der' Basalhälfte ziemlich dick, dann sehr schnell stark verduinnt.

Thorax glänzend schwarz, mit bläulichem Glanz und grauem Peif, besonders an den Pleuren; Behaarung wic auf dem Kopfe. Scutellum etwas gewölbt, etwa $2^{1 / 4}$ mal so breit wie lang. Abdomen ziemlich schlank, Seiten nahezu parallel und erst im Endviertel stark zugespitzt; mässig stark dorsorentral zusammengedrückt; oben und unten glänzend schwarz mit schwarz bläulichem Glanz. An den Seiten des 2., 3. und 4. Tergites nahe am Vorderrade liegt je ein mässig grosser hell ockergelber runder Fleck, dessen Durchmesser halb so gross wie die Segmentlänge ist; 1. Tergit sehr kurz, 2. Tergit fast quadratisch, 3. und 4. Tergit etwas kürzer als breit, 5. fast 3 mal so breit wie lang; dahinten bemerkt man noch 2-3 schmale und sehr kurze Tergite und das winzige Endsegment; Pubeszenz spärlich und sehr kurz, an der Spitze etwas länger; 2. Tergit an den Seiten fast wie der Kopf pubesziert. Beine hell ockergelb, Coxen und Trochanter schwarz, Hintertarsus schwarzbraun.

Flïgel grauhyalin, Adern schwarz, Pterostigma hell rostgelb. Geäder wie bei Melanostoma mellina (L.) der europäischen Fauna. Membran sehr stark irisierend, besonders rot und grün.

Körperlänge $5^{1 / 2} \quad \mathrm{~m} m$.

Flïgellänge $5^{1 / 2} \mathrm{~mm}$.

Feuerland. Uschuaia. 1 o im Wralde. März 1902.

\section{Melamostoma stermum (SAX 1829).}

Syrphus stegnus, Say. Jonm. Acurd. Nat. Sci. Plijacl. V1. 1829. 1\% 163. (Nord-Amerika.)

Syrphus fenestratus. Macquart, I'ipt. exot. II. Iart. 2. 1842, \%. 103.

Macu., Rigot, Miss. Cap Horn. Diptères, 1888. 1. 26. (Feuerland: Orange Bai.)

Jelanostoma stegnum. (Say), Kertész. Cat. Dịt. VII. 1910, 1. 86. (Ganz Amerilia.) [Hier die ubrige Synnonynie.]

\section{Subfam. Eristalinae.}

Elistrlis Latr. 1804.

\section{Evistalis ronreimarmlate JACOBS 1900.}

Eristalis croceimaculata, Jacols, Anu. Soc. Ent. Belg. 44. 1900, p. 107. (Staaten Inseln.) Jac., Jacobs, liés. Yoy. Belgica. Kool. Ins. 1906, p. 69. Pl. III, Fig. 3. 


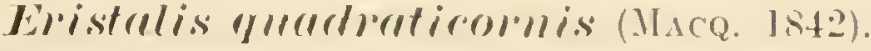

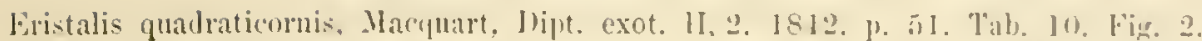

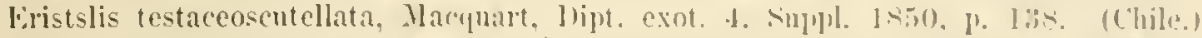

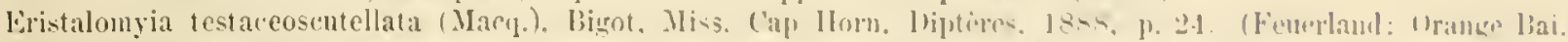

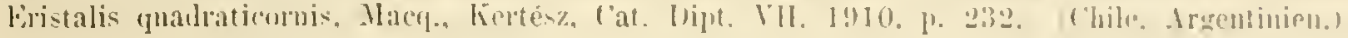

H(C)

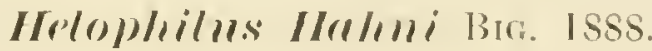

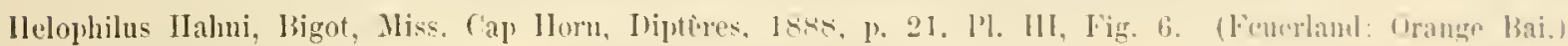

Kertész stellt diese Art als fraglich zu M. chilensis WaL. Is:37.

Fam. Dolichopodidae.

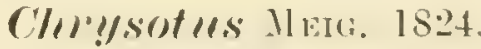

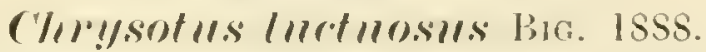

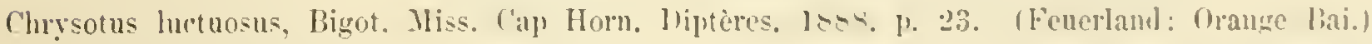

Fam. Empididae.

Subfam. Hybotinae.

spllicosil Phil. 1865.

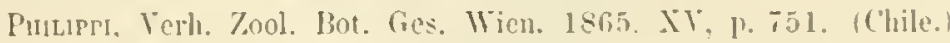

sylliroser (?) hirolom Bia. lsss.

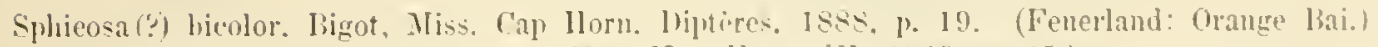

Bir.. Bezzi. Anul. Mus. Nal. Ilumg. III. 1!10). 1. 15s.

\section{Subfam. Empidinae.}

Eimpis I. 1763.

Emmpis antlurarinn Bra. 1888.

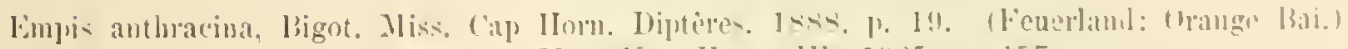

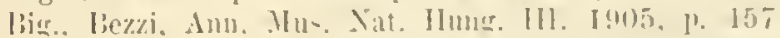

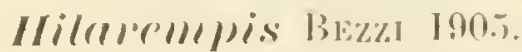

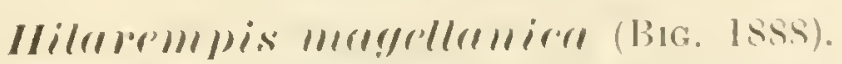

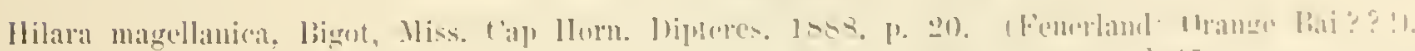

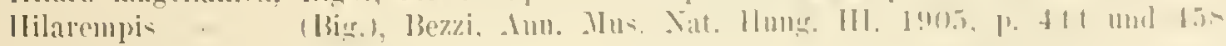

In der Finleitung pag. I sagt Brgot, dass das ihm rorliegencle Fliegen-.llaterial ron der Umgebung der Orange Bai im siiden ron Fuerland stammt. Fir gibt bei den Artbeschreibungen keine Fundortsangaben und so ist es leider fraglich. Hoher obige Diptere stammt: der Same diurte eigentlich auf die Magellan Strase denten. 


\title{
Hilarempis laticomis (Big. 18s8).
}

Hilaria laticonus, Bigot, Miss, Cap IIorn. Dipteres, 1888, p. 20. (Fenerland: Orange Iai.) Hilanempis laticornis, (Ihig.). Bezzi, Ann. Mus. Nat. Hung, 11!. I!05, 1) 444 und 458.

\section{Hillorempis ochureer (BIG. 1888).}

Ileleodromia oclnacea, Bigot, Miss. Cap Horn. Diptères. 18s8, I. 22. I'l. III, Fig. 4. (FeuerIand: Orange 13ai.) Ililara

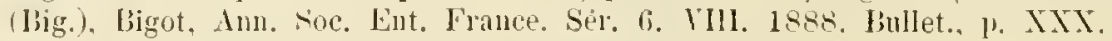
Big., libot, Isullet. Soc. Zool. France. XIII. 1888 , p. 101. Big., IBigot, Wien. Ent. Zeit. 1888. VII, T. 109.

IIilarempis IBig.. Bigot, Anı. Soe. Enst. France. Sér. 6. IX. 1889, p. 113. (Iiig.). liezzi, Anı. Mus. Nat. Hung. III. 1905, ए. 444 und 458.

Leptopesel MACQ. 1828. Leptopear rirosel Big. 1888.

Leptopeza rivosa. Bigot, Miss. Cap IJorn. Diptères. 1888, I. 21. (Fenerlanu: Orange Bai.) Big., liezzi, An11. Mus. Nat. Hung. III. 1905, 1. 458.

\section{Subfam. Ocydromiinae.}

Oc!glromial Mets. 1820. Ocyerlomia elegams Bia. 1888.

Ucrhomia elegans, Bigot, Miss. Cap IIorn. Diptères. 1888, p. 21. I’l. III, lig. 5. (Fenerland: Orange Bai.) Big., [Bezzi, Ann. Mus. Nat. Jung. JII. 1905, p. 458, Nota 4.

Fam. Tipulidae.

Subfam. Tipulinae.

Tipule L. 1735.

Tipula mefiorstris BIG. 1888.

Tipula lutirostris. Bigrot. Miss. Cap IIorn. I)iptires. 1888, 1. ก. I'. I, Fig. 3. (Fenerland: Orange Bai.)

Nepllentomme Meig. L803.

Nepllerotome rerimentrel Bug. 1888.

Nephrotoma rarineura, Bigot, Miss. Calp IJorn. Diptères, 1888, p. 6. M. I, Fig. 4. (Fenerlami: Orange Bai.) Tipula raninervis, (Ligr.), liergloth. Wien. Int. Zeit. Vh. 1888, 1. 240 [nom. emend.).

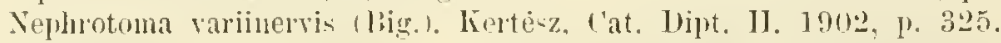

Isrllllothrix Bia. 1888.

BHow, Miss. Cap Hon. Diptères. 1888, 1. 7.

Ischuothrix aetherea Big. 1888.

Ischnothrix aetherea, Bigot, Miss. (ap IIorn. Diptèes. 1888. p. T. I’I. II, Fig. 1. Fenerlani: Orange IBai.)

\author{
Fam. Limoniidae. \\ Lillomirl IlEta. 1803. \\ (= Timnobia MEIG. 181S.) \\ Limominl limeirollis Bunch. 1852. \\ 13anch., l'hilipui. Verh. zool.-bot. Ges. Wien. XY. 1865, 1) 612. \\ Blanch., Bigot, Miss. (ap Horn. Jiptires. 1888. 1. \&. (Fonerlant: Orange I3ai.)
}

Limnollia lineicollis, IBlanchard, in (iay, Historia de Chile. Jipt. 1852, 1). 341. (Chile. 
Limomill Bignoti nov. nom.

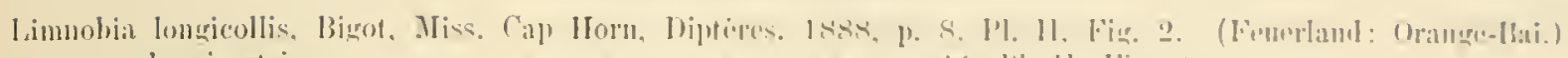

$\Rightarrow$ lomgirustris

1. 11. 1\%. 11, lïin.

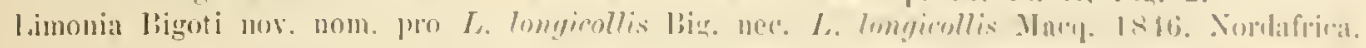

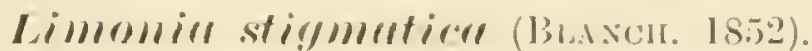

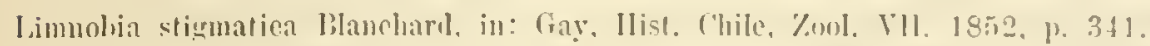

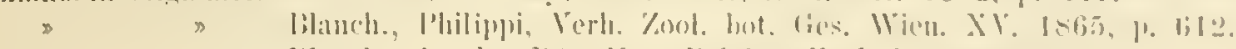

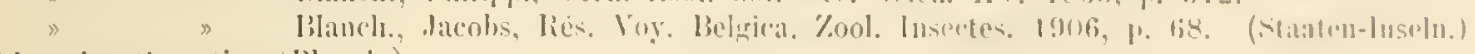

limonia stigmattea (blanch.) m.

\section{Limmophiln Mlice. 1834.}

Limmoplliln rentremintu Bra. Issis.

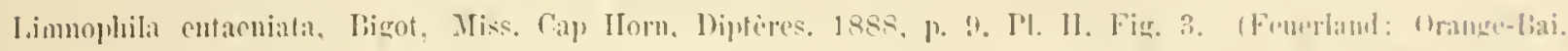

Joerilostoll Scurs. 1863.

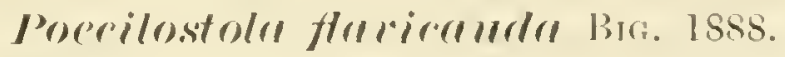

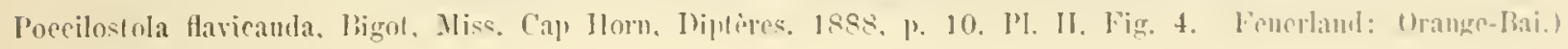

Sulfatm. Pedicinae.

Ammlonis HaLto 18 siti.

Amalomis mosille (BIG. 1858).

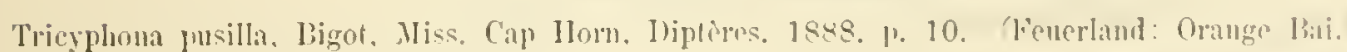

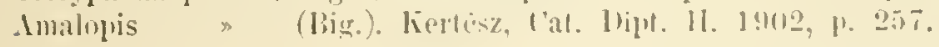

Fam. Culicidae.

Subfam. Culicinae.

C'ilex L. 1761.

Culex fluripres Mace. 1 s.3.

Culex Alavipes, Naequart, Jipl. exol. I. 1838, p. 35.

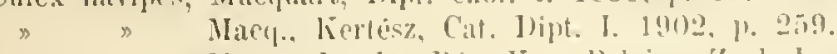

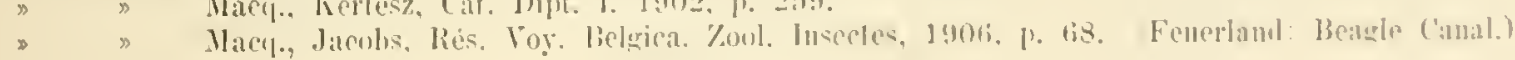

Fam. Psychodidae.

Subfam. Psychodinae.

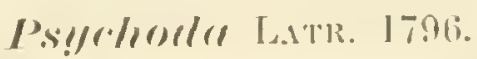

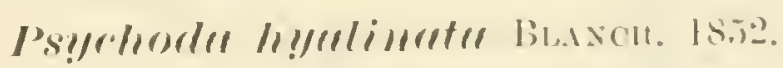

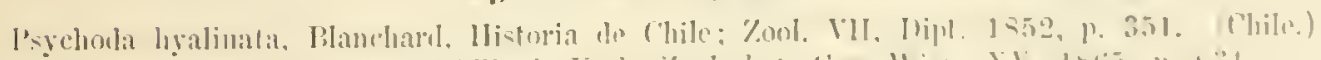

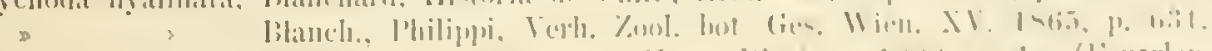

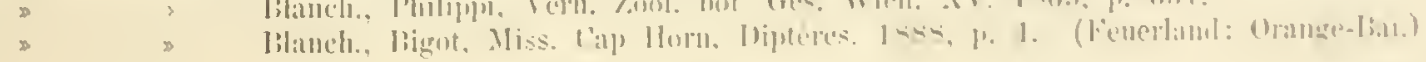

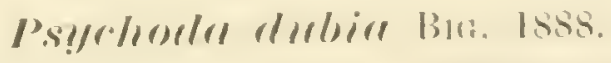

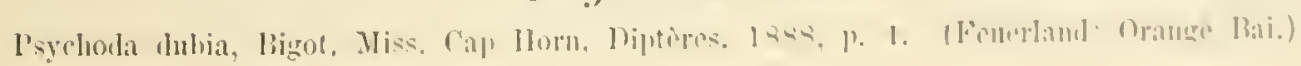

h. Siv. Yet. Akad. Mandl Band 48. Ni:o 3. 


\section{Fam. Simuliidae.}

Simulium Latrr. 1803.

Simmlimm fulvesrens BLANCh. 1852.

Simulium fulrescens, Bhanchard, in: Gay Hist. de Chile. 7ool. VII. 1852. Dipt. 1) 353. (Chile.)

Blauch., Philipri, Vesh. Zool. bot. Fes. Wies. XV. I865, 1. 633.

Blanch., Bigot, Miss. Cap Horn, Diptères. 1888, 1. 15. (Fenerland: Orange-Bai.)

Simuliume chilense Phн. 1865.

Simulium duilense, Philipi, Verlı. Zool. Bot. Ges. Wien. XV. 1865, 1. 634. (Chile.)

Plil., ligot, Miss. Cap, IIorn, Inipteres. 188s, j. I5. (Fenerland: Orange-Pai.)

Simulimm anthrercimm, BIG. 1888.

Simulium anthracimm, Bigot, Miss. Cap Horn, Diptères. 18s8, p. 15. (Fenerland: Orange-Bai.)

Simulium antaretirum. Big. 1888.

Simulium antareticum, Bigot, Miss. Cap Horn, Diptères. 18s8, 1. 15. (Fenerland: Orange-Bai.)

Fam. Chironomidae.

Sulbam. Chironominae.

Orthocladius v. D. WUne 1874.

Orthochadius perpusillus nov. spec. - Textfig. 21, 22.

오. Der ganze Kïrper hell gelbbraun. Fühler, Taster und Beine blass gelbbraun. Angen oben weit getrennt; wie es scheint vorn nur sehr wenig eingedrückt; unbehaart. Fühler (Fig. 21). 6-gliedrig, 1.-5. Glied mit einzehnen langen Haaren; Endglied nur mit feinen kurzen Haaren besetzt, schlank und so lang wie die beiden vorhergehenden Glieder zusammen. Palpus 4-gliedrig. Thorax in eine dieke stumpfe Spitze über den Kopf hinweggezogen (Fig. 21). Die Längen der Glieder des Vorderbeines be-

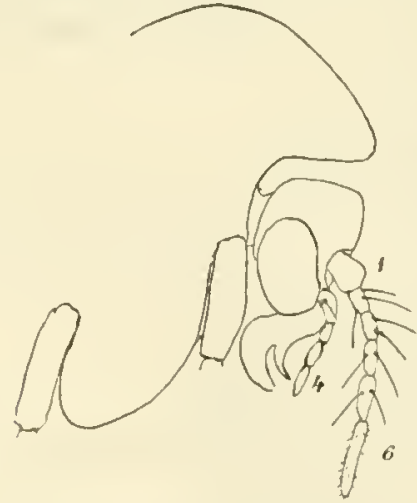

Fig. 21. Orthocladius perpusillus ENDERL. O Kopf und vorderer 'loil des Thorax ron der Seite. Vergr. $80:$ I

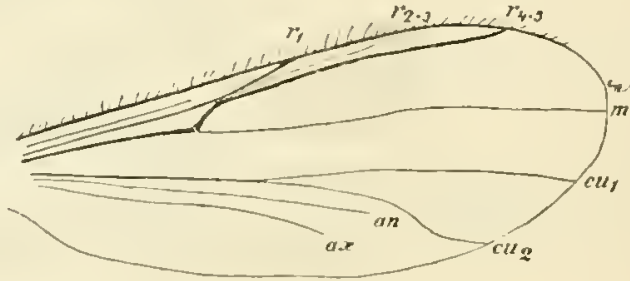

Fig. 22. Orthocladius perpusillus IFNDERt. F'lígel. Vergr. $46: 1$. 


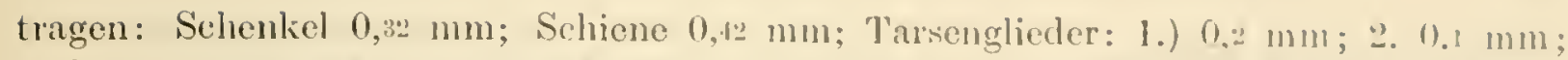

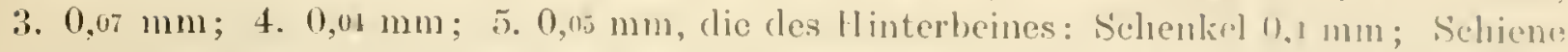

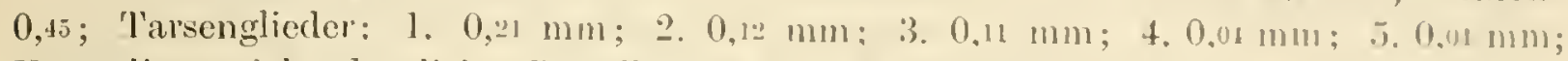
Empodium nicht dentlich. P'ulvillen fehlen. Kopf und Thorax ohne Puhesten\%, Abdomen mit einzehnen längeren Haaren.

Flïgel (Fig. 22) hyalin. mit schwaeh gellslichgranem l'on. Aclem blass bräinnlichgelb. $r_{2+3}$ deutlich. Zelle $R_{1}$ und $R_{2+3}$ schmal. $r_{4+5}$ schwach gekrïmmt, cndet zicmlich weit proximal der Flïgelspitze. m endet in die Fliigelspitze, selnwach gekriimmt. $\mathrm{en}_{2}$ etwas wellig gebogen. Vorderrandbehaarung relativ wenig dicht, alser nur kur\% und ziemlich abstehend.

Körperlänge $\mathrm{I}^{1} / \$ \mathrm{~mm}$.

Fliigellänge $1.3 \mathrm{~mm}$.

Fühlerläinge ea. $0,31 \mathrm{~mm}$.

Feuerland. Süsswassersee siidwestlich ron I'schaia. 3. Oktober 1902. 1 f.

Einige dem rorliegenden Exemplar an dem Legerrohr anhängende Fier lıaben eine Länge ron $0,11 \mathrm{~mm}$, eine Breite ron ca. $0,05 \mathrm{~mm}$ und eine ovale form.

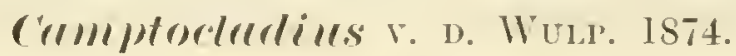

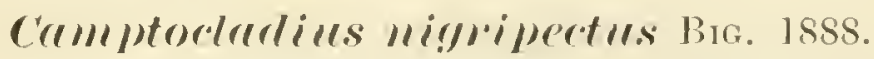

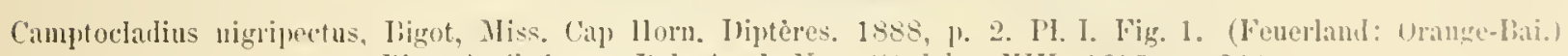

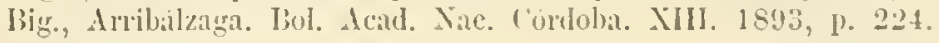

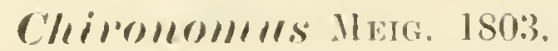

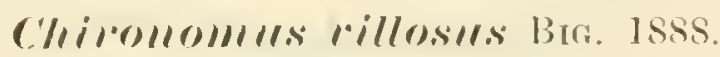

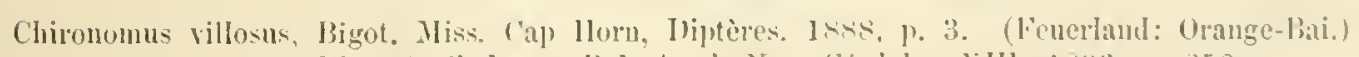

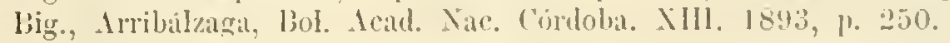

\section{Subfam. Tanypodinae.}

Uchlls nor. gen.

Typus: O. uschuiensis nor. spece. Fenerland.

Augen stark nierenförmig gebogen, oben weit getrennt. Fühler (q) 11 -gliedrig.

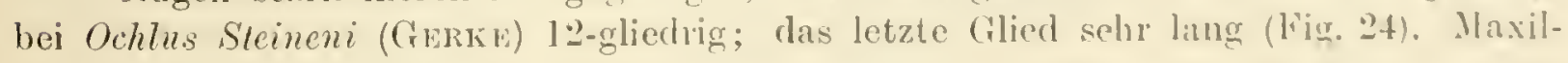
larpalpus (Fig. 25) 4-gliedrig.

Fligelmembran unbehaart; Rand pubeszient, hinten alternierend nit langen und kurzen Pubeszenzhaaren. $r_{1}$ an linde ungegabelt. aber im Findteil stark verdickt (Fig. 23). Radialramus (rr) cinfach, ron $\mathrm{r}_{2+3}$ keine spur crkenubar. Zelle li, breit. Media cinästig. Die Mediocubitalyuerader trifft die C'ubitalirabel (nalue den Basis) und die Nedia ein wenig distal ron der Radiomedianquerader. 1)ie Randaler geht ein Stück ïber das linde ron m hinwer. 


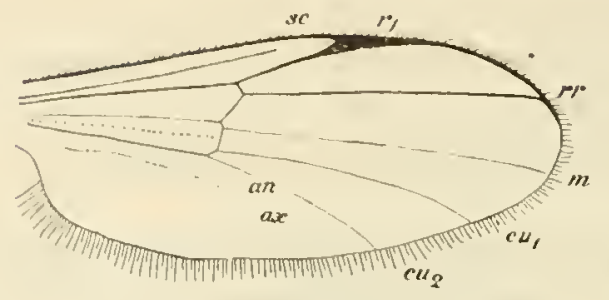

1Hig. 23. Ochlus uschuaiensis ENDERL. f. Fliigel. Vergr. 35: 1.

Die Gattung Ochlus unterseheidet sich von Protanypus KineF, 1906 dureh das Fehlen des vorderen Artes des Radialramus und durch die etwas auswärts von der Radiomedianquerader stehende Mediocubitalquerader. Sie stelıt der chilenisehen Gattung Podonomus PhiL. 1865 (mit den einzigen Art $P$. stigmaticus PhiL.) nahe, die aber nach der Diagnose und den Abbildungen nieht mehr als 7-8 Fïhlerglieder im weibliehen Gesehlecht hat; resp. nielit mehr als 9, wenn der Einwand KiefFer's (in: Wytsman, Gen. Ins.) bereehtigt sein sollte, dass das erste Glied übersehen worden ist.

In diese Gattung ist auch der T'anypus pilosus BIG., 1888 aus Fenerland und der Tanypus Steineni Gerke 1889 ans Siid-Georgien einzuordnen.

\section{Ochlus uschuaiensis nov. spee. - Textfig. 23-25.}

․ Kopf, Thorax und Abdomen schwarzbraun. Augen selıwarz. Fühler, Palpen, Beine und Halteren hell braungelb. Maxillarpalpen schlank (Fig. 25). Fühler 11gliedrig. Augen nierenförmig gekrümmt, am Selseitel breit getrennt. Fühler (Fig. 24)

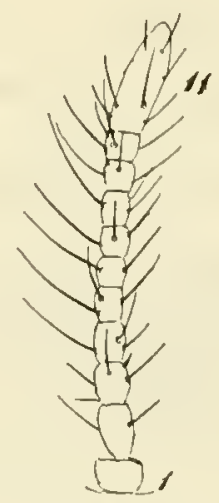

Fig. 24. Ochlus uschuaiensis ENDEHL. Fiiller. Vergr. 160:1

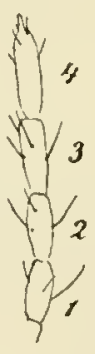

lig. 25. Ochlus uschuaiensis HNUERL. 우 Maxillarpalpus. Vergr. 160:1.

ungefähr doppelt so lang wie der Kopf; Behaarung lang und abstehend. Kopf ohne Pubeszenz. Thorax mit spärlieher kurzer Pubeszenz. Abdomen nur an der Spitze mit kurzer Pubeszenz. Beine schlank, kurz pubesziert, die Schenkel nur oben am Ende. Hintersehienen aussen mit einigen langen dümnen Borsten.

Die Hinterbeinglieder haben folgende Längen:

Halteren breit keulig. Flügel (Fig. 23) mässig breit; hyalin, Adern blass braun. Zelle $R_{1}$ sehr breit. rr völlig gerade. Die Randader geht $1 / 3$ der Entfernung zwischen rr und $m$ iiber $r r$ hinweg und erreicht nieht ganz die Flïgelspitze.

Fliigellänge $1,0 \mathrm{k} 11 \mathrm{~m}$.

Körperlänge $1,9 \mathrm{~mm}$. 
Fïhlerlänge $0,3 \mathrm{~mm}$.

liinge des Maxillarpalpus $0,2 \mathrm{~mm}$.

Fenerland. Uschuene. 11. Mär 1902. I f anf cinem ciletscher.

\section{Orhllls pilosils (Burs. lsss).}

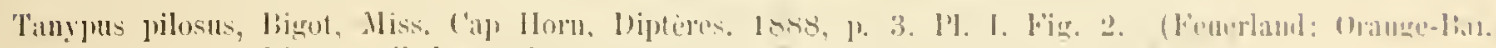

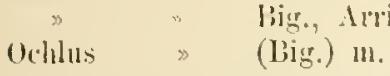

Diese Species scheint nach der Diagnose und besonders nach der Abbildung ebenfalls in die Gattung Ochlus zu gehören; sie unterscheidet sieh von O. uschunirmsis ENDERL. leicht dureh die viel sehmïlere \%elle $R_{1}$ und steht daher näher dem ()chlus Steineni (GERCKE) ron Süd-Georgien.

\section{Prororlulus nov, gen.}

\section{'Typus: l'. fuegiemus nor. spee. (lieuertand).}

Perochlus unterscheidet sich ron Ochlus dadurell, dass die Randader mit dem an der Spitze mïndenden Radialramms endet und nicht iiber ihn hinwegreicht.

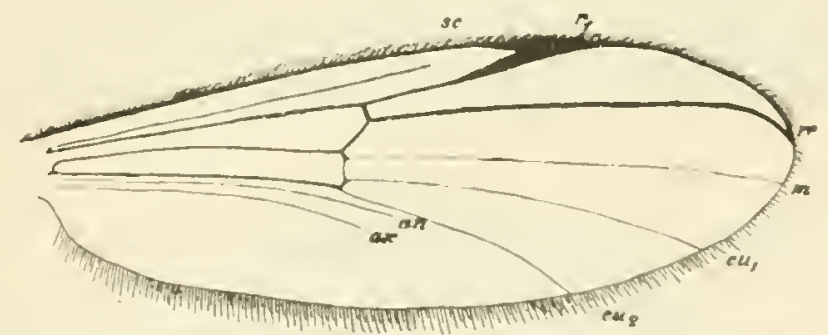

Fig. 26. l'arochlus juctirunus Exdirn. f. liligel. Vergr. 351.

P(1):0r/Mlls file!firllls nov. spec. - Textfig. 26, 27.

․ Der ganz Körper, Fïhler, Taster und Beine ziemlich hell braungelb. Fïhler mit zienlich langer Pubes\%enz (Fig. 27); 12-gliedrig. Kopf mpubesziert. Thorax mässig lang pubesziert. Abdomen ohne Pubeszenz, an der Spitze mit knrzer Puheszen\%. Beme ziemlieh schlank, mit ziemlich langer Puheszen\%.

Die Hinterbeinglieder haben folgende lä̈ngen:

Sehenkel 0,: mm. Sehiene $1,0,0 \mathrm{~mm}$, 1. 'Tarsenglied 0, mm, 2. Tarsenglied $0,3 \mathrm{~mm}, 3$. Tarsenglied $0,11 \mathrm{~mm}$, 4. Tarsenglied $0,06 \mathrm{~mm}$, 5. Tarsenglicd $0,19 \mathrm{~mm}$.

Haltere breit kenlig, brimulichgelb. Fligel (lig. 26) relativ schlank. Zelle $R_{1}$ mässig breit. r gelade, kurz vor den Aussenende stalk nach hinten nmgebogen und genau an bik. der Flïgelspitze mit dem Ende der Randader zusammentreffend. 
Fliigellänge $2,2 \mathrm{~mm}$.

Körperlänge $2,5 \mathrm{~mm}$.

Fiihlerlänge $0,5 \mathrm{~mm}$.

Feuerland. Uschuia. 11. März 1902. 1 q auf einem Gletseher.

Subfam. Clunioninae.

(KíkfFeli, Ann. Soc. Se. libuxelles. Tol. 30. 1906.)

.Jacobsiella Rü̉s. 1906.

Rübsamex, Rés. Yoy. S. Y. Belgica. Zool. Insectes. 1906. p. 83.

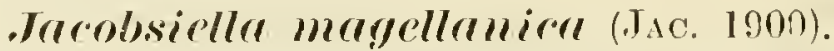

Belgica magellanica, Jacols, Ann. Soc. ent. Belg. T. 14. 1900, 1. 106. (Fenerlant, Magellanes, (hili.) Jacobsiella $\gg$ Jac.) Jacobs, Rés. Voy. S. Y. Belgica. \%ool. Inscetes. 1906, 1. 65.

(Jae.) Liïbsamen, Rés. Voy. S. Y. Belgica. Zool. Insectes. 1906, 1. 83. 'Taf. IV. Fïg. 1 1. 3. Taf. V. Fig. 3.

\section{Fam. Rhyphidae.}

\section{Rllypleles Latr. 1804.}

Rh!nhums fusripemis Maco. 1838.

lihyplus fuscipenus, Macunart, Diptères exotiques. Tom. 1. Part. I. 1838, p. 80. Tab. Xf, Fig. 2.

Macr., Blanchard, in Gay, Ilist. de Chile, \%ool. VHI. I852, P. 352.

Mact., Philiuni, Yerl. Zonl. bot. Ges. Wier. XV. 1865, 1. 633.

Maeq., Bigot, Jiss. Cap Horn, Diptères. 1888, p. 11. (Feuerland: Orange-l’ai.)

\section{Fam. Bibionidae.}

Subfam. Bibioninae.

Dilopluls MEIG. 1803.

Dilophous voldiviamus Pнin. 1865.

Dilophus valdivianus, l'hilipu, Verls. Zool. But. Ges. Wien. XV. 1865, 1. 636. (Chile: Valdivia.) Phil., Jacolıs, liés. Yoy. Belgiea. Zool. Ins. 1906, p. 67. (Staaten-Inselı.)

\section{Dilopllus migloipes Beanch. 1852.}

bilophus nigrines, Blanchard, in Gay, Hist. de Chile. Zool. V11. Mipt. 1852, p. 354. Chile.)

Bian'l., I'hilipui, Verl. Zool. bot. Ges. Wien. XY. $18655_{2}$ p. 635.

Blanch., Bigot, Miss. Caj Hon. Diptères. 1888, 1. 17. (Fenerland: Orange-lBai.)

Aremthormemis Beanch. 1852.

Ibusculan1, in Gay, Hist. de Chile. Zool. 171. Mipt. 1852, 1. 355.

Die Vorderschiene hat hier vor dem mittleren Dornenkamm anssen nahe der Basis noch 2 Dornen neben einander (selten - und zwar bei einer Art - nur einen) und so izt diese Gattung meines Erachtens neben Dilophus zu halten.

Arentleornemis renstamibes Bra. 1888.

Acanthoenemis castanipes, Bigot, Miss. Cap Hom, Hiptìes. 1888, 1\% 17. (Feuerlanl: Orange-Bai.) 1)ilophus

(Big.), liertesz, Cat. Dipt. 1. 1902 , p. 150. 


\section{Falı. Mycetophilidae. \\ Subfam. Mycetophilinae.

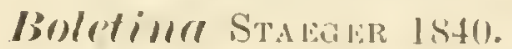

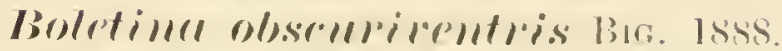

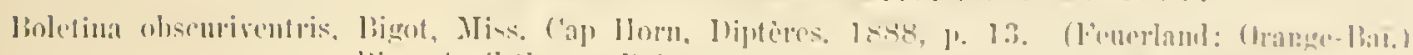

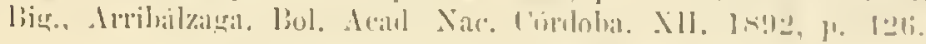

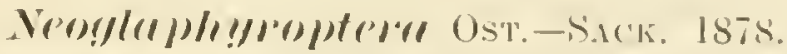

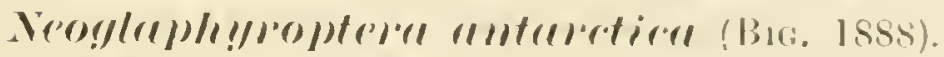

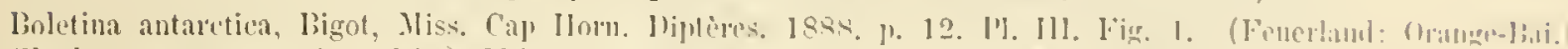

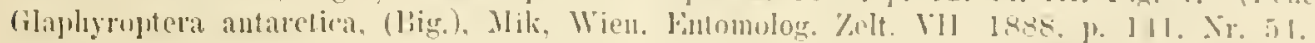

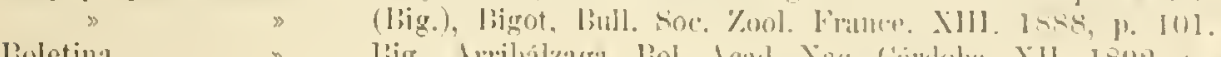

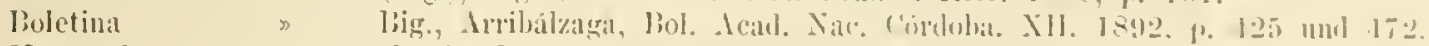

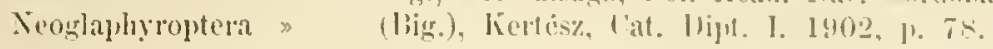

\section{Sublan. Sciophilinae.}

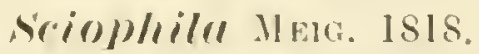

scioplrill rllilensis Braxcir. 1852.

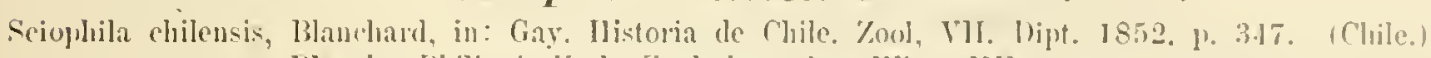
" $\Rightarrow$

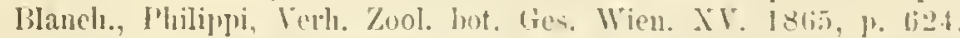

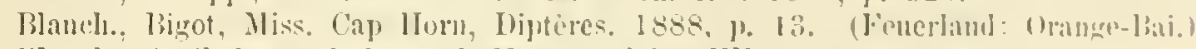

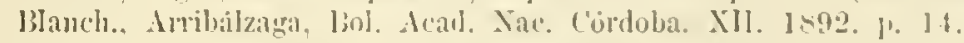

\section{Srinpllill tristis Big. 1888.}

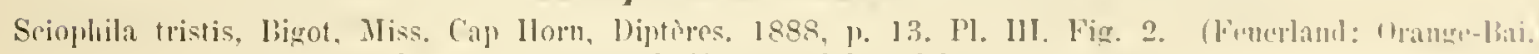

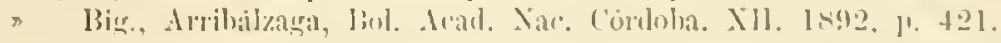

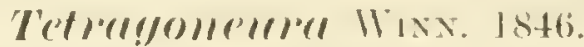

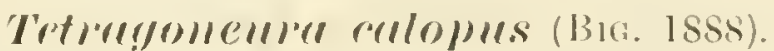

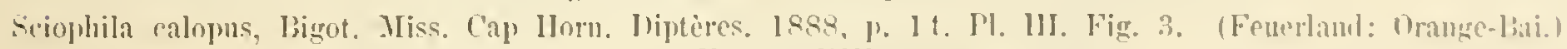

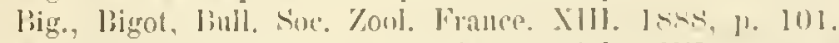

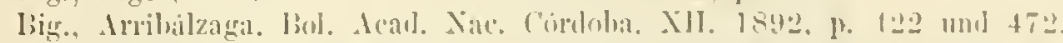

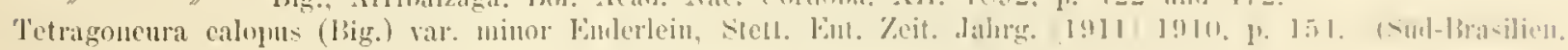
Santa (atlarina.)

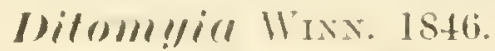

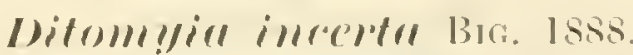

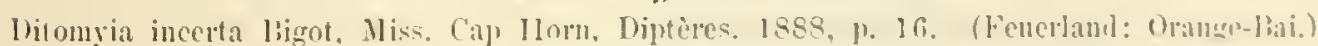
lige., Arribilzaga, liol. Aral. Nace. C'ordoba. Xll 1s!12. 11. 13\%.

Orilo: Rhynchota.

Suborlo: Heteroptera.

Fin. Pentatomidae.

Subfam. Acanthosominae.

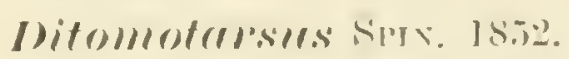

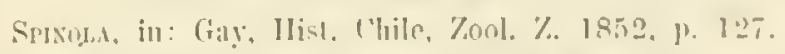

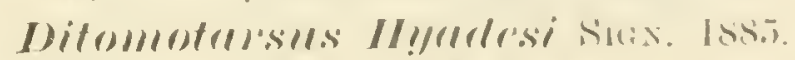

Ditomotarsus Ilyadeci, Signoret, Ann. Soc. lint. I'rane. 188.5. p. a.t.

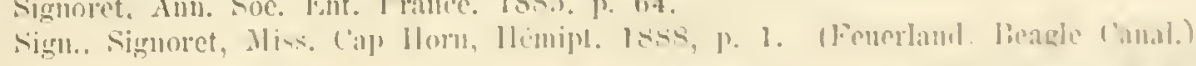

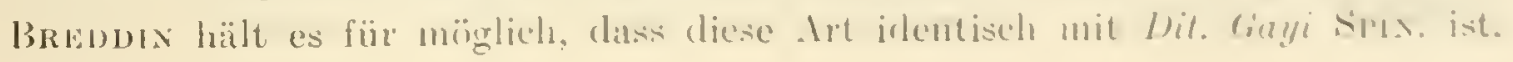




\section{Ditomotarsms Gami SpIn. 1852.}

Ditomotarsus Gayi, Spinola, in Gay, Ilist. de Chile. Zool. VII. 1852, p. 127. Ian. 1. Fig. S. (Chile.) punetiventris. Blanchard, in Gay, Ilist. de Clile. Zool. VII. 1852, 1. 129. lam. 1. lig. 9.

liuscolıa sanguiniventris, Stål, Öf. Kongl. Yet. Akat. Förl. 1858. p. 436.

Stål, Walker, Cat. IIemipt. IJeteropt. III. 1868, 1. 575.

litumotarsus Gayi Spin., Signoret, Ann. Soc. France. 4. IIl. 1863, p. 549.

Spin., Stål, Öfv. Kiongl. Yet. Akad. Fürls. 1867, p. 534.

Spin., Walker, Cat. Henipt. Heteropt. III. 1868, p. 574.

Spin., Stål, Enum. Ilemipt. II. 1872, p. 63.

Spin., Berg, Addenla et Em. ad IIemipt. Arg. 1884, 1. 18\%.

Spin., Breddin, Hamb. Magall. Sammelr. Henipteren. 1897, 1.4 1. 25. (Fenerland: Lschuaia, Stad-I'atagonien.)

Spin., Itaglund, Srenslia Fxpedit. till Magellansl. II. No. 9. 1899. 1. 174.

Fam. Lygaeidae.

Subfam. Lygaeinae.

Nysims DaLL. 1852.

N!ssius imoreates (SPIN. 1852).

Heterogaster irroratus, Spinola, in Gay, ITist. de ('hile, Zool. VIl. 1852, p. 154. (Chile.)

Nysius (Spin., Signoret, Ann. Soc. Ent. France. 1863, 1. 164.

Spin., Walker, Cat. IIemipt. Ileteropt. V. 1872, p. 68.

Spin., Stål, Eumm. Ilem. IV. 1872, 1) 122.

Spin., Berg, Ann. Mus. Nac. Buen. Aires. IV. 1895, p. 198.

Spin., Breddin, IIamb. Magalh. Sammelr. Hemipteren. 1897, 1. 27. (Chile u. Fenerland.)

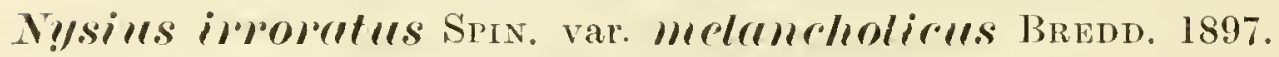

Nysius irroratus, Spiu. rar. melancholicus, Breddin, IIamh. Magalh. Sammelr. Hemipteren. 1897, 1. 5 u. 27. (Fenerlant: Uschuaia.)

\section{Nysius puberulus BERG 1895.}

Nysins puberulus, Berg, Ann. Mns. Nac. Buenos Aires. IV. 1895, p. 197. (Fenerland.)

lierg, Breddin, Hanb. Magall. Sammelr. Ilemipteren. 1897, ю. 27.

\section{Subfam. 'Cyminae.}

Ischmorh?mchus Fiев. 1861.

\section{Ischmorliymchus Ingalimutus (SPIn. 1852).}

Pachỵmerns lyyalinatus, Spinola, in Gay, Iist. de Chile, Zool. VII. 1852, p. 148. T. I. Fig. If. (Cyile.) poecilus, Spinola, in Gay, Hist. de Chile, Zool. VII. 1852, p. 149. 'Taf. 1. Fig. 15.

Rhyparochromus hyalinatus (Spin.), Walker, Cat. Hemipt. Heteropt. Y. 1872, 1. 91. poecilus (Spin.), Wallier, Cat. Hemipt. Heteropt. T. 1872, p. 91.

I'acluymerus hyalinatus, Spin., Signoret, Ann. Soc. Ent. France. 1863, p. 563. poecilus, Spin., Signoret, Ann. Soe. Ent. France. 1863, p. 563. (Varietät.)

Kileidocerus $\gg$ (Spin.), Signoret, Ann. Soc. Ent. France. 1855, p. 67.

Clidocerus „ (Spin.), Signoret, Miss. Cap Ilorn, Tl. Ilémipteres. 1888, p. 5. (Feuerland: Orange-Bai.) lyyalinatus, (Spin.), Berg, Ann. Mus. Nac. Buen. Aires. IV. 1895. 1. 196.

lschuorhynchus » (Spin.), J3erg, Ann. Mus. Nac. linen. Aires. 1896, p. 132.

Spin., Breddin, IIamb. Magall. Sammelr. ILeminteren. 1897, 1. 6 и. 27. Fig. 1. (Isl. Navarin, I'uerto Toro.)

Feuerland. Uschuaic. I Exemplar. März 1902 im Walde. 


\title{
Subfam. Pachymerinae.
}

\section{Beregirlia Branur. IS97.}

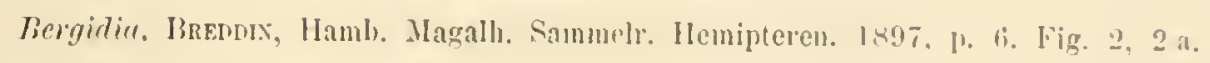

\section{Bergidia pol!grhmomme (SPIN. ISñ2).}

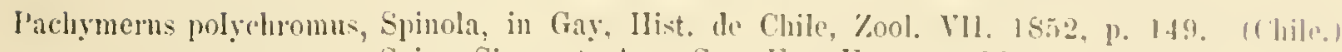 \\ spin., Signoret, Ann. Soc. Ent. France. 188:3. 1\%. \\ $\Rightarrow \quad$ Spiu., Stâl, Enum. IIemipt. 1871. 11. 1. 169. \\ Rhyparochromus " Spin., Walker, Cat. IIemipl. IIeternil. V. 1872. 1. !)1. \\ Pamera polychroma. Sinin., Berg, Aum. Sue. ('ient. Arg. Xil. 18s1, 1). 261. \\ Spin.. Berg, Ald. et Fim. ad. Ilen. Argent. 1881, 1) 56 (Larre.) \\ Spin., Berg. Am. Mus. Xac. 13uen. Iiros. IV. 1895, 1). 199.

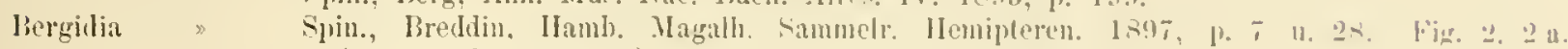 \\ (Feuerland: Uschuaia.)
}

\section{Subfam. Heterogastrinae.}

\section{Irliostolus B ERG 1884 .}

Idiostolus, BERG, Adu. et lim. Ilemipt. Argent. Isst, 1. 201.

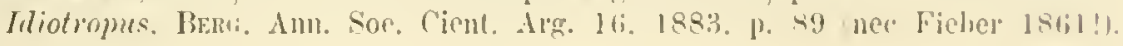

\section{Irlinstolus insmlen is Btag 1583.}

Idiotropus insularis. Berg, Ann. Soc. Cient. Argent. 16. 1-83, 1\%. 87.

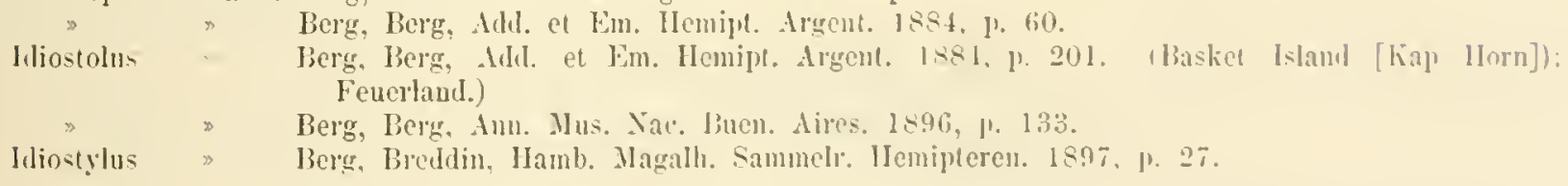

\section{Fam. Reduviidae.}

Subfam. Nabinae.

Nabis Latr. 1807.

\section{Nebis fomimei stal 18.59.}

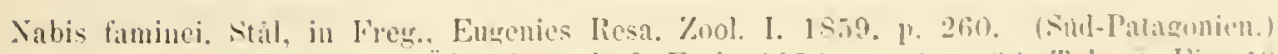

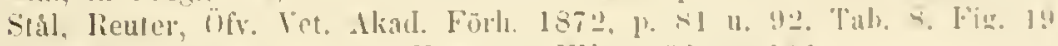

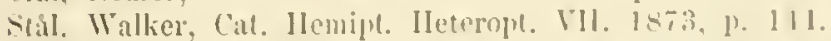

Stal, Signotel, Anu. Soc. Ent. France. 1s8a, J. (is. (thile.)

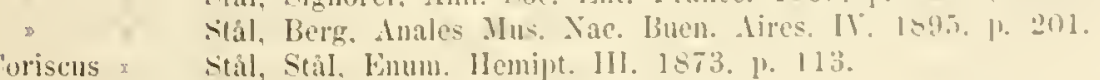

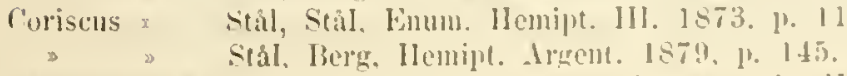

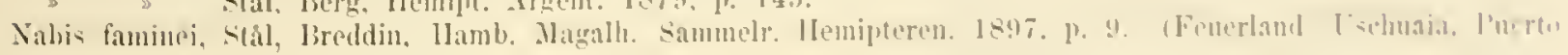
Bridges.)

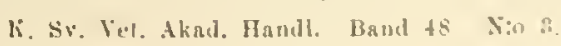


Fan. Aradidae.

Subfam. Isoderminae.

(STiL. Enumer. Tol. III. 1). 147.)

IsorlevmIrs ERICHS. 1842.

Isodermms ERICHON, Ach. VIII. 1842, p. 281.

Andmomichon Splxou, in Gay, llist. Chile. Zool. V1l. 1852, 1. 214.

(Typus: 1. planus Erichs. 1842, Tasmanien.)

Isodermus Gulfi (Srix. 1852). (Taf. 3, Tig. 39.)

Anchomichon Gayi, Spinola, llist. de Chile. Zool. V'11. 1852. 1. 2216. Pl. I. Fig. 14. (Chile.) Spin., Signoret, Ann. Soc. Ent. Franee. 1863, 1. 577.

Mezira(?) patagoniea, Stål, Fregg. Eugenies Iiesa. Zool. I. 185?, 1) 260 (aneh die Larve).

Stål, Walker, Cat. Ilemipt. Ileteropt. WII. I873, p. 24.

Brachrornychus Gayi, (Spin.). Walker, Cat. IIemipt. Ileteropt. VI. 1873, 1). 9.

Isorlermus patagonieus, Stål, Fum. Henipt. Vol. 11. 1873, p. It7. (I'atagonien.)

Gayi. (Spin.), Stål, Enmm. Ilemipt. III. 187:, 1). 147.

Spin., Berg, IIem. Argent. 1879, 1. 140.

Spin., Signoret, Amn. Soc. Ent. France. 1885, p. 65.

spin.. Berg, Anu. Mus. Nac. Buenos Aires. IV. 1896, p. 134.

* (Spin.), Signoret, Hiss. Cap llor'u, T1. llemint. 1888, p. 3. (Fenerland: Orange-Jai.)

Spin., Breddin, Hanb. Magall. Sammeh. Hemipteren. 1897, p. 8 и. 29. Fig. 3. (Fenerland: Uschuaia, Sür-Patagonien.)

Es liegen ror:

Feuerland. Uschuaia. Im Wald. März 1902. 3 Exemplare.

Fam. Henicocephalidae.

Henirorephalus Wrstw. 1837.

\section{Henicocephalus subuntarticus Berg 1884.}

Henieocephalus snbantarctiens, Berg, Addenda et Em. ad. Hen. Argent. 188.1. 1). 115. (Fenerland: Staaten-Insel.) l'erg, liergroth, Revue d'Entom. Caen. 1889, p. 319.

Berg, Uhler, Trans. Maryl. Acad. Science. 1891, p. 180.

$(?)$

Berg, Karseh, Berlin. Ent. Zeitsehr. 1892, p. 486.

Berg, Breldin, Hanb. Hagalh. Sammelr. Heminteren. 1897, 1. 8 и. 29. (Fencrland: Puerto Pantalon.)

Bei dieser Gelegenheit will ich erwähnen, dass die Gattung Systelloderus Bu-1xcH. 1852 mit der einzigen Art: S. moschatus BLANCI. 1852 aus Chile nicht mit Henicocephalus zusammengezogen werden kann. sondern eine ausgesprochene Gattung darstellt, die durch Körper- und Kopfform und besonders durch das Geäder isoliert steht. Über die Berechtigung der Henicocephaliden-Gattung Phthirocoris ENDERL. 1904 mit der Species H. antarclicus ENDERL. 1904 von den Crozet-Inseln vergl. ENDnRLEIs, Die Insekten der Antarktis; Dentseh. Südp. Exp. Bd X. Zool. II. 1908, p. 403. Taf. 54. Fig. 163-166. Textfig. O-R. 
Fam. Peloridiidae.

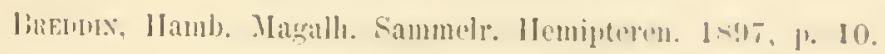

Premeillillll BREDH. IS!97.

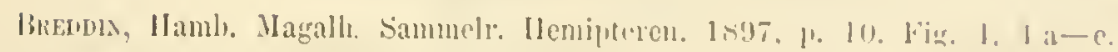

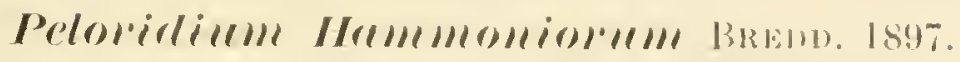

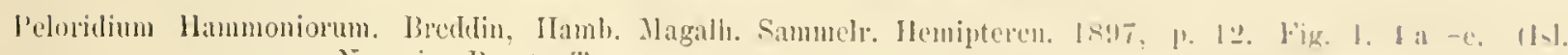
Nararin. l'nerto 'oro.)

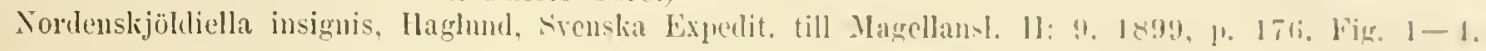

\section{Fan. Corixidae.}

\section{Livemmonstrifl nor. gen.}

Typus E. quadrata (SIGN. IS85).

Im Basaldrittel der Vorderfliigel tritt der Vorderrand gegen den iibrigen Rand ein ziemlich breites Stiick zuriick, so dass der iibrige Vorderrand ziemlich steil gegen das Basaldrittel abfällt ('Textfigur' 28).

Schläfenstrcifen hinten den Augen breit. IIembran vorn Corium nieht abgesetzt, lederartig wic dieses. Pronotum quergefurcht; Pronotum und Flïgeldecken gerastert. Vorderfliigel mit sehr feinen, langen, abstehenden Haaren wenig dicht besetzt.

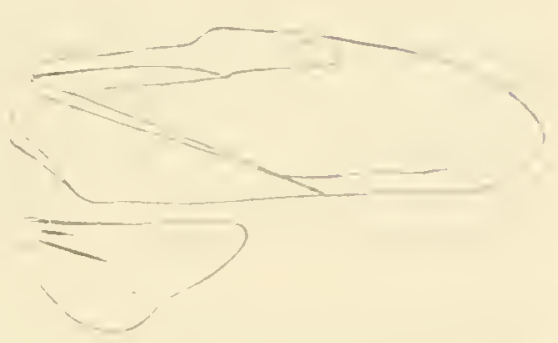

Hinterfliigel stark verkürzt.

1. Fühler 3-gliedrig. Schildchen ron den Flïgeln nicht verdeckt (von oben sichtbar in "3-eekiger Gestalt). . . (Subfam. Sigarinae m) Sigara F.

(Typus: S. minutissima L.)

Fiihler 4-gliedrig. Sehildehen von den Fliigehn rerdeckt (von oben nicht sichtbar).

(Subfam. Corixinae m) 2.

2. Vorderrand der Vorderfligel dicht einwärts von der Querader der Subeostalzelle mit cinem grossen höckerartigere Absat\%, so dass eine ziemlieh breite Zone des Vorderrandes wie herausgeschnitten ersehcint. - Membran von Corium nicht abgesetzt, lederartig wic letzteres. Sudnlïfenstreifen hinter den Angen breit. (Pronotum quergefureht; Pronotum und Fligeldecken werastert.

Ectemnostega nor. gen.

Typus: R. quadratu (Sllis. 1855.) 
Vorderrand der Vorderflïgel geradlinig (olme Absatz).

3. Schläfenstreifen hinter den Augen breit bis sehr breit Subcosta in die Querader selbst nahe seines Ausgangspunktes vom Radius miindend. (Pronotum ohne Querzeichnung;) undeutlich gerastert

Schläfenstreifen linter den Angen äusserst 3. schmal. (Subeosta in den Ausgangspunkt der Querader vom Radius mündend, im Endteil zuweilen undeutlich; Pronotum mit Querzeichnung.) 4.

4. Pronotum in der ganzen Länge (oder fast in der ganzen Länge) mit deutlichem medianem Längskiel. (Pronotum stark verlängert.) . .

Pronotum nur vorn mit kurzem medianem

Längskiel. Pronotum wenig verlängert. . . 5.

5. Pronotum und Vorderflïgel nicht rastriert. Dic Männchen (im Gegensatz zu allen ïbrigen, die es rechterseits sind) linkerseits asymmetriseh. (Subcosta im Endtest Indentlich.) . . . . .

Pronotum und Vorderflïgel mehr oder weniger rastriert. (Subcosta im Endtest dentlich.) . . Corixa GEoFfr. 6.

6. Männehen mit Striegel (ein am Hinterrande der Oberseite des 6 . Abdominalsegment befindliche anf kurzem Stiel befestigtes gezälntes Plättchen - of. White, Entom. Monthl. Mag. X, 18, p. 60). (Grundglied der Hintertarsen an seinem Ende blass.). . . . . . . . Subgen. Corixa Geofrr. Männchen ohne Striegel. (Grundglied der Hintertarsen an seinem Ende schwarz.) . . . . Subgen. Callicorixa White.

Ectemmostegr qundlutu (Sign. 1885). - Taf. 3, Fig. 38; 'Textfig. 28.

Corixa quadrata, Sigu., Signoret, Ann. Soc. Ent. Fr. 1885, 1. 68. (Magall. Str.)

Sign., Signoret, Miss. Cap IIorn, Ilemipt. 1888, 1. 6. (Feuerland: Orange-Bai.

Sign.. Berg, Anales Mus. Nac. Bnen. Aires. IV. 1895, 1. 196.

Sigu., Breddin, Hamb. Magalh. Sammelr. Henipt. 1897, p. 13. Tat. 30. Fig. 5, 5 a-r. (Feuerland: Uschuaia. Süd-Patagonien.)

Éctemuostega (Sign.) m.

Feuerland, Halbinsel südwestlich von Uschnaia. - 3. 10. 1902, 12 Exemplare - in 2 Siisswasserteichen, von denen der eine völlig, der andere nur teilweise mit Eis ïberzogen war.

$1(=$ areinocorixe ]3. Whits). 


\title{
Fam. Capsidae. \\ Subfam. Phytocorinae. \\ Miris li, 1803. \\ Mivis Dollllli S'ril, 1859.
}

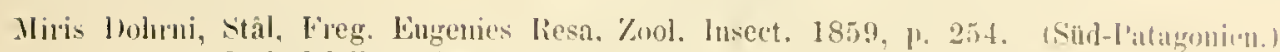

Stål, Walker, Catal. Hemint. Ieterojt. 11. I-73, ए. 53.

stål, Berg, Hemipt. Argent. 1. 187!, 1) 118.

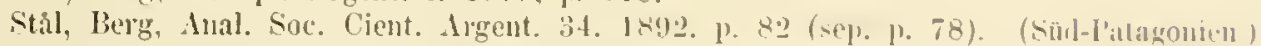

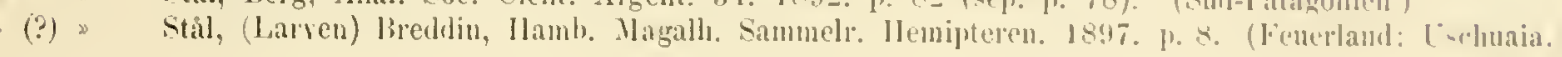

\section{Subfam. Lopinae. \\ Restlenill Sp1s. 1840. \\ Resthenie fllegirmen BERG 1895.}

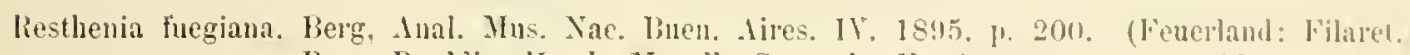

Berg, Breddin, Ilamb, Magallı. Sammelı. Ilemiptereנ, 1х97. I. 28.

\author{
Subordo: Auchenorhyncha. \\ Homoptera. \\ Fam. Jassidae. \\ Subfam. Bythoscopinae. \\ Alyallill CURT. 1833. \\ Algullia insuluris Bera 1854.
}

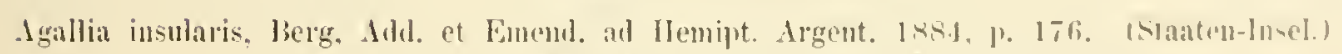

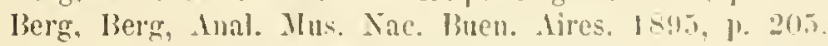

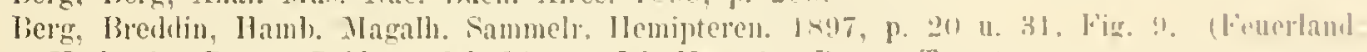
Usedmaia; Puerto Bridges; Isl. l'icton: Isl. Navariu: I'ueren Toro.l

\section{Subfam. Gyponinae.}

Teroplleloen Geru. 1839.

Nempleloe"e rividis (F. 1794).

Cercopis viridis, Fabricius, lintom. Nyst. 11. 17!9. P. 50. (West-Indien.)

F, Fabricius, Syst. Rilyzur. 1803, 1. 91.

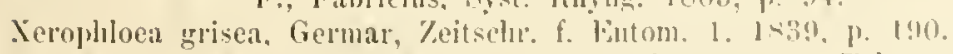

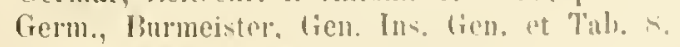

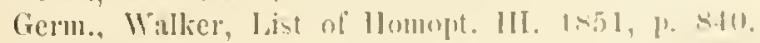

lierm., Stål, lío Inucipo. Ilemipt. Il. Isti1. 1. ill.

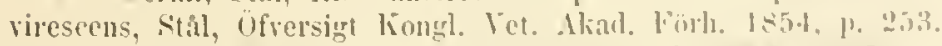

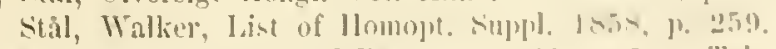

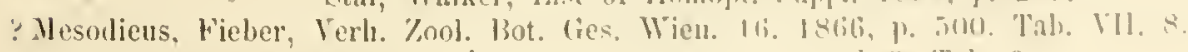

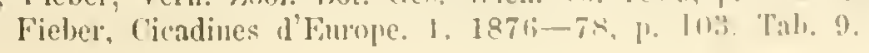


Terophloca viridis, Stat, Hemipt. Fabriciana. 1. 1869, 1. 59.

Stil, Herg, Hemipt. Argent. I. 1879 , p. 257.

Stíl, Berg, Anal. Soc. Cient. Argent. 12. 1881, 1. 267.

stâl, Jierg, Anal. IJus. Nac. Bnen. Lires. 18!5, 1\%.202.

Stal, Brendin, Hanh, Magalh. Sammeln. Hemipt. 1897, 1. 31. (Brasilien, Truguar, Algentinien, Chile, Sül-Jatagonien. Fenerland: Filaret.)

\section{Subfan. Jassinae. \\ At/!!sull/s Burn. 1838. \\ Ath!somus fill)etullls BERG 1895.}

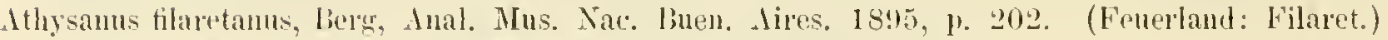

Rerg, Anal. Mns. Nac. Bnen. Aires. 1896, 11. 135.

Berg, Bredhin, Hamh. Magalh. Sammelr. Hemipteren. 1897, p. 32.

Deltoreplerelus Burir. 1838.

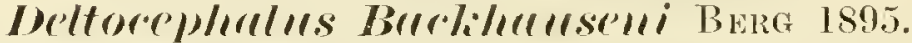

Deltoeephalus Backhanseni, Berg, Anal. Mus. Nae. Buen. Aires. 1895, 1), 209. Fig. 1. Fenerland: Filaret.

lierg, Breddin, Hamb. Magalh. Sanmehr. Hemipteren. 1897, 1. 32.

\section{Ineltoreplenlus fromimei STÅL 1859.}

Jassu (Deltocephalus) liminei, Stål, in Freg. Eugenies Riesa. Ins. 1859, p. 293.

l)eltocephalus faminci, Stål, Berg, Anal. Soc. Cient. Irgent. 1879, 1. 266.

Stål, Berg, Hemipt. Argent. J. 1879, 1. 270.

Stăl, Berq, Aual. Nus. Nac. Buen. Aires. 18!66. 1. 13 i.

Stảl, Breddin, IIamb. Magalh. Sammelı. Hemipteren. 1897, 1. 32. (Chile, Siid-l'atagonien, Fenerlant.

\section{Subfam. Typhlocybinae. \\ T!лl/locyly, Gers. 1833. \\ T!mbluorybu ful!gilull BERG 1895.}

'Typhloryba fulgidula, Berg, Inal. Mus. Nac. Buen. Aires. 1895, 1. 205. Fenerland: Filaret.)

Lerg, Breddin, Hamb. Magalh. Sammelr. Henipteren. 1897, p. 32.

Fam. Aphidae.

Myj:Ils Passerini 1860.

MyะUs Mirdecelseni Schoutr. 1904.

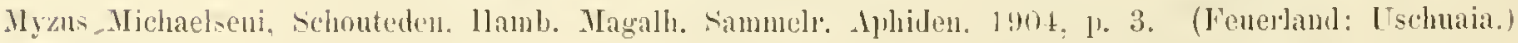

Rleoprelosiplen!ll Kocir 1854.

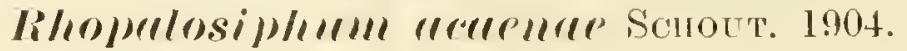

lihopalosiphum acaenae, Schouteslen, Hamb. Magalh. Sammelr. Iphiden. I904, 1. 4. Fenerland: Lischnaia.) 
Ordo: Odonata.

Fan. Aeschnidae.

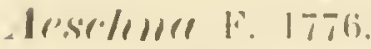

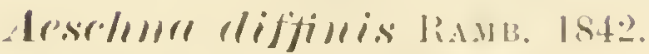

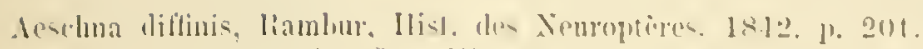

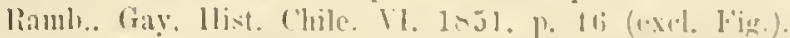

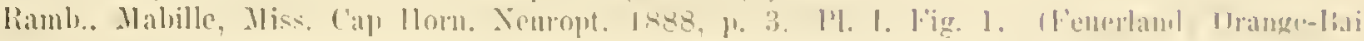
II. (ischuaii.)

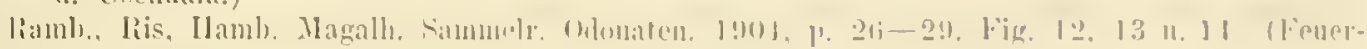
lane, l'atagonien, l'hila. l'arm.)

var. Risi nor.

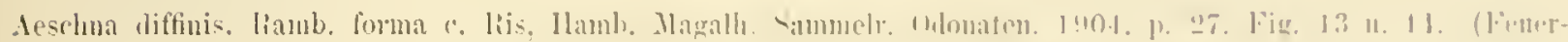
land, Süd-Patagnnien.

Diese dureh ihr viel dichter netzmaschiges Ceäden ron der A. diffinis ausgezeichnete Form ist zumindest als besondere Form zu fühen: es will mir sogar scheinen. dass die reeht wesentlichen morphologisehen Differenzen zu eiuer Abtrennung als besondere Art genügen können.

\section{Ordo: Trichoptera. \\ Fam. Limnophilidae.

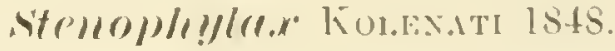 \\ stemol)}

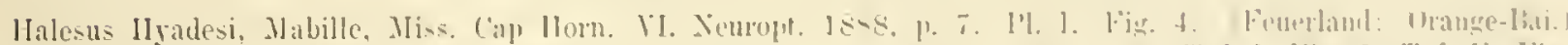

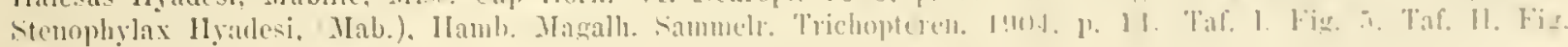

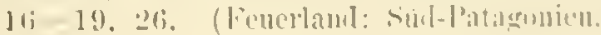

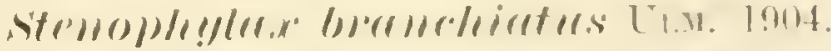

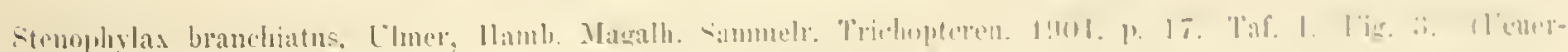

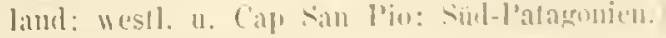

\section{strmol)}

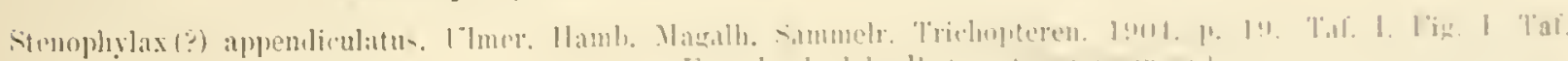

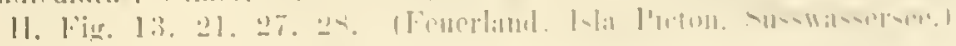

(ve)

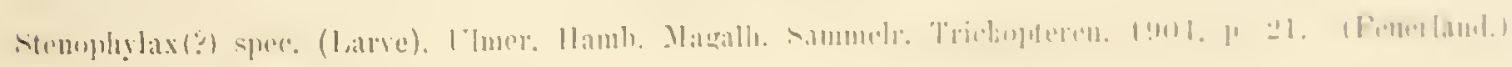

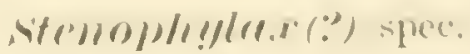

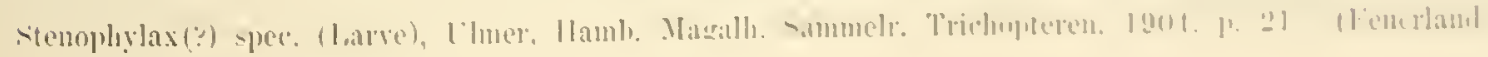




\section{Limmophills Leach. 1815. \\ Limllollills Michrelsen; Una. 1904.}

Limnophilus Michaelseni, Ulmer, Hamb. Magalh. Sammelr. Trichoptera. 1904, p. 7. Taf. II. Fig. 8-12. (Feuerland: Harberton Harbonr; Sür-Patagonien: Punta-Arenas.)

Allabolia Sтерн. 1835.

Anabolia spimosa Ulat. 1904.

Anabolia spinosa, Ulmer, Hamb. Magall. Sammelr. Trichoptera. 1904, 1. 11. Taf. I. Fig. 2. 'Taf. II. Fig. 20, 22. (Fencrland: 'Tschuaia. Harberton Harbour; Süd-Patagonien.)

\section{Ordo: Plecoptera.}

Subordo: Holognatha.

(Experiesix, Zool. Anz. 34. ThI. 1909, 1. 386.)

Fam. Gripopterygidae.

(ExDEMLEN, Zool. Anz. 34. Bd. 1909, 1) 388.)

Subfam. Antarctoperlinae.

(Finelileix, Zool. Inz. 34. I3t. 1909, p. 392.)

\section{Bestimmungstabelle der Antarctoperlinen-Gattmoen.}

1. Cerei lang, vielgliedrig (30- oder melır-gliedrig). . 2.

Cerci sehr kurz, den Hinterleib wenig äberragend, mit wenigen Gliedern (bei den beliannten Arten 7-8-gliedrig. Cubitus 1 im Hinterfliigel mit kurzer Gabel. Von der basalen Analzelle geht im Vorderflügel linten eine gegabelte Axillaris aus, dessen vorderer Art keine Querader naeh der Analis entsendet. (Erste Cubitalzelle im Hinterfliigel nur mit 1-2, resp. 4 Queradern.)

Antarctoperla ENDERL. 1905.

[Typus: A. Anderssomi EnderL. 1905. Feuerland.]

2. Erste Cubitalzelle im Hinterflïgel nur mit einer Querader. Von der basalen Analzelle im Vorderflügel geht hinten eine gegabelte Axillaris aus, deren vorderer Art eine Querader nach der Analis entsendet. Cubitus $1 \mathrm{im}$ Hinterflügel ungegabelt. . . . . . 3.

Erste Cubitalzelle im Hinterfliigel mit zahlreiehen Queradern (ea. 6-10). 4. 
3. Cerei fast doppelt so lang wie der ganze liörper. Leptoperla NEws. 1834.

Cerei viel kïrzer als der ganze Köpler. Paranotoperla livwlis. 1909.

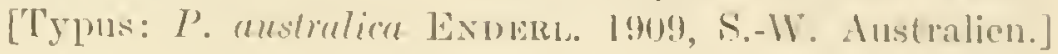

4. Von der basalen Analzelle in Torderflügel scht linten eine gegabelte Axillaris ans, deren vorderer Ast keine Queradern nach der Analis entsendet.

Erster Cubitus im Hinterfligel mit kurzer Gabel. Notoperla livulsı. 1909.

[Typus: $\mathrm{Y}$. fuegiume lisulias. 1905, Feuerland.]

Von der basalen Analzelle im Vorderfliggel gelit hinten eine gegabelte Axillaris aus, deren vorderer Ast eine Querader nach der Analis entsenclet. Erster C'ubitus im Hinterfliigel olme Gabel.

Aucklandobius ExinERI. 1909.

[Typus: A. complementurins Exwlert. 190!), Auckland-Inseln.]

Alutriratoperla ENDERL. 1905.

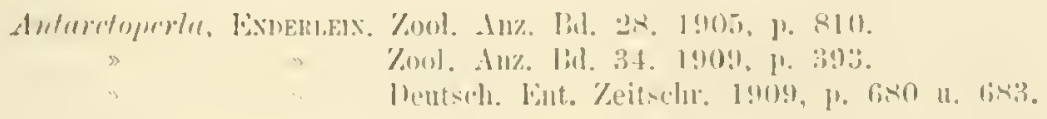

Radialramus im Vorder- und Hinterflïgel ungegabelt. I. Cubitalast im Vorderfliigel nugegabelt, nur einige Queradem hinter ilm, im Hinterfliigel kur\% gegabelt oder ungegabelt. Vor dem Vedianstamm des Vorderfliigels keine Querader. Cubitalzelle $\left(\mathrm{Cl}_{1}\right)$ in Hinterflïgel mit einer oder melı Queradern. Cerei schu kur, mit. wenigen Gliedern (bei den bekannten Arten sieben-bis aeht-gliedrig). Cubitus 1 im Hinterfliigel mit kurzer Gabel. Ton der basalen Analzelle geht im Vorderfligel hinten eine gegabelte Axillaris ans, deren vorderer Ast keine Qnerader nacli der Analis cntsendet. Erste Cubitalzelle in Hinterflïgel nur 1-2, resp. 4. Queradern.

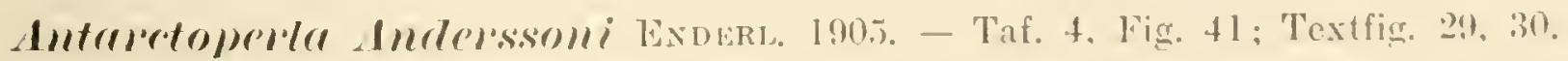

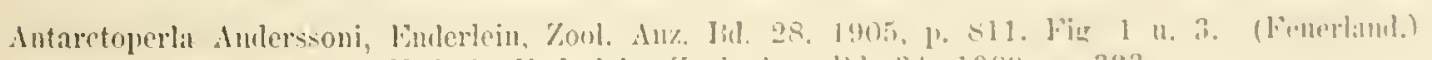

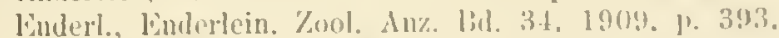

Euderl., Vinderlein, Dentsche Hnt. Zaitsch. 1!10!. 1. lis3.

Körper sehlank. Rotbraun, Pronotum dunkelhraun, ebenso der Kiopf oben. Heso- und Metanotum schwarz mel poliert glatt. Die Fiiller dunkel rolbram. Cerci braun, kur\%, 7-gliedrig. Naxillartaster dunkelbram, 1. Clied rotbrann: 1. Glied so lang wie diek: Verhältnis der Glieder etwa $1: 3: 2: 4$. Beine gelblieh brams: Sechenlicl

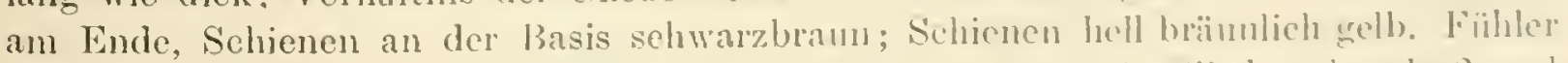
lang, borstenförmig; 2. Glied $1^{13} / 2$ mal so lang wie breit. 2. (ilied mehn als 2 mill so lang, 3. so lang wie breit. Verhältnis der Vordertarsenglieder $4: 1$ : sª, der llittel-

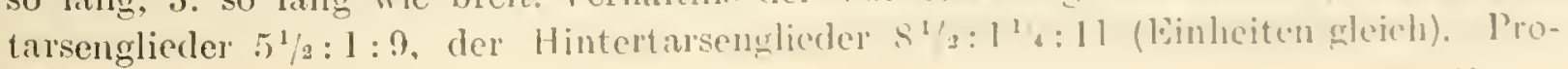

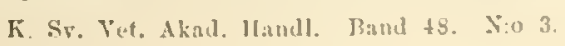


notum wenig breiter wie lang, Seiten kaum merklich nach vorn konvergierend, Vorderund Hinterrand nach voln, resp. naeh hinten vorgewölbt; ohne Medianlinie. Cerci sehr kurz, nur 7-gliedrig. Flügel braun, sämtliche Queradern, an vielen Stellen auch die Längsadern hyalin gesïumt; Vorderrandzone beider Flïgel mit rötlichvioletter Färbung gemischt. Pterostigma ohne Queradern, Queradern im Vorderflïgel zahlreich, im Hinterflïgel spärlich; im Vorderflügel: zwischen $r_{1}$ und $r_{2-5}: 3$, zwischen $r_{2-5}$ und $m_{1}: 5$, zwischen $m_{1}$ und $m_{2}: 5-6$, zwischen $m_{2}$ resp. $m$ und $\mathrm{en}_{1}: 12$, zwisehen $\mathrm{eu}_{1}$ und $\mathrm{Cu}_{2}$ resp. Flïgelrand 12 (davon 5 nach dem Flïgehand); im Hinterfliigel: zwischen $r_{1}$ ind $r_{2-5}: 2$, zwischen $r_{2-5}$ und $m_{1}: 2$, zwischen $m_{1}$ und $m_{2}: 1$, zwischen $e_{1}$ und $e u_{2}: 2$, von denen die äussere im linken Hinterflïgel fehlt.

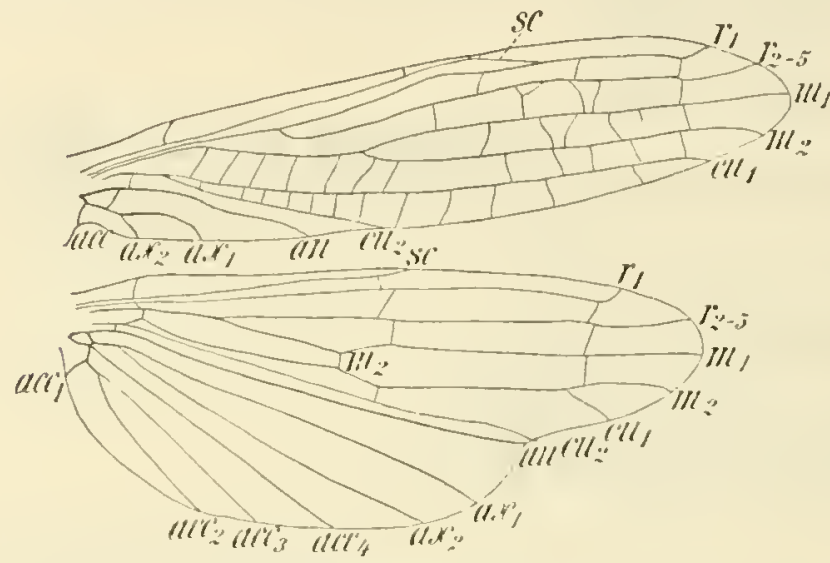

Fig. 29. Antarcloperla Anderssoni EnDERL. 1905. ㅇ. Flügelgeäder. Vergr. 4: 1.

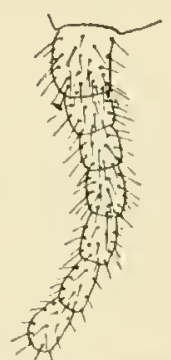

Fig. 30. Anturctoperla Andersoni ENDERL. Rechter Cercus. Vergr. $50: 1$.

Körperlänge $12 \mathrm{~mm}$. Länge des Hinterleibes $6^{1 / 2} \mathrm{~mm}$. Vorderflïgellänge $13^{\mathrm{I}} / 4$ $\mathrm{mm}$. Länge der Cerci $0,7 \mathrm{~mm}$. Fühlerlänge $9^{1} / 2 \mathrm{~mm}$.

Süd-Feuerland. Uschuaia. Im Wald, März 1902. 1 ․

Diese interessante Speeies wurde dem Sammler Hern Dr. K. H. Andersson in Upsala gewidmet.

In der Flïgelfärbung dïrfte Antarctoperla Anderssoni an Gripopteryx reticulata BR. 1865 aus Brasilien erinnern. Sollte diese Species in die Gattung Antarctoperla gehören, was mir sehr unwahrseheinlieh ist, so ist sie doch spezifisch scharf von der vorliegenden Art durch die Anwesenheit ron 3-4 Queradern im Pterostigma und durch weitere Untersehiede getrennt.

\section{Antaretoperla Michaclseni (KLAP. 1904).}

Gripopteryx Michaelseni Ǩlap., Ḱlapálel, Hamb. Nagalh. Sammelr. Tlecopt. 1904, 1. 12. Fig. 9 11. 10. (Feuerland.) Antarctoperla

(Kilap.), Enderlein, Zool. Anz. J3u. 28. 1905, p. S11.

(Klap.), Enderlein, beutsch. Ent. Zeitschr. 1909, p. 683.

Die Abbildung des Geäder's zeigte deutlich, dass diese Form in die Gattung Autaretoperla ENDERI. einzuordnen ist. 


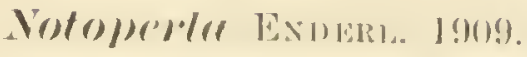

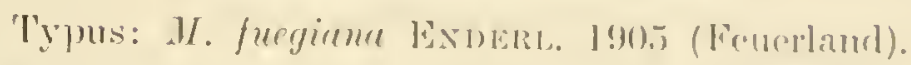

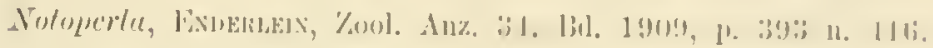

Radiatramus im Vorder- und Hinterfligel ungegabelt. I. Cubitalast im Vorlerfliigel ungegabelt, nur cinige Queradern hinter ilum; im Hinterflïgcl kurz gerabelt oder ungegabelt. Vor dem Medianstamm des Vorderfliigch kejne Gueradern. Eiste Cubitalzelle $\left(\mathrm{Cu}_{1}\right)$ im Hinterflïgel mit zahlpeichen Queradern (ea. (i). Cerci lang, otwa 32-gliedrig. Von der basales Analzelle im Vorderfligel geht hinten eine gegabeltn Axillaris aus, deren vorderer Ast keine Querader nach der Inalis entsendet. Cubjtus 1 in Hinterflïgel mit knrzer Gabel.

Notoperle file?

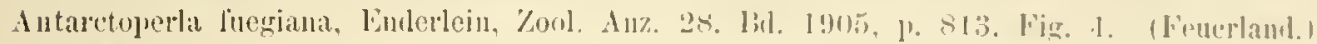

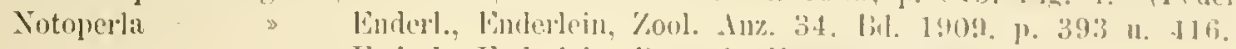

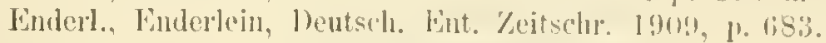

Körper kräftig; oben: braun, Pronotum und Kopf blassbraun; unten: hell gelbłraun. Füller und Cerei gelbbraun. Maxillarpalpus hellgelb, mit 4 ziemlich liurzen fast gleiellangen Gliedern, Endglied braun. Labialpalpus kurz, Endglied bräunlich. Beine hell bräunlieh gelb, Sehenkel aussen brąun, Sehienen nahe der Basis mit einem schmalen, in der Mitte mit einem breilen braunen Ringe. distales Ende braun. Tarsen oben, besonders an Ende jedes Gliedes, braun. Mittleres Tarsenglied kurz, 1. u. 3. lang: Terhältnis der Hintertarsenglieder etwa 3:1:4. Fiihler lang, borstenfömig, etwas kiirzer als die

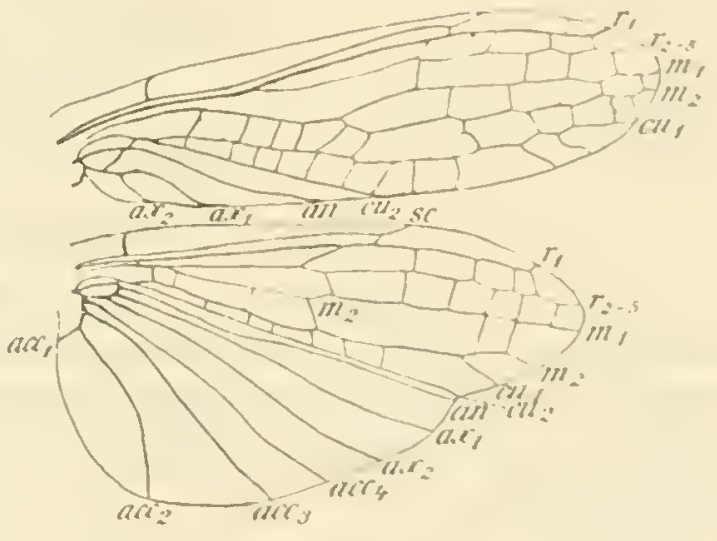

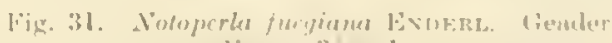
lergr. $3: 1$

Vorderflïgel; 3. Glied etwas länger als breit, 4. halb so kmrz wie breit; vom linde des 1. Drittels ab $\mathrm{I}^{1}$ a bis 2 mal so lang wie breit. Pronotum rom so breit (2." + mm) wie lang, hinten breiter; in der Medianlinie eine feine cingeritzte Lingslinic. (orei lang, borstenförmig, cirea 32-gliedrig. Vorderflïgel hellgelbbraun angehaucht. mit unregelmässigen branen lieeken so dicht besprenkelt, dass mur zorstrent die ('rundfarbe zu sehen ist. Hinterflïgel dunkel. bram, nur undeutlich fleckig. Qucradern sehr zahlreich: Im Pterostigma nur auf dem rechten Vorderfliigel I (puerader: sumst im Vorderflïgel: zwisehen $r_{1}$ und $r_{2-5}: 4$. zwischen $r_{2-:}$ and $m_{1}: 4$, zwischen $m_{1}$ mul

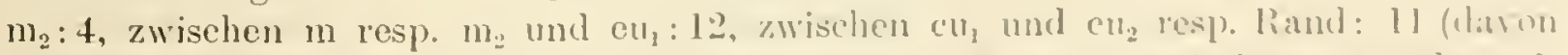
4 nach dem Rand); im Hinterfligel: zwischen $r_{1}$ und $r_{2-. .}$.

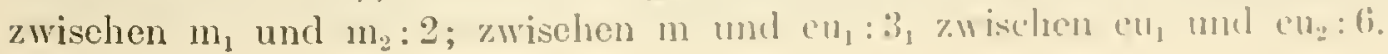


K゙örperlänge $15 \% \mathrm{~mm}$. Länge des Abdomens $9 \mathrm{~mm}$. Fïhlerlänge $14 \mathrm{~mm}$. Länge der Cerci $9^{1 / 2} \mathrm{~mm}$. Vorderflügellänge $17^{1 / 2} \mathrm{~mm}$.

Suid-Feuerland. Uschnaia. Im IVald. März 1902. 1 q.

In der Flïgelfärbung erimnert Antarctoperta fuegiana an Gripopteryx ligrina KLAP. 1904 von Peru, nur sind hier die braunen Flecke kleiner, spärlicher und fliessen selten zusammen.

\author{
Subfam. Gripopteryginae. \\ Gipopteryx PICT. 1841 . \\ Gripopteryx. PICTET, \\ ENDelilein, Zool. Anz. Bid. 34. 1909, 1). 39:. \\ Gripopter!y.x m!midon (1Lав. 18Ss).
}

Perla myridon, Mabille, Miss. Scient. du Cap Ilorn, 1888. T. YT. Nenr., p. 6. P. I. Fig. 3. (Fenerland.) Gripopteryx myridon (Mal).), Klapálek, llamb. Magalh. Sammels. I'lecopt. 1904, 1. 10.

Mab., Lunderlein, \%ool. Anz. 28. Iid. 1905. 1) 814.

Fam. Nemuridae.

Endelilein, Zool. Anz. Bil. 34. 1909 , 1. 388.

Subfam. Nemurinae.

Ud/lmocelrill ENDERT. 1909.

Typus: U. antarctica ENdert. 1905, Feuerland.

Dritte Apicalzelle (Zelle $R_{5}$ ) im Vorder- und Hinterflügel an der Basis stark erweitert $\left(r_{4+5}\right.$ und $m_{1}$ nach aussen konvergierend). [Hierdureh entsteht eine $\mathrm{X}$-förmige Figur.] Radialramus und Media im Hinterflügel eine Strecke verschmolzen. Pterostigma ohne Queradern. Radialramus und Media im Vorderfliigel normal (getrennt entspringend).

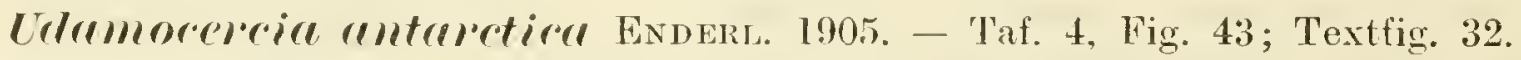
Leuctra antarctica, Enderlejn, 7ool. Anz. 28. Bil. 1905, 1. 814. Fig. 5. (Fenerland.) Udanocercia : Enderl., Enderlein, Kool. Anz. 34. Bı. 1909, p. 394.

Körper schlank und zart. Hell rostbraun, Thorax und die 3 letzten Abdominalsegmente dunkler. Beine hell gelbbram, Tarsen braun, Fühler braunschwarz. Maxil-

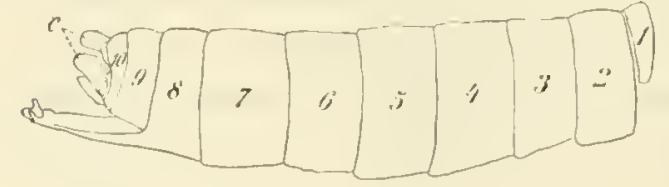

Fig. 32. Leuctra antarctica nov. spec. \&. Thdomen von der Seite. Vergr. $11: 1$. lartaster braun, I. Glied kurz, die beiden folgenden gleichlang ziemlich dick, etwa doppelt so lang wie dick, 2. nach dem Ende verdickt, 4. Glied diinn, zart, elliptisch, halb so lang wie das 3. und doppelt so lang wie dick. Verhältnis der Hintertarscinglieder 2:1:2. Pronotum doppelt so breit wie lang, Vorder- und Hinterrand sowie die Seiten 
parallel; rorn mit einer Spur einer medianen Lïngslinie. Cerej l-gliedrig, doch findet sieh an der Aussenseite der Basis noeh ein Rudiment eines Basalgliedes in Form eines Halbringes, 8.-10. Segment kürzer als die ïbrigen. 8. Stemit in einen langen spatelförmigen Fortsatz verlängert, der die Hinterleibspitze ibberagt nnd knr\% ror dem Ende jederseits einen etwas zugespitzten Zapfen trärt. Wälnend der iibrige Hinterleib und die Cerei pubesziext sind, felılt die Pubes\%enz dieser zapfenförmigren Sul)genitalplatte völlig, nur an der Basis finden sich unten einige feine Häreben. Flijgcl gelblich angehaucht, Stigma im Vorder- mnd Hinterflïgel mit Ausnahme des proximalen Viertels rostrot. Im rechten Vorderflïgel findet sieh dicht an der Spitze eine Querader zwisehen $r_{1}$ und $r_{4+5}$, die wohl sicher abmom ist. Zwischen m und $\mathrm{cu}_{1}$ finden sieh im Vorderfliigel 2 Queradern, zwischen m. und $\mathrm{eu}_{1}: 1$ (im Hinterflügel je 1). zwisehen $\mathrm{eu}_{1}$ und $\mathrm{eu}_{2}: 4$ (im Hinterfligel: 1). Flïgelrand dieht pubesziert.

Körperlänge $S \mathrm{~mm}$. Länge des Abdomens 4, 2 mm. Fiihlerlänge 6 mun. Vorderfliigel $7^{1 / 2} \mathrm{~mm}$.

Suid-Feuerland. Uschuaia. März 190:。 1 운.

Ordo: Agnatha.

Fan. Ephemeridae.

brrïtis Isliscu. 1S15.

Bärifis(?) spec.

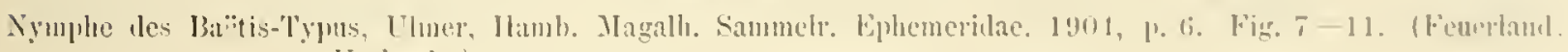
Uschutia.)

Ordo: Collembola.

Fam. Poduridae Liris.

Subfam. Hypogastrurinae C'B.

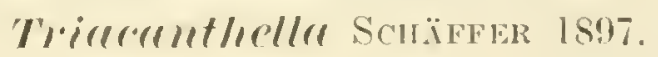

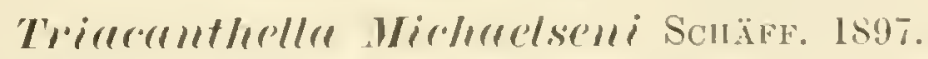

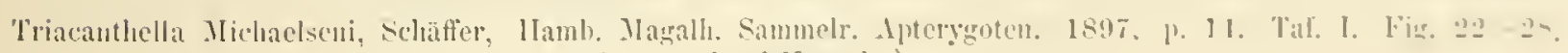
(Fenctand: Lichuaia ete.; lnsel-Narariu.)

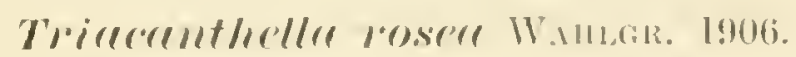

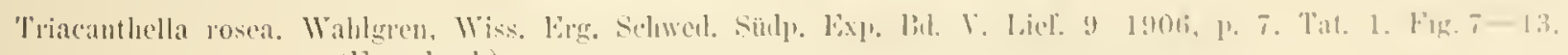
(Fenerland.)

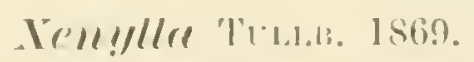

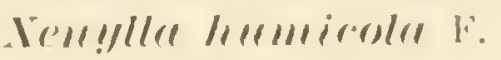
vergl. par. 13is.

Subfan. Onychiurinae 1 ' $\mathrm{s}$.

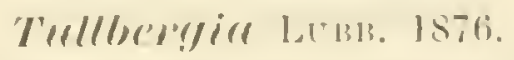

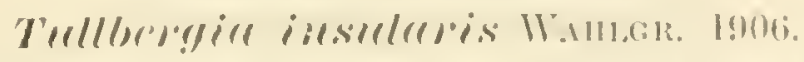

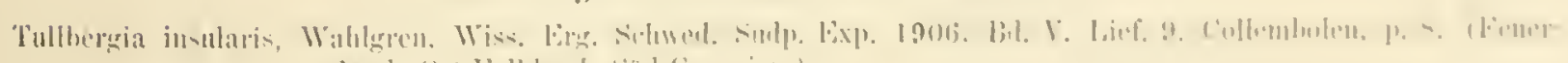

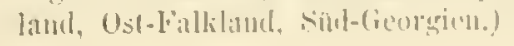


Tulbelyil trisetosu Scü̈Fr. 1897.

Aphorura trisetosa, Siltïticr, Hamb. Magalh. Sammelr. Aptergoten. 1897, 1. 5. Taf. I. Fig. 1 1. 2. (Feuerlant: Usehuaia; Insel-Navariu.)

Tullbergia „ (Scluäfi.), Börner; Zool. Anz. Bel. 26. 1902, 1) 126.

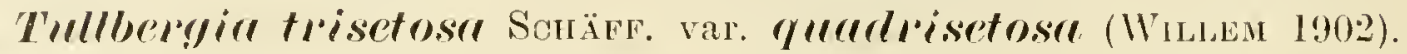

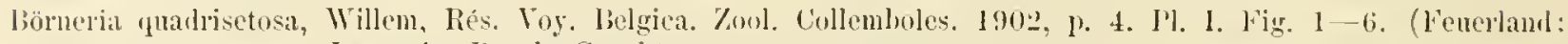
Isapataia, Jieagle Canal.)

Tublberegia trisetosa, Schüft. var, quadrisetosa, Wijl., liorner, Zool. Anz. Md. 26. 1902, 1. 125 (Fussnote 6) nud 1. 126.

\section{Tullbergie spillosissille W WhHar. 1906.}

Tullbergia spinosissina, Walıgren, Wiss. Ergelm. Schwen. Südp. Exp. Bu. V. Liel. 9. 1906, 1). 9. 'Taf. 1. Fig. 14-15. (Fenerland.)

Subfam. Achorutinae.

Tribus: Pseudachorutini.

Alllida Laboulb. 1865.

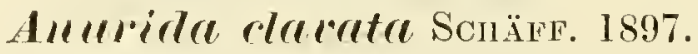

Antrilla elarata, Schiffer; Hamb. Magalh. Sammelr. Apterygoten. 1897, 1. 7. Taf. 1. Fig. 5-8. (Fenerland.)

Psecurlarlloimes Tulub. 1871.

(= Schöttella ScHÄFFER).

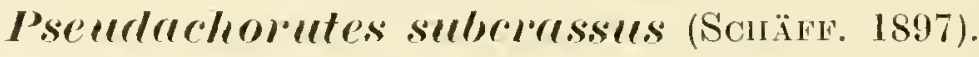

Schöttella subcrassa. Schäfer. Mamb. Magalh. Sammelr. Apterygoten. 1897, p. 13. Taf. I. Fiur. 18-21. (Feuerland: ITschuaia.)

Pseudachorutes subcrassus (Sehäffi. 1897) $\mathrm{m}$.

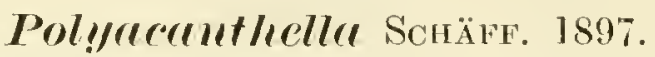

Sснйffer, Hamb. Magall. Sammelr. Apterygoten. 1897, p. 15.

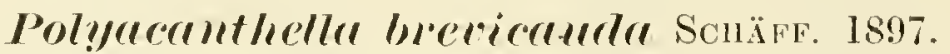

I'olyacauthella brevicaula, Schäfler. Ilamb. Magalh. Sammelr. Apterygoten. 1897, 1. 15. Taf. 1. Fig. 29!-32. (lecuerland: Uselıaia.)

Tribus: Achorutini.

Arloriltes Tenpl. 1835.

Achorates riaticas (L.).

Achorutes viaticus (1.), Schätier, IIamb. Magalh. Sammelr. Ajterggoten. 18:7, 1. 11. (Fenerlaul: Uschuaia; Sǜ-Patagonien.) 


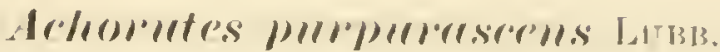

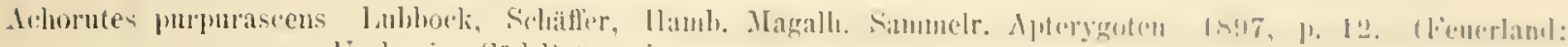

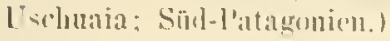

Faul. Entomobryidae.

Subfain. Isotominae.

Tribus: Isotomini ('B.

Isotomall bovrt. 1839, C. B. s. str. 1906.

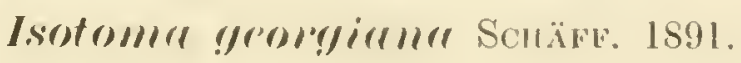

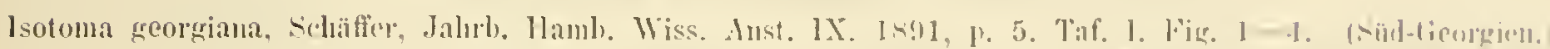

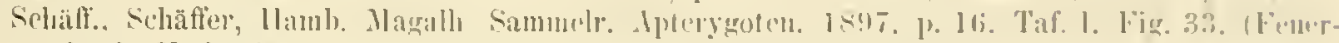
land: Usehmaia.)

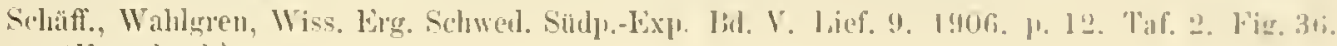
(Fenerland.)

Isotomer pulletell WAHLGR. 1906.

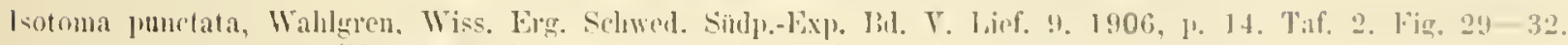
l'enerland, Osi- und West-Finlianl.)

\section{Isotomer silvetirel ScnÄFs. 1897.}

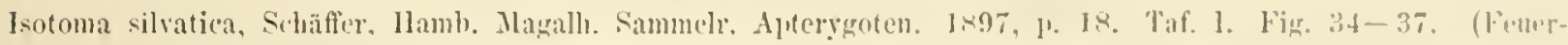
l:url: Uscolunia.)

\section{Isotomma Brssolsi PACK. 187is.}

Isntoma l3esselsi, l'acliarel,

(\%) pulchella. Moniez. Jiev. 13iol. 1I. 1890. P. 43I. ('roisic.)

s spitzbergensis. Lubbock, 18!9. Spitzherwen.)

„ arctiea, Stscherbakow, Zool. Anz. 1S99, p. 47. (S)itzluergen.

» Jiesselsi Pack. Folsom, ]'syche, 8, 1899, 1) 360.

» jaumayensis, Wahlgren, Ofv. Ak. Forh. 57. 1900, I1. 35t. (Jammayen.)

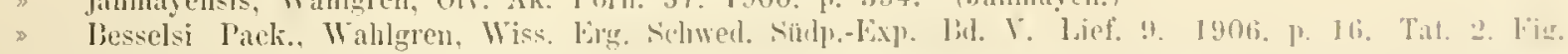
37-39. (Femerlaud.)

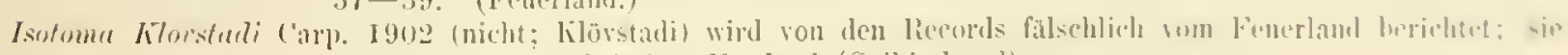
stammt von antarktisclien Festland (Geikie-land).

\section{'Tribus: Anurophorini.}

\section{(ว!)}

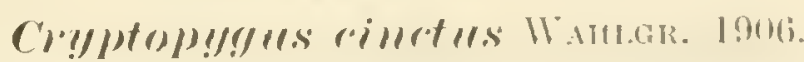

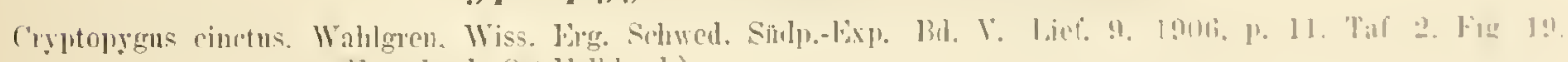
lonerlaul. Oct-loalliand.)

\section{Subfam. Entomobryinae.}

Tribus: Isotomurini.

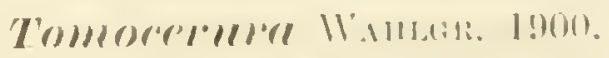

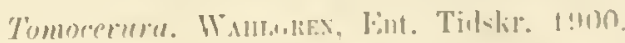

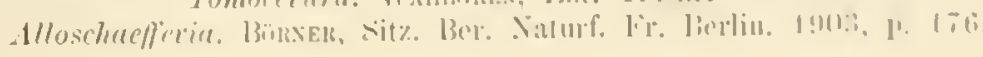




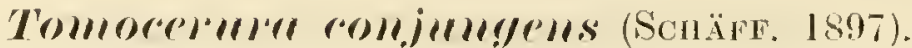

Isotoma conjungens, Schäffer. IIamb. Magall. Sanmelr. Aptergoten. 1897, p. I9. Taf. II. Fig. 46-48. (Fenellanil.)

Alloschätferia conjungens (Schäffo). Börner, Sitz. Ber. Naturf. Frenude. Berlin. 1903, 1) 176.

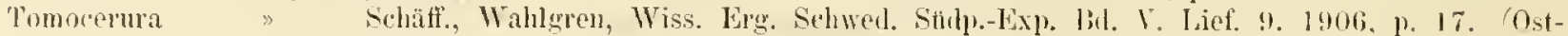
Falkianı.)

\section{Tribus: Entomobryini. \\ Eutomobr?/l RONDANi 1861 .

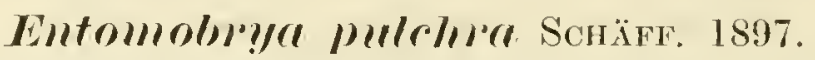

Entomolnya pulelıra, Schäffer. Ilaml. Magall. Sammelr. Apterygoten. 1s97, 1. 21. Taf. II. Fig. 52-55. (Fenerland: Iischnaia, I’nesto Ibridges; Insel Navarin.)

\section{Ptemmrer Templ. 1843.}

Ptenuru, TEMPL,

Sira, I.UBbock,

Itemar, IBiner, Mitt. Naturh. Mus. IJambnrg. XXIII, 1906, p. 164.

\section{Prenmel varabilis (SсmÄғF. 1897).}

Sira variabilis, Schäffer, Haml, Magall. Sammelr. Apterygoten. 1897, p. 23. Taf. Il. Fig. 60--61. (Fenerlanl lnsel Nararin; Insel l'icton.)

Schäft., Wahlgren, Wiss. Ere. Sehwerl. Südp.-Exp. B. V. Iief. 9. 1906, 1. 18. (Ost- und WestFallilanil.)

I'tenura » (Sclüff.) m.

Fam. Sminthuridae.

Subfam. Sminthurinae.

Smint7ullus Latr. 1804, C. B. s. str. 1906.

smimtlmmens promimosus Tuleb.

Sminthurus pruinosus Tullb., Sehäfer, IIanl). Magalh. Sammelr. Apterygoten. 18:17, p. 26. (Fenerland: I'schuaia.)

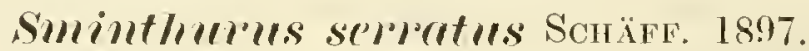

Suninthrus serratus, Schiffer, Hamb. Magall. Sammelr. Apterygoten. 1897, 1. 26. Taf. II. Fig. 67-69. (Fenerland.)

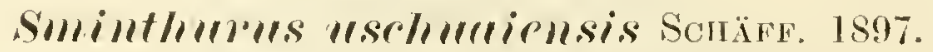

Sminthums uschuaiensis, Schäfer, IIaml. Magallı. Sammelr. Apterygoten. 1897, p. ⒍ Taf. 11. Fig. $70-72$. (Feuerlani.) 


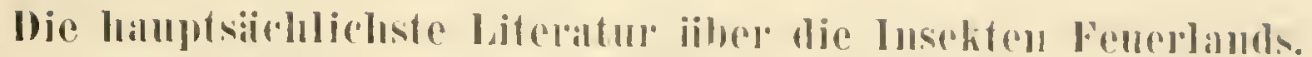

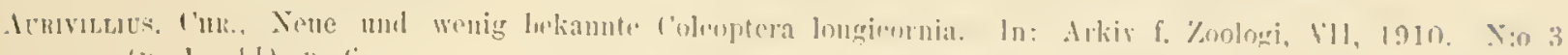
(1). 1-1.1). 1). (i.

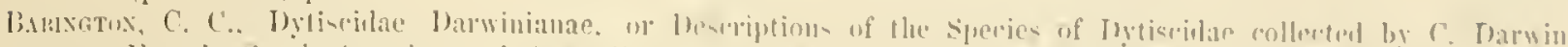

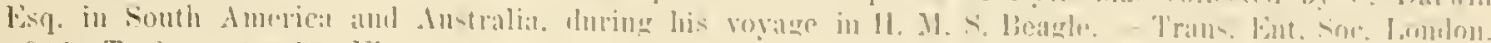
1811. T. 3. \%. 1-17. l\%ig.

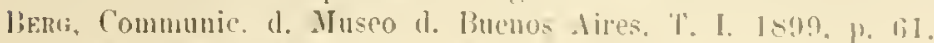

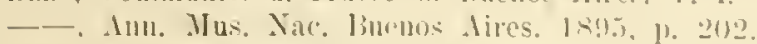

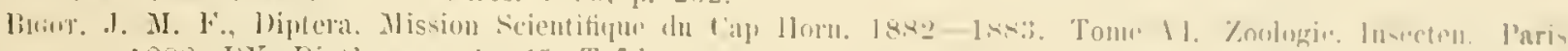
1888. I). Dipteres, 1. 1-4. Tafel 1-1.

BLaxcound, In fray, vergleiche muten.

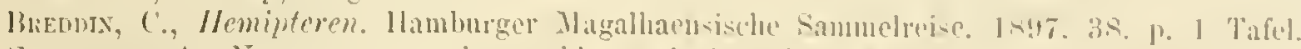

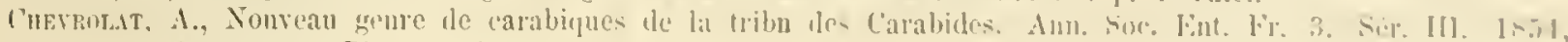
1. $665-668$. Pl. 19. Jig. 11 \&.

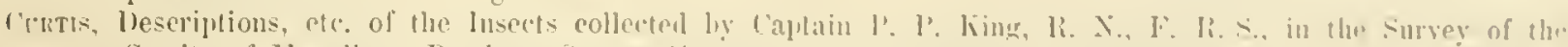

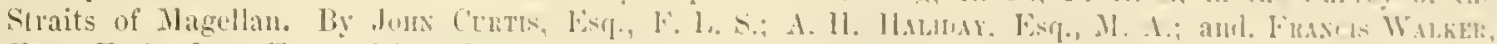

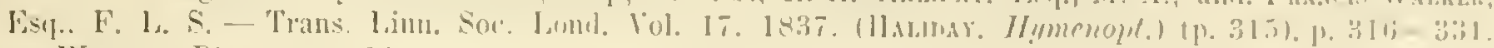
- Wilker, Dijutera, 1).331-359.

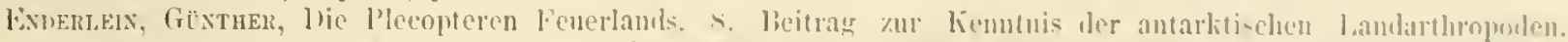

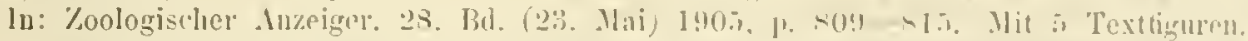

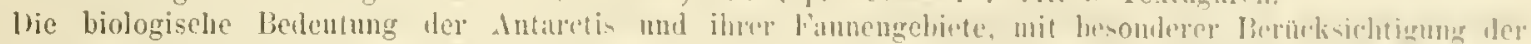

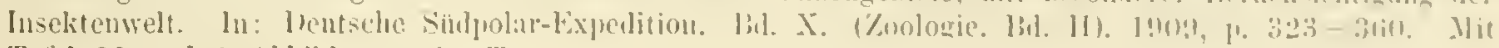
Tafel 39 und 2 Abbiddungen im Text.

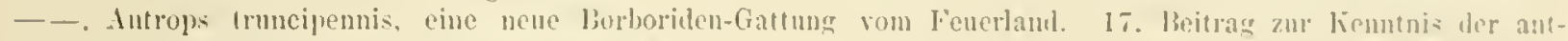

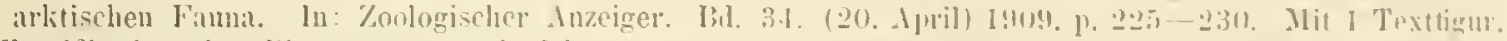

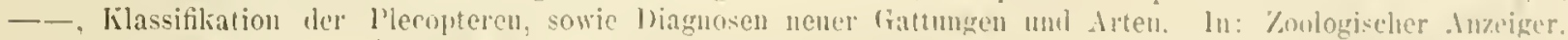
Bd. 34. (15. Juni) 190!1, 1. 385-41!).

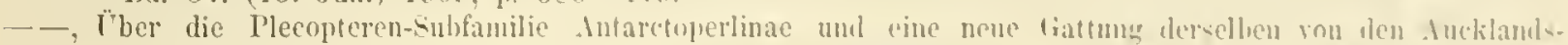

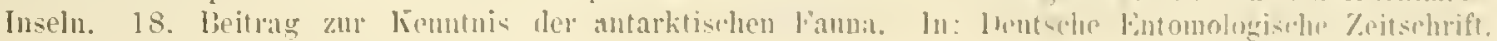
1909, p. 679-684. Mit : Textfiguren.

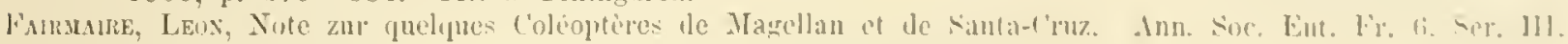
1883, p. $483-506$.

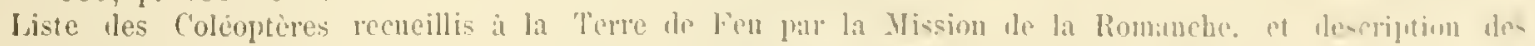

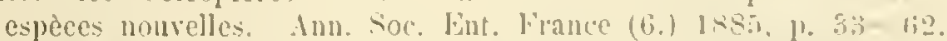

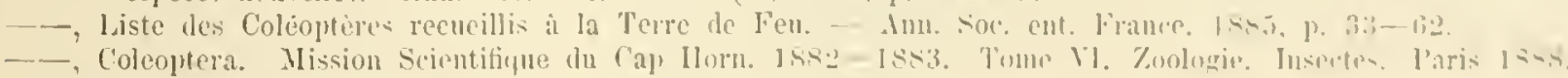

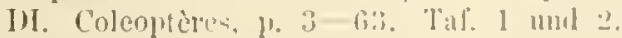

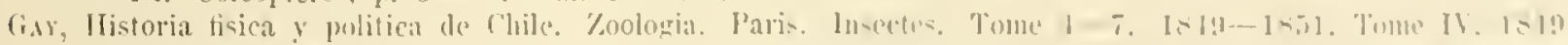

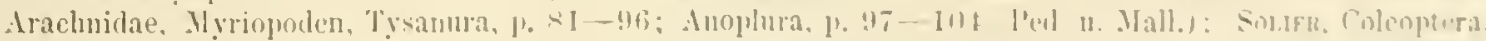

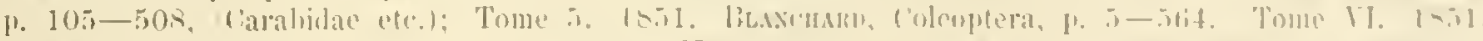

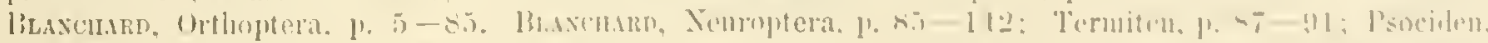

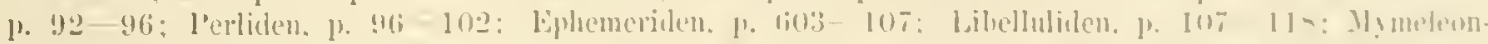

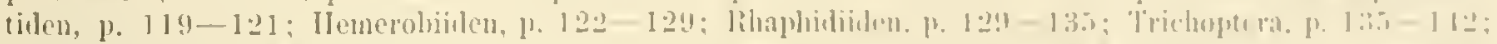

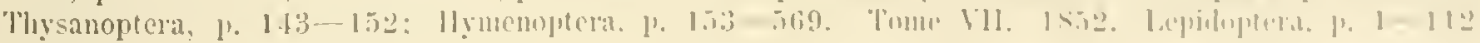
IIeniptera, 1) $113-327$; Jijtern. 1).327-46S.

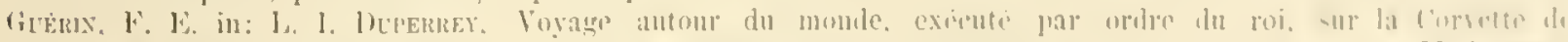

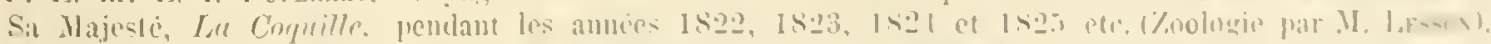

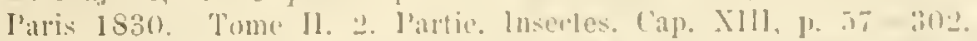

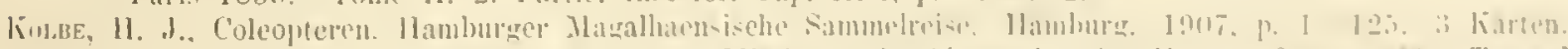

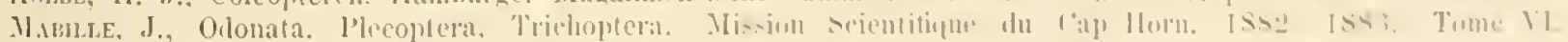

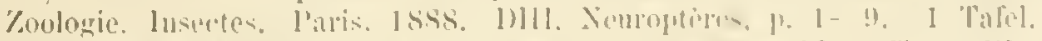

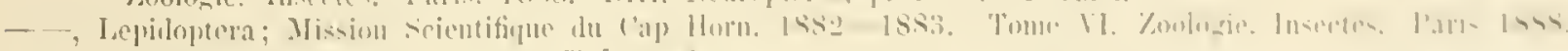

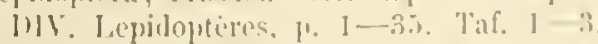

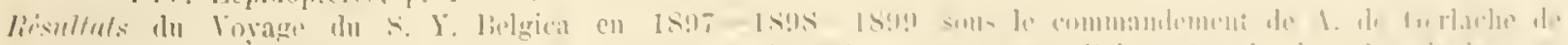

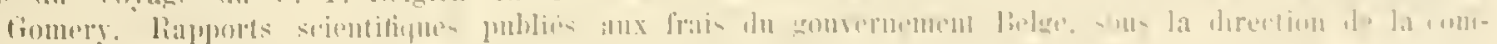

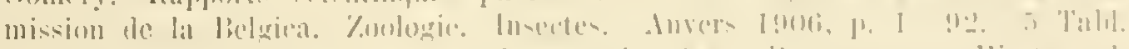

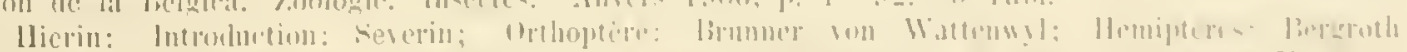

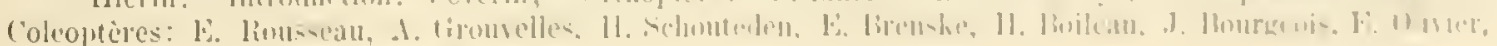
ti. sis. Pet. Akad, llandl. Busd f4. Xit) 3. 
L. Faimaire, G. Stierlin, A. Borie, A. Laneere: Hyménoptères: J. Tosı̨ninet, C. Emery. İ. Antré, .T. Vachal; Diptères: I. Ch. Jacols, Th. Becker, fr. H. Rïlısaamen.

Iis, F., Odonaten. IFamburger Nagahthensische Sammelreise. 1904,14 p. 14 Jiguren.

licesanex, Ew. H., Pteromalinen. IJamburger Magalhaensische Sammehreise. 1902, 7 p. 1 Taf'el.

Schäffer. C., llamburger Magalhaensische Sammelreise, Alterygoten. Jamb. 1897, 48 1. : Tat.

Schotredex, II., Aphilen. Ilamburger Magahhaensische Sammelreise. 1904, $6 \%$ \%

Sharp, I)wid, On aquatic camivorous Coleoptera or Dytiscidac. In: Scientific 'l'ansactions of the royal Inublin Society. Yol. 2. Ser. 11. 1882, 1). 177-1003. Plate VII-XVlll. (Jancetes, 1).602-605, 897-898.)

Signuret, H., Hemiptera. Mission bcientifique du Cay Joln. 1882-1883. Tome V1. Yoologie. Insertes. Paris 1858. Dll. IJémijutères. p. 1-7.

Sulier, ill Gay, (vergleiche dort).

Statinger, O., Jepillopteren. Hamburger Magalhaensische Sammelreise. 1899, 1. 118. 1 'T'afel.

Uhmer, Geori, Triehopteren. Hamburger Magalhansische Sammeheise. 1904,26 j. 2 Tafeln.

- Ephemeriden. llamburger llagalhaensische Sommelreise. 1904, 8 p. I Talel.

Wahlgres, Einar, Antaktische und subantarktisehe Collembolen. Mit 2 Tafeh. - Wissensch. Grgelmisse dro sehwedischen Südpolar-Expedition t90t-1903 unter Leitmig von hr. Otto Norlenskjölrl. 1906i, p. 220.

WALKER, F., (vergl. unter Curtis).

Waterhouse, F. II., Trans. Fintom. Soc. London. 1872, p. 332.

- - Descriptions of new Coleopteri of geographical interest, eollected by Charles Darwin. Fsip. in: .Jomrial of the Linnean Saciety. Jondon. Yol. XIY. 1879, p. 530-534.

Waterhiuse, G. R., Description of some new Coleopterous Insects from the sonthem parts of sontli America. - Ant. Mag. Nat. Hist. Vol. X. 1842, 1\% $131-147$, 1. $217-224$.

1)escription of a new genus of Carabideous Insects brought from the Falkland Islands by Charles Warwin, Esq. - Mnl. Mag. Nat. llist. Vol. XI. 1843, 1. 281-283.

_- Carabidous lisects collected by C. Darwin Esij. during the Voyage of II. S. M. S. Beagle. 'Tal. 1. -Ann. Mag. Nat. Hist. 1841. T. fi, p. $254-257$, 1. $351-355 . \quad$ T. 7, p. 120-129. 1842. 'T. 9. p. $134-140$.

Waterhouse and Butuer, Lists of Coleoptera, Lepidoptera, Orthoptera. and llemiptera, collected in the Straits of Magellan and on the coast of Patagonia, during the survey ol II. M. S. Alert. - Proc. Zool. Soc. Lonton. 1881, p. $80-87$.

Wilıes, V., Les Collemboles recueillis par l'expedition Antaretique helge. Ann. Sor. ent. Belgique. XIV. 1901, P. $260-262$. 


\section{Die Inselitenfauma von Süil-(keorgien.}

Siid-Georgien beherbergt nul 1.j Insektenarten und zwar 4 Käiferarten. 4 Fliegenarten, 2 Mallophagen nud 5 Collembolenarten. Mit Ausnahme einiger ('ollembolen haben sie alle Bezichmngen zu Formen des siidamerikani=chen Festlandes, besonders zu Fenerland und den Falklands Inseln, einige Formen sind sogar identisch. die meisten Species jedoch enclemiseh.

Eine neue Fliegengattung fand sich unter dem Material der sehwedischen Sürlpolar-Expedition.

\section{Ordo: Coleoptera. \\ Firm. Dytiscidae. \\ Dytisci Fragmentati. \\ Subfam. Colymbetidae. \\ 'Tribus: Lancetini.}

(Vorderrand der Hintereoxen nm sehwach gewölbt. Fliggel des Mctasterunu ziemlieh breit, nicht sehmal.)

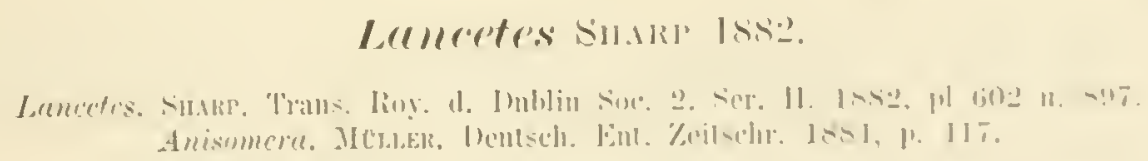

Elytren an der Spitze seluäig, seht secht buchtig absestutz. butwlied der Palpen nicht oder nur schwaeh verdickt, mit schwacher Indentung eines bindans. sehnittes. Cosallappen verlängert und tief ron einander getromt. (Niemals mit der linearen Haargruppe an der hinteren Aussenecke des Minterselienlicls der Agahini: obere und innere Ecke der 1. Ventralplatte ohne Querfalten oder (Querfurehen.) 
Lamretes Clamssi (MÜLl. 1884). - Taf. 1, Figg. 6.

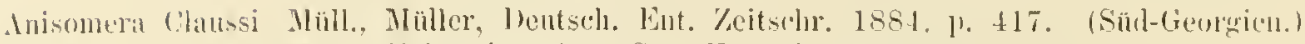
Mäll., Fairmatre, Ann. Soc. Ent. Fr. 1885,1 . 42.

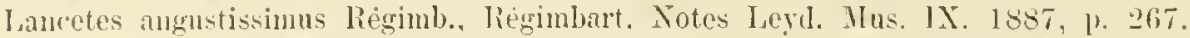

Anisonera C'laussi Müll., Fairmaire, Miss. Cap Horn. 1888. Colenpt. [), 1\%. "23.

I'fefler, Die niedere Thicrwelt 1. anturkt. [forgeb. 1890, 1) 48.

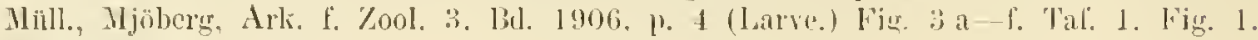

liollo, Hamb. Magalls. Sammeld: Coleopt. 1907, 1. 51.

Lametes $\gg$ (Mïll.). Enderlcin. Dentsche Sudp.-Lxp. Bi. X. Zool. 11. 1909. 1) 193.

Durch Vergleich der beiden Beschreibungen mit mir rorliegenden Exemplaren ron der sehwedischen Südpolar-Expedition bin ich zur U̇berzengung gelangt, dass Anisomera Claussi und Lanceles angustissimus synonym sind (ef. l. c. 1909).

Siid-Georgien. Cumberland-Bay. Jason Harbour, in einem T'eich. 6 Exemplare und 1 Larve. 23. April 1902. - Bores Thal. In einem Sce. I Larre. 3. Mai 1902. - Cumberland-Bay. In einem Teiche nahe den Moränfjord. 18. Mai 1902. 2 Exemplare. - Bores Thal. In einem Süsswassersee. 24. Mai 1902. 1 Exemplar. - Bores Thul. Auf dem Boden eines eisfreien Sees. Oberflächentemperatur $+2^{\circ}$ Celsius, 1 Larve.

Lang elliptisch, schwach gewölbt, nach hinten etwas verschmälert; Oberseite gelb; Kopf breit, schwarz; Vorclerstirn und Nlund gelb, matt sehr fein punktiert, neben den Augen auf der Stirn jederseits ein aus starken Punkten gebildeter eingedrïckter Strich. Palpen und Fühler gelb, Halsschild ziemlich flach, fast doppelt so breit als lang, im Verhältnis zu den Fliigeldecken schmal, an den Seiten fast gerade, nach hinten nur wenig verschmälert. Vorderwinkel spitz und stark vorspringend, Hintereken stumpf-winkelig, Seitenränder scharfkantig, kaum aufgebogen, neben denselben flach niedergerliickt, gelb, auf der llitte mit einem ziemlich grossen dunkeln Flecken, welcher sich manchmal in zwei anflöst. Flïgeldeeken langgestreckt, nach hinten etwas verschmälert, an der Spitze schräg nach aussen abgestutzt, gelb, mit ziemlich dicht stehenden schwarzen Punkten bedeckt, Seiten- und IVurzelrand jedoch ziemlich frei davon, dazwisehen sind noch 6-8 schwarze Längslinien bemerkbar. Beim Männchen glänzend glatt mit einigen Reihen eingestochener Punkte, beim Weibchen selir fein nadelrissig mit renselben Reihen von Punkten. Unterseite schwarz. Hinterleibsringe bräımlich gerandet, Prosternum seiner ganzen Länge naeh hochgekielt, hinter den Vorderhüften in eine scharfe Spitze verlängert, welche in eine Rinne der Mittelbrust passt. Die Vordersehenkel mit zwei Reihen dicht stehender kurzer Bor'sten, Mittelschenkel mit einer Reihe sehr langer Borstenhare versehen.

Die Männchen haben die drei ersten Glieder an den Vorderfiissen stark verbreitert und ein jedes mit einer Reihe Saugnäpfehen und langen borstenartigen Haaren dicht bedeckt. Ebenso die Mittclfiisse, doch sind dieselben nur zwei Drittel so breit als die Vorderfiisse. 
Fam. Tenebrionidae.

Subfam. Helopinae.

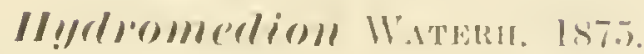

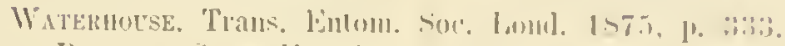

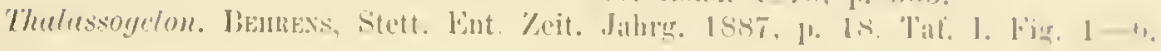

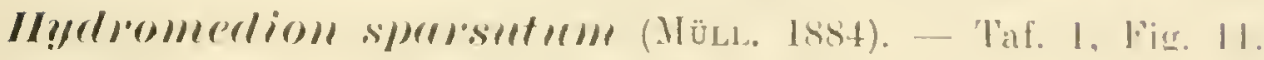

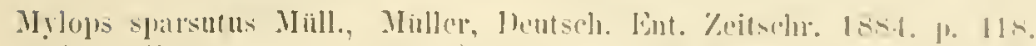

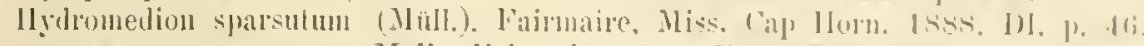

Mull., Faimaire. Amn. l'1. 1885, p. $5 \%$ \%

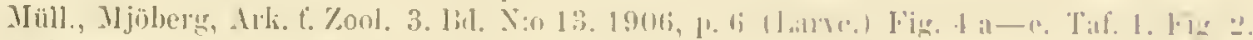

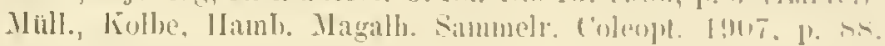

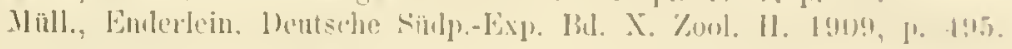

Benrevs beschrieb diese Speeies fälschlich als Pythicle.

Süd-Georgien. Cumberland-Bay. 2\%. April 1902. - Larven und :3 Exemplare (f).

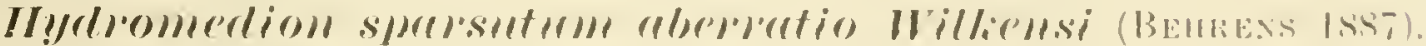

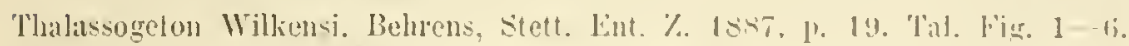

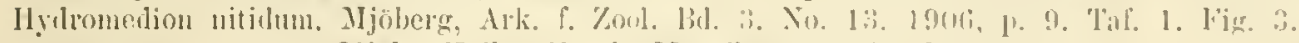

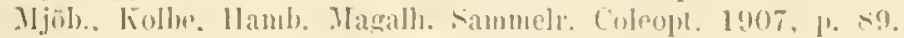

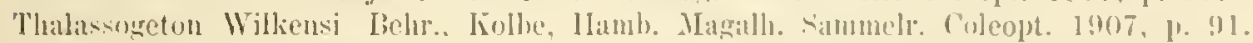

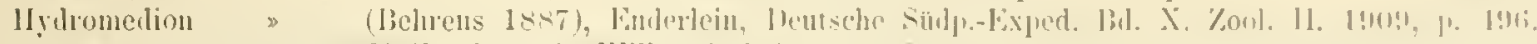

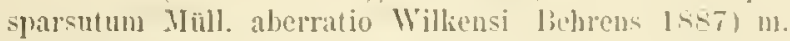

Ich hielt friiher (1909) diese Species fiir das männliche Gesehlecht ron $/ /$. Sprorsulume \ÜLL.

Nachdem ich noch weitere Exemplare des Alkohol-Hateriales genadelt habe, zeigt es sich, dass Wilkensi tatsëehlich identisch mit spmsulum ist. da der Mediankiel des Halsschildes mehr oder weniger dentlieh sein kann und Stüclie mit verschwindendem Kiel führen direkt ïber zu spursum. Männliche Stücke dieser Species ganz ohne Kiel sah ich nicht. Dagegen lommen weibliche mit hiel ror. der aber wohl selten schr deutlich ist.

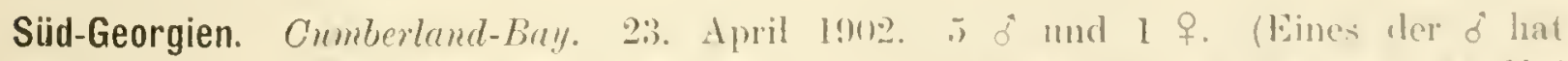
nur cine Spur eines Mediankieles.) - Cumbolund-Bay. (irytoiken. 2., Mai 1902. 1 \& auf Schnec.

Diese Speeies ist dem Hydromedion mugellumicum Fank. schr ähulich mud unterscheidet sich ron ihm durch die ziensich lange (feine) behanrung der libtren. Hydromedion magellanicum hat wie alle formen dieser (iattung vom festland mur fast verschwindend kurze Pubeszenz.

\section{P(PIII!!)}

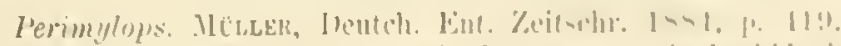

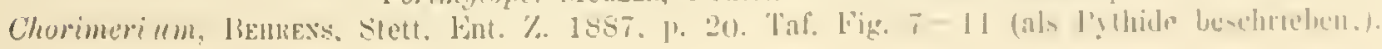


Perim!lops antarcticls MüLLER 1884. - Fig. 9.

I'erimylopss antarcticus Müll., Müller, Deutsclı. Ent. Zeitschr. 18s4, 1. 419.

Müll., Fairmaire, Aun. Soc. Ent. Fr. 1885, p. 50.

('horimeriun antarcticum Behrens, Stett. Ent. Zeit. 1887, 1. 21. 'Jaf. Fig. 7-11.

I'erimylops antancticus Mull., Fairmaire. Miss. Cap IIorn. VI. 1888. M, p. 4.

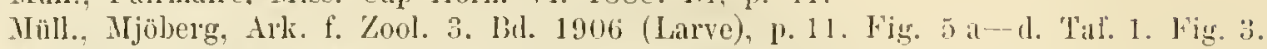
Miill., Kolbe, Iamb. Magrilı. Sanmelr. Coleopt. 1907, 1) 88.

C'horinerinn antareticum Behr., Kolle, Hanb. Magall. Sammelr. Coleopt. 1907, 1. 91.

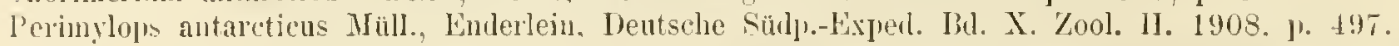

Süd-Georgien. Cumberland-Bay. 23. April 1902. 2 Exemplare. - Antarctic-Bay. Unter Steinen. 3. Mai 1902. 1 Exemplar und Larven.

Benrens beschrieb diese Form gleichfalls fälschlich als Pythide; an der Hand ron Exemplaren der schwedischen Südpolar-Expedition konnte ich die Synonymie nachweisen.

Halsschild ohne Seitenrand. Die Episterna (die Parapleuren LacordaIRe's) der Vorderbrust reichen bei Perimylops nicht bis an den sich hinten schwach gabelnden intercoxalen Prosternalfortsatz heran (Gelenkhöcker hinten ein wenig offen), ähnlich wie es auch bei der Tenebrioniden-Gattung Boros Herbst 1797 wenn auch weniger stark anftritt. Ähnlich ist es anch bei manchen Melandriiden-Gattmigen, z. B. bei Stenotrachelus Latr.; diese Gattung hat überhaupt manche Beziehung zu Perimylops.

Bei den Pythiden, die gleichfalls keinen Seitenrand des Halssehildes anfweisen, fehlen die Episterna der Vorderbrust völlig (die Gelenkhöhlen sind hinten also gänzlich offen).

Bei Hydromedion reichen dagegen die Episterna der Vorderbrust bis an den sich hinten stark gabelnden intercoxalen Prosternalfortsatz heran (Gelenkhöhlen hinten geschlossen).

Fam. Staphylinidae.

Subfam. Oxytelinae.

C'!!lm!rs Fauvel 1904.

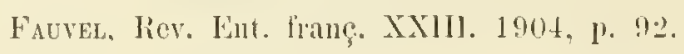

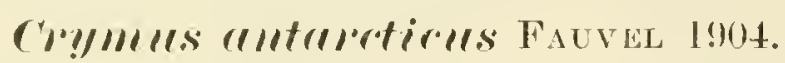

Crynus antarcticus, fanvel, liev. Ent. liane. Xxill. 1904, 1). 93.

Fauv. Enderlein, Deutsche Sinlp.-Lxped. Bal. X. Zool. 11. 190s, 1. t98.

Ordo: Diptera.

Subordo: Cyclorrhapha.

Superfam. Schizophora.

Holometopa.

Acalyptera.

Fam. Dryomyzidae.

Prelerrotorer Bisot 1891.

(Bmot, Miss. Cap IJorn. Zool. Insect. 1891. WT (Diptera), ]. 38. ! 


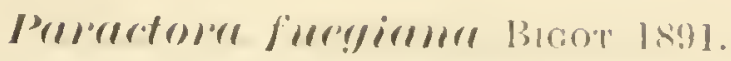

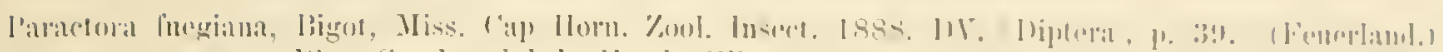

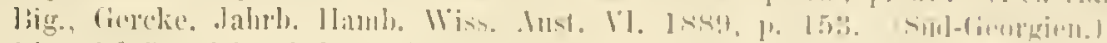

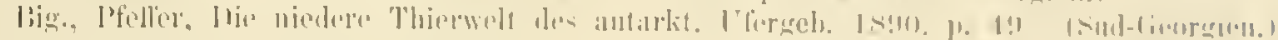

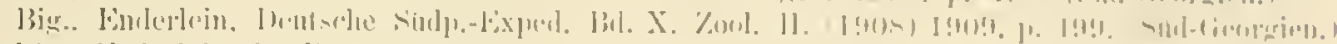

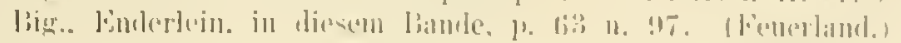

\author{
Fam. Borboridae.

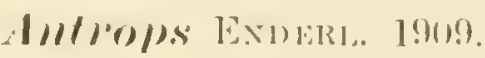

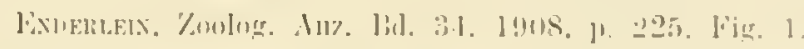

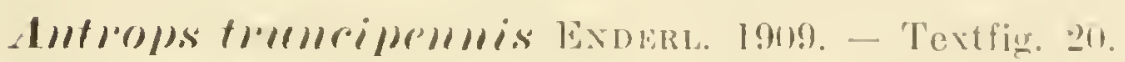

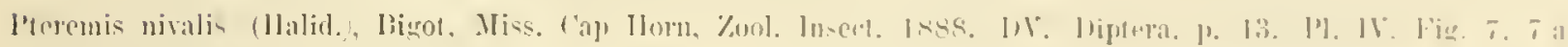
(nee Ilalidaly). (Finerland.)

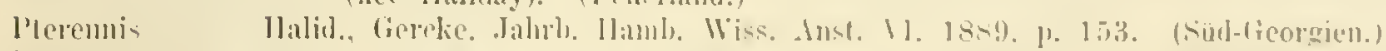

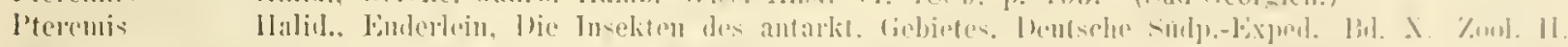

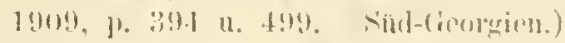

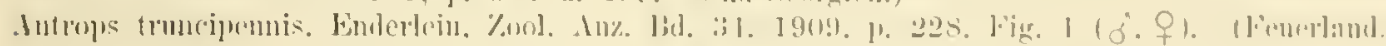

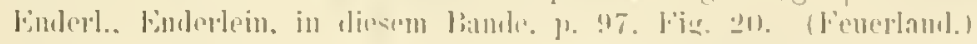

Soll nach GEacke anch anf Sïd-fieorgien rorkommen.

\section{Fam. Coelopidae.}

Fïr den Familiennamen wählte Hendel (Wien. Lint. Zeit. 29. .lahrg. 1910, p. 30s) die für die Familie schr charakteristische (attung Coelopu. Mrig. 1830 mit dem 'Typus:

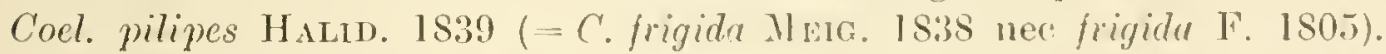

Die emropäische Phycodromr fucormm '/sTT. IS47 ist nach den Originalheschreibungen identisch mit Phyc. sciomyzina HaLb. 1833. Ich komte ausserdem 2 typische

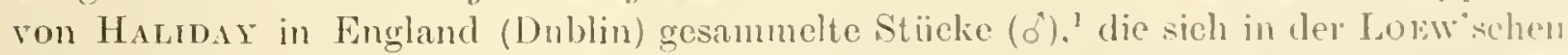
Sammlung in Berliner Zoolog. Ilusem befinden, mit einer Roihe ron stielien vergleichen, die ich im Sommer loos in Frankreich an der normannischen Kiiste (hei

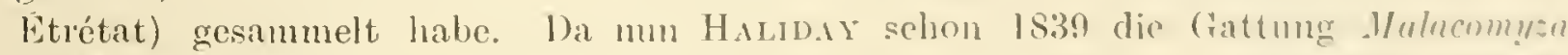

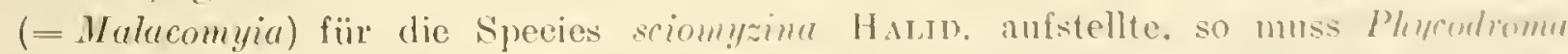
Stexi. 1855 (nicht Phycolromia. wie Becker im Kat. (l. pal. 1)ipt. linos. lin. Il. pag. 20 angiebt) als synonym hierzu fallen.

\section{Proset)}

Typus: P'. anstrinmm nor. spece.

․ Kopf mudlich. Hinterhaupt völligr abgerundet. Untergexicht stark ointe-

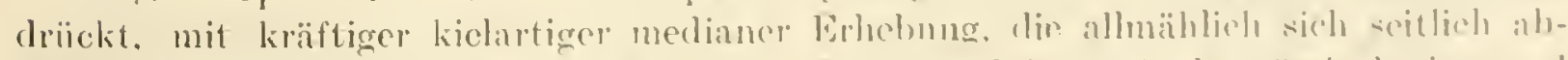
flacht, aber nirgends scharf abgesetze ist. (lypens (bpistoma) als miisig broites mul

1 llas aine o ist antiallig blain. 
sehr kurzes Streifehen sichtbar; abgerundet. Backen mässig breit und fast gleiehbreit; etwa halb so breit wie der kïrzeste Augendurchmesser. Behaarung der Backen gleichmässig und wenig dieht, kräftig und ziemlich lang; eine dichtere Reihe längs und dicht an der Backenleiste. Letztere dicht an unteren Backenrand, wenig seharf. Der Subgenalsamm daher verschwindend schmal. Eine kräftige und lange Knebelborste am äusseren Backenrande an der Fülergrube. Randleiste des äusseren Grubenrandes nur als scharfe Kante sehr nahe am Augenrand. Zahnhöcker am unteren Ende der äusseren Fïhlergrubenleiste fehlt, ebenso die Backenvorderecke. Fïhler kurz, 3. Glied rundlich; Fühlerborste abgebrochen. Angen kurzoval, ziemlich gross, mässig stark abstehend, unbehaart. Stirn mässig dicht und kurz pubesziert, ohne Borsten. Seheitel mit einigen längeren Borsten, und zwar je 4 am Augenrand, 2 an den Ocellen, 2 kürzere hinter diesen; Scheitel hinten pubesziert.

Thorax wenig dicht und kräftig behart, an den Seiten und hinten einige lange Borsien. Eingedrïckte Thorakallinien fehlen. Spuren der Seitensuturen sind vorhanden, 4 Macrochaeten des Scutellum, die hinteren sehr lang und dicht an einander gerückt. Pubeszenz des Scutellum fehlt. Pleuralpubeszenz des Thorax fehlt. 2 sehr lange Randmacrochaeten an den Seiten des Mesosternum, das nur in der Mitte und cin wenig an den Seiten mässig dicht und ziemlich kräftig behaart ist. Prosternaldreieek mässig gross, in der Mitte mit Längsfurche; völlig unbehaart.

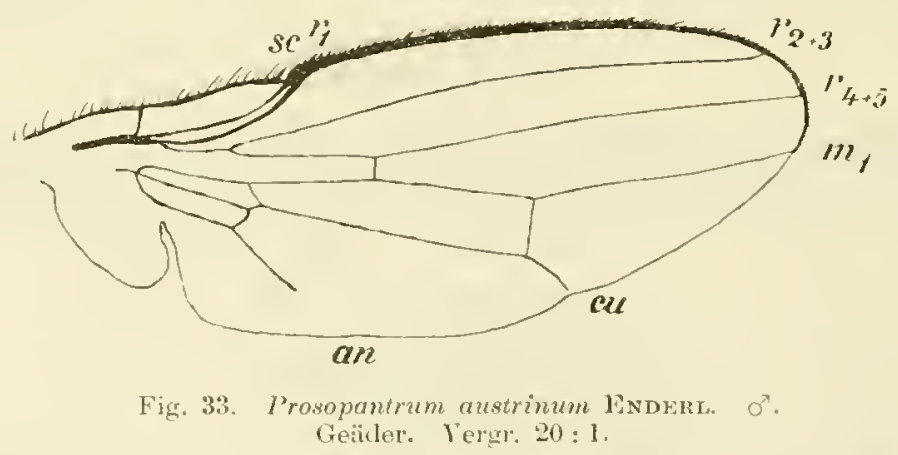

Die Abdominaltergite umfassen den Kööper nicht. Abdominalpubeszenz (ठَ) kräftig, ziemlich kurz und wenig dicht; am Hinterrande des 1.-4. Tergites eine Reihe längerer Borsten.

Beine mässig kräftig. Beimpubeszenz (ठ) kurz, mässig dicht und mässig kräftig. Eine Anzahl kräftige zum Teil sehr lange Spomen am Hinterrande der Nittelschiene. Metatarsus der Vorderbeine nur behaart, am Ende ohme Dornen. 1. Hintertarsenglied am Ende unten etwas an der Aussenseite mit einem kurzen stumpfen zapfenartigen Dorn, der aber nicht verdunkelt ist. Subapikalborste der Oberseite der Sehiene (abgesehen vom Endsporn) an allen Beinen lang und kräftig, besonders an der Mittelschiene. Vorder- und Hinterschenkel ( $\left.\sigma^{*}\right)$ schwach verdickt.

Haltere aufgeblasen, fast kugelig, nach dem dïnnen Stiel zu allmählich rerjüngt.

Flügel mässig schlank (Fig, 33). Pterostigma fast völlig rednziert. Dornen an der Costa ausser der Pubeszenz wenig kräftig, nur bis zur Miindung ron $r_{1}$. Subcosta mässig stark an $r_{1}$ genähert. 
Prosoprumtrum allstrillm, nor. spec. - Textfig. 33.

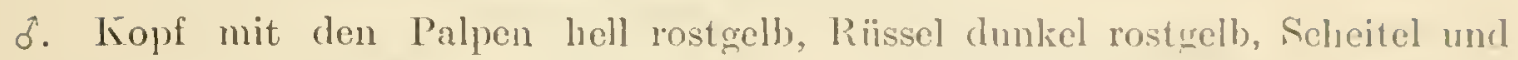
Hinterhaupt schwarz mit weissgrauem Reif. Angen hell, kum oval. Haare und Borsten sehwarz und senkrecht abstehend.

Thorax sehwal" mit grauweissem Reif. Haare und Borsten schwar\%. Abdomen schwarz mit weissgrauem Reif; die Hinterüinder der hinteren Tergite schmal hellex' gesäumt. Beine mit den Coxen hell rostgelb, Hinterschenkel leicht gebräinnt, Vordersehenkel gebräunt, aussen fast sehwärzlich nit grauem Reif. Endhälfte des Vorderschenkels unten mit einer Längsreihe mässig langer abstehender Horsten. Klauen lang, mässig dïnn, gebogen und selhwarz.

Flïgel hyalin mit sehwaeh granweisslichem 'Ton. Adern hell branngell,. Vorderrandborsten rötlich gelbbraun. Membran leblaft grïn bis rot irisierend.

Körperlänge $3^{3} / \mathrm{s}$ mm.

Fliigellänge $4,2 \mathrm{~mm}$.

Siid-Georgien. Bay of Islets. 8. Mai 1902. 1 o..

Subordo: Orthorrhapha.

Superfam. Nematocera.

Eucephala.

Fam. Chironomidae.

Subfam. Tanypodinae.

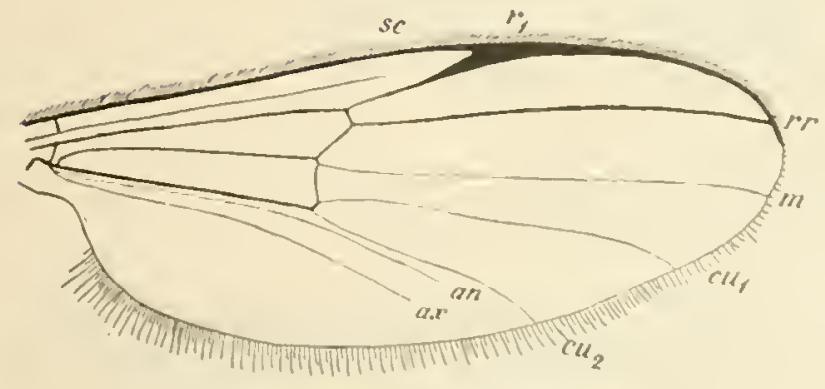

Fig. 34. Ochlus Stcineni Ifreck Feidler. Vorgr. 40:1

K. Sr. Vet. Akud. II:andl. 13:and 48 . X:o 3

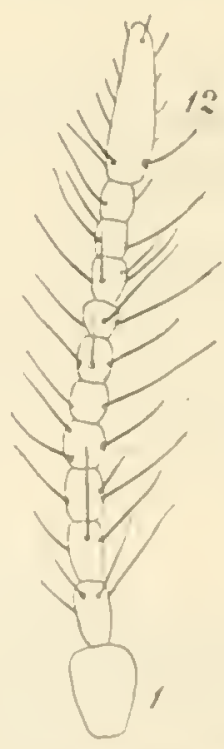

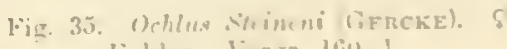
lubler. Verger. lie 1. 
Or/hlH.S ENDERL. 1912.

Enderteis, In dieser Abhandlung pag. 107.

Orhlls steimeni (GERck 1889). - Textfig. 34, 35.

Tanymus Steineni, Gercke, Jahrb. IIamb. Wiss. Anst. VI. 1889, p. 153-154. Textfig. (Süd-Georgien.)

" " Gercke, Pfefter, Die niedere Thierwelt des antarkt. Ufergeb. 1890, p. 48.

Ochlus \# (Gercke) m.

Kopf, Thorax, Abdomen sehwarz. Beine, Fïhler gelbbraun. Flïgel hyalin, Adern hell bräunlich ockergelb. Fühler 12-gliedrig.

Suid-Georgien. Cumberland-Bay. Bores Tal. 29. Mai 1902. 1 ․ An einem See. 'Temperatur + 1,20 C. - Cumberland-Bay. 23. April 1902. - 21. Mai 1902.

q in Anzahl anf Schnee. - Grytviken. 28. Mai 1902. $q$ auf Schnee.

Superordo: Haplognatha.

Ordo: Mallophaga.

Subordo: Ischnocera.

Fam. Ricinidae.

Eurymetomus Taschenb. 1883.

Eurymetopus tamms (NiTzscII 1818).

Süd-Georgien. Bay of Islets. Vom Albatros (Diomedea exulans L.) 9. Mai 1902. $\delta$ und $q$ in Anzahl.

\section{Lipenms Nitzsch 1818. \\ Liperrols tiomerlae (L.).}

Siid-Georgien. Bay of Islets. Von Albatros (Diomedea exulans L.) 9. Mai 1902. 2 Exemplare.

Ordo: Collembola.

Subordo: Arthropleona CB.

Fam. Poduridae.

Subfam. Hypogastrurinae CB. 1906.

Yem!lla Tulab. 1869.

Yenylle mumicoln O. Fabr.

Xenỵlla lumicola (O. Fabricius).

affinis, Schäfter, Frgeln. Ilamb. Magalh. Sammelr. 2. Lief. Apterygota. 1907, 1. (Magellau Strasse.)

lınnicola (O. l'abr.), Walılgren, Wiss. Ergebn. schwed. Sürlp-Experl. Bul. V. Lief. 9. 1906, 1) 5. (SürtGeorgien.)

O. Fahr., Enderlein, Dentsche Siidp.-Exped. Bd. X. Zool. 11. (1908) 1909. p. 500. (Süd(ieorgien.) 


\section{Subfam. Onychiurinae. \\ Trullberyirl Lubrs. 1876.

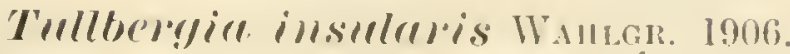

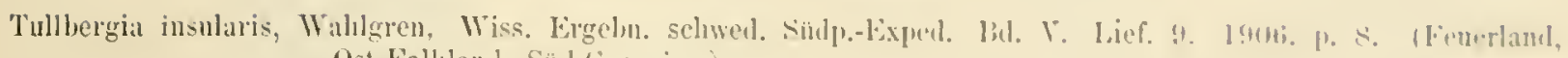
Ost-Falliame. Sül-Georgien.

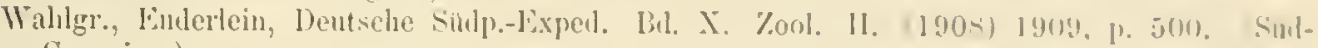
Georgien.)

Fam. Entomobryidae.

Subfam. Isotominae (ScrïrF.).

Tribus: Anurophorini CB. 1906.

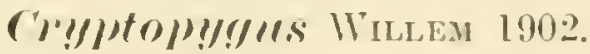

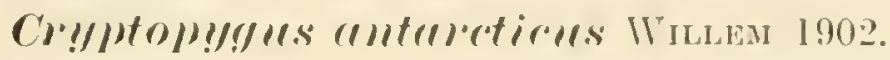

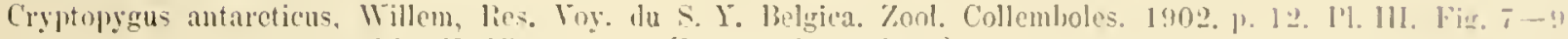

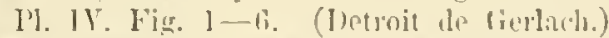

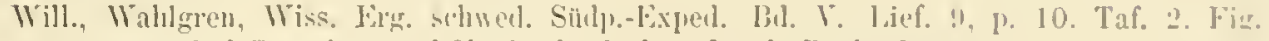
16-18. (Süd-Georgien, Siu-Shotland. (iraham-I,and, Panlet-Inecl.)

Will, Enderlein, I) entsche Sirdp.-Jxped. lid. X. \%ool. 11. 190!), 1. 500.

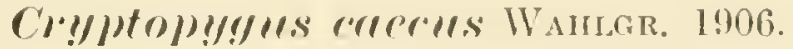

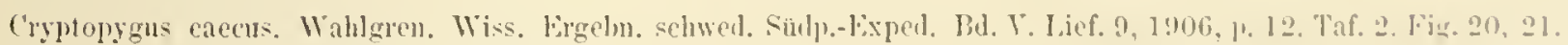
Sül-Georgien.)

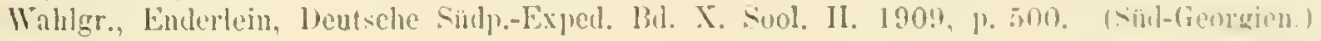

Tribus: Isotomini CB. 1906.

Isotomar BoukL. 1839, C. B. s. str. 1906.

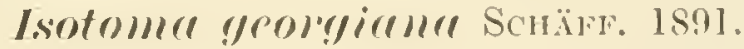

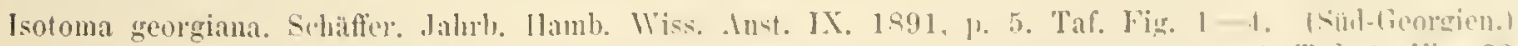

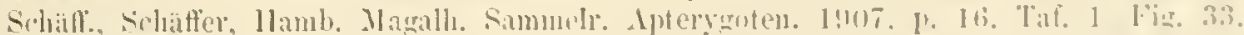

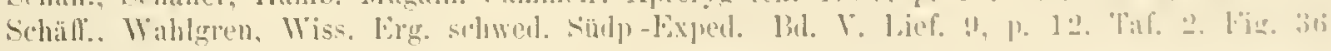
(Fenerlame, sul-(ieorgien.)

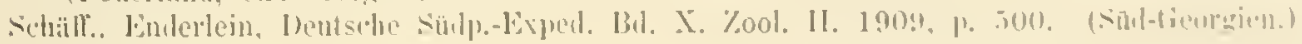

\section{Entomologische Literatur iiber Siill-(ieoreicu.}

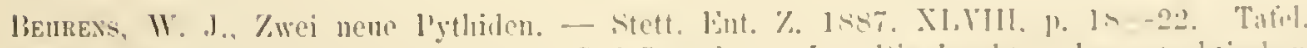

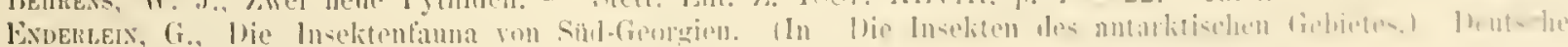

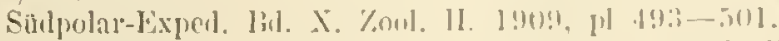

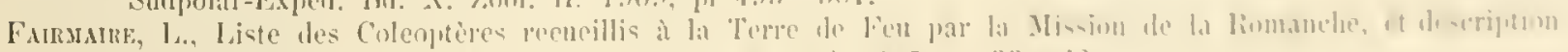

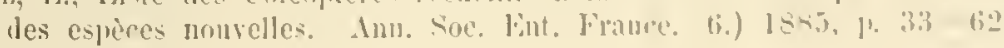


Futvel, A., Staphythides exotiqnes nouveaux. 2e Partie. Lev. Ent. franç. XXIII. 1904 (p. $76-112$ ), p. 93.

Genclie, G., Vorlünfige Nachricht über die Fliegen Süd-Georgiens, nach der Ausbente der Deutschen-Station. 1882 -83. Jahrb. Ilamb. Wissensch. Anst. Yll 1890, 1). 153-154. (1 Textfig.)

Muöberg, Eric, '/ü Kicuntuis der Insektenfauna vou Sid-Georgien. Arkiv för Zool. IBd. 31 1906. Nr. 13 , p. 1-14. Tat. 1. 1. 5. Textig.

Hüller, Clemess, Käfer vou Süd-Georgien. Deutsche Entomolog. Zeitschrift. XXVIII. 1884. Heft II, I. $417-420$.

Preffer, G., Die niedere Thierwelt des antarktischen Ufergebietes. 1890. 120 p. Selarat aus: Ergebnisse der dentschen Polar-Expeditionen, Allgemeiner Theil. Bant II, 17. IH. Systematische Darstellung der' Fauma ron Süt-Georgien, p. 31-68. (Insecten p. 48-49.)

hégmbart, M., Description de deux Dytiscides nouveaux. Notes Leyd. Mus. 1887. IX, p. 267.

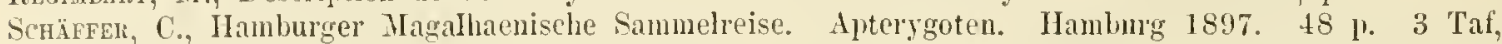

Wahlghex, Einar, Autarktische und subantarktische Collembolen gesammelt von der sehwed. Sijdpolar-Txpedition; Wiss. Ergebn. schwed. Südpolar-Expedition 1901-1903. 1906, p. 1-22. 'Taf. I u. II. 
Übersichtstabelle über die Arten- und Gattungs-Verteilung über die gesamte Antarkto-Archiplata-Region.

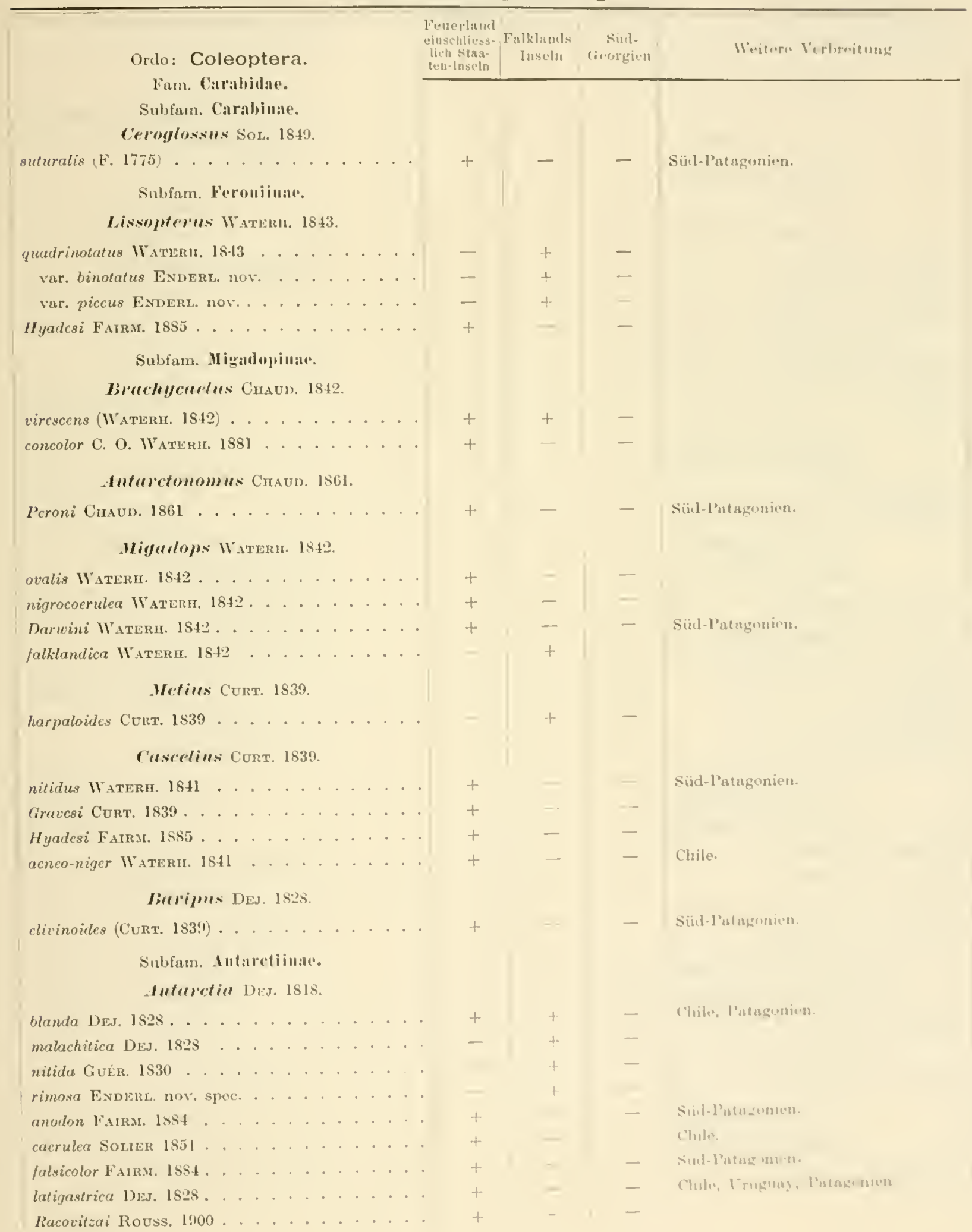




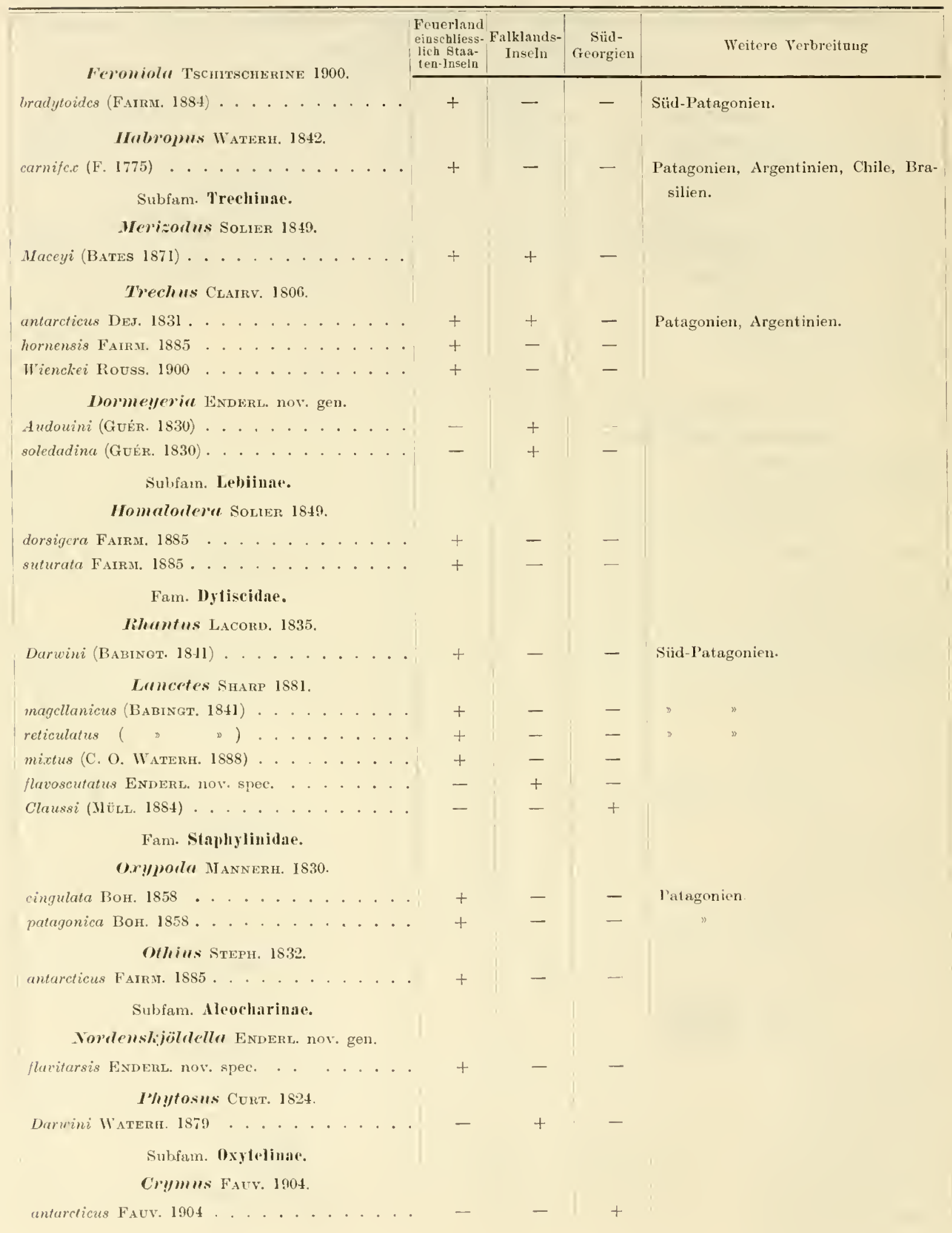




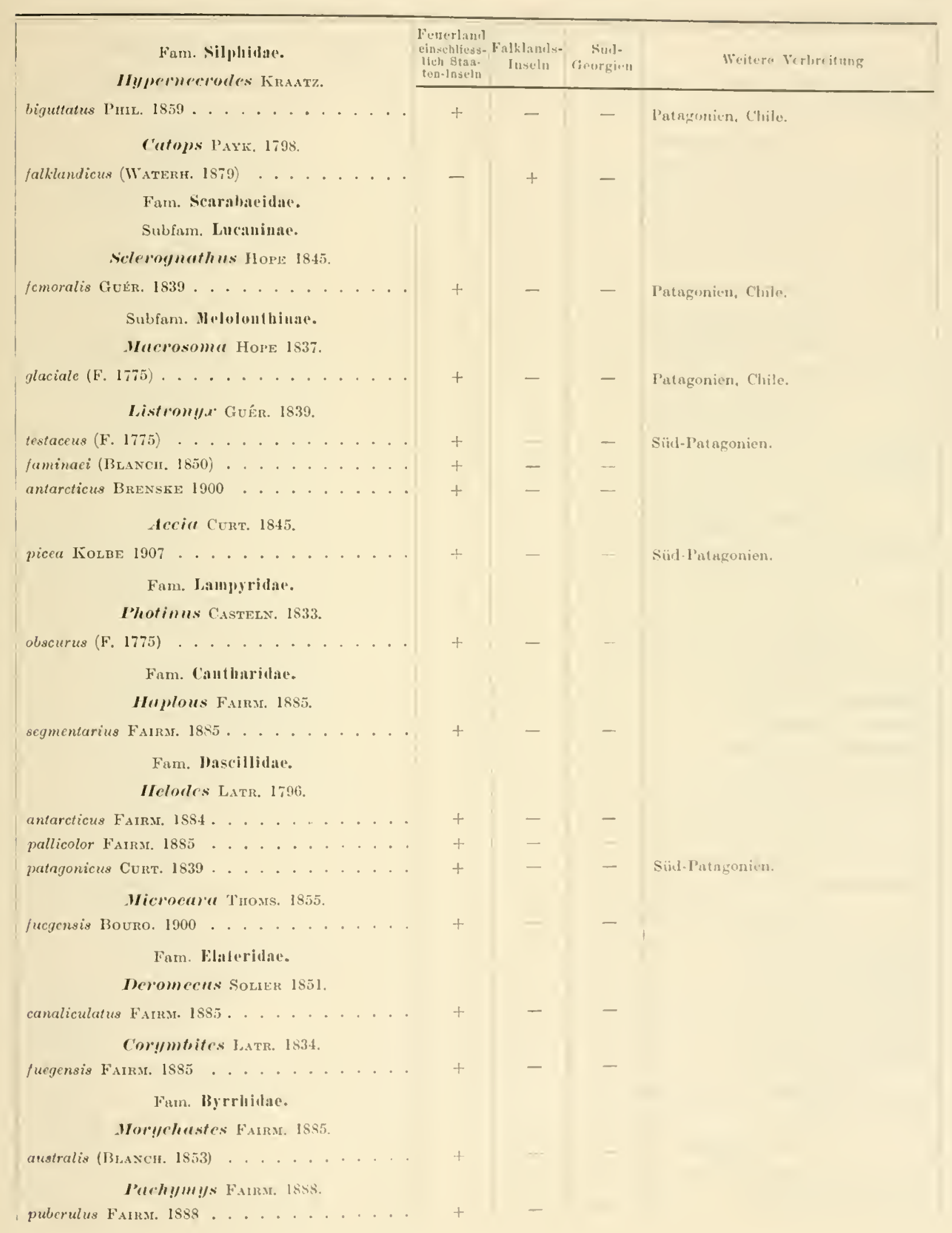




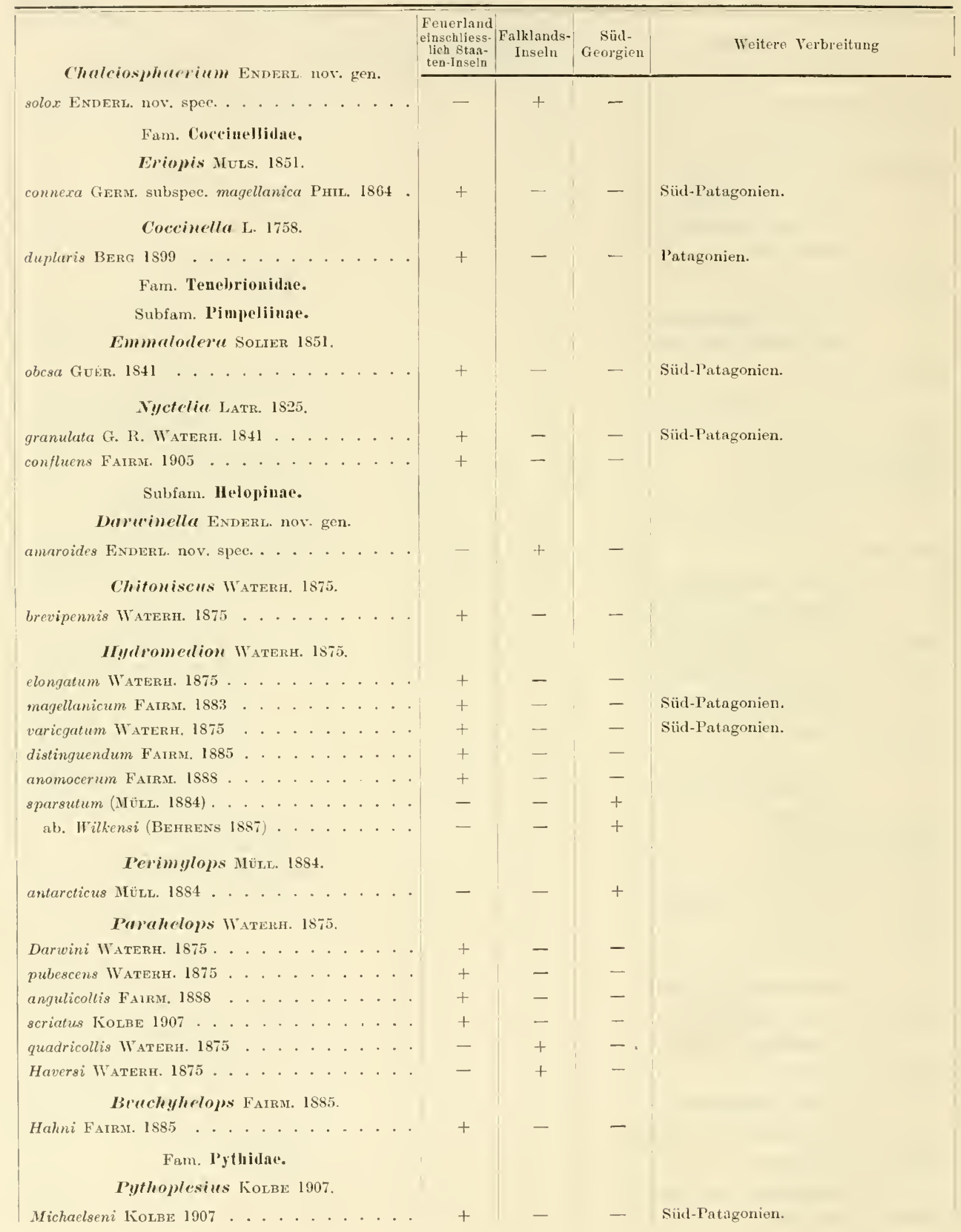




\section{Fam IIrlautryilat.}

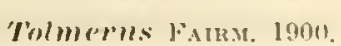

Fivurerland

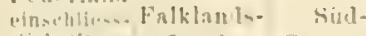

lich Kisa Inmeln ficurgen

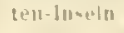

livere Vislentung

lontiperuis FATRM. 1900

Fam. Cerambycidate

subfam. Prionihat.

Microplophorus BR.ANCH. IR.T.

custanens BeAnCIT 1851 . . . . . . . .

("hile, Sïrl Patugunien.

Subfam. Cerambetuac.

Holoptej"lis Branch. 185.).

antarcticus Aurrv. 1910

sigbilla.

Dancoi I.AM. 1900

Calloplly, NEWM. 1540 .

semicaligatus Fatrm. I\$59. . . . . .

Hormibills Fatrat. 1SS5.

sulcifrons FAIRM. 1855

Fam. Clirysomelidar.

Subfam. lialerucinac.

LUMN"WS GEOFFR. 1762.

marginalis ALL 1890 .

Peltobothrus ENDERL. now, gen.

Ohlinianus FiderL. nov. ge

Fam. Curculionidare.

Subfam. Ofiorrhyuchilate.

Mior\%hluchls: GerM. 1824.

antarcticus STIERL. 1903

Subrom. Cyliulrorthinina.

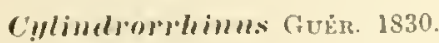

con/useanus Berc 1899 . . . . . . . .

fliouistus W AтекH. 1847.

sulcrutus Faimur 1885 . . . . . . . .

fuegianus $13 \mathrm{ERa} 1899$.

Scotoeborus scröoxu. 1843.

Interalis BERG 1899

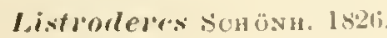

Hyadesi (Famm. 1N85).

lacunosus ( - ).

dissimilis (

salebrosus

Esmert. $190 \%$

divuricatus

bicaudutus

Nordenskiouldi

vulsus

gibber

fulkfunticus

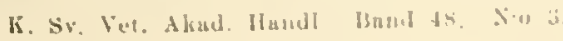


Feuerland

einschliess- FalkIands- Süd-

lich Staa- Inseln Georgien

Weitere Verbreitung

bracteatus

FNDERL. 1907......... ten-lnseln

abditus

compressiventris

Rierichrertill ENDERL. nov. gen. exsculpticollis (ENDERL. 1907) . . . . . . . . 1 insquamea scabra

F'alklalldils ENDERL. 1907.

brachyomma ENDERL. 1907 . . . . . . . . turbifinatus

sufforens

Subfam. Merpinae.

Lophotus SсH ÖNH. 1834.

vilulus (F. 1775) . . . . . . . . . . . . -

strumosus (OLIV, 1789-1808) .......... +

Subfam. Ipioninae.

LPioll HERBST 1797.

fuegianum ENDERL. nov. spec.

Ordo: Lepidoptera.

Subordo: Harmoncopoda.

Fam. Pieridae.

l'iris schr. 1801.

theodice Borso. 1832 . . . . . . . . . . . +

argyrodice STAUD. 1899 . . . . . . . . +

microdice (BLANCH. 1852) . . . . . . . . . +

Fam. Nymphalidae.

Subfam. Symplatinat.

Heylmis F. 1807.

Cytheris (DRURY 1773 . . . . . . . . . . +

Daruini StaUd. 1899. . . . . . . . . . +

Fam. Saf yridae.

Evobill DaL3. 1816.

plumbeola (BоT⿺. 1816) . . . . . . . . . + +

Fam. I.inantridat.

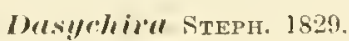

platyptera WAB. $1885 . \ldots . .$.
Fam. Lasiocalluidae.

Jirjhil HÜвN, 1826 .

(zmphimone (F. 1775)

Farn. Aaturuidae.

Ceveophama FeLd. 1862

Frumenfeldi FELD. IS62. . . . . . . . .

- +1

- +

- +

$\begin{array}{rrr}+ & + & - \\ + & + \\ - & + & -\end{array}$

$$
\text { ב }
$$$$
+
$$$$
+1
$$

$+$

$$
-
$$$$
\text { . }
$$

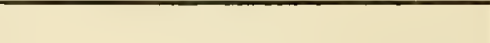


Fan. Xuctuilar.

Subfun. Inrotinat.

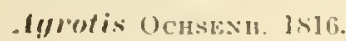

lispidult GuEs. 1852

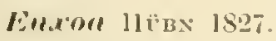

Intcscens (Bus (B)H. I85:)

falklandica HAMPS. 1903

\section{Felti" WaLk. 1)50.}

malefida (Guen. 1852)

clerica (13UTr. 18S.

pexa (13ERG 1877)

Episilee Hนва, 1827.

grarida (MA B. 1SS5) . . . . .

bicolor (Mla B. 1895, .

flavicosta (11.ALLGR. 1860)

frigida (MAIB. 1855

xanthostola (.MAB. 1SS5

perdila (STAUD. 1899

typhlina (1IAB. ISS5)

Lyeophotie Hïв.. 1827.

mersict (Given. 1852 )

minna (ButL. 1SS2)

molibdoidca (STAUD. IS99)

hostilis (Watk 1557) . . .

Subfam. Hadenitrate.

thatena scm. 1802.

tetragonn $21 \mathrm{AB} \quad 1855$

Imarta Ochs. 1816.

trisema МАв. 1955.

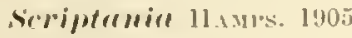

Michaclseni STAUD. 1899

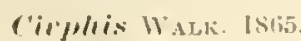

falklanetice (BUTL. IS!3)

Lenerenie HïBs. ISIS.

anterctice sir.ued. 1899

remola STAUD. 189!

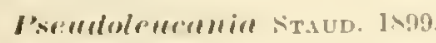

igniculu STAUD 1 s:19.

subfau. Orthosínae.

(1)thosice 0. 1816.

Duruini STAOD 1599 .
Chile.

( hul.

Von Irgentmun lis Nord-Imurika.

('hile, siul-l'utagunum.

- Pratagonien.

$-$

Süd l'atagonien.

I'ntagonien.

Siid-Pastagonien.

l'atngonien.

l'ntagonicn.

Sïd-Patagunien.

l'atagomian.

Chile

Sïrl-Patugmient.

siul l'atagiunt.-1 


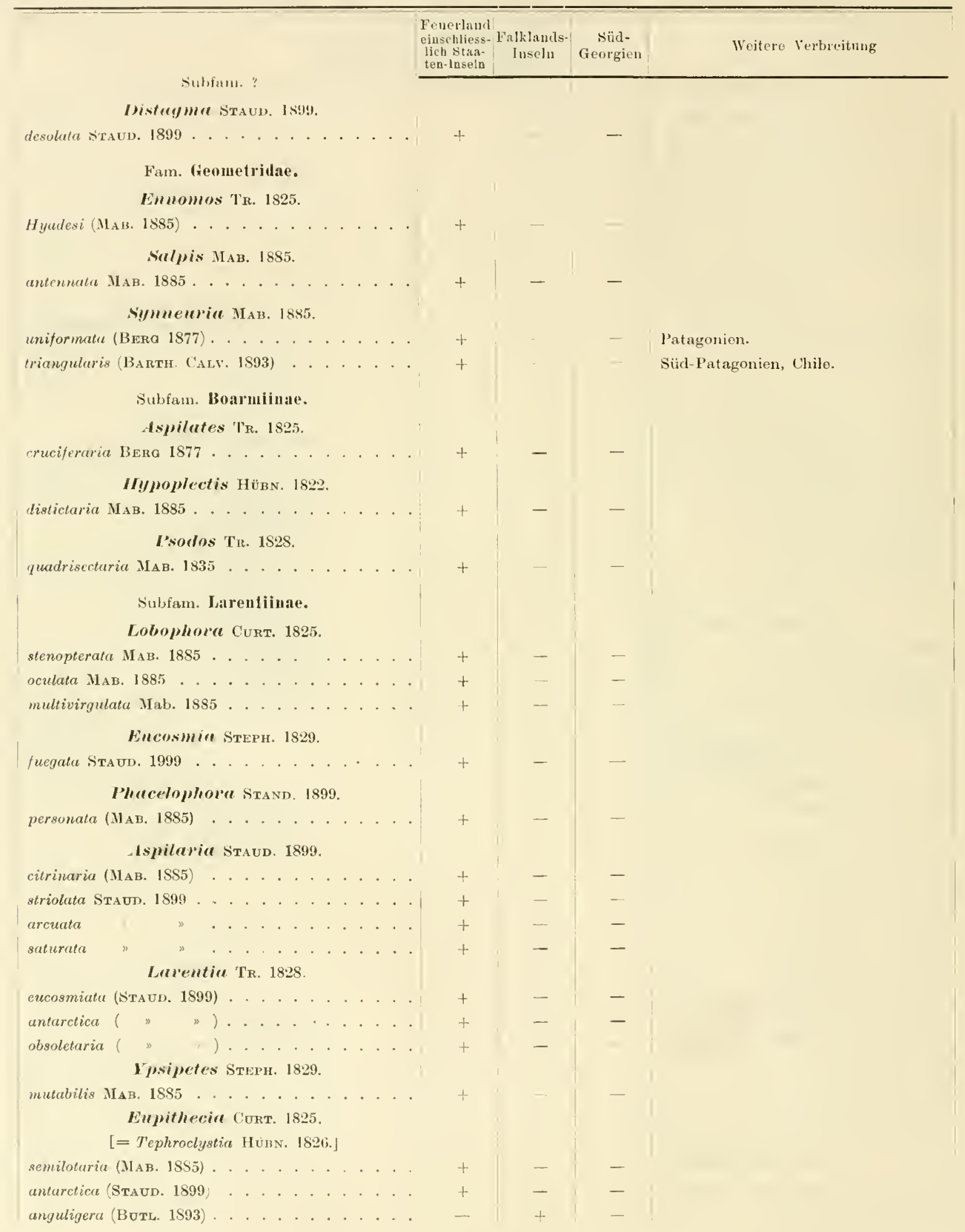




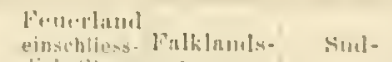

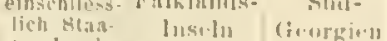

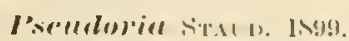

debilis suen. IS99

Fun. ?

Ifurima 11. ILk. Ist3.

spoc. Buther 1893

Sulurilu: Stemmatoncopoda.

l'un. Hepialidale.

Ilepirlus F. 1775.

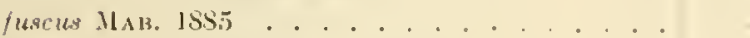

lutcicomis (BERo 1S8.2) . . . . . . . .

andarclicus STAUD. 189

Fun. Pyrafidar.

Subiam. ('raul)lune.

Cormluns F. 1798

birudiellus М Aн. 1SS5. . . . . .

iynicola StaUd. $1899 \ldots . . . .$.

spee. Staud. 1899

falklandiccllus HAMP. 1895

Sropmria 11 w. 1803.

antarcticalis STAUD. 1899

qlanculalis HAMP. 1897

Fam. Timeidac,

Sulfan. 'Tineinat.

Tiure L. 1755

guleutella $11 \mathrm{AB}, 1888$

Timeole H. S. 1853

biselliella $\mathrm{HML}$

Fam. (ielechlidae.

Hepressthrie Hw. 181:

vemutelhe Sitaud. 1859

(ing)tolerhire \%. 1853

tortricelle STAOD. 1599

ONeophom Latr. 1806.

spec. SitAud. 1999

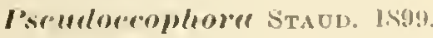

vilcllinclla STAUd. 1899.

Eurloris $11 \mathrm{R}, 1 \mathrm{~s} 1 \mathrm{~s}$.

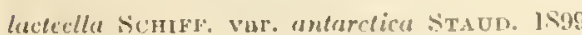

Fum. l'terophoridae.

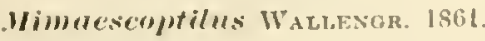

amearcticus STAUD. 1899
Miritar.r. Pirbresteng
Kosmopolit.

Kosmopolit. 


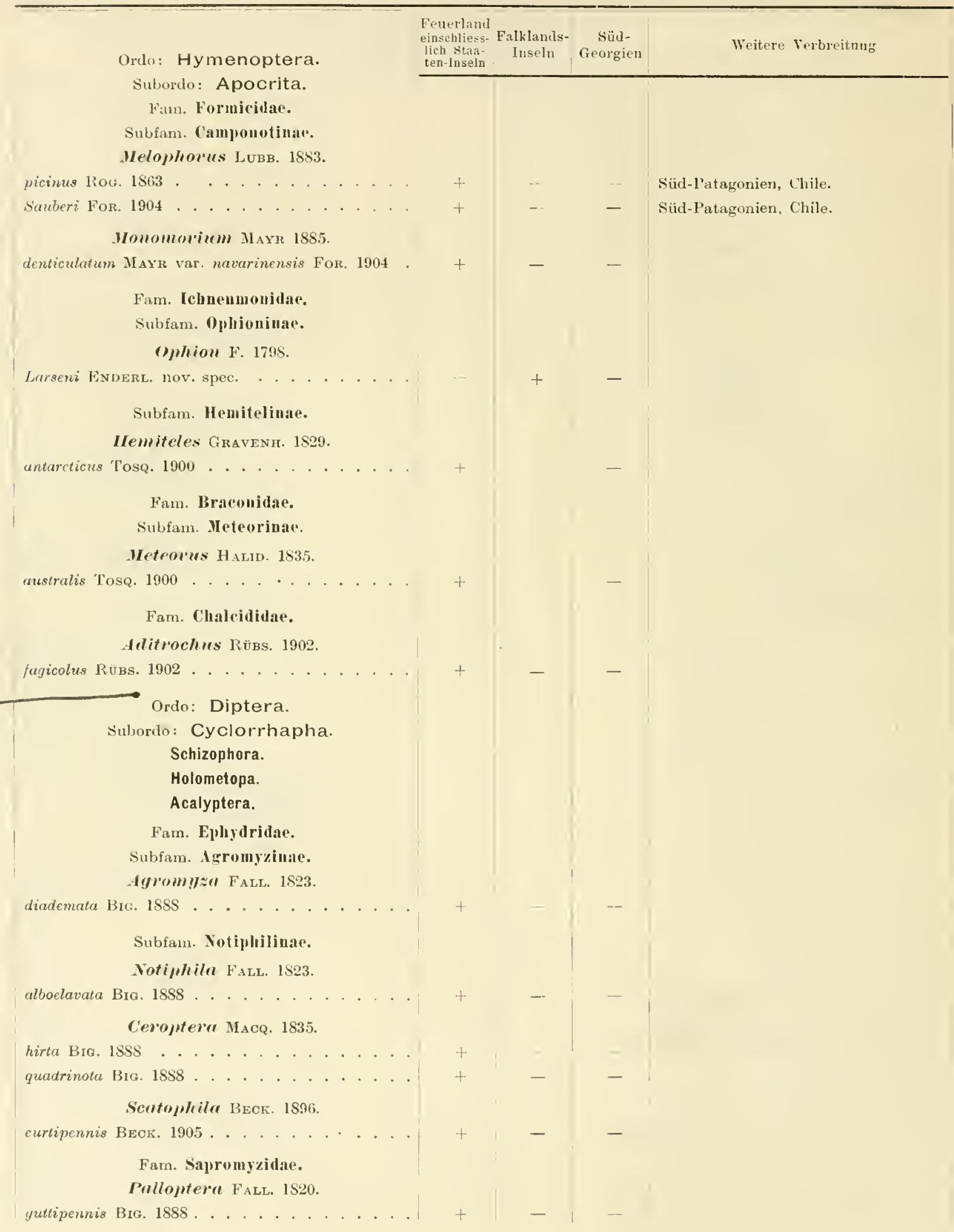




\begin{tabular}{|c|c|c|c|}
\hline [*เm. Il $\cdot$ ] & $\begin{array}{l}\text { FentrlatuI } \\
\text { einochlinss. Falklanils- } \\
\text { lieb Gian- Inselu } \\
\text { ten-inmeln }\end{array}$ & $\begin{array}{l}\text { Sinle } \\
\text { (ivos) }\end{array}$ & Wi it. re Verloresensig \\
\hline
\end{tabular}
reneris 131G. IKSS.........

\section{Irrilt RoB. Dist: 1830.}

rufifroms BIr: 1SSS.

picticornis BIG. 1SSS . . . . . . . . .

penicillipes FNIERI. nor. sper.

Heloperia Finger. nov. gen.

Ekelófi ENIJERL. nov. spec............ - - -

Fam. Oryomyidate.

Ietorel MEIc: 1826.

cinerascens B1G. 1SSS. . . . . . . . . . . +

rufina Big. ISSt. . . . . . . . . . + t

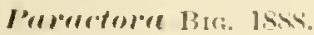

Juegiama BIA. ISSS

flaripes (MACQ, 1543)

Artoceless ENDERL. nOv. gins.

abscondila JiNDERL. nov". spec.

Fam. ('oclopidare.

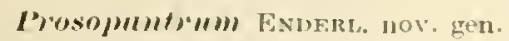

austrinum ENDERL. nov. spec.

Fan. Borboridac.

lioblurtes Mkrg. 1503.

varipes Bia. 1 sss

IUtMJPS ENUERL. 1909.

trunciponnis ExDERL. 1909

l'an. Ścionyzidate.

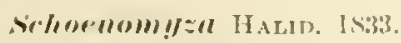

fenestrata B310. ISSS

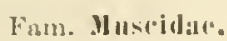

Subfum. Ilnsciuae.

Iynulesim!gin BIo. ISSS.

clausa 13IG. 1SSS . . . . . . . .

sarcophanidea lisa. ISSS

Sishfan. Intlomyinat.

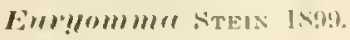

lispaniense S'TEIN $1 \$ 99$.

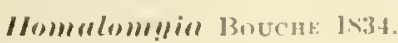

erythropis 131\%. ISTS . . . . . . . . . . t t

Fan. Tachinialat.

Subfam. 'Tachiแinat.

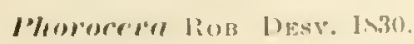

trimusulifers Jac. 1:00 ........ 


\section{Aschiza.}

Fam. Syrphidae.

Subfarn. Nyrphimae.

Melamostomal Schin. 1860.

longigena Endert. nov. sper......... + + +

stegnum $(\mathrm{SAY}$ [829) ............ +. +.

\section{Subfam. Eristalinate.}

Eristulis LATr. 1804.

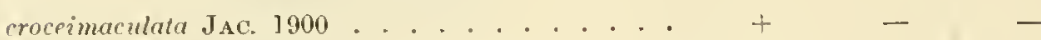
quadrirornis (MACQ. 1S42)......... + +

Holophilus MEIG. 1803.

Hahni Bre, $15 s e$

\section{Subordo: Orthorrhapha. \\ Brachycera.}

Fam. Dolichopodidate.

C'hrysotus MErC. 1824.

luctuosus Big. 18SS.

\section{Fam. Empididae. \\ Subfam. Hybotinate.}

Shluicosal PhiL. 1865.

bicolor Bif. $188 \mathrm{~s}$

Subfam. Empiliuac.

Empis Z. 1763 .

anthracina BIG. $188 S$

Milarempis Bezzi 1905.

megellanica BIG. ISSS . . . . . . . . . + + . . . . .

maluinensis ENDERL. nOv. spec........ -

Inticornis (B1G. 1S8s) . . . . . . . . . + +

orhracea (BIG. ISSS)

Lrptopezu MaCQ. 1828.

rivosa Bra. 1858 .

Suhfam. Ocydromiinae.

ocydromill VEJG. 1820.

elegans 13IG. 1SSS

Nematocera.

Polyneura.

Fan. Tipulidae.

Subfam. 'lipn]iuate.

Timulı L. 1735.

- (vergl. unter Zusätze am Schhuss!) 
Jemerlanil einschliess- linlhlat l- siml-

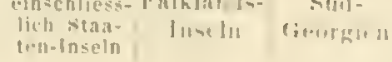

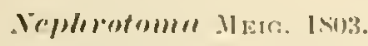

merincure BIG. ISSS

Iscllmothri.r Bar. Isis.

aetheren 13Is. 1SSX . .

$$
\text { Fum. Limunidae. }
$$

Limmin Meir. 1503 (= Limmol,in MeIa. ISIS lineicollis (13Lanc11. 19.52 . . . . . . . . Bigoti nos nuan. . . . . . . . . . stigmatira BL.uncur. 1\$5\%?

Limmophilu Mace. 1834. eutaeniratu 13ra. 1859

tmalopis H.tem. 18.56. pusilla (Bro. 1958) . .

I'uecilostole sichis. 1863. flericaude BIt: ISSS

Yalusa ENHERL 190. julkluntica W.NoErL. 190.).

$$
\begin{aligned}
& \text { Fim. ('ulicidae. } \\
& \text { Subfam. f'ulicinate. } \\
& \text { r'mled J. 17til. }
\end{aligned}
$$

Iluripes varre 1535 .....

$$
\begin{aligned}
& \text { Fam. l'sychoslialas. } \\
& \text { I'st/rllodla Litr. 179ti. }
\end{aligned}
$$

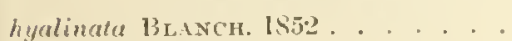
dubia list. loss

Fam. Simullidar (Mrdusinilate).

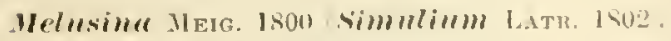
fulveacens (Braxcri, 1\$52) . . . . . . . chilense (1'11L. 1S65) ......... unthracinum (13IG. ISSY) anfarcticum (13rG. 1858)

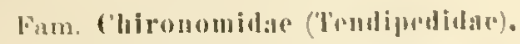
Subfan. 'Temdijudinat.

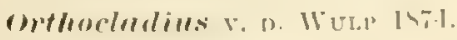
perplesillus FoviderL. nov, speer.

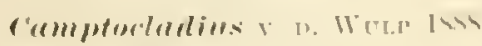
nigripectes 131G. IKS: .

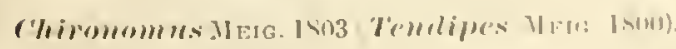

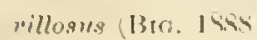

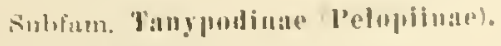

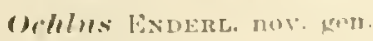
uschurrensis Forntart. nos: spece,

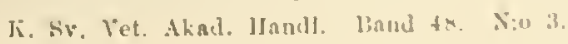




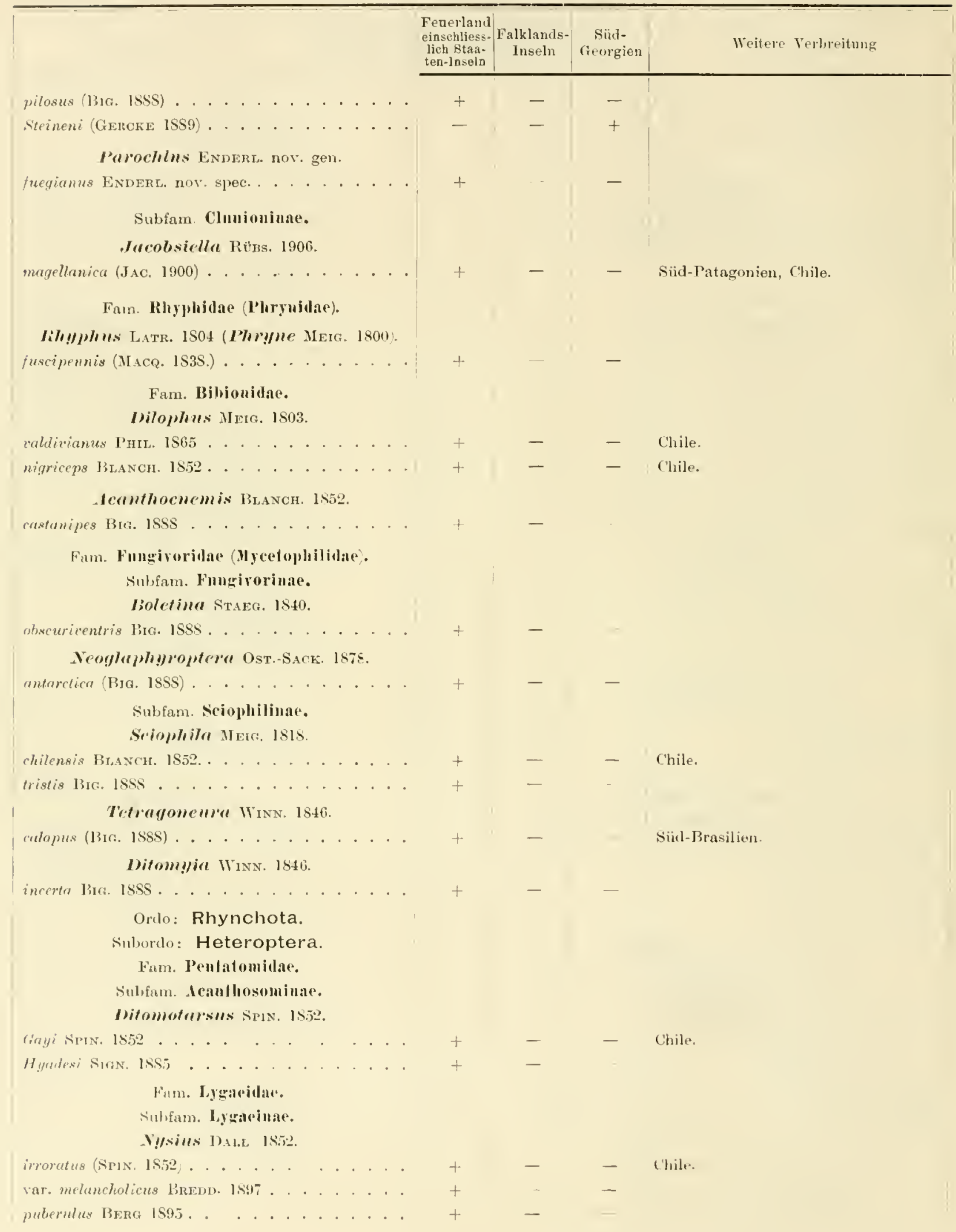


Fonirlani

einstlaliess. Falklamdno Siud.

Subfan. Cyminge.

lich biat Inqu ln diengreu

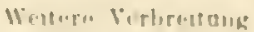

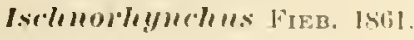

hylinatus (SPPIN. 1852).

Subfan. Phachymerimac.

Bevgidia 13REHD. 1897.

polychrome sprs. 1852). . . . . . . . + +

Subfam. Hoterogastrinate.

Irlostoles: Bеко 1844.

insuleris 13ERG $18 \$ 3$

Fan. Reduvidala.

subfam. Sablune.

Nubis L.atr. 1807.

faninei șRL $18.59 \ldots \ldots+\ldots \ldots$

Fam. Aralidar.

Subfam. Isoderminta.

Isorlermus Erichs. 1812

Gayi (SpIN. 1852) . . . . . .

Fam. Henicorephalidar.

Henicoceplualus Westw. 1537.

subantarcticus BERG 1SS4..........+ + + -

Fam. Peloridac.

I'eloridium BREDD. 1597.

Hammoniorum BrEDD. 1897

Fum. Corisidate.

Ectemmosteg" ENDERL. nor. gen.

quadrala (Sian. 1585) . . . . . . . .

Frm. Cupisidae.

Subfam. lhytocorinae.

Miris F. 1803.

Dohrui ṡtat 1950

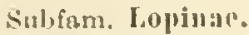

liesthenirl Sin. 1841).

/uegiane 13ERo 1895

\section{Subordo: Auchenorhyncha.}

Homoptera.

liam. dassidie.

Subfam. Icoceplatinate.

deorepholus Germ. 1833.

(?) falkilundicus Evnere. nov. spec.

subfau. Bythoscopinar.

Alyullin Cernt. 18:33.

Insularis BERO 1SSH ..... 


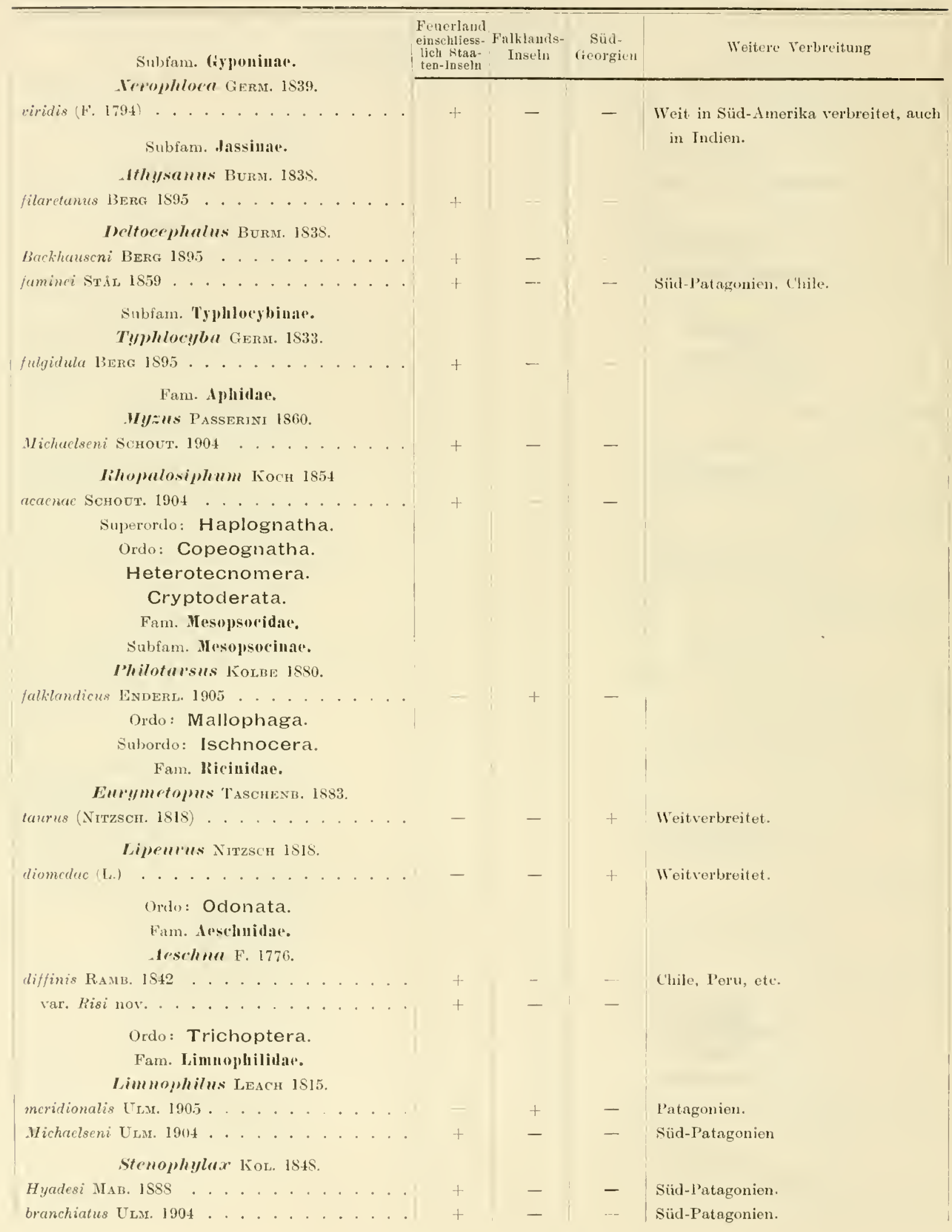




\section{Fenerland}

einsubless- Fulklitme- Siud-

lich stait- Insmln diempin

tich siart-

licorgin'th

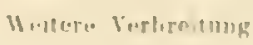

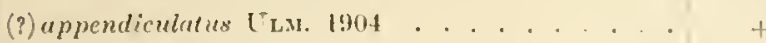
spec. [tlu. 1904 . . . . . . . . . +

spec. Ular. 1904

I mabolil STEPH. 1535.

spinosa Ulsr. 1904 . . . . . . . . . . +

Ordo: Orthoptera.

Fam. Phasgounilate.

subfam. Rhaphidophorin:u.

Tribus: Ceuthophilini.

I'Trudemis ENDERL. I909.

falklandicus ENDERL 1909 . . . . .

Ordo: Plecoptera.

suborlo: Holognatha.

Fam. (iripopterygilate.

Subfan. Antaretoperlinar.

Inturetoperla ENDERL. 1905.

Anderssoni EnderL 1905. . . . . . . . . t

Michaelseni (KLLAP. 1904) . . . . . . . . . .

Sotoperle ENDERL. 1909.

fuegiana ENDERL. 1905.

Subfam. Gripopteryginae.

Gripopteryx P1ст. 1S41.

myridon (MAB. 1SSS)

Fam. Semuridite.

Subfam. Yemurinae.

CAlumocereil ENDERL. 1909.

untarctica ENDERL. 1905. .

Ordo: Agnatha.

Fam. Ephemuritue.

BrePtis LEACH IS15.

spece, Uhaer 190.t.

Ordo: Collembola.

Fans. Pouturidice.

Subfam. Iypogastrurillate.

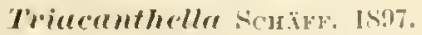

Michaelseni SicnïF. 1897 . . . . . . . . t

rosea W AHLGR. 1906 ...........

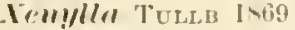

humicola (F.)

Subfam. Onyehiurine.

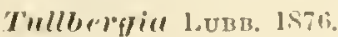

insularis WAnLoR. 1906 . . . . . . . +

trisclosa SсH.іFE. $1897 \ldots \ldots+\ldots$

var. quadrisctosa (W1LL. I902).

spinosissima WAHLR. 1906 
Fenerland

einschliess- Fallilamis- Sïd-

lich Staa- Inseln Georgien

Weitere Verbreitang

Subfan. Ichorntiunc.

'l'ribus: Pseudachorutini.

rhomalachorntes WAHLGE. 1906.

tuberculutus WA WLer. 1906 .

Iriesere D. 'T. 1895

yrisea (SCḦ̈FF. 1891).

Ammida LABOULB IS65.

clavalı SсnӥғF. 1897 . . . . . . . . . .

siteincui " 1891 .

Psenaluchorutes ToLis. 1871.

subrrassus (SсḦ̈FF. 1S97) . . . . . . . . .

l'olyacentliellı ScnÄFF. 1897.

brevicuuda Бснд̈FF. 1897

"l'rilus: Achorutinl.

fehorutes TEMTI. 1835.

viaticus (L.) . . . . . . . . . . . . .

purpurascens Lовв. 1868

Fam. Entomobryidac.

Subfam. Isotominat.

Tribus: Isotomini.

Isotomar Boure. 1839, C. B. s. str. 1906.

georgiana SсḦ̈F. 1 S91 . . . . . . . . .

punctato WAHLGR. 1906 . . . . . . . . .

silvatica $\mathrm{SCH}$ ÄFF. 189

Besselsi ГACK. 1873

malvinensis WAHLCR. 1906 . . . . . . .

tigrinella $1 V^{\top}$ AHLGR. 190

ornata WAHTCR. 1900

Tribus: Anurophorini.

Cryllofllgus Hits. 1912.

Cinctü WAHLGR. 1906

antarcticns WILL. 1902
caecus IVAHLGR. 1906.

Subfan. Eutomobryiuse.

Trilus: Isotomurini.

Tomocemllin WAIIGR. 1906.

conjungens (ScHÄFF. 1897).

Tribus: Entomobryini.

Eutmothy!r Rosn. 186l.

whlch⿱ SСH ̈̈FF. 1897

I'fenm'r T'EMPL. 1843

variabilis (Son.̈̈F. 1897)

Fam. Siminthuridac.

Subfam. Siminthurine.

Smintllm.s Latr. 1804, C. B. s. str- 1906. pruinosus TULLB.

serrulus SсHÄFF. 18.9
Gralıam Land u. Siid-ShetlandInseln.

Weit verbreitet.

Voit verbroitet.

Arlitische Region.

Siid-Shetlands-Inseln, Graham Land. 


\title{
Verschleppte Insekten.
}

Auch gelegentlieh dieser Expedition \%eigte es sich, wie leicht Irrtiimer des Fundortes entstehen kïnnen.

So fand sich in Nloos ron Siid-Ceorgien und Falklands-lnseln, das Herr Professol Dr. Ricnters auf Moosbewohner durchsalı, cin kileiner Käfer, eine Lathridicle, der sich als Carlodere filiformis Guzb. herausstellte, ein Tier (las nach bricflicher Angabe ron A. REICnERT in Leipzig unter anderem anch in Kellern und in Bienenwaben gefunden worden ist; es ist weit ïber Enropa rerbreitet. Es ist kein \%weifel. dass dieses Tier auf dem Sehiffe nachträglieh in das Moos gelangt ist.

Es empfielt sieh daher, Moosproben röllig dicht, vielleicht in geräumigen (ilis. röhren, abzuschliessen.

Ein zweiter eigentümlicher Fall ron Verschleppung ist der folgende. lis handelt sich um eine grosse grine Orthoptere, die im Bote mitten in der Antarlis gefunden wurde, und die einer in Süd-Amerika weit bis nach Argentinien verbreiteten Art angehört, von wo dieses lnselit mit im Sehiffe gebracht wurde. Es ist folgende Art:

\author{
Subfim. Conocephalinae. \\ Tribus: Conocephalini.

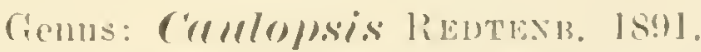 \\ liedtexbartel, Verh. \%ol. Ihot. Ges. Mien. 1s!1. 11. 37 li.
}

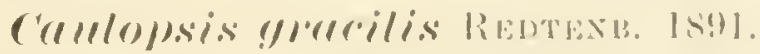

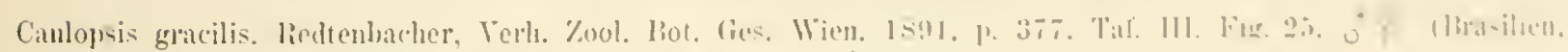
Argentinieu, l'ryguag, liusitio, (uha.)

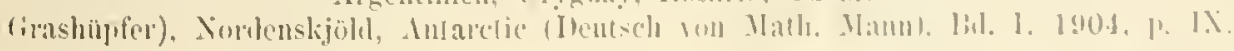

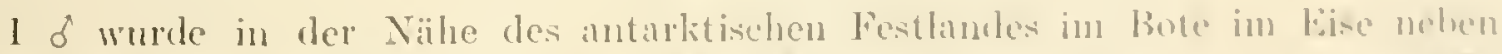

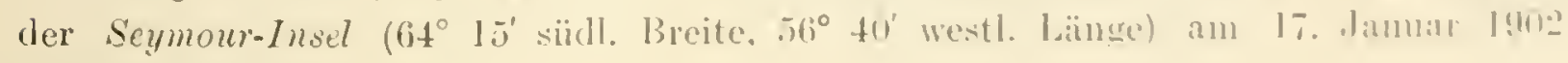
lebend gefangen. 
Da die Antarctic am 6. Jan. 1902 die Staaten-Insel berührte, am 1. Janıar 1902 an Falklands-Inseln anlegte und die Abreise von Buenos Aircs am 21. December 1901 stattfand, so unterliegt es keinem Zweifel, dass das Exenplar von Argentinien (Bnenos Aires) auf dem Scliffe mitgenommen worden ist und dureh Zufall auf das Bot geraten ist, auf dem es etwa 4 Woehen später aufgefunden wurde.

Die Diagnose des $\delta$ l. e. stimmt völlig mit dem vorliegenden Exemplar überein und ieh gebe nur noch die Längenmasse an und füge noch hinzu, dass die Vordersehenkel völlig ohne Dornen sind.

Körperlänge $34 \mathrm{~mm}$. Länge des Kopffortsatzes $5 \mathrm{~mm}$. Länge des Pronotum $6 \mathrm{~mm}$. Länge der Elytren $45 \mathrm{~mm}$. Länge der Hinterselıenkel $17 \mathrm{~mm}$. Länge der Mittelschenkel $6,8 \mathrm{~mm}$. Länge der Vorderschenkel $6,7 \mathrm{~mm}$. Fürılerlänge ca. $73 \mathrm{~mm}$. 


\section{Alphabetisches Verzeichnis.}

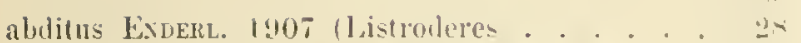
abscondita ExDEuL. nov. sleer. (Actoreles) . . 1.1 acrenae scust. 190.1 bihopalosiphum) . . 1] Icauthocnemis Bunch 1852 . . . . . . 110 dehorules TeMpt. 1835. . . . . . . . 106 Icocephalns Geru, 1833 . . . . . . . . 52 Ireia Curt 1845 . . . . . . . 711

Acloceles HNDERL. HoK gell. . . . . . . . 13 Actora MElí. 1826 . . . . . . . . . \$16

Idioristus Waterh. 1841. . . . . . T!)

Iditrocluus liébs, 1902. . . . . . . . . $19: 3$ aeneonige W WTER, 1841 (Cascelius).... lit

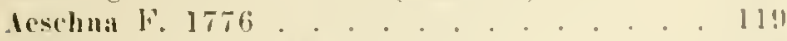
actlercil lig. 1882 Ischuothrix) . . . . . 104 uffinis Scuäff. (Xenyla) . . . . . . 138 Ixallia Curt. 1833 . . . . . . . 117 Imromyza Fuit. 1823 . . . . . . . Igrolis Ocns, $1816 \ldots 38$ alboclavata Big. lses (Totiphila) . . . . . 93 llloschäfferia Börs. 128 Imalopis IlaLd 1856. . . . . . . . . . . . . . . amaroides ENDERL. nor, spece. (Darwinella) amplimone (1.. 1775) (Himphia)

dnabolia STEPH. 183:

Anderssoni Exdert. 1905 Antaretoperlal amgnligera lictu. 1893 (liupithecia).

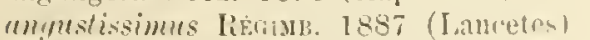

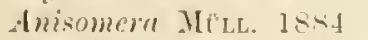
anodon Fans. 1884 Intartia

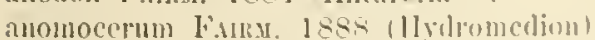
ancrulicollis Fumar. 1888 (l'araholop-) Intarctia DEJ. Is.ę

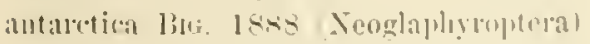

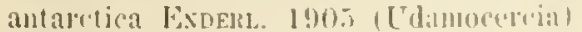
antaretica Sitad. 1899 (1ajentia) antaretica Stratd. (I.cucauia) . antaretica Sratr. 1899 (liupitheria) antareticalis Srato, 1899 Sunpitrial antareticus Aurs. 1910 (1lolnjterm-

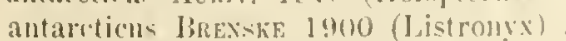
antajeticus ['Ea. 183] (Trechus) K. Sr. Vet, Akad llandl. Band $4 \mathrm{M}$. X:1 3

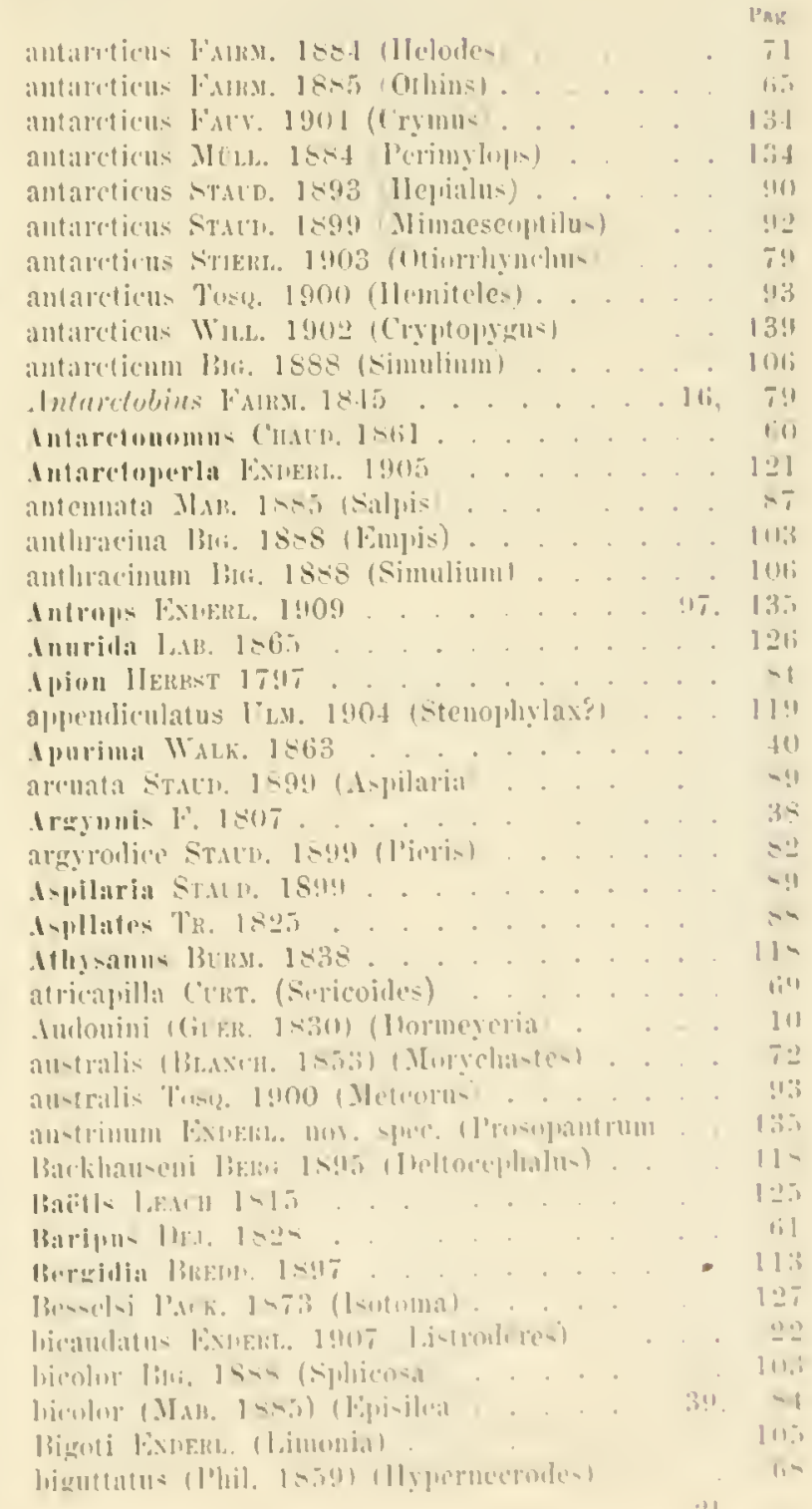


Uinotutum SuL 1849 ('yractomena) . . . 70

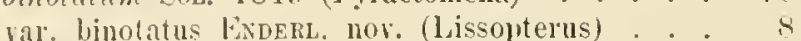
bioculatus Jilaxi'H. 1853 (Chandiognathus) . . 70 biradiellns MAB. 1885 (Crambus) . . . . . . . 91 hiselliella HnL. (Tineola) . . . . . . 9 9

Blanchardi Bektr 1882 (Agrotis) . . . . . . . \$3 blanda Des. 1818 (Antartia) . . . . . . 9, 62 Boletima STAEG. 1840 . . . . . . . . . . 111

Borborus MleIG. 1803 . . . . . . . . . . 100

Bïmerir W1LL. 1902 . . . . . . . . . 126

Brachycoedus Chatd. 1842 . . . . . . 8. 60

Brachyluelops Farrot. 1885 . . . . . . 75

brachyomma ENoerL. 1907 (Falklandius) . . . 35

lraeteatus ExderL. 1907 (Jistroderes) . . . 27

bradytoides (Fanm. 1884) (Feroniola) . . . . 62

Jranchiatus T1,3. 1904 (Stenophylax . . . . 119

brevicaurla Schäf. 1897 (T'olyacanthella) . . 126

hrevipenis Waterh. 1875 (Chitoniscus). . . . T.

calecus Wahlok. 1906 (Cryptopygus) . . . . 13!)

caerulea SoL. 1851 (Antarctia) . . . . . . 62

('allisphyris Newn. 1840........ . . . . 76

(*alopus (Bur. 188s) (Tetragoneur'i) . . . . . 111

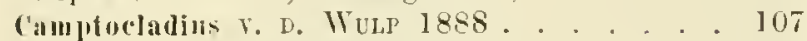

camaliculatus Fark. 1885 (Deromerns) . . . T1

carlionifera MAB. 1885 (Agrotis). . . . . S4

(arnifex (1., 1775) (Habropus). . . . . . . 63

('ascelius Curt. 1839 . . . . . . . 61

castaneus BLANCH. 1851 (Microplopliorus) . . . T6

eastanipes Hrig. 1888 (Aeanthoenemis) . . . 110

Catops PaYk. 1798 . . . . . . . 12. 67

('ercophana Feld 1862 . . . . . . . . 83

Ceroglossus Sol. 1849 . . . . . . . . . . 59

Ceroptera Mace. 1835 . . . . . . . . . . 93

Chanliognatus . . . . . . . . . . 70

Chalciosphacrum ExderL. noy. gen. . . . . . 12

chilensis Bцален. 1852 (Seioplila) . . . . . 111

chilense Pннц 1865 (Simulinm' . . . . . 106

Chironomus Neit, 803 . . . . . . . 107

Chitoniscus Waterh. 1875 . . . . . . . . 74

Choleva Latr. 1796. . . . . . . . 12, 67

Chondachorntes WaHLGR. 1906 . . . . . . 56

Chorimcrizm BeHneNs 1887. . . . . . . 134

flurysotus Iew. 1824 . . . . . . . 103

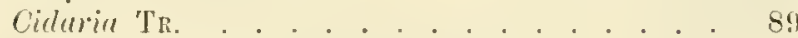

(oidchs WaHugr. 1906 (Cryptopygus) . . . 56, 127

ciuerascens Big. 1388 (Actora) . . . . . 96

cingulata Boн. 1858 (Oxypoda) . . . . . . 65

rimumomea Thaxch. 1854 COmiseorles' . . . 83

CHphis WaLK. 1865. . . . . . . . . . 3!

ritrinaria (MAB. 1885) (Aspilaria . . . . 89

clansa 1316. 1888 (Hyadesinyia). . . . . 101

Claussi (Mült. 1884) (Lancetes). . . . . 132

clavala Schärf. 1897 (Anurida) . . . . . 126

-Jeriua (Butu, 1882) (Feltia) . . . . . 38, 84

clivinoiles Curt. 1839 (Baripus) . . . . . . 61

coccinella 1. 1758 . . . . . . . . . 73

compressiventris ExDERL. 1907 (Listroderes) • 30

concolor WATERH. 1881 (Brachycoelus) . . . 60

contluens Falru. 1905 (Xvetolia) . . . . . . 73 ronfuseanus Bergi 1899 (Cylindromhinus) coujungens (SoHäff. 1897) (Tomocerura) . 57, 128 comexa Geru. subsp. magellanica Phu. (Friopis) T3 ronsucte WALK. (Agrotis) . . . . . . . . . 38

Coriscus . . . . . . . . . . . 113

corticca HAr. 1888 (Agrotis) . . . . . . 83

Corrmhites Latr. 1834 . . . . . . . . 71

Crambins 1. 1798............. . 91

crinita BLANCH. 1854 (Bombrx) . . . . . . . 83

("roceinaculata JAc. 1900 (Ejistalis) . . . . 102

rrucileraria BeRt 1877 (Aspilates) . . . . . 88

Crymes Fatv 1904 . . . . . . . . 134

Cryptolechia Z. 1853 . . . . . . . . . . 12

Cryptopggus WiLl. 1902. . . . . 56, 127, 139

Culex L. lT6i . . . . . . . . . . . 105

(curticipennis Beck. 1906 (Sratophila) . . . . . !4

('ylindrorrhinus GuER. 1830 . . . . . . . . . 79

(rtheris (1)RUkY 1773) (Argyumis) . . . 38, 82

Dulci Betc. 1893 (Agrotis). . . . . . . 39,85

Daucoi LAM. 1900 (Sybilla) . . . . . . . 76

basychira steph. 1829 . . . . . . . . 89

barwinella EXDEkL, not gen. . . . . . . 14

Darwini Bal. 18tl (Jilantus) . . . . . . 64

Jumini llope sclegognathus) . . . . . . . . 68

J)arwini Stale. 1899 (Argymin) . . . . . 82

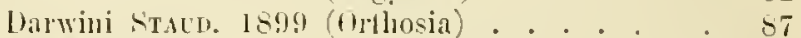

Jarmini WАTEH. 1879 (I'lytosus) . . . . . 12

J)arwini Waterh. 1875 I'arahelopss) . . . . 75

Darwini Watern. 1812 (Nigadojs) . . . . . 61

debilis Straun. 1899 (T'seuilaria) . . . . . . 90

bellocephalus Burg. 1838 . . . . . . . 118

demodire (BLaxch.) (Tatochila) . . . . . 81

Jepressaria IIw. 1812. . . . . . . . . . . 91

denticulatum MAYr. rar. navarinensis Fur. Monnmorium) . . . . . . . . . . . 92

desolata StAlin. 1899 (Ilistagma). . . . . . 87

beromecus Sol. 1851 . . . . . . . . T1

riademata Jig. 1888 (Agromyza . . . . . . 93

diagramma MAB. 1885 (Agrotis) . . . . . 85

Hilophus MeIG. 1803 . . . . . . . . 110

diffinis Ramm. 1842 (Aesclina) . . . . . . 11!

Dirphia IIÜu. 1806. . . . . . . . . 83

dissimilis (Fairm.) (Listroderes) . . . . . . 80

Distagma STAYD. 1899 . . . . . . . . . . 87

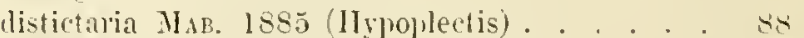

distinguendum Farrm. (Hydromedion) . . . . T.t

bitomotarsus Sipn. $1852^{\circ}$. . . . . . . 111

bitomyia Wixy. 1846 . . . . . . 11]

diomedae (1..) (Lijeurus) . . . . . . . . . . 13i

dibaricatus ExDERL. 1907 (Listroteres) . . . 21

Molnui Stal 1859 (Miris) . . . . . 117

Dormeyeria Finers. not. gen. . . . . . . . 10

dorsigera Fanz. 1885 . . . . . . . . . tit

dubia Jja. 1888 (Psychola . . . . . . . 105

duplaris l3erg 1899 (Coccinella) . . . . . . 73

Juponti Cllaud. 1842 (Brachycoelus) . . . . 60

Latemuostega Exderi. nov. gen. . . . . . . 115

Ekelöfi lixdenL. nov. spec. (Heloparia) . . . 47

elegans Bit. 1888 (Oevdromia) ...... 104 
elongatum Waterh. 1s75 (Hylomedion) . . . 7.

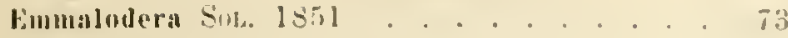

Vimpic 1. 176i3 . . . . . . . . . 103

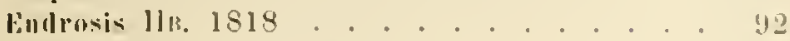

linnomos 'l'k. 1825 . . . . . . . . 87

lintomolirya Rusb. 1861 . . . . . . 128

Episilea Hüm. 1827. . . . . . 3!) 81

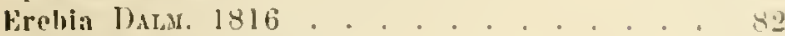

lirinpis MuLs. 1851 . . . . . . . 73

Eristalis Latr. 1804. . . . . . . 102

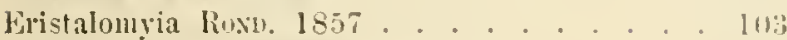

erythojus 13m. ls8s (Homalomyia) . . . . 101

Furosmia STern. 182! . . . . . . . . . . . s!

eucosmiata (STacD. layg) (lamenlia . . . . s!

Bupiflecia C'vrt, 1825 . . . . . . . . 90

Burymefouns Taschexr. 1883 . . . . . 188

Vuryomma Stem 1899......... . 101

entaeniata blu. 1880 limmophila) . . . . 105

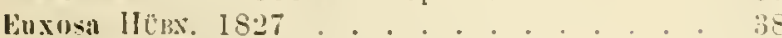

excuvatus DE.T. 1837 (1.0photus', . . . . . . So

exseulpticollis HNDERL 1907 (lieieltertia) . . 3.

farricolus liubs. 1902 (Aditrochus) . . . . . 13

lalklandica (Buts. 1893) (Cirphis) . . . . . . $3 !$

falklandica EXDERL. 1905 (7alusa) . . . . . il

falklandica Hamps. 1903 (Enxoa) . . . . . . 3o

falklandica WAтеRи. 184:- Migalops).

lalkiandicellus llamps. I 895 (Crambus)

falkiandieus Exoeri. now. spec. Leocephalus). 52

falklandicus ExderL. 190 T (1.istruderes).... 20

falliaulicus FxderL. 1909 Parulenus) . . . . .

falklandieus Exoert. 1905 (Philotarsus) . . . 55

falklandicus Warerh. 187!) (Catols) . . 12, lid

Falklandius Expers. I!not . . . . . . 35

filsicolor Furm. 188 \& (Autaretial) . . . . tie

lanintei (Bunctu. 1850) (I,i-lrony) . . . . 70

iaminei Sric 1859 (Daltocephahis) . . . . 118

faminei sric 185! (Tabis) . . . . . . 113

Fellia Wak, 1956 . . . . . 38 st

femoralis Guer 183!) (Suleroguathus) . . . . he

fenestrata Big. 1s8s (schomomyza) . . . 100

fencstrates Hico 1812 (sypuhis) . . . 102

Feroniolia Tschitzen, 1900 . . . . . . . 6i.

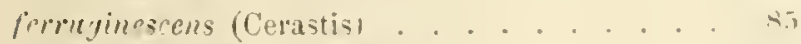

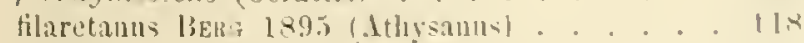

fissicolle Siu. 18t9 (Priactomena) . . . . . T0

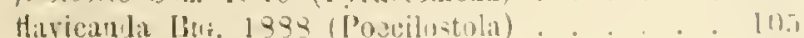

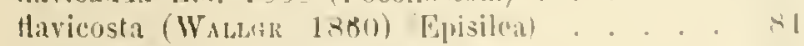

Havipes Mace. 13t3) (Paractora) . . . . . 4t

Havipes IIsce 18:9 (Culex) . . . . 10.5

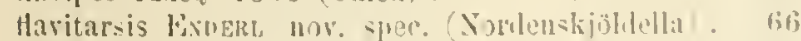

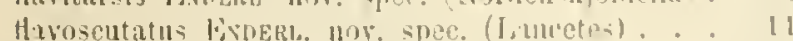

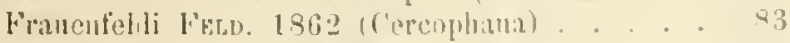

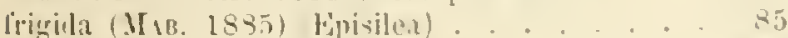

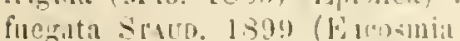

fuerensis liurs. 1!non Marrocaral)

fuerensis livru. $188 . \overline{1}$ (inembites)

linegiana lien; 1895 (liotlienia)

linegiama lixoert. L!00. (Notoprella

liseriana Bn: 1884 (l'atactnis)

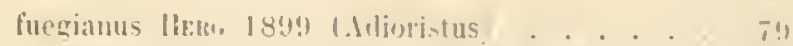

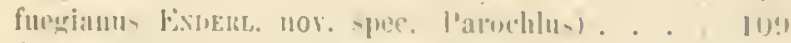

luegianum l:vems. nus. sper. (.1punt). . . B]

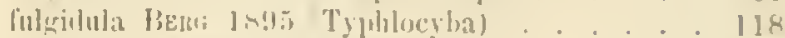

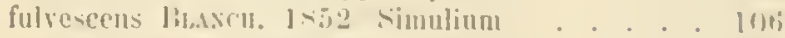

furciforn WH. 18.5.5 Agrotis . . . . . . . .

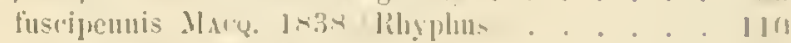

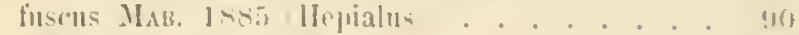

fies're 1. Melolontha ........... 6it

(iayi Srs. 1852 l)itomotarsus . . . . . . 112

(iayi Spr. 18.) 2 lsodtermus . . . . . 111

galentella .1. в. lns8 l'ineal . . . . . . (1)

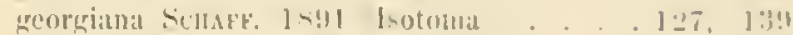

gihber ENokre 1907 listruteres

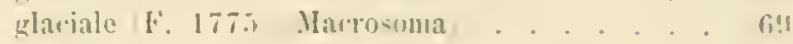

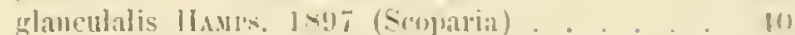

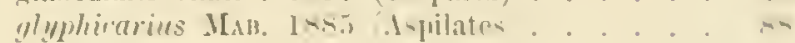

gracilis Reot. 1891 ((aulopsis) . . . . . . 111

granulata G. K. Watesh. JAll Nirtelia . . is

Gravesi Cert. 1839 Cilvelius . . . . . fi]

gravila M.ur. 1885 Épivileal. . . . . - 1

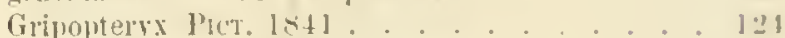

grism Gers. 1839 Xerophloen . . . . 117

entlipenuis Hifo Isas l'allopter:a . . . ! !

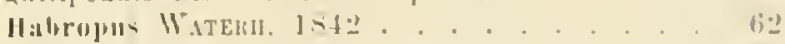

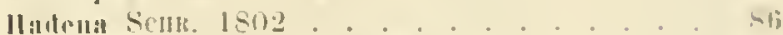

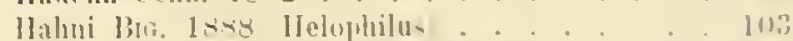

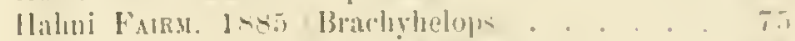

Hammoniormu Bkeno. I\$97 Peloridimu. . 11.5

Haphus Fum. 1885 ....... 711

liappaloiles C'crt. 1839 Metius . . . . . Q

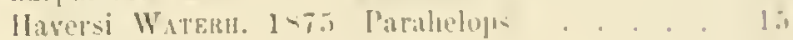

Juentromia Hatid. 1833 . . . . . 101

Jelomez Tatre. 17!ni. . . . . . . il

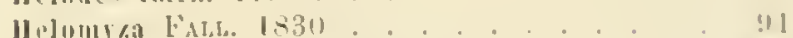

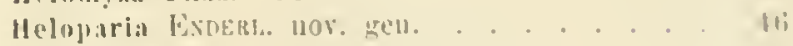

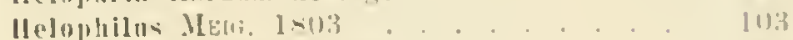

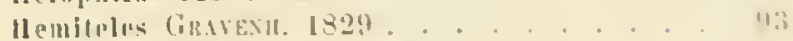

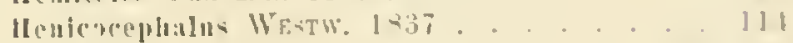

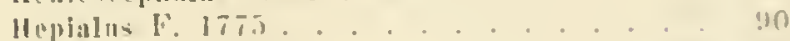

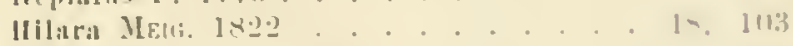

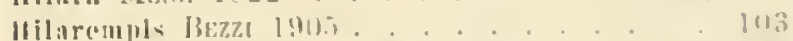

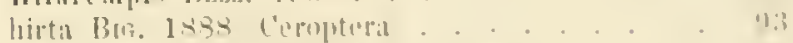

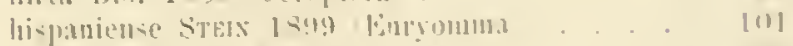

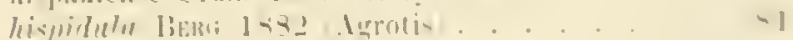

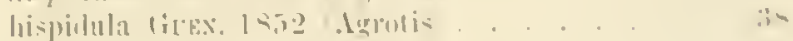

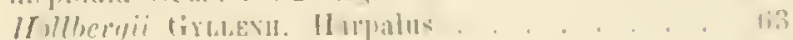

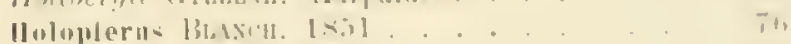

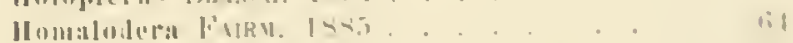

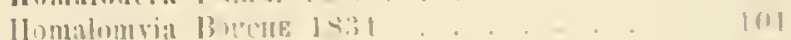

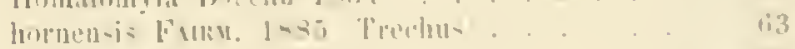

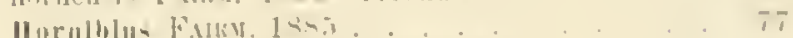

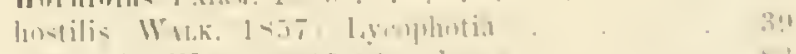

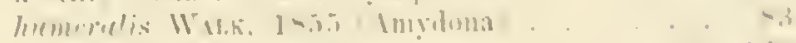

lumicola F. Xemill, . 1:2i. 1:3-

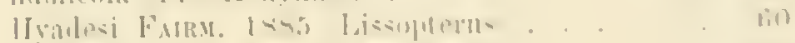

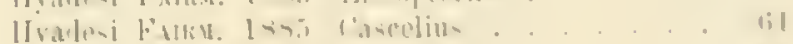

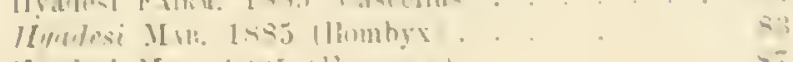

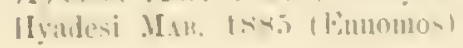


llyadesi Slix. 1885 Ditomotarsus, . . . . 111

Hyalesi (Faim. 1885) Listroderes) . . . 80

Hyadesi Mar. 1898 Stenoplylax . . . . . 119

Ilyalesimyia Bu, 1888 . . . . . . . . . . 101

lyyalinata Bisncer. 1852 (P'syclioda) . . . . 105

hyaliuatus SPIN, 1852 (lschorhyudus) . . . I12

llydromedion WATERIS 1875 . . . . . 71, 1:33

llypoplectis IItten. 1822 . . . . . . . . . . 88

Iyperneorodes KRatz . . . . . . . . . . 68

jacintaria Staun. 1899 (Lohophora) . . . . . 88

Jacolsiella Roubs. 1906 . . . . . . . . 101

Idienstolus l3ER: 1884 . . . . . . . . . . . 113

Idiostylus (BERG 1884) BrEIDIX 1897 . . . 113

ignicola STaud, 1899 (rambus) . . . . . . . 91

ignicola Staur. 1899 (Pseudolencania) . . . 86

incerta But. 1888 (Ditomyia) . . . . . . . 111

Ingoufii MAr. 1885 Agrotis) . . . . . . it

inspinosa Guen, 1852 (Agrotis) . . . . . . 38

insquanea kxDEku, 1907 (leichertia) . . . . . 33

insularis Berti 1884 (Agallia) . . . . . . . 117

insularis Berg 1883 (Idiostolus) . . . . . . 113

insularis (WAHLGR, 1906) (Tullbergia) 56, 125, 139

irroratus (Spix. 1852) (Nysius). . . . . . 112

Ischnothrix Bit. 1888 . . . . . . . . . . 104

Isodermis Frichs. 1812 . . . . . . . . 114

Isoloma Bourt. 1839 . . . . . . . . 56, 127, 139

(Klorstadi CARP, 1902 (Isotoma) .. . . . . . . 127

lacteella Schüff, var. antarctica STAUd. Hudrosis) 92

lacunosus (Fairm. 1885) (Listroderes) . . . . . 80

lactaria Staud. 1899 (Iobophora). . . . . 88

laeris Buanch, 1853 (liaripus). . . . . . 61

Lancetes Sharp 1882 . . . . . . 11, (i4, 131

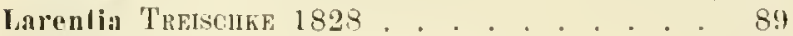

Larseni Exdert. nov. spec. (Ophion) . . . $\$ 1$

lateralis Bers 1899 (Scotocborls) . . . . . 79)

lathoniaides Ibasch. 1852 (Argymis . . . . 82

laticornis (Iir, 1888) (Hilarempis) . . . . . 104

latigastrica DEJ. 1828 (Antaretia) . . . . . 62

leprosus OLIV. Iophotus). . . . . . . . 80

Leplopeza Mace. 1828. . . . . . . . 104

Leria Rub. Desy. 1830 . . . . . . . \$4

Lencanía Hö́n. 1818 . . . . . . . . . . . 86

Limnobia MEIT, 1818 . . . . . . . . 104

Limnoplita MAcQ. 1834 . . . . . . . . 105

L.mophilns LEACH 1815 . . . . . . 52, 120

J]monla WEIG, 1803, . . . . . . . 104

lineicollis (Buaxch. 1852 (Limonia). . . . 104

Jpenrus Nitzscir. 1818 . . . . . . . . 138

Lissoplerus WATERH, 1843 . . . . . . 7, 60

Idstroderes Вснӓхн. 1826 . . . . . . . 16, 79

Mlstronyx GUÉR. 1839 . . . . . . . . . . . 69

Tobophora CIтR. 1825 . . . . . . . . . . . . 88

longicollis B1\%. 1888 (Limonia) . . . . . 105

longigena ENDERL. nov. spec. (Melanostoma . . 102

longipennis Farns. 1900 (Tolmerus). . . . 76

longipes WATERH. 1840 (Iophotus) . . . . . . 80

Inphotus Scurisu, $1834 \ldots 80$

var. lucilla Buts. 1882 (Cerastis) . . . . . 85

luetnosus BERG 1888 (Chrysotus). . . . . 103 layullore Sot. 1849 (Pyractomena;. . . . . . 70

Mpexus GeOFer. 1762 . . . . . . . . 15

lnteicomis (Ber. 188.) Hepialıs) . . . . . . 90

lutescens (Blanch. 1852) (Euxoa). . . . . . 83

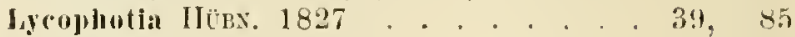

Macevi Bates 187 1 (Merizolus) . . . . 11, 63

Incleyi Bates (Kolbe) Merizodas) . . . . 11, 63

Marrosoma Hope 1837 . . . . . . . . . . ti9

magcllanire Butu. 1881 (Ochropleura) . . . . 84

magellanica Bu 1888 (Hilara). . . . . . . 103

magellanica Jac. 1900 (Belsica) . . . . . 110

magellanica (.JAC, 1900) (Jacobsiella . . . . 110

magellanicus BA: 1811) (Lancetes) . . . . 1i4

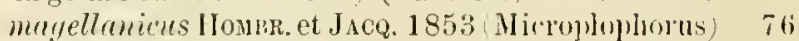

magellanicus lioLe 1907 nom. nut. (l'ythoplesius 75

magellanicun Fank. 1883 (Iydromedion) . . T4

malachitica DEJ. 1830 (Antarctia) . . . . . !

malefida (Goen. 1852) (Feltia) . . . . . . . 38

maluineusis ExDEk1. nov. spec. (Hilarempis) 48. 168

malvinensis Wanlek. 1906 (Isotoma) . . . 56

margiualis ALt. 1890 (Luperus) . . . . . . 15

Melanostoma Schin. 1860 . . . . . 101

melanocephalus Hoxbr. (Listronyx) . . . . . 6!!

var. melancholicus BrEDd. 1897 (Nysius) . . 112

Molophorns LUBB. 1883 . . . . . . . . . . 12

meridionalis ULa. 1905 (Limnophilus) . . . . 52

Merizodus SoL, 1849 . . . . . . . 11, 63

messia (Guen, 1852) (Lycophotia). . . . . . 85

Metiıs (urt. 1839 , . . . . . . . . . . s

Mcteorus Hatid 1835 . . . . . . . 93

Michaelseni (KidP. 1904) (Antaretoperla) . . 122

Michaelseni Koure 1907 (I'ythoplesius) . . . 75

Michaelseni Scräfr. 1897 Triacauthella) . . 125

Michaelseni Scnovt. 1904 (Myzus) . . . . . 118

Michaelseni (Staud, 1899! Scriphtania . . . S6

Michaelseni Uนx. 1905 (Limnophilus) . . . . 120

Nicrocara Tirons. 1851 . . . . . . . . . 71

microdice (Buñcr. 1852) (l'ieris) . . . . . . 82

Nicroplophorns Buaxch. 1851 . . . . . . . 76

Migadops Wateki. 1842 . . . . . . . . 8, 60

Mimaeseoptilıs Wablexar. 1861 . . . . . 92

minua (BuTL. 1882) (Lreophotia) . . . . . . 85

Miris F. 1803 . . . . . . . . 117

mixtus (Waterh. 1888) (Lancetes) . . . . . 64

Mollberyii Grú. (IIarpalus) . . . . . . . . 63

mollis МАв. 1885 (Orthosia) . . . . . 85

molybloidea (STAUD. 1899 (lycophotia) . . . 86

Monomorium MaYr 1885.... . . . . 9. 92

Morychastes FalRM, 1885 . . . . . . 72

multipunctata CurT. 1845 Hinmalodera) . 73

multivirgulata МАв. 1885 Lobophora) . . . . 88

mutabilis Mar. 1885 (Yusijetes) . . . . . . 90

myridon (Mab. 1888 (Fripoptery) . . . 124

Myzis Passerini 1860 . . . . . . . . . 118

Yibis Latti. 1807 . . . . . . . 113

Seoslaphropteral Os'-SACK. 1878 . . . . 111

Sephrotoma Meki. $1803 \ldots . . . . .104$

niger Buscri. 1853 Cascelins) . . . . . . (i1

nigricens Guer. (Jistronyx) . . . . . . . . . 
nigripeclus Big. 1888 ('ampulucladius . . . . 16. nigripes Buach. 1852 Inilophus . . . . 1111 nierncocrulea Watent. 1812 Migad(t)!s. . . Mi(l nigrorematus B.13. 18.11 Colymbetem.... (i) nitilat treke. 1830 Antalctia nilidus Witrum. 1811 Caseclius

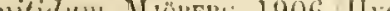

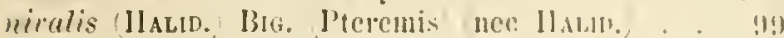

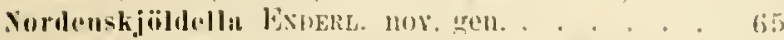
Nordenskjöldi liNonek. 1907 Iistroderes . . 23 Soliphila Fald, 182\% . . . . . . . .

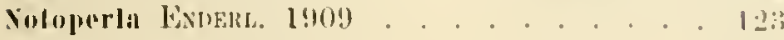

ryclelia LotTr 1825 . . . . . . . . . 73 Vysills Disu, 1852 . . . . . . . 112 obesa Grér. 1841 Emunaloulera . . . . . . 73 obscmirentris 1311. 1888 (lioletina) . . . 111 obscurus (F. 1775) Photinus . . . . . T0 obsoletaria STACD. 1899, Iarentia . . . .90

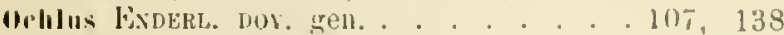
ocbracea (Bh, 1888) Hilarempis, . . . . 104 oculata MLA. 1885 I obophora

Orylromia Nela. 1820 .

Oecophor: IATR. 1806 .

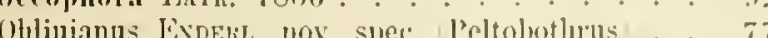

Ipluion F. 1798............. 41

Ormiscorles . . . . . . . . . . . . . . . . . . . . .

ornata WanLir. 1!06 Isotoma

"rollocladius v. D. WuLp 1874

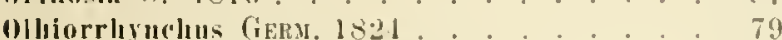

M) Mins STEPH. 1832 . . . . . . . . 1i.

ovalis Watern. 18t2 Migalop!s....... 60

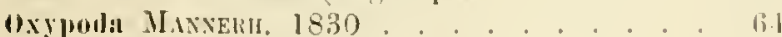

Pachymys Farmo le88. . . . . . . . . 7.?

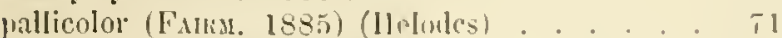

pallipes Stura Latpalus . . . . . . . . . 6 .

Palloplera lide. IS:0.

Paractora ling. 1888

l'arahelops Watrkh. 1875

P'aruchlos ExDERt. nov, geu.

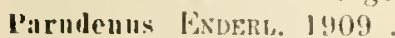

patagonica linti. 185s Oxyporlat

patagonicus Cirr. I 839 I Ielorle.

matagonieus siris 1873 Isorlermus

pellionella 1. (Tinea)

Probridium liliede. 1897

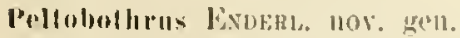

penicillipes liNDERs. Hov. sper. levia

perdita strum. 189! lipicilea

Perimylops Mru. 1831

P'eroni C'mun, Isfi Antarciomommus

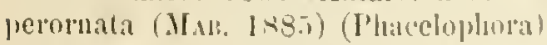

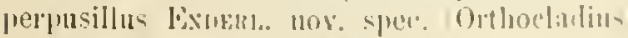

l'esronii tiues. 1852 Ierotis

pexa (Bemi 187t lidtia.

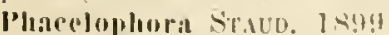

Ploilotarsus líube 1880

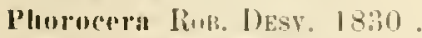

Plutimus Casters. 1833

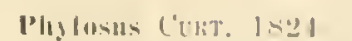

picea lindBe lont (Acria) .

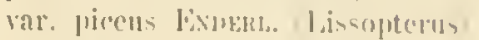

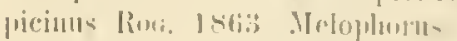

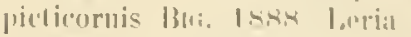

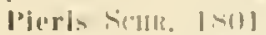

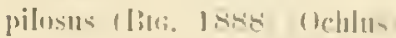

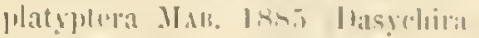

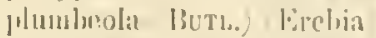

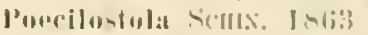

porcilus sips. 18.1.2 l'aclaymerus

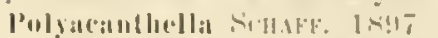

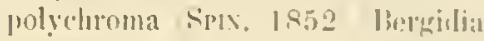

prosopantrum livntis. nor. gem.

pruiunsus T'LLs, Siminthuru,

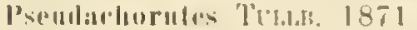

P’spularia Sral?, lis(y)

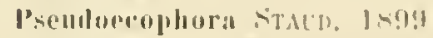

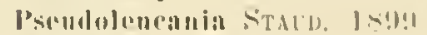

P'sollos TR. 1,528

Psyclooda Lattk. Is!it;

Pliuma TEMPa. 1\&43

puberulus Bem; Is!1: Xysius

puberulus liaks. P’andrums:

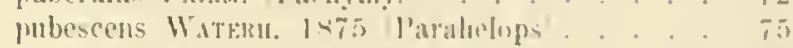

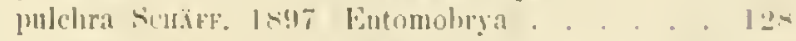

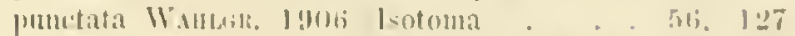

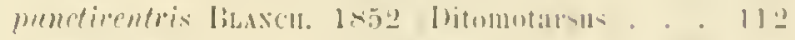

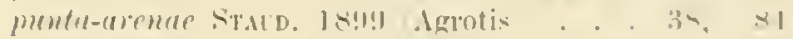

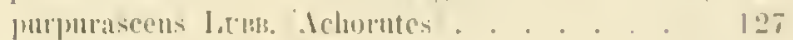

pusitla Bu. IRAd Amalopis . . . . . . 1155

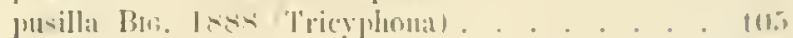

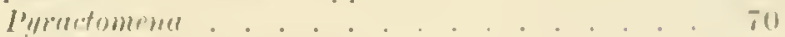

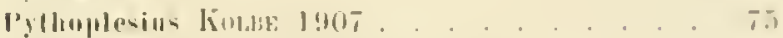

fluatlata Stos. 1x85 (1'orixil) . . . . 11ti

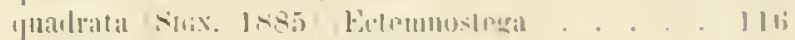

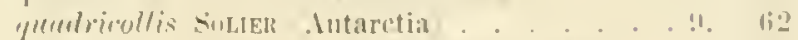

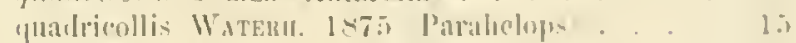

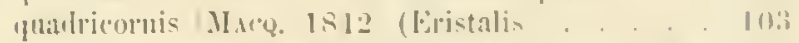

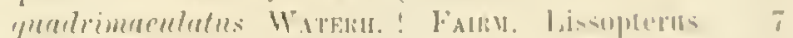

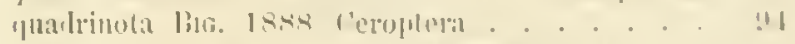

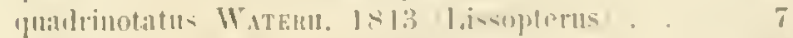

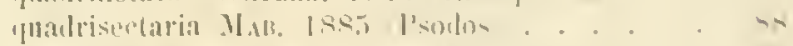

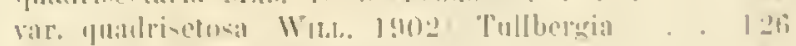

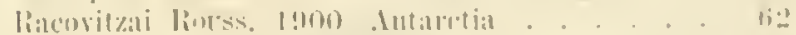

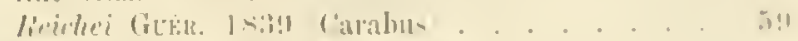

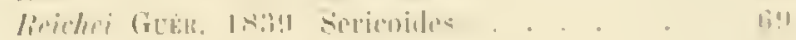

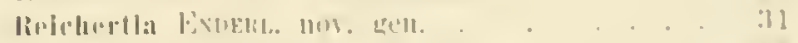

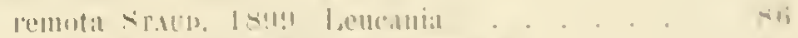

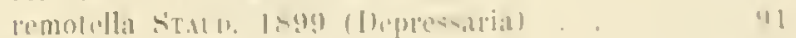

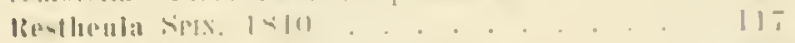

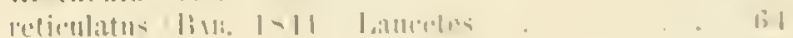

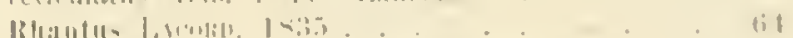

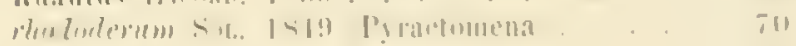

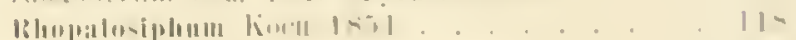

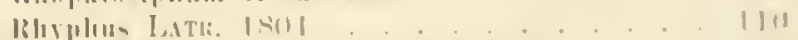

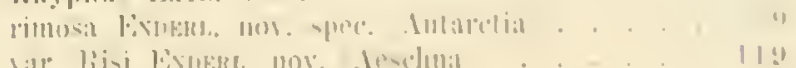

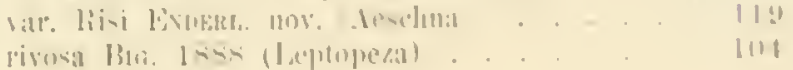


losea WaHLdi. 1906 Triacauthella . . . . 125 luhripes Bun. 1847 Neleroguathus . . . . 69 lutifrons 131G. 1888 Leria . . . . . . . 94 Infina lig. 1888 Aetora . . . . . . . 96 rufina rar. minor Extekl. (Actora) . . . . . . 97 rufirostris Big. 1888 T'ipula . . . . . . 104 mefomorutus ('un 1845 sielerognatlus . . 69 salebrosus ExderL. $1 ! 107$ I istroderes. . . . 20) Silpir Mati, 1885 . . . . . . . . . . . . . . . stmgumirentris ST.AL 1858 liuseoha . . . . 112 sareophagidea IBr. 1868 Ilyakesimyia . . . 101 saturata StTALd. 1899 (Aspilaria) . . . . . s! Sauberi For. 1904 Melophorus . . . . . . 92 sraber lWDERL. 1907 (I istrolleres) . . . . . $\$ 33$ scahra ENDERL. I907 lieicliertia) . . . . . 33

Scatophila Becli. 18!6. . . . . . . . . . 94

schoenomyza Hald, 1833 . . . . . . . . . 100

Schötella Sehд̈ғ. . . . . . . . . . . . 126

Schythei l'hil. 1864 (Callisplyyris . . . . . . 76

sciophíla MIElt. 1818 . . . . . . . . . 111

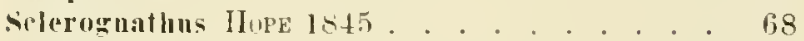

Nicoparia $\mathrm{H} \pi$ 1803 . . . . . . 40, 91

scotoehorus Senöxн. 1643 . . . . . . . . 79

Scriptania IIAMPs. 1905 . . . . . . . . . . 86

segnentarins FadRx. 188 j Haplous) . . . . . 70

semicaligatus Fıна. 1859 Callisphyris! . . . 76

semilotaria (MAB. 1885) Tepluroelystia . . . 90

seriatus KítBe 1907 Parahelops . . . . . 75

Serratus SснӓғF, 1897 Sminthurns). . . . . 128

siga Hüв. $1 \triangleleft 32$ (Algymis) . . . . . . 38, 82

silvatieal SснÄF, 1897 Isotoma . . . . . 127

simulinm LATR. 1803 . . . . . . . . . . 106

Sminthurus late, I804 . . . . . . . 128

soledadina Guer. 1830) Dormeyeria). . . . 10

solox ExoerL. nor. spee. Chalciosphaerium . . 13

sprarsutum MüLL. 1884 Hydromedion: . . . . 133

Sphicosa l'hul. 1S65. . . . . . . . . . 103

splendidus Guer. 1839 Metius . . . . . . . 63

spinosa Úu. $190 \pm$ Anabolia . . . . . . 120

spinosissima WAHLGR. 1906 Tullbergia . . . 126

stegnum (SAY 1829) (Melanostona) . . . . . 102

steguus SAY 1829 (Syphlus)........ . . 102

Steineni Gercke I889) (Oclltus) . . . . . 138

slenophylax liodee 1848 . . . . . . . . . 119

stenopterata Maв. 1885 Lobophora . . . . 88

stigmatica BLAуer. 1852 Limonia. . . . . 105

striolata Stazt. 1899 Ispilaria . . . . . 89

strumosus OLiv. (Lophotus) . . . . . . . . . 80

subantareticus Berg ls8t (ITenicoceplatus. 114

subcrassu= SchäFf. 1897 l'seulachorutes'. . 126

suffodens ExDERL. 1907 Falklandlus: . . . . 37

sulcatns Furu. 1885 Mdioristus . . . . . . 79

suleifrons Fatra. 1855 IIormibius, . . . . 77

suturalis F. 1775 (Ceroglossus, . . . . . . 59

suturata Fark. 1885 Homalorlera . . . . . 64

Sybillat . . . . . . . . . 76

Synuenria Mab. 1885 . . . . . . . . . 87

sypulus F. 177\% . . . . . . . 102 tauns Nitzsch. Is 18 linymetopus .... 130

Tephortystiu IIúw. 1820 . . . . . . . . 90

testaceoscutellata HAce. 1850 Eristalonyial. . $10: 3$

testaceres licarrir. Trechus . . . . . . Jo

testacens F. 1775 Listrongx . . . . . . 69

tetragona Maßs. 1885 IIarlena . . . . . . S6

Tetragonenta Wix. 1846 . . . . . . . . 111

Thulussogfon IiEHLES 1887 . . . . . . . 13ij

theodice Bown. 1832 Pieris) . . . . . . . 81

tigrinella WanLGi. 1906 lsotoma . . . . . 56

'Yineal L. 1758 . . . . . . . . . . . . . ! !

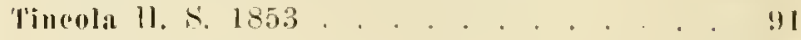

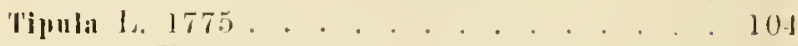

'l'almorus Falro. 19000 . . . . . . . . 76

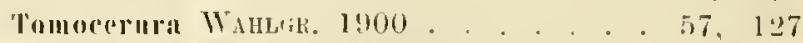

tortriecla Statd. 1899 Cryptolechia . . . . 9.2

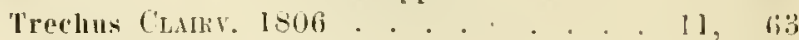

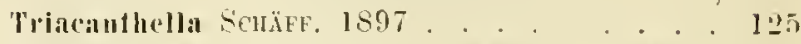

1riangnlaris baнth. Calv. 1893 symuria . S 85

triangulifera Jac. 1900 (Phorocera . . . . 101

trisema MLAB. 1885 dnarta . . . . . . 86

trisetosa Sснӓға. 1897 (Tulbergia) . . . . 126

tristis Bitr. 1885 riciophila........ . 111

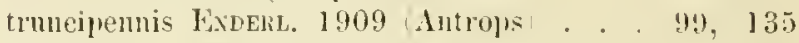

tuberenhatus WaHLgk. 1906 Chondrachonutes. .

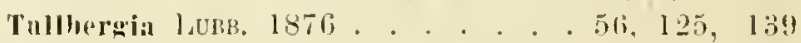

turbifieatus FNDERL. $190 T$ (Falkinulius) . . . 36

typhlina $\mathrm{IAB}_{\mathrm{AB}}$ I885 Episilea! . . . . . 85

Typhloeyha Germ. 1833 . . . . . . . I I8

Vilamocercia ExDERL 1909 . . . . . . 124

nuiformata Bekg 1889 (Symeuria . . . . . 87

nseluaiensis Finen. nov. spee. Ochlus . . . It/8

usrhuaiensis SchäfF. 1897 (Sminthurns) . . . 128

valdivianns P'JuL. 1865 Dilophus) . . . . 110

variabilis (Schis. 1897) (Ptenura) . . . 57. 128

variegatum Waterh, 1875 IIydromedion . . 74

verineris (Bie.) liergroth (Tipmla...... . 114

rarineura Bit. 1888 Tephrotomal. . . . . 114

varipes B1G. 1885 Borborns) . . . . . . . 100

veneris Mig. 1888 llelonyza . . . . . . . 94

viaticns I., (Achorutes) . . . . . . . 126

villosus 13ı. 1888 (Chironomns) . . . . . . 107

vireseens Stau 1854 (Xerophloea) . . . . 117

virescens (Waterh. 1842 Brachyeoehs. . \&, i)

virgelata Maв. 1885 (Symeuria) . . . . . 87

viridis F. (Cereopis).... . . . . . 117

ririblis F. 1791 (Xerophloea) . . . . . . 117

vitellinella STAlD. 1899 Psendoecophora . . 92

vitulus F. 1775 , loplotus). . . . . . . . so

rulsue Exnerc. 1907 Listroderes . . . . . 24

var. Wilkensi l'eur. 1887) IIylmmedion . . 133

Wienchei Rorss, 19010 Trechus; . . . . . . 1 (i3

renthodic 11.1\%. Is8s Pieris . . . . . . \$2

xantliostola Mab. 1885 Episilea . . . 39, 85

Xemylla Tello la69 . . . . . . . . . 125. 138

Xerophloe: fiers. 1839 . . . . . . . . . . 117

Ypipiptes Sтерн. 182! . . . . . . . . . . . 90

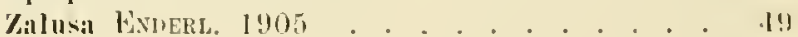




\section{Verzeichnis der Textfiguren.}

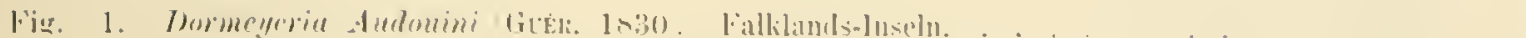
labium nud Zunge von unten gesphen. Verger. (i5): 1.

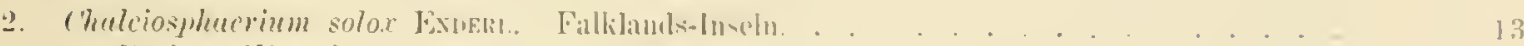
liteches llimferbein. Virgr. $43: 1$.

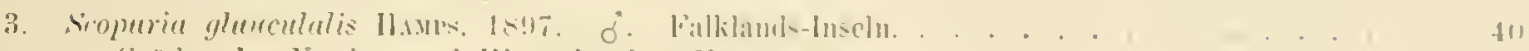

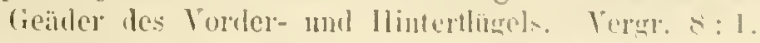

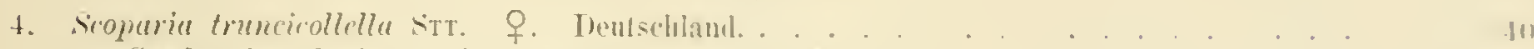
Geäder des Vorder- und llintertlürẹls. Vererr. 8: 1.

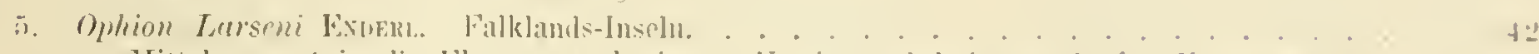

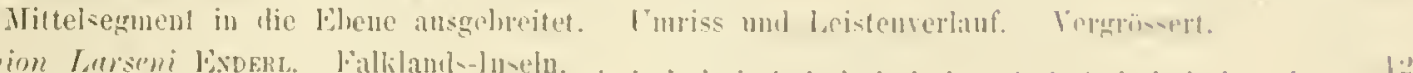

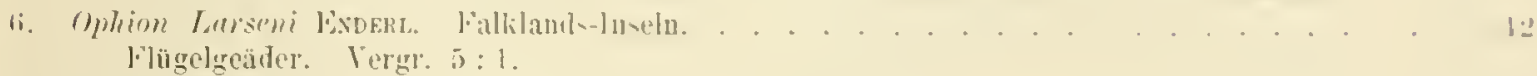

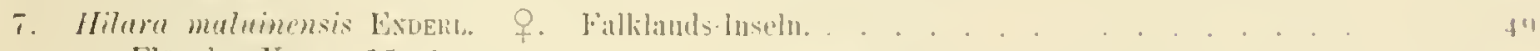
Flïgel. Veror. 15:1.

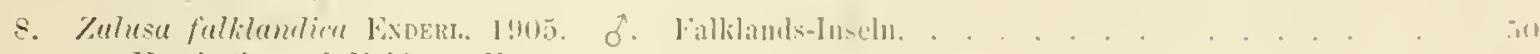
Jumiteile und lishler. Verert. $100: 1$.

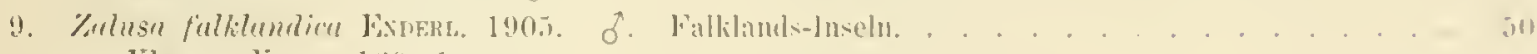
Klaue. Vergr. $160: 1$.

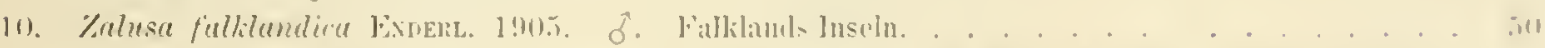

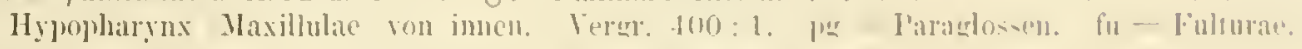

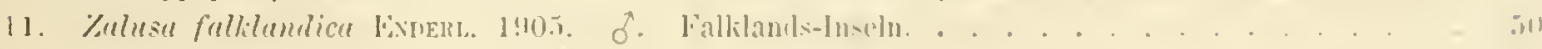
F"lügel mul Ilallere. Vergr. $80: 1$.

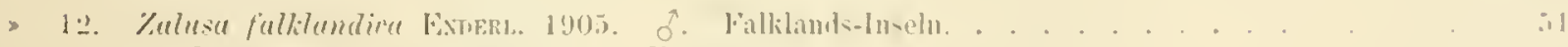

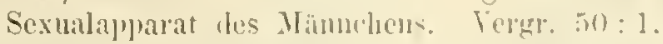

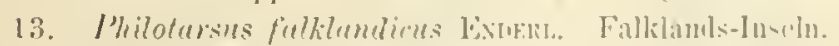
l'ühlerspitze. 1‥ und 18 . Vilied. Verert. 270:1.

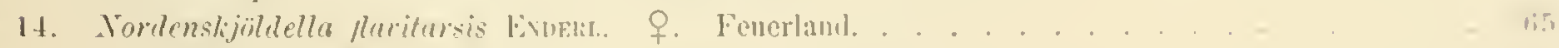
I.alium und Menfun von unlen. lingr. 130:1.

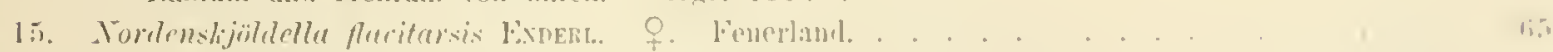
Jaxillarpalpus, Verere. 100:1.

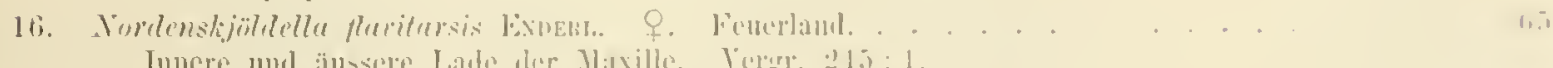

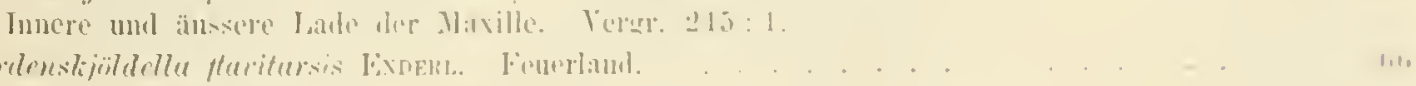

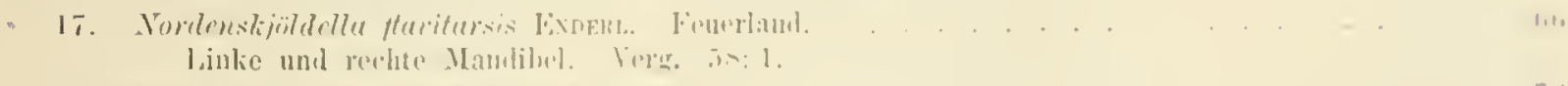

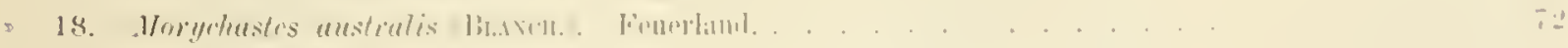

Ilintertar=lls. Vergr. $35: 1$.

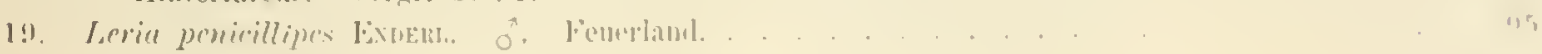
Flizerel. Verent. 11:1.

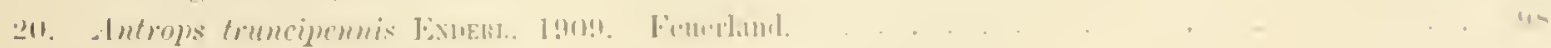
lititgel. Vergri: fi: 1 .

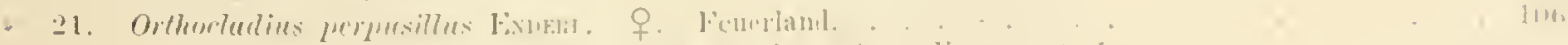

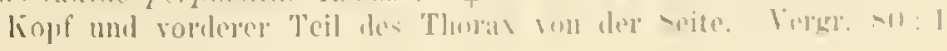


Fig. 22. Orthocladius perpusillus Exdert. O. Fenerland. . . . . . . . . . . . . . . . . . . 106

Flïgel. Vergr. $46: 1$.

23. Ochlus uschluaiensis ENDERL. \&. Fenerland. . . . . . . . . . . . . . . . . 108

Flügel. Tergr. $35: 1$.

21. Ochlus uschuaicnsis Enderl. \&. Fenerland. . . . . . . . . . . . . . . . . 108

Füller. Vergr. 160:1.

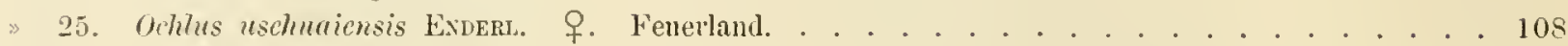

Maxillarpalpus. Vergr. $160: 1$.

^26. Parochlus fuegiums Exdert. ․ Fenerland. . . . . . . . . . . . . . . . . . . . 109

Flïgel. Vergr. $35: 1$.

> 27. Parochlus fuegiunus Faner. 9 . Fenerland. . . . . . . . . . . . . . . . . . . . . 109

Fühler. Vergr. $105: 1$.

2. 28. Eetemnostegu quadratu Sigs, 1885) . . . . . . . . . . . . . . . . . . . . 115

Flïgel. Vergr: 10:1.

»29. Anturctoperlu Anderssoni Exdez. 1905. ․ Fenerland. . . . . . . . . . . . . . . 122

Flügelgeäder: Vergr. $4: 1$.

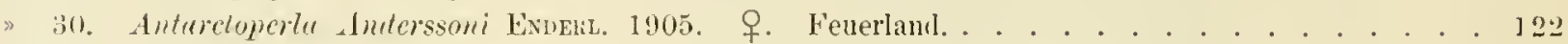

Rechter Cercus. Vergr. $50: 1$.

31. Notoperla fuegianu Exnerl. 1905. \&. Fenerlanl. . . . . . . . . . . . . . . . . . . 123

Geäder. Vergr. $3 \frac{1}{2}: 1$.

2) 32. Vdamocercia antartica ExDert. 1905. ․ Feuelland. . . . . . . . . . . . . . . 124

Abdomen ron ter Seite. Vergr. $11: 1$.

33. Prosopantrum austrimm Exdelit. o. Sül-Georgien. . . . . . . . . . . . . . . 136

Geäder. Vergr. $20: 1$.

34. Ochlus Steinemi (Gencke), 오. Süd-Georgien. . . . . . . . . . . . . . . . . . . . 137

Geäder. Vergr. $53: 1$.

»35. Ochlus Sleineni Gerckè. 9. Süd-Genrgien. . . . . . . . . . . . . . . . . . 13S

Fühler: Vergr. 160:1.

\section{Verzeichuis der Druckfehler.}

\begin{tabular}{|c|c|c|c|c|c|c|c|c|}
\hline Seite & 44 & Zeile & 5 & von & unten & 1888 & statt & 1891 \\
\hline & 45 & y & 20 & $"$ & » & ISSS & $s$ & 1891 \\
\hline » & 60 & $"$ & 21 & " & oben & Bracliycoclus & ” & Brachycoelia \\
\hline * & 60 & " & 17 & " & unten & Peroni & " & Poroni \\
\hline
\end{tabular}

\section{Nachtrag.}

Hilarempis maluinensis ENDERL. Hilaria maluinensis p. 48.

Hilarempis Bezzt 1905 unterscheidet sich durch die kurze Radialgabel, wobei $\mathbf{r}_{4}$ ziemlich steil ist, und durch die nicht verbreiterten vorderen Metatarsen von Hilara. Nun ist ja alierdings bei Hilara flavipes MEIG. 1822 (Europa) der Metatarsus der Vorderbeine des $\sigma^{7}$ ebenfalls nicht verdickt, ohne dass obige Geädcrdifferenz auftritt und bci Hilara clypeala MeIG. (Europa) ist die Radialgabel bein $\sigma$ ebenfalls so kurs wie hei Hilarmpis, nur ist $r_{4}$ nicht ganz so stcil, aber lier tritt die metatarsale Verdickung beim Vorderbein des $\sigma^{7}$ auf. In wieweit die Gattung Hilarempis berechtigt ist, lasse ich vorläufig mentschieden, jedoch hat sie eine notocrate Verbreitung und zwar im Archiplatagehiete (Argentinen, Chile, Feuerland, Peru etc.). Australien und Siil-Afrika und ist dalıer biogeographisch von Interesse. Hilara maluinensis gehört gleichfalls zu Hilarempis. 


\section{Erklärung der Tafeln.}

Tafel 1.

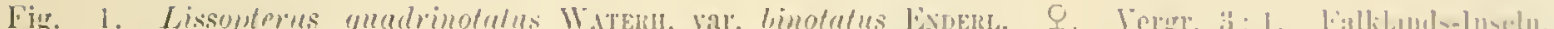

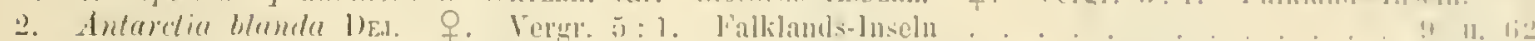

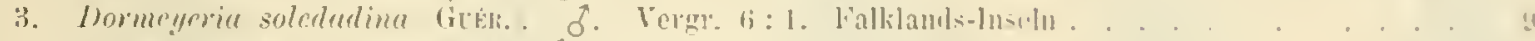

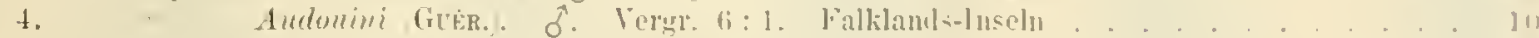

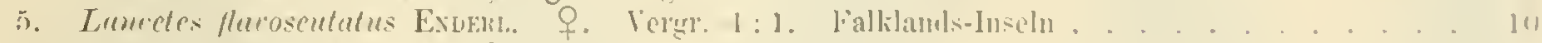

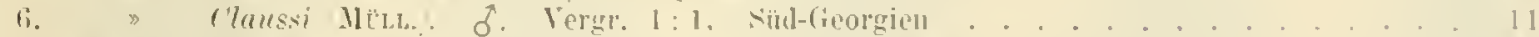

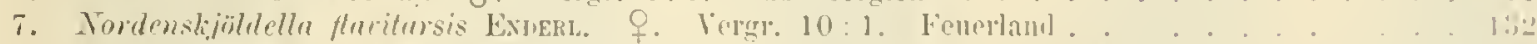

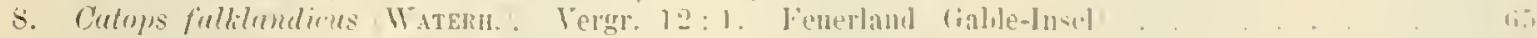

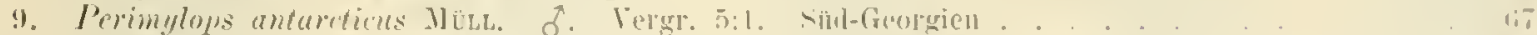

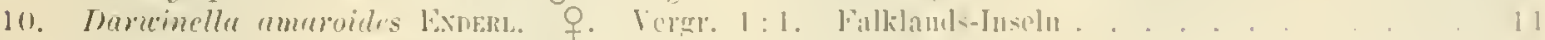

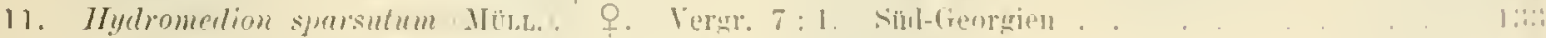

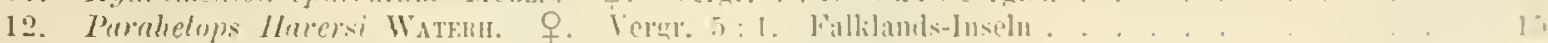

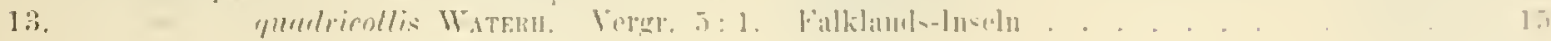

Tafel 2.

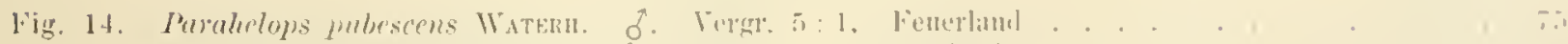

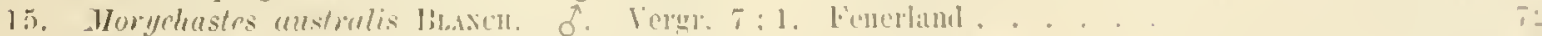

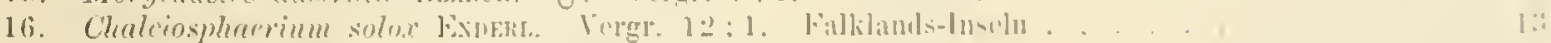

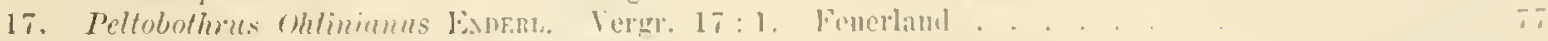

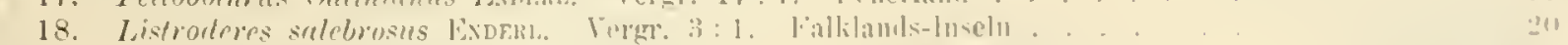

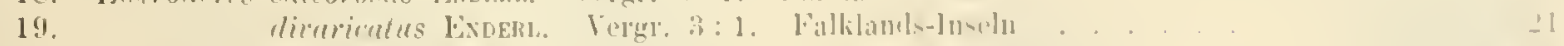

b)

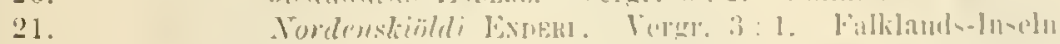

$2: 2$.

23.

24.

25.

26 .

27.

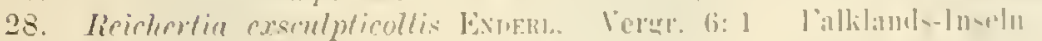

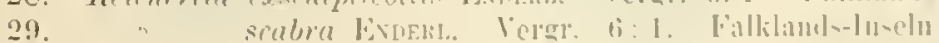

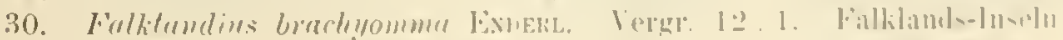

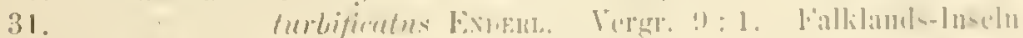

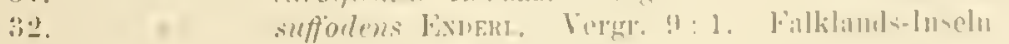

K, sv. Vel, Akad, Hamdl, linul tr. S:0 3 
Tafel 3.

l'ext hierzu Seite

Fig. 33. Actocctes absconditu Exuem. o. Vergr. 5: 1. Falliands-Iusehn . . . . . . . . . . . 4t

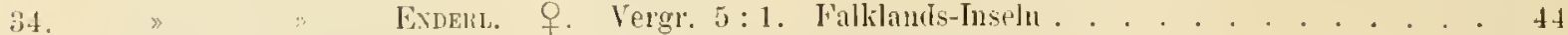

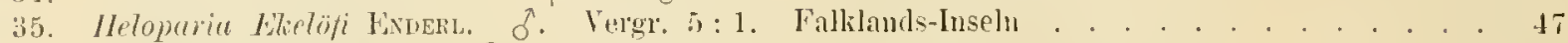

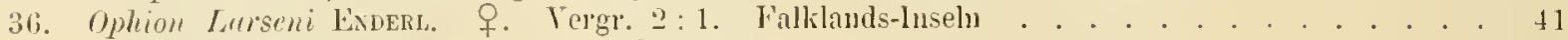

37. Scoparia aluuculatis Havps. 1897. o. Vergr. 2:1. Falklands-lnseln . . . . . . . . . 40

38. Letemostegu quadralu isuis.) o. Vergr. 5: 1. Feuerland . . . . . . . . . . . . . 110

39. Isodermus Gayi Srux. Vergr. 5:1. Fenerland . . . . . . . . . . . . . . . . . . . 114

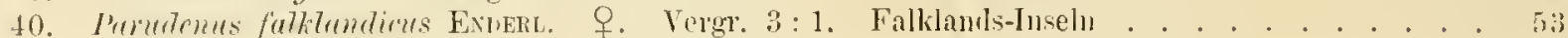

\section{Tafel 4}

Fig. 41. Anlaretoperla Anderssoni Federt. Flügel. Vergr. 8: 1. Fenerlant . . . . . . . . . . 121 42. Notoperla furgianu lxwert. Flügel. Nach Fhotographie. Yergr. 15:1. Fenerland . . . . 12:3

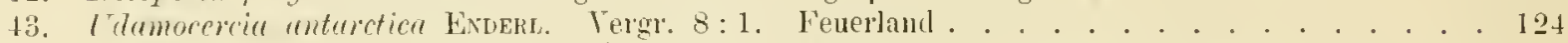

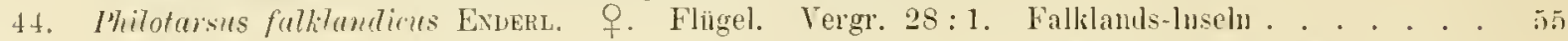

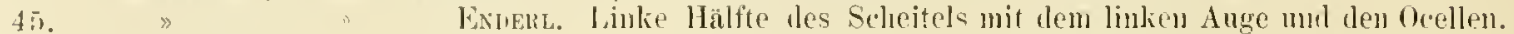

Veryrössert

\section{Inhaltverzeichnis.}

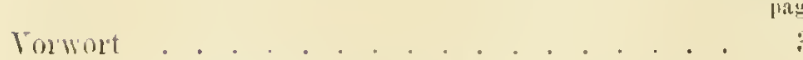

Beziehung der Fauna Fenerlands etr. zu der vou

Neu Seeland und Australien

Jie Inseliten ler Falklanıls Jnseln . . . . . .

Coleopitera

Lepidoptera

IIymenoptera

Iiptera.

Riliyneliota

Orthopitera

Copeoguatlia

Collembola

Die hauplsichlindste literatur iiles" die Inscliten iler Falkiands lıselı

Ine Inseliten Fenerland.

Coleoptern

l.epicloptera

llymenopitera

Diptera.

liliynchota

3
5
7
7
3
41
43
52
53
54
56
5
59
$5 !$
81
9
9
111

ay.

Trichoptera . . . . . . . . . . . . 119

I'lecoptera . . . . . . . . . . 1201

Agnathia . . . . . . . . . . 125

Collembola . . . . . . . . . . 125

I)ie hauptsäclidiste literatur uber die Insekten

Fenerlands . . . . . . . . . . 129

bie Insektenfama ron Sün-freorgien. . . . . . 131

Coleoptera . . . . . . . . . . 131

Diptera . . . . . . . . . . . 131

Mallophaga . . . . . . . . . 138

Coliembola . . . . . . . . . 138

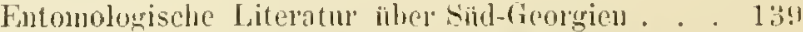

Ubersicht über die Inseliten dor Antarkto-Archi-

plata-liegion . . . . . . . . . $t+\mathrm{t}$

Versehlepute luseliten . . . . . . . . . 15!

Alplabetisches Terzeichnis . . . . . . . 161

Verzeichmis der Textliguren . . . . . . 167

ler Inuclifeller . . . . . . lik

Emlinmog der Tafelı . . . . . . . . 16! 

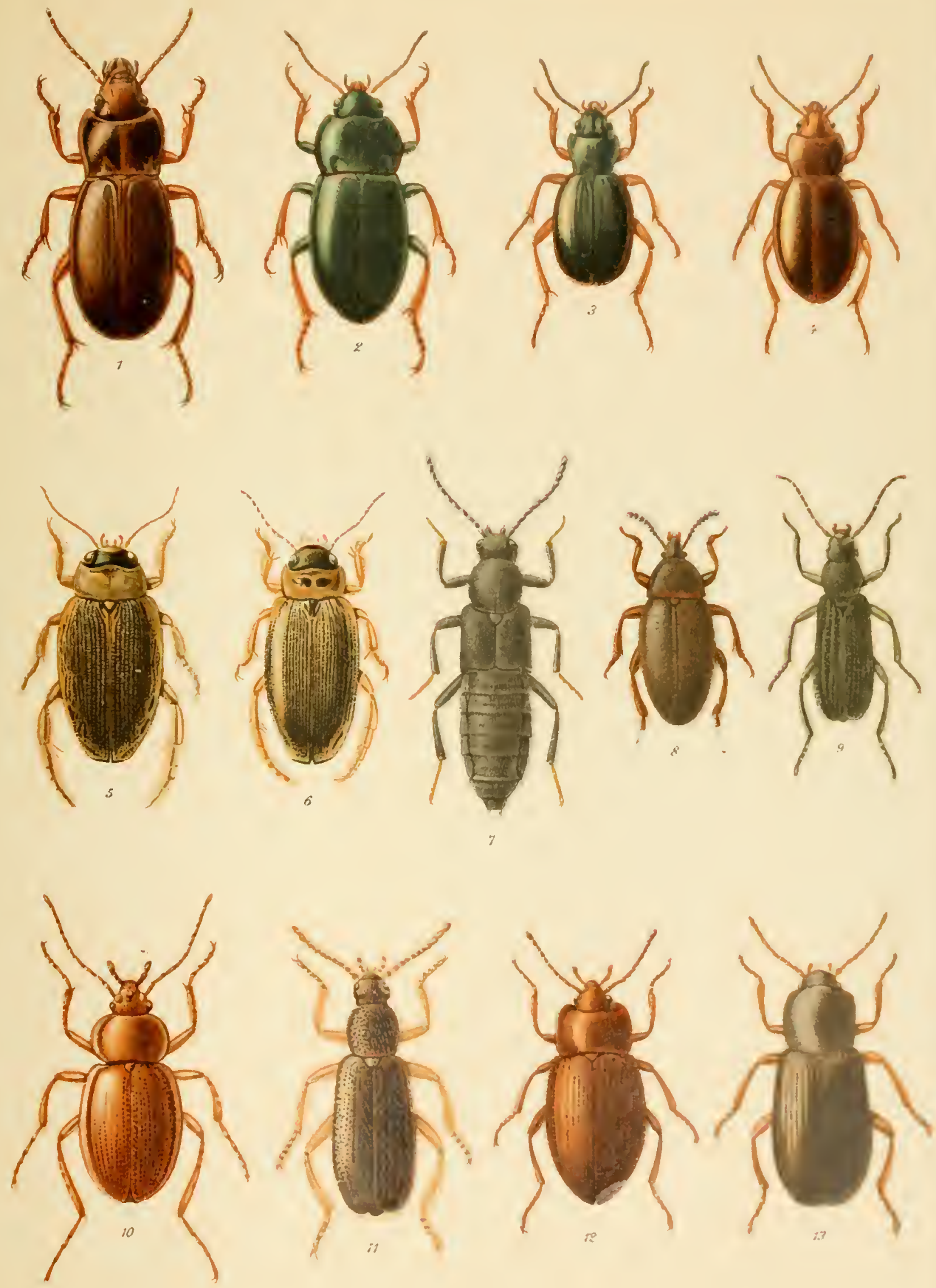


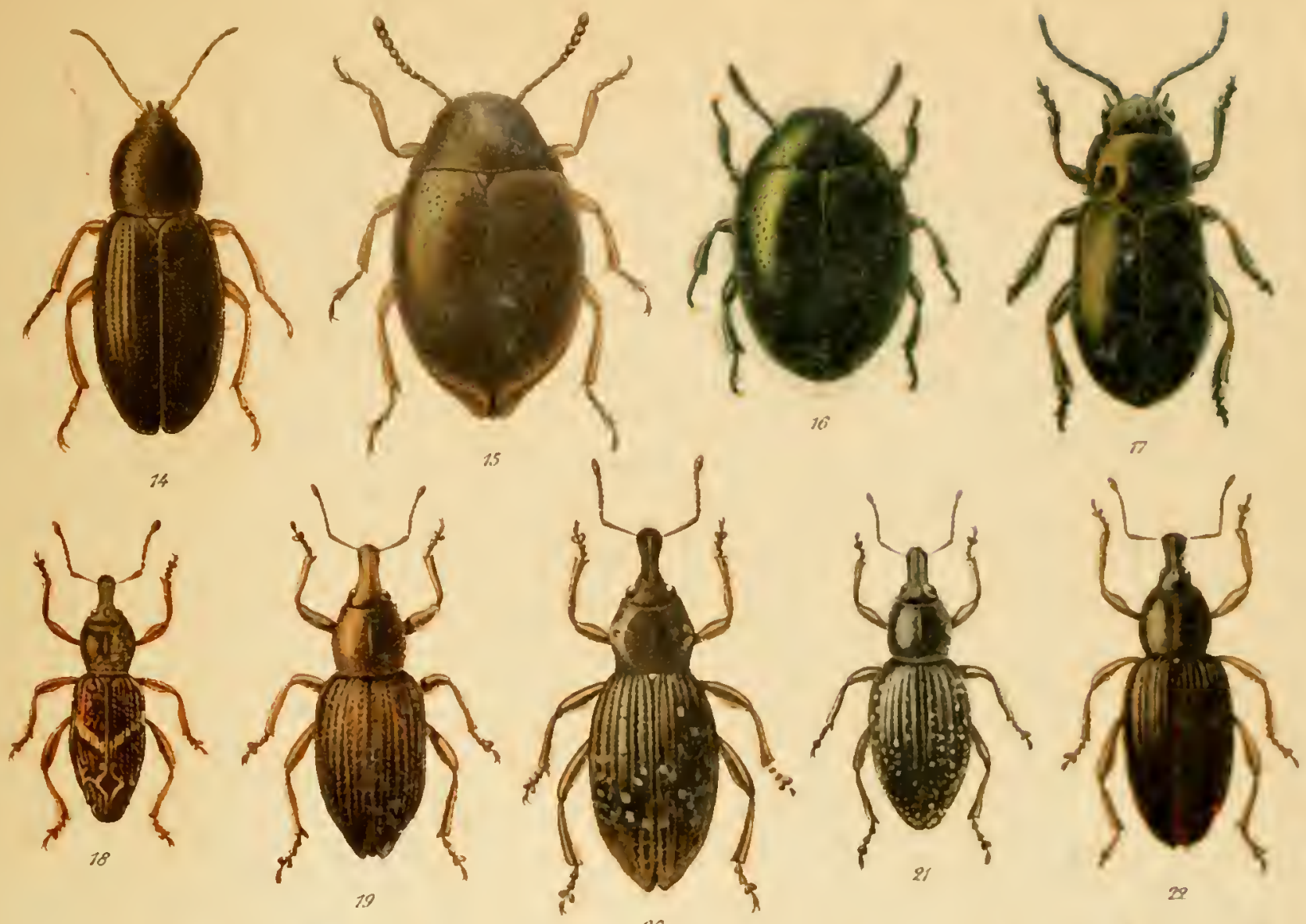
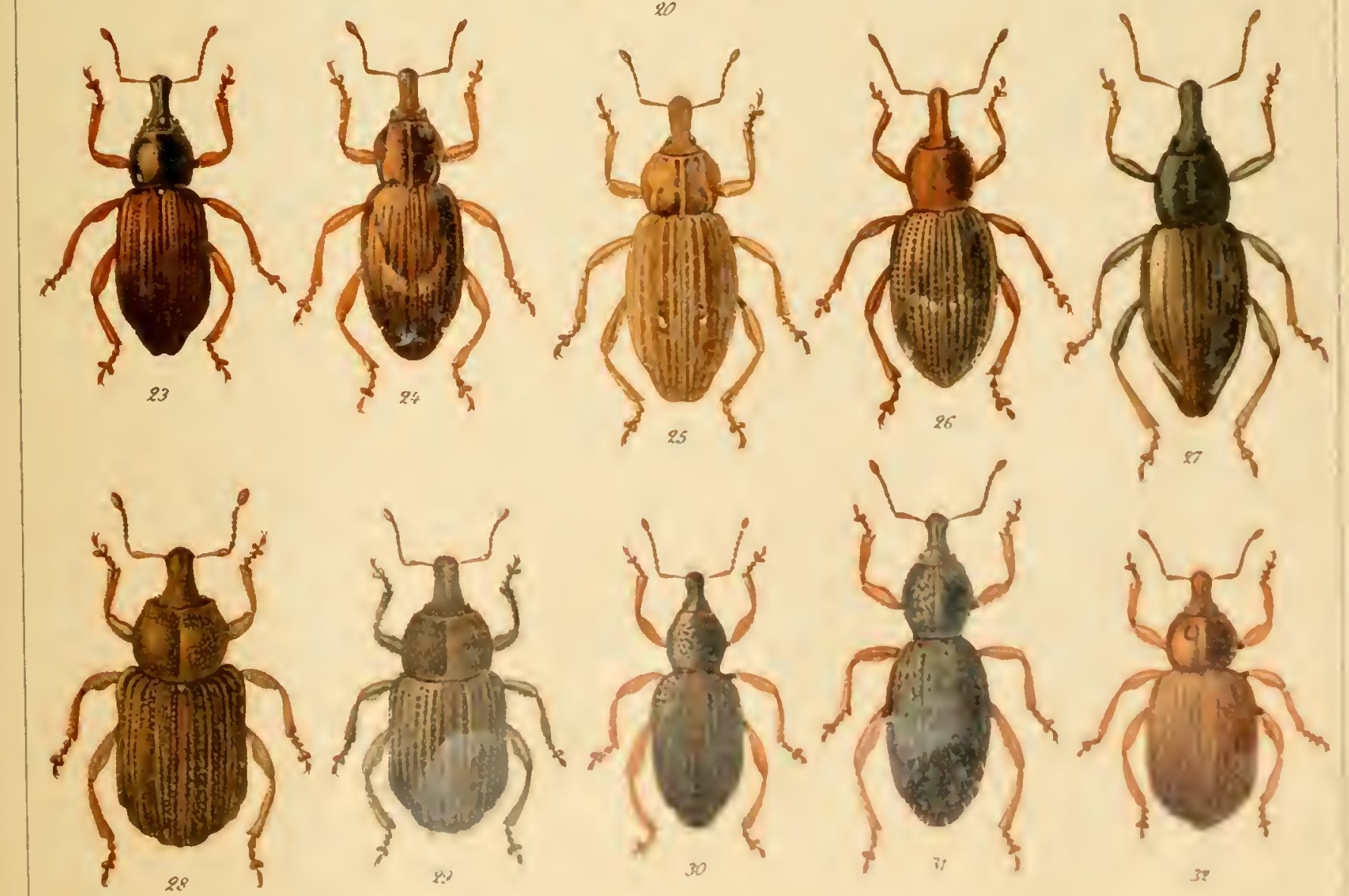


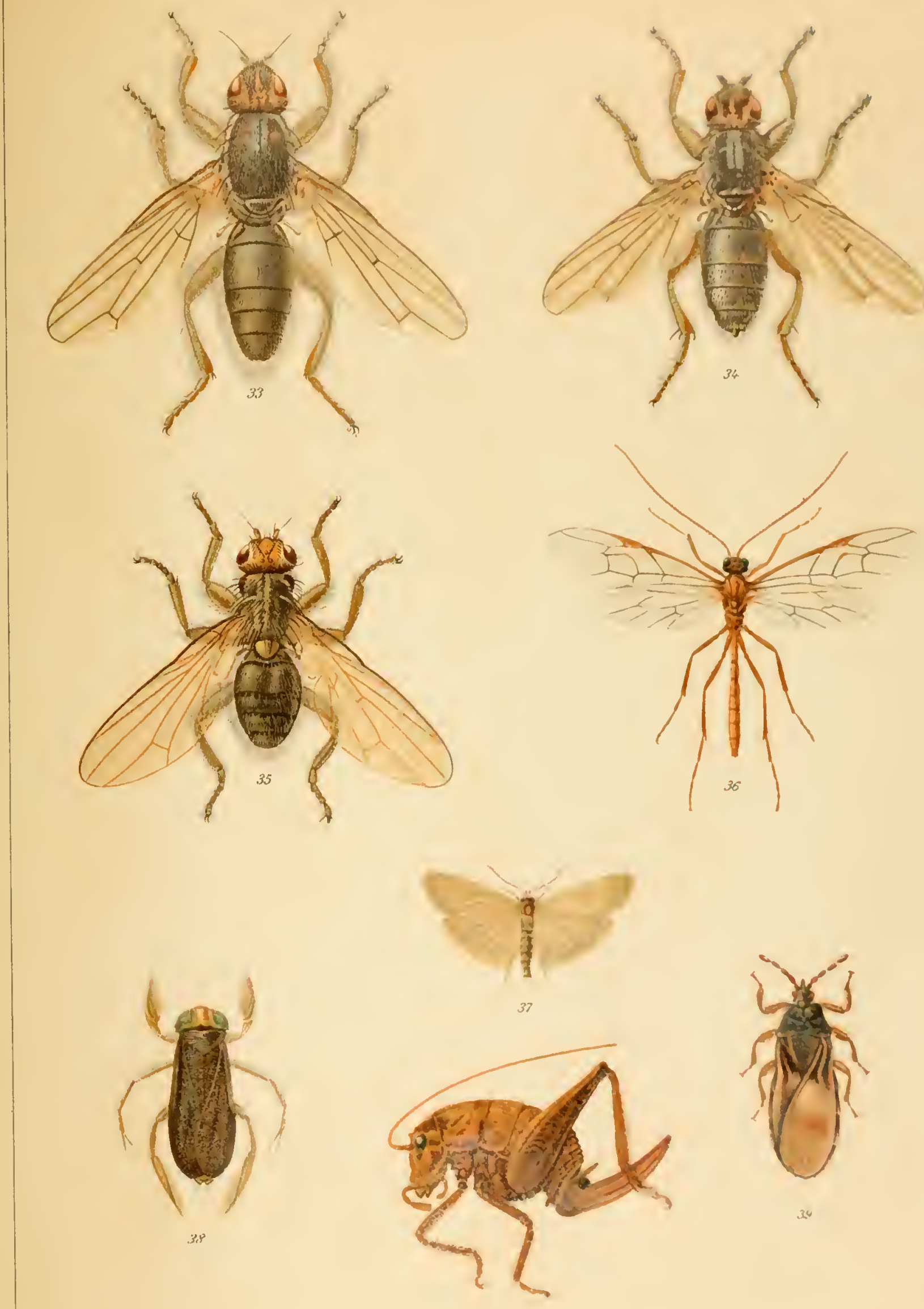


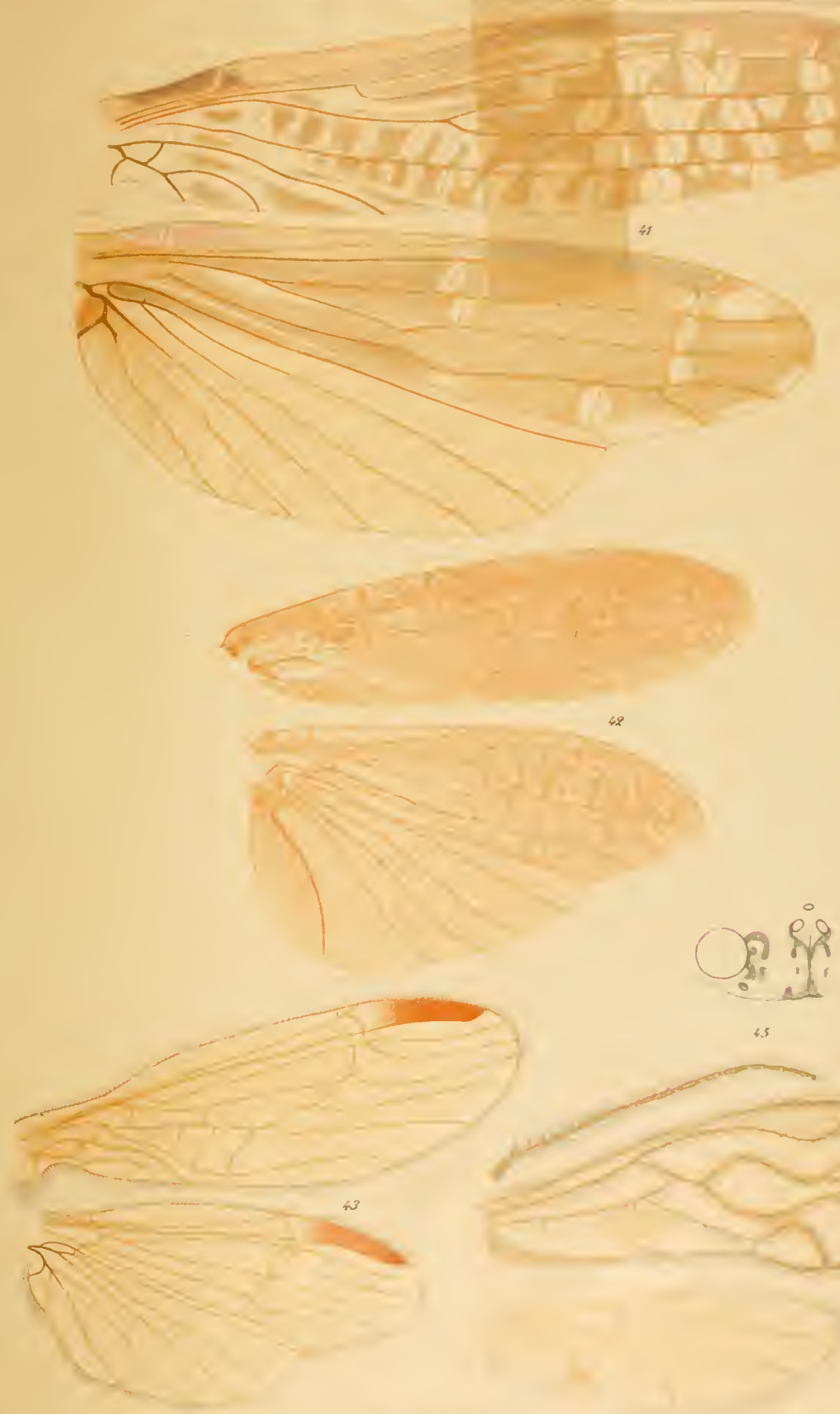

45

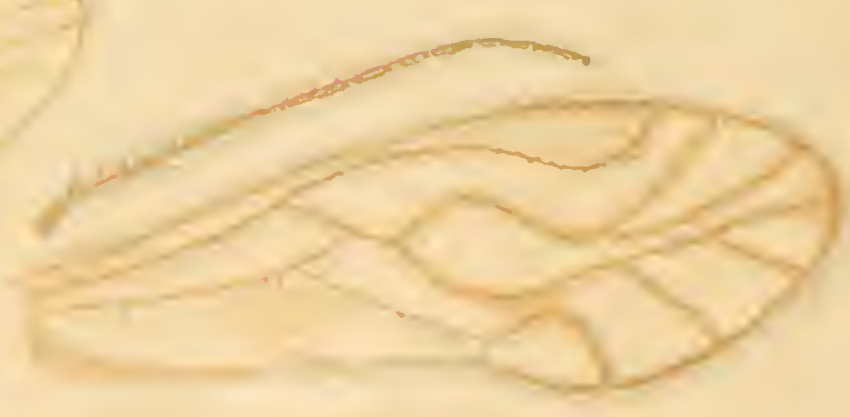

ti 


3)

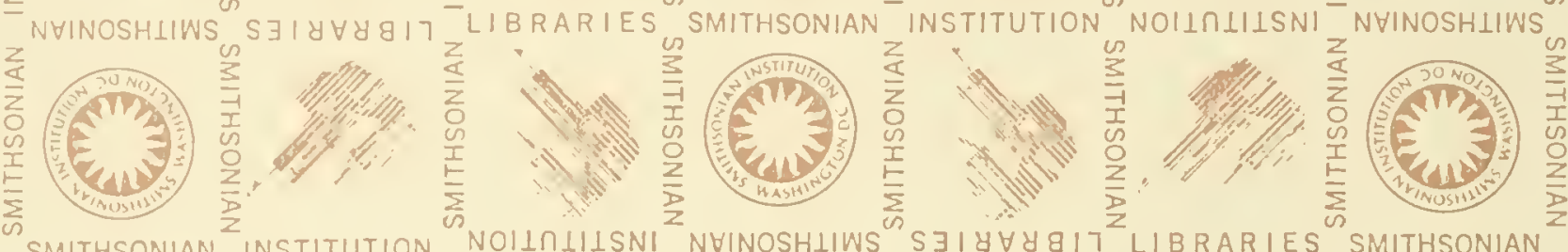
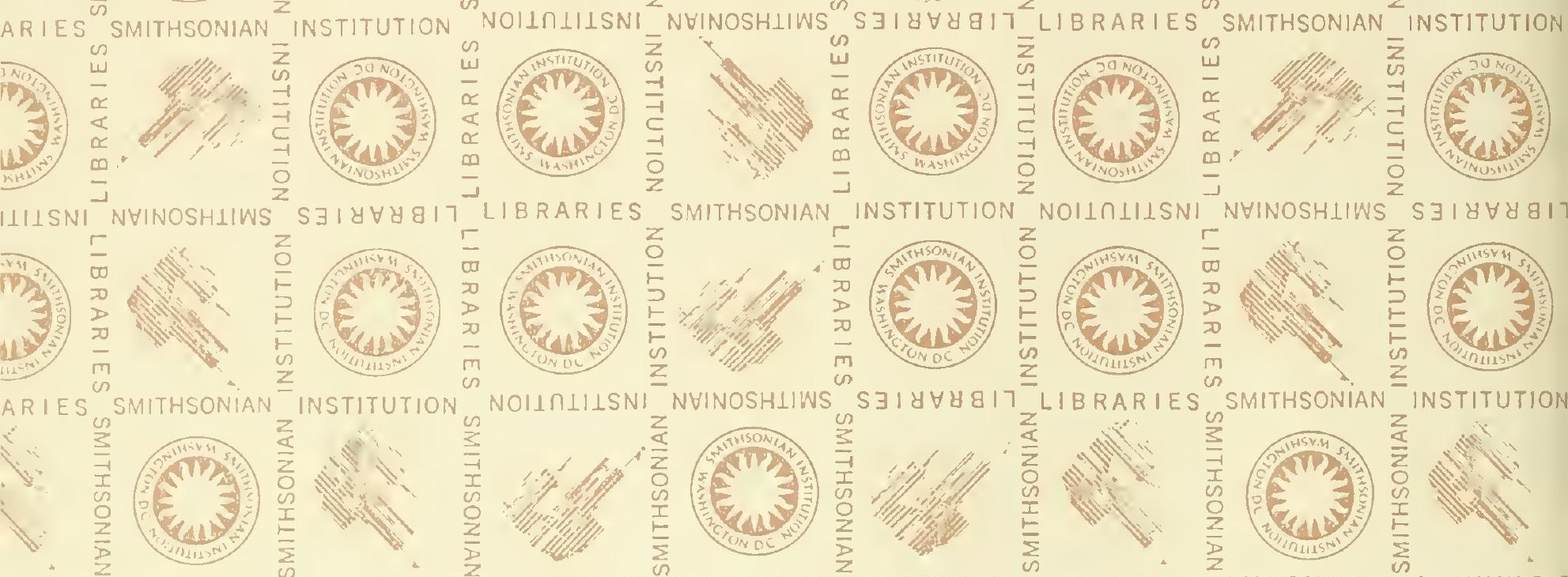
(
(1)

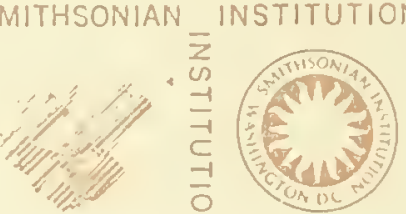

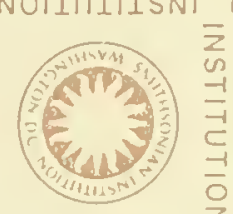
of
(3)

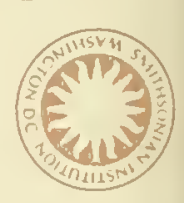

INSTITUTION

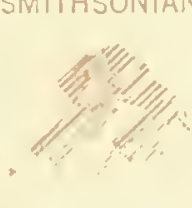

(n)

$(6)$

the

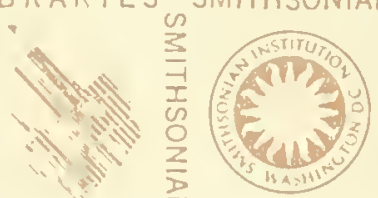

Whe

(1)
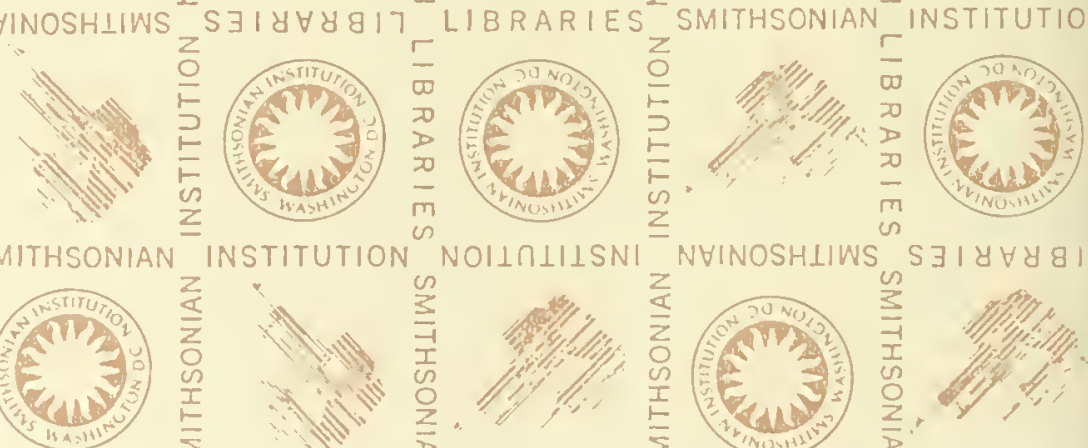

(1)

(n)

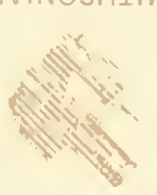

(․)
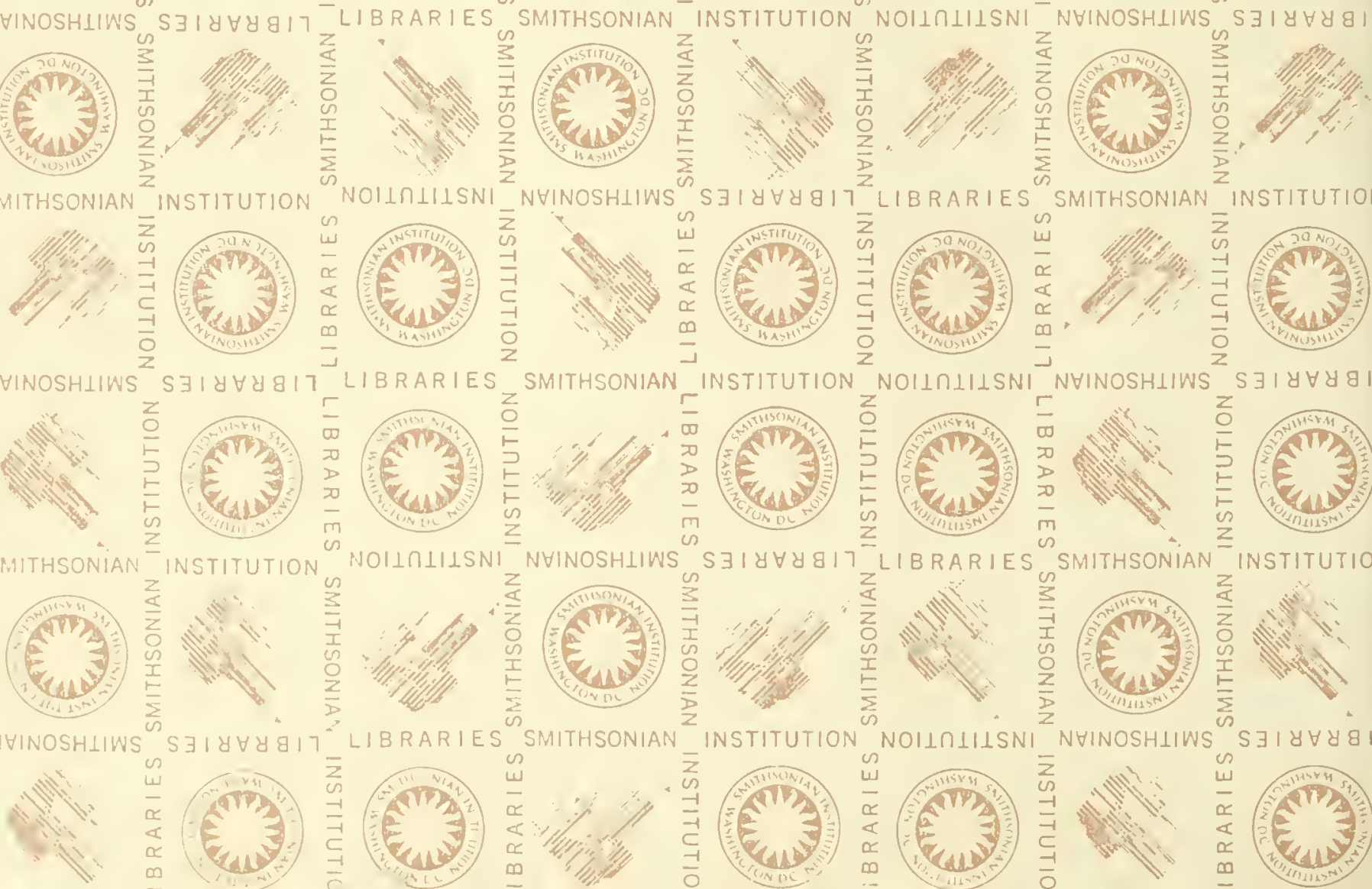
